\title{
The position of mediation in contemporary Chinese civil justice
}

Citation for published version (APA):

Chan, P. C. H. (2016). The position of mediation in contemporary Chinese civil justice: a proceduralist perspective. [Doctoral Thesis, Maastricht University]. Maastricht University. https://doi.org/10.26481/dis.20160610pc

Document status and date:

Published: 01/01/2016

DOI:

10.26481/dis.20160610pc

Document Version:

Publisher's PDF, also known as Version of record

\section{Please check the document version of this publication:}

- A submitted manuscript is the version of the article upon submission and before peer-review. There can be important differences between the submitted version and the official published version of record.

People interested in the research are advised to contact the author for the final version of the publication, or visit the DOI to the publisher's website.

- The final author version and the galley proof are versions of the publication after peer review.

- The final published version features the final layout of the paper including the volume, issue and page numbers.

Link to publication

\footnotetext{
General rights rights.

- You may freely distribute the URL identifying the publication in the public portal. please follow below link for the End User Agreement:

www.umlib.nl/taverne-license

Take down policy

If you believe that this document breaches copyright please contact us at:

repository@maastrichtuniversity.nl

providing details and we will investigate your claim.
}

Copyright and moral rights for the publications made accessible in the public portal are retained by the authors and/or other copyright owners and it is a condition of accessing publications that users recognise and abide by the legal requirements associated with these

- Users may download and print one copy of any publication from the public portal for the purpose of private study or research.

- You may not further distribute the material or use it for any profit-making activity or commercial gain

If the publication is distributed under the terms of Article $25 \mathrm{fa}$ of the Dutch Copyright Act, indicated by the "Taverne" license above, 


\title{
The Position of Mediation
}

in

\section{Contemporary Chinese Civil Justice:}

\section{A Proceduralist Perspective}

\author{
Dissertation \\ to obtain the degree of Doctor \\ at Maastricht University, \\ on the authority of the Rector Magnificus, \\ Prof. Dr. L.L.G. Soete \\ in accordance with the decision of the Board of Deans, \\ to be defended in public \\ on Friday 10 June 2016, at 12:00 hours
}

by Peter Chi Hin Chan 


\section{Supervisor:}

Prof. Dr. C. H. van Rhee

\section{Co-Supervisor:}

Dr. Agustin Parise

Assessment Committee:

Prof. Dr. Rene de Groot (Chairman)

Prof. Dr. Yulin Fu (Peking University)

Dr. Annie de Roo (Erasmus)

Prof. Dr. Jan Smits

Prof. Dr. Stefaan Voet (Leuven) 
Institute(s) and/or organization(s) that contributed financially to the creation of the thesis:

China-EU School of Law, At the China University of Political Science and Law (CESL Programme of Visiting PhD of Law Students) 
The author dedicates this book to his beloved wife, Irene Lee and his two children, Arthur Emanuel Chan and Grace Christine Chan. 


\section{Acknowledgements}

This book is the result of more than four years of research. The author is indebted to his doctoral supervisor, Professor C.H. (Remco) van Rhee for his encouragement, guidance and support throughout the research project. The author has learned so much from Professor van Rhee not only in terms of academic research, but also the way to approach work and life. Anyone who knows Professor van Rhee well would agree that his wisdom and humour are as impressive as his academic accolades.

The author would like to express his heartfelt gratitude to Professor Albert H.Y. Chen for his mentorship and encouragement. Professor Chen has inspired the author to pursue a career in academic law since the author read law (LLB) at the University of Hong Kong.

The author would also like to thank Professor Jan Smits, Professor Burkhard Hess and Professor Yaxin Wang for their support during the author's research visits at the Maastricht European Private Law Institute, the Max Planck Institute Luxembourg for International, European and Regulatory Procedural Law and in Beijing respectively.

This research also benefited significantly from the generous funding provided by the China-EU School of Law, At the China University of Political Science and Law (CESL Programme of Visiting PhD of Law Students), which allowed the author to undertake on-site research trips to courts in China to collect the necessary empirical data.

The author is fortunate to be surrounded by supportive family members, who have encouraged him all along, especially his beautiful loving wife, Irene Lee. Without their patience and understanding, this book would not have become a reality. The author would also like to thank his parents, Prof. Kai Ming Chan and Mrs. Chloe Chan, for their support and encouragement.

Last but not least, the author would like to take this opportunity to mention his late grandfather (Mr. Chan Yun Sin (陳恩銑先生)), a figure whom the author respects and admires. Mr. Chan Yun Sin was an accomplished accountant and one of the 150 graduates in 1946 in the renowned Guangdong Provincial Rangqin School of Business (广东省立颉勤商学院), one of the earliest business schools in modern China. Without his grandfather's influence, the author would not be the person he is today. 


\section{Table of Contents}

\section{Acknowledgements}

\section{Chapter 1: Introduction}

1.1 The research question and the scope of this book

1.1.1 Research question

1.1.2 Why civil procedure?

1.2 The concept of mediation in Chinese legal tradition

1.3 Fundamental concepts in contemporary Chinese civil justice

1.3.1 Overview

1.3.2 Substantive justice and material truth

1.3.3 Social effect of judgments and populist views of justice

1.3.4 Legal distinction between pre-action mediation and court mediation

1.3.5 The nature of a settlement reached through court mediation

1.3.7 Fused role of the judge-adjudicator in judicial conciliation

1.4 The European definition of 'mediation'

1.5 The Hong Kong experience

1.6 Fundamental conceptual differences between contemporary Chinese mediation and mediation processes in Europe

1.7 The Chinese court system

1.7.1 Vertical hierarchy of the Chinese judiciary

1.7.2 The role of the Supreme People's Court

1.8 Methodology: A proceduralist perspective supplemented by an empirical enquiry

1.9 Synthesizing thoughts in previously published articles

\section{Chapter 2: $\quad$ Legal history of civil mediation in China}

2.1 Chinese legal culture of wu song

2.2 Mediation as a communal disputes resolution mechanism

2.2.1 Official recognition of the informal justice system

2.2.2 Special features of the informal justice system

2.2.3 Community mediation in the Song, Yuan, Ming and Qing periods

2.3 Magisterial adjudication: the role of mediation in civil disputes resolution in imperial China 
2.3.1 Introduction

2.3.2 Understanding China's imperial civil justice within the historical context

2.3.2.1 Limitations of the Weberian model

2.3.2.2 The nexus between Chinese legal history and China's contemporary legality

2.3.2.3 The importance of the historical context

2.3.3 The need of a paradigm shift: from Weberian formalism to the practice-based legality of China

2.3.4 The Chinese imperial legal order: a 'thin' version of civil justice 2.3.4.1 The distinctiveness of Chinese civil law and procedure 2.3.4.2 Adjudicatory rationality

2.3.4.3 Individual entitlements upheld in civil adjudication

2.3.5 The magisterial adjudicative philosophy - the application of multiplevalued logic

2.3.5.1 Moral judgment or legal judgment

2.3.5.2 Understanding the concept of 'qing li' and its relationship with statutory law in traditional Chinese legal culture

2.3.5.3 The magistrate's civil adjudicative philosophy

2.3.6 Understanding Huang's theories of 'centralized minimalism' and the 'third realm of justice'

2.3.6.1. Huang's theory of 'Centralized minimalism'

2.3.6.2. Huang's theory of 'The third realm of justice'

2.3.7. Magisterial adjudication in imperial China: Concluding remarks

2.4. Court-referred pre-action mediation in the Republican era (1911-1949)

2.5. The shadow of the legendary Ma Xiwu: the legal history of the 'people's judge' and the impact of his adjudicatory approach in contemporary China

2.5.1. The Ma Xiwu model of adjudication

2.5.2. Characteristics of the Ma Xiwu model of adjudication

2.5.3. Should the Ma Xiwu model be adopted in contemporary China? Why is Ma Xiwu still relevant to today's civil justice landscape in China

2.5.4. The reception of the Ma Xiwu adjudicatory philosophy by the contemporary Chinese Judiciary

2.6. Early civil procedural designs on court mediation and regulation of out-ofcourt mediation in the People's Republic

2.6.1. Phase I: 'Mediation as the principal method'

2.6.2. Phase II: 'Emphasizing Mediation'

2.6.3. Phase III: the 'voluntariness and legality' principle

2.6.4. Phase IV: 'U-shaped' development - reverting to prioritizing mediation

2.6.5. Phase V: 'Normalization' of court mediation

2.7. Xiao Yang and the rise of formalism in Chinese civil procedure

2.8. Wang Shengjun's judicial philosophy

2.9. Chapter conclusion 
Chapter 3: Connecting China's Private and Public Spheres of Civil Disputes Resolution: Grand Mediation, People's Mediation and Social Engineering

3.1. The 'Da Tiaojie' (Grand Mediation) system and the ideological basis for the rise of mediation: A bird's eye view of the Chinese mediation regime under Da Tiaojie

3.1.1. The concept of social harmony in Chinese politics and law

3.1.2. Introducing the 'Da Tiaojie' (Grand Mediation) System

3.1.3. The 2010 SPC Opinion

3.1.4. The Judicial Confirmation Procedure and its significance in the Grand Mediation system

3.1.5. Non-political 'sensitive cases'

3.1.6. Inherent problems of the Grand Mediation System

3.2. People's mediation

3.2.1. Legislative scheme: the People's Mediation Law and relevant interpretations

3.2.2. Policy considerations

3.2.3. General operative principles governing people's mediation

3.3. Origins and ideological underpinnings of people's mediation

3.3.1. From Maoist mass-line ideology to Post-Mao 'social harmony'

3.3.2. Recent developments

3.3.3. Special features of people's mediation and procedural issues

3.3.4. No 'accreditation' of mediators: the issue of lack of professionalism and uniformity

3.3.5. Caseload management: the channeling of disputes back to the community, keeping them away from the courts

3.3.6. Limitations of people's mediation

3.4. Nexus between private and public spheres of civil disputes resolution

3.4.1. Pre-action mediation to be attempted first?

3.4.2. 'Commissioned mediation': the effectiveness of court-referred mediation programmes in China

3.4.3. Pre-action commissioned mediation: the role of the court

3.4.4. Court-coordinated 'private' reconciliation: invading the private dispute resolution space?

3.4.5. Outside parties assisting with court mediation

3.4.6. Judicial confirmation procedure in commissioned mediation: futile or necessary?

3.5. Chapter Conclusion 


\section{Chapter 4: Court Mediation in the 'Wang Courts' and the impact of Wang Shengjun's policies on future developments}

4.1. Introduction - the relevance of a study on the Wang Courts

4.2. Introducing mediation in the Wang Courts: the judicial responsibility system, case management and social harmony

4.2.1. Introduction

4.2.2. Procedural stages of court mediation

4.2.3. The Policy Preference for Court Mediation in the Wang Courts

4.2.4. Legislative scheme and judicial interpretations

4.2.5. The 'new' Article 122 of the Code

4.2.6. Judicial policy documents and policy development trend

4.2.7. Brief procedural notes on court mediation

4.2.8. Legal effect of a mediation statement

4.3. The position of the individual judge within the Chinese judiciary

4.3.1. The position of the courts within the Chinese constitutional structure and the bureaucratic hierarchy of the Chinese Judiciary

4.3.2. The lack of adjudicatory independence and the inferior position of the individual judge within the judicial power matrix

4.4. Critical examination of court mediation in the Wang Courts and beyond: procedural problems and solutions

4.4.1. Policy preference for mediation: skewing the landscape of civil justice

4.4.2. A policy-driven court: parallels with adjudication supervision

4.4.3. Judicial conciliation? Or facilitative judging? The Chinese spectrum of JDR

4.4.4. Judicial preference for mediation/conciliation - a career decision? Assessment of judges and court mediation settlement rate as a key index of performance

4.4.5. Judicial conciliation at the appellate stage

4.4.6. Coerced conciliation: a brief qualitative empirical analysis

4.4.7. Circumstances under which the conciliating judge would communicate to the parties the outcome of the case should conciliation fails

4.4.8. The virtues of synthesizing adjudication and judicial conciliation: a Chinese perspective

4.4.9. Didactic and supervisory function of judicial conciliation

4.4.10. Civil justice without 'without prejudice privilege'

4.4.11. Court mediation as a caseload management tool

4.4.12. Court-sanctioned settlement at the enforcement stage: abusing the system in the name of 'social harmony'

4.4.13. How judicial conciliation negatively affects fact-finding

4.4.14. Judicial conciliation in civil cases connected with criminal proceedings (minshi fudai xingshi anjian): when justice completely fails

4.4.15. Judicial populism and social harmony: A grand retreat from constructing a formalist legality? 
4.5. Settlement rate in appellate review and re-adjudication

4.6. Chapter conclusion: Reforming court mediation in China by separating conciliation from adjudication

\section{Chapter 5: An Empirical Analysis of Judicial Conciliation in China}

5.1. Judicial perception is reality: the value of qualitative empirical research on Chinese law and procedure

5.2. Methodology

5.2.1. Limitations of this study

5.2.2. Strengths of this study

5.2.3. The Surveys

5.2.4. Interviews conducted since March 2013

5.2.5. An anecdotal note on conducting empirical work in Chinese courts 5.2.5.1. Getting started

5.2.5.2. What to ask and what not to ask

5.3. Social Effect vs. Procedural Justice: Is Anjie shiliao still a paramount goal in Chinese civil justice?

5.3.1. Overview

5.3.2. The Judges' Survey

5.3.3. The Litigation Practitioners' Survey

5.3.4. Analysis

5.4. Is the policy of 'prioritizing conciliation' still in effect? What is its impact on adjudication?

5.4.1. Is the policy of 'prioritizing conciliation' still in effect?

5.4.2. Does the policy of 'prioritizing conciliation' affect the total number of judgments rendered by individual judges and the freedom of parties in selecting conciliation?

5.5. Coerced conciliation and undue influence from the bench

5.6. Effect of judicial conciliation on ultimate judgment should there be no settlement

5.6.1. Conciliation as a fact-finding tool and its influence on ultimate judgment

5.6.2. Effect of party statements made during judicial conciliation on the ultimate judgment

5.7. The position of substantive law in judicial conciliation

5.8. Trial management, case quality evaluation and settlement rate 
5.9. Practical aspects of judicial conciliation as revealed in the surveys

5.9.1. Common phases of judicial conciliation

5.9.2. Efficiency in Judicial Dispute Resolution: adjudication vs. conciliation

5.9.3. Cases suitable for conciliation

5.9.4. To conciliate or not to conciliate

5.9.5. Court enforcement rate of mediation statements

5.10. Chapter conclusion: the position on judicial conciliation since March 2013 as revealed in the latest interviews

\section{Chapter 6: Commercial Mediation in China: A Guide for Foreign Enterprises}

6.1. Chapter Introduction

6.1.1. Mediation options for resolving commercial disputes involving foreign enterprises in China

6.1.2. A brief overview of the dispute resolution system involving foreign enterprises in China

6.1.2.1. The Chinese court system

6.1.2.2. Understanding the arbitration regime in China - recent reform and limitations

6.2. Institutional commercial mediation - the Mediation Centre of the China Council for the Promotion of International Trade/China Chamber of International Commerce

6.2.1. Overview

6.2.2. Mediation Rules and Code of Conduct - entrenching principles of modern mediation

6.2.3. The mediation procedure and methodology

6.2.4. Enforcement of a mediated settlement agreement

6.2.5. Joint mediation centers

6.2.6. Non-institutional commercial mediation

6.3. Court mediation and its impact on commercial disputes resolution involving foreign enterprises

6.4. Med-Arb: Mediation in CIETAC Arbitration

6.5. Chapter Conclusion

Chapter 7: Fundamental Tenets of Contemporary Chinese Civil Justice: Substantive Justice, Material Truth and the Chinese Judicial Mind-set

7.1. Chapter Introduction: The underlying philosophy of contemporary Chinese civil adjudication 
7.2. The Pre-eminence of Substantive Justice in Chinese Civil Adjudication: using civil appeals in China as illustration

7.2.1. An outline of the appellate procedures

7.2.2. The nature of Chinese appellate review - real appeal or de novo hearing?

7.2.2.1. Fact-finding at the appellate level

7.2.2.2. Power of the appellate court to review beyond the remit of the request for appeal

7.2.2.3. Entertaining new evidence at the appellate level

7.2.2.4. Entertaining new points of law at the appellate level

7.2.2.5. A complete review system with Chinese characteristics

7.3. The Pre-eminence of Substantive Justice in Chinese Civil Adjudication: Using the Adjudication Supervision Procedure as illustration

7.3.1. The nature of adjudication supervision and its underlying policy considerations

7.3.2. Adjudication supervision: a critical review of the procedural issues

7.3.2.1. Adjudication supervision through party application

7.3.2.2. Adjudication supervision: ex officio power of the court to reopen final judgments

7.3.2.3. Procuratorial supervision: enhancing accountability or violation of adjudicatory autonomy?

7.3.2.3.1. Procuratorial protest

7.3.2.3.2. Procuratorial recommendation

7.3.2.4. Adjudication supervision through non-party application

7.3.2.5. Issues with enforcement of an effective judgment challenged under the adjudication supervision procedure

7.3.3. Critical examination of the new powers of the Chinese procuratorate

7.3.4. Interference from other institutions

7.3.5. Recent trends in civil appeals and re-adjudication

7.3.6. Recommendations for reform in China's civil appellate system: establishing the principle of finality in Chinese civil justice

7.4. Civil Fact-finding in China - the search for material truth

7.4.1. Efficiency and Fact-finding

7.4.2. The Evolving Role of the Judge in Civil Fact-Finding

7.4.2.1. Background

7.4.2.2. Evidence Collection: Party Responsibility System and Judicial Intervention

7.4.2.3. Civil Burdens of Proof - A Big Step Forward?

7.4.2.4. The Paradox of Party Responsibility in the Absence of the Principle of Party Presentation

7.4.2.5. Judicial Clarifications in Chinese Civil Fact-finding

7.4.2.6. Evidence Exchange and Management with Efficiency in Mind

7.4.3. Institutional constraints in reforming Chinese civil fact-finding

7.5. Chapter conclusion 
Chapter 8: Trial Management in China: The Institutionalisation of Judicial Preference for Court Mediation in Civil Litigation - Overview of Principles and Practice

8.1. Trial management and civil justice: bureaucratic justice or managerial excellence?

8.2. An overview of the 2011 SPC Case Quality Opinion

8.3. Operational aspects of civil trial management in China

8.3.1. The Trial Management Office

8.3.2. Assessment of individual judges

8.3.3. Mass case-processing in China, not a rights-based justice

8.3.4. Constitutional dimensions

8.4. Effect of the trial management system on court mediation in China: an institutionalized distortion of (what is supposed to be) an ADR mechanism

8.5. A critical examination of Case Quality Evaluation system from the perspective of procedural justice

8.6. Chapter conclusion

Chapter 9: Conclusion: Seven Areas of Tension in Chinese Disputes Resolution - The Impact on In-Court and Out-of-Court Mediation

9.1. 'Chinese Exceptionalism' and civil justice

9.2. First Area of Tension in Chinese disputes resolution: Black-Letter Law v.s. Judicial Practice

9.3. Second Area of Tension in Chinese disputes resolution:

Official representation of justice vs. the reality of mass case-processing needs

9.4. Third Area of Tension in Chinese disputes resolution: SPC Policy vs. local implementation

9.5. Fourth Area of Tension in Chinese disputes resolution: Procedural justice vs. substantive justice

9.6. Fifth Area of Tension in Chinese disputes resolution: Bureaucratic Supervision vs. Adjudicatory Autonomy

9.7. Sixth Area of Tension in Chinese disputes resolution: International Norms of Practice vs. Chinese Exceptionalism

9.8. Seventh Area of Tension in Chinese disputes resolution: Regulatory State vs. 'Autonomy' of the Judiciary 
9.9. Final Remarks

9.9.1. Empowering Chinese courts in the civil process

9.9.2. The position of court mediation in Chinese civil justice going forward

9.9.3. The position of people's mediation in Chinese civil justice going forward

9.10. Legal culture and civil mediation in China

9.11. Political culture and civil mediation in China

9.12. A final word

Afterward: The Recent Judicial Reforms in China and Its Impact on Civil Justice and Mediation

10.1. Pre-reform indicators

10.2. Pilot Programmes and SPC Circuit Courts

10.3. The latest SPC reform package (2015)

10.3.1. Overview

10.3.2. Reforming the administrative structure of the court system

10.3.3. Constructing an 'adjudication-centred' judiciary

10.3.4. Formalizing the functional systems within courts with clear 'terms of reference'

10.3.5. Improving and calibrating the operational mechanisms of the adjudicative process

10.3.6. Constructing an 'open, dynamic, transparent and people-centred' judicial system

10.3.7. Formalizing and professionalizing court personnel appointment and management

10.3.8. Guaranteeing the independent exercise of adjudicative powers by the courts

10.4. Redefining the power structure: Re-distributing powers of the Chinese Communist Party to procurators and courts

10.5. Concluding remarks: Reform's impact on mediation: superficial change or real overhaul?

\section{APPENDICES:}

APPENDIX I: $\quad$ Bibliography

APPENDIX II: Table of Statutes, Statutory Instruments, Judicial Interpretations, Rules and Regulations of the Supreme People's Court and other acronyms 
APPENDIX III: $\quad$ Interview Log

APPENDIX IV: $\quad$ Survey Questionnaires and Master List of Interview Questions

APPENDIX V: $\quad$ List of published articles by the author: the contents of which were repeated in this book

APPENDIX VI: $\quad$ Valorization Addendum

APPENDIX VII: $\quad$ English Summary

APPENDIX VIII: Curriculum Vitae 
Chapter 1:

Introduction 


\section{INTRODUCTION}

\subsection{The research question and the scope of this book}

\subsubsection{Research question}

This work focuses on the manner in which mediation is conducted in-court and outof-court within the context of civil justice in contemporary China. The main research question that needs to be answered is this: given the current judicial culture that emphasizes the social effect of the civil process, is it practically feasible (i.e. as a matter of actual judicial practice and not just a change of policy), for the mediation of civil disputes in China to take the shape of genuine alternative dispute resolution, rather than being used by the courts as a means to preserve social stability? The official line-to-take today is that the policies of the immediate past leadership of the Supreme People's Court (SPC) that preferred mediation to adjudication (the so-called policy 'prioritizing mediation' (tiaojie youxian)) are no longer in force. The official position is that, following the de facto abandonment of these 'mediation-favouring' policies, the function of mediation is now 'normalized' (changgui hua (常规化)), meaning that the ADR function of mediation is completely restored. However, this may not be the case in actual judicial practice (especially in lower courts) if one looks at empirical data, the views non-official stakeholders of the civil procedural system and institutional designs that remained intact despite the policy change. If the general objective of civil justice remains to be social control, there can be significant discrepancies between the official representation and the actual practice when it comes to the function and conduct of mediation. This work will answer this main research question based on a detailed proceduralist analysis, which is supplemented by a qualitative empirical enquiry.

Apart from attempting to answer the main research question, this work seeks to address another issue, albeit relatively ancillary in nature. While there are quite a number of articles of the subject of Chinese mediation from a socio-legal perspective (and there is an abundance of overviews on the subject), a focused procedural study of this subject in the English language is lacking. This work intends to fill this gap in the international literature.

The main research question is particularly relevant given the history of courts using mediation to further the agenda of the ruling elite during Wang Shengjun's tenure as President of the SPC (March 2008 - March 2013). This question is important not only as a civil procedural topic, but also from a socio-legal standpoint. From a procedural perspective, mediation occupies a unique position in any civil justice system in that it (if appropriately deployed) provides an alternative to litigation while preserving the parties' right of access to court. The procedural nature and function of mediation changes if policy is allowed to dictate the mediation process, especially when such policy contravenes the law. This is exactly what happened in China under Wang Shengjun's presidency. Mediation, in particular court mediation, became a policy tool to further the ruling objective of maintaining social harmony, and to a varying degree, at the expense of procedural justice. This work tracks the influence of Wang's policies in shaping China's mediation regime and the extent to which Wang's legacy in this area affected the construction of a modern mediation system in 
China in the wake of current judicial reforms. From a socio-legal perspective, a broader issue needs to be considered: is the ruling elites in China still using courts as a medium to secure its dominance, rather than respecting the judicial process (whether adjudication, court mediation or court-annexed mediation) as a uniquely important domain in its constitutional matrix that is best left to do its business alone without external interference. This question is particularly relevant to an international audience that seeks to understand what China is doing in its new wave of judicial reform that allegedly aims to construct 'the rule by law'.

It is important to highlight at the outset that conciliatory procedures in contemporary China (whether in-court or out-of-court) are referred to, in English, as either 'mediation' or 'conciliation' (both being translations of the Chinese word 'tiaojie' (调 解). The Chinese language, however, makes no distinction between the concepts of 'mediation' and 'conciliation'. The concept of tiaojie in the Chinese language, is incredibly vague and perhaps deliberately remained so to allow flexibility in practice. In this regard, China is not alone. As Hopt and Steffek noted, 'In the large majority of jurisdictions, the development of procedures and definitions is still in flux. Sometimes English language terminology is borrowed, but is then used in a manner that has a different meaning'. 'Given its directive and interventionist nature, contemporary Chinese 'mediation' (with the exception of private mediation of commercial cases) falls within the definition of 'conciliation', and not 'mediation' as understood in present-day Europe. It is therefore important to highlight the distinction between mediation and conciliation. Alexander provided a useful formula for this: 'Conciliation can be similar in many ways to mediation, yet it differs in one important respect. Conciliation refers to a mediation-like process in which an impartial third party, the conciliator, is able to provide the parties with legal information and/or suggest solutions to them. Conciliators can be much more directive and interventionist than interest-based mediators'.

For ease of reference, this book will use the term 'Chinese mediation' or 'mediation as practiced in China' to refer to the broad array of conciliatory processes in the Chinese disputes resolution system (both in-court and out-of-court).

\subsubsection{Why civil procedure?}

The study of civil procedure is much more than simply looking into the court processes and out-of-court mechanisms for resolving day-to-day commercial and civil disputes. Research in civil procedure allows the enquirer to see the very fabric of a society, the philosophical underpinnings of the political establishment and the way private disputing parties interact with one another under a system of procedural rules. These rules, and the way courts apply them, spell out the policy preferences and societal inclinations of a jurisdiction. In other words, the justice delivered to the commoner (or the absence of which) in a local county court speaks louder than any elaborate theory on how well a country is doing in terms of social equity and the protection of fundamental rights. In a way, civil procedure (as with any type of procedural law) should be regarded as public law. In fact, the way courts handle civil

\footnotetext{
${ }^{1}$ Hopt \& Steffek 2013, p.15.

${ }^{2}$ Alexander 2006, p. 1.
} 
lawsuits could well be more telling of how a nation views justice and rights than the way courts handle purely constitutional or administrative matters given the sheer size of civil case volume. This is particularly true for China as the agenda for its civil justice system has always placed policy needs above the delivery of justice in individual cases. The study of the position of court mediation (and different ways to connect out-of-court mediation regimes with formal court proceedings) explains the intricate scheme put together by court leaders to pursue a policy goal that seeks to promote social stability above anything traditional goals of civil justice.

\subsection{The concept of mediation in Chinese legal tradition}

Confucianism prized the concept of 'litigation-less' (wu song (无讼)). Collective interests and harmony should supersede individual rights. Disputes, therefore, should be resolved without jeopardizing 'harmony' (hexie (和谐)). Modern principles of mediation (e.g. party autonomy, the neutrality of the mediator and mediation confidentiality) are generally alien to the Chinese traditional legal culture. Whether it was magisterial mediation or mediation conducted by community leaders, mediators in imperial China had the inherent mandate to maintain social order and educate the people on Confucian morals and the law. The imperial mediator was therefore not an impartial and neutral third party, but rather a conciliator with a quasi-official mandate to advance the governing discourse and value system.

The traditional Chinese understanding of mediation is categorically different from modern-day concepts of mediation. The common term for mediation in imperial China is tiaochu (调处), which translate into a process that combines conciliation with adjudicative discretions. The conciliatory processes during the imperial times, in its various forms, were designed not just to provide an alternative to litigation, but also to showcase the moral virtues of resolving disputes in an amicable manner. The 'didactic function' of conciliation epitomized the soft power of imperial rule: using the conciliation of community disputes to illustrate what the 'desired norms' of practice were and educate the public who were generally ignorant of the law and policies of the imperial state. To achieve these goals, the conciliator must be prepared to be interventionist, evaluative and even express his own views on what the moral, customary or legal norms were. That is why conciliation in imperial China (in its various forms) was never a facilitative process that respected party autonomy. Even nowadays, where the law has supposedly entrenched principles of party voluntariness and impartiality of the conciliator, conciliation processes frequently take the form of the conciliator directing what the parties should do, in terms of what facts were to be established, what the relevant substantive legal provisions were, and what the possible settlement options were. These traits look very familiar to how community mediators operated during the imperial times in 'lecturing' the disputants on Confucian concepts of acceptable behavior and recommending settlement options that were consistent with the interests of the community. The discussion on contemporary Chinese mediation is placed into the appropriate context when one understands that conciliatory processes in China today (whether it is judicial conciliation or People's Mediation) still operate to a certain extent under the shadow of China's historical legal culture. 


\subsection{Fundamental concepts in contemporary Chinese civil justice}

\subsubsection{Overview}

Chinese justice, in particular civil justice, is a complex concept. Contemporary China projects itself as a strong nation rising to the ranks of great power status. Its judicial system cannot be seen as backward and out of touch with the rest of the world. Hence, recent reform efforts are designed to strengthen procedural formalism, meet public expectations and re-establish the position of adjudication after years of displacement due to the preferential policy for mediation. But the historical roots of Chinese justice had such great influence over the litigation culture that even judges today subscribe to fundamental tenets of these 'time-honoured' traditions. For instance, the preoccupation of searching for substantive justice, a heavy reliance on various forms of court-directed or court-mandated conciliation processes and the (almost obsessive) interest in finding the material truth, all stemmed from China's imperial magisterial justice under which the 'judge' performs much more than a judicial role in local governance.

\subsubsection{Substantive Justice and Material truth}

Contrary to the modern emphasis on procedural justice (in common law jurisdictions and many of the continental European jurisdictions), the Chinese judiciary focuses on substantive justice while deliberately downplays the importance of procedural formalism. ${ }^{3}$ The common Chinese judicial notion that an adjudicator must 'distinguish right from wrong' (分清是非), a notion embedded in court mediation as well, embodies this philosophy at work. While lip service is given to the importance of following procedural rules in adjudication (especially following a new wave of reforms since 2013 that sought to fortify the 'rule by law' in China), judges of the people's courts are much more interested in seeing the final resolution of a dispute where parties are satisfied with the outcome. The goal of 'Anjie shiliao' (案结事了) (i.e. the case is closed and the dispute is [truly] resolved) remains an overriding objective in Chinese civil justice. ${ }^{4}$ Apart from historical and cultural reasons, ${ }^{5}$ there are strong institutional reasons for the emphasis on substantive justice: the absence of finality in Chinese procedure means that judges' focus in adjudication is not the delivery of justice by defending the sanctity of procedure, but to reach a judgment where the losing party is least likely to re-open the case on appeal or by way of readjudication. Furthermore, judges are assessed on the basis of, among other parameters, their ability to avoid citizens petitions (xinfang (信访)) and appellate reversals. The populist undertone is obvious: courts must do whatever it takes to help maintain social stability and public order. These are institutional defects that no single reform attempt could rectify.

\footnotetext{
3 Interview 2012/2.

${ }^{4}$ See Chapter 5 of this book on the empirical findings relating to the principle of Anjie shiliao.

${ }^{5}$ See Chapter 2 of this book for a synopsis of China's traditional legal culture in civil litigation.
} 
Another key guiding concept in Chinese civil adjudication is that it is the duty of the judge to find the 'material truth' in every case. The fact-finding process is still in practice dominated by judges despite efforts in civil procedural rule-making that entrust parties with greater fact-finding responsibilities. A Chinese judge reserves the residual right to actively investigate into a factual matter. While Article 63 of the Civil Evidence Rules is said to have repealed the doctrine of factuality, ${ }^{6}$ the traditional preference for material truth and the retention of the judge's ex officio powers of investigation and evidence collection suggest that the doctrine of factuality still exerts considerable influence over contemporary civil adjudication in China.

In China, it is a statutory requirement that court mediation must be conducted on the basis of accurate fact-finding and a proper determination of liability (i.e. the notion of the need to 'distinguish right from wrong'). ${ }^{7}$ As such, a proper investigation of Chinese court mediation must be premised on clear and comprehensive understanding of the two fundamental tenets governing Chinese civil adjudicatory conduct: i.e. substantive justice and material truth.

\subsubsection{Social effect of judgments and populist views of justice}

It is ingrained in the psyche of Chinese judges that the judicial process must take into consideration the social effect of judgments. In various processes in civil litigation, one could see clearly how populist agenda sway the decisions of courts, which in certain situations at the expense of procedural justice. One important thing to note is that 'social effect' is poorly defined within the context of Chinese civil justice. It could range from concepts of maintaining public order to promoting certain collective good within the community. The ill-defined objective of searching for 'social' justice is further complicated by the culture of petition by disputants as a means to air their grievances. No judge would ever be sure what would happen next in a culture where social sentiments dictate the daily schedules of courts. The issue of judicial populism is partially addressed in the recent reform effort (especially in the framework laid down by the SPC in 2015). ${ }^{8}$

\subsubsection{Legal distinction between pre-action mediation and court mediation}

Chinese law places great emphasis on the distinction between pre-action mediation (suqian tiaojie (诉前调解)) and 'litigation-mediation' (susong tiaojie (诉讼调解)) (also known as 'court mediation' (fayuan tiaojie (法院调解)). The former is characterized by the absence of underlying proceedings. Any settlement agreement reached under pre-action mediation processes is not directly enforceable unless it is 'confirmed' under the judicial confirmation procedure (司法确认程序). For court mediation, any settlement would generally be reduced into a written 'mediation

\footnotetext{
${ }^{6}$ Zhang \& Zwier 2003, p. 451.

${ }^{7}$ Article 93 of the Code.

${ }^{8}$ See the Afterward of this book for an overview of the current judicial reforms in China.
} 
statement' (tiaojie shu (调解书)), ${ }^{9}$ which is directly enforceable like any civil judgment. A pre-action settlement that is judicially confirmed would not be in the form of a 'mediation statement'. ${ }^{10}$ The presence and absence of a 'mediation statement' distinguishes court mediation processes from pre-action mediation processes.

\subsubsection{The nature of a settlement reached through court mediation}

Court mediation is considered an 'adjudicatory act' (shanpan xingwei 审判行为). A 'mediation statement' reached through court mediation (tiaojie shu) has the effect of a civil judgment. Hence the principles governing adjudication should equally apply to court mediation (even without the express requirements under Article 93 of the Code). The analysis of the two fundamental tenets of Chinese civil adjudication in this work is crucial as it provides a solid conceptual foundation to better understand the intricate dynamics in Chinese court mediation. Without such a conceptual premise, it would be difficult to rationalize the predominant role of the judge-conciliator, the deference of parties to the judge-conciliator in the conciliation process and the unique judicial 'logic' that any conciliated settlement must be consistent with the factual findings of the case and the substantive law in question.

\subsubsection{Institutional inferiority of the individual judge}

The individual judge in China is institutionally weak. The Chinese court system embraces the principle of collectivism. For instance, a decision by the individual judge is capable of being re-opened under the adjudication supervision procedure by the Adjudication Committee of the court. The way judges are evaluated also demonstrates the top-down management philosophy of the Chinese judiciary. ${ }^{11}$ Even barring formal rules and official policies, the court leadership wields enormous 'soft power' over the individual judge in all matters relating to civil litigation. The recent reform seeks to empower the individual judge in adjudication. But nothing in the reform changes the authoritative powers of the Adjudication Committee of the court (a procedural design that is fundamental to the Chinese judicial system), nor could existing reform measures be able to prevent the abuse of power under the adjudication supervision procedure. ${ }^{12}$

\subsubsection{Fused role of the judge-conciliator in judicial conciliation}

Judicial conciliation, which is an integral part of court mediation, combines the role of the adjudicator and conciliator. The process takes place in the course of the hearing by the trial judge. There are usually four stages during trial to commence judicial

\footnotetext{
${ }^{9}$ The term 'mediation statement' encompasses any court-sanctioned settlement reached under the judicial conciliation procedure and other court-directed mediation procedures.

${ }^{10}$ The only way for a pre-action settlement to be transformed into a mediation statement is to commence proceedings and settle the case under court mediation procedures.

${ }^{11}$ See Chapter 8 of this book for an analysis of the evaluation system for Chinese courts and judges.

12 See the Afterward of this book for an overview of the current judicial reforms in China.
} 
conciliation: (1) before the start of the substantive hearing (before the bench); (2) after court investigation (and before party debate); (3) after party debate (and before final submissions; and (4) after the hearing (before the rendering of judgment). ${ }^{13}$

Among the various integral processes of court mediation, judicial conciliation proves to be the most problematic and controversial due to its lack of procedural safeguards against the apparent bias of the conciliator who also hears the case.

Proponents argue that judicial conciliation embodies the historical role of the magistrate (who was both a judge and a mediator). It is also argued that the trial judge is in the best position to conduct conciliation given his knowledge about the case.

Critics, however, question the voluntariness and genuineness of the conciliation process when the conciliator is so heavily involved in the adjudication of the case. It is almost impossible for a judge-conciliator to act impartially (or at least fairly) given his exposure to the legal and factual arguments of the parties. Impartiality of the conciliator can only be fully secured if the conciliator is insulated from the litigation procedure. In common law jurisdictions, for instance, the mediator must be someone who has no conflict of interests with the parties. While the adjudicator has no conflict of 'interests' per se, there is a conflict of roles that is likely to give rise to partiality and unfairness.

\subsection{The European definition of 'mediation'}

There is nowhere better to begin the discussion about European views on mediation than the European Union's framework on mediation: DIRECTIVE 2008/52/EC OF THE EUROPEAN PARLIAMENT AND OF THE COUNCIL of 21 May 2008 on certain aspects of mediation in civil and commercial matters (Mediation Directive). While the Mediation Directive only applies to mediation in cross-border disputes, member states are free to adopt provisions of the Mediation Directive in their internal mediation processes. ${ }^{14}$ Under the Mediation Directive, mediation is defined as 'structured process, however named or referred to, whereby two or more parties to a dispute attempt by themselves, on a voluntary basis, to reach an agreement on the settlement of their dispute with the assistance of a mediator. ${ }^{15}$ However, this definition is overly wide for it to be a pragmatic working definition.

It would be fair to say that Europeans today generally view mediation as a process that possesses certain core attributes: 'Mediation is a procedure based on the voluntary participation of the parties, in which an intermediary (or multiple intermediaries) with no adjudicatory powers systematically facilitate(s) communication between the parties with the aim of enabling the parties to themselves take responsibility for resolving their disputes. ${ }^{, 16}$ From a comparative perspective of definitions of mediation, Hopt and Steffek identified that there is 'a broad consensus in terms of (1) dispute, (2) voluntary nature, (3) systematic promotion of

\footnotetext{
${ }^{13}$ NPCSC Publication 2012, p. 146.

${ }^{14}$ Para. 8 of the preamble, the Mediation Directive.

${ }^{15}$ Article 3(a) of the Mediation Directive.

${ }^{16}$ Hopt \& Steffek 2013, p.11.
} 
communication between the parties and (4) resolution for which the parties bear responsibility and where there is no decision-making power on the part of the intermediary'. ${ }^{17}$ There seems to be consensus that mediation cannot work well unless it is a predominantly voluntary process. While certain jurisdictions tend to limit the voluntary nature of mediation (by enacting rules that makes mediation mandatory prior to the commencement of proceedings, e.g. in Italy), ${ }^{18}$ voluntariness remains 'an essential element in mediation'. ${ }^{19}$ On the core attribute of systematic promotion of communication, it is observed that 'mediation is characterized by a conscious and expert support of communication between the parties rather than a spontaneous or arbitrary approach'. ${ }^{20}$ This view coincides with what Jagtenberg and de Roo described as 'modern mediation':

'By modern mediation we mean mediation as a professional activity. Mediators need to be able to demonstrate that they have mastered a new body of expert knowledge; they must be certified (at least in some countries); and they are expected to know how to navigate through a negotiation on the basis of their expertise. This sets modern mediation apart from generic or traditional mediation, where anyone could assume a mediatory role as a side-activity, operating on the basis of intuition, authority or one's life experience. ${ }^{21}$

While there are varying degrees to which the mediator may intervene with the process, there is common consensus that the mediator should not be given substantive decision-making powers. ${ }^{22}$ Settling a dispute is ultimately the business of the parties, not the mediator. ${ }^{23}$ If the mediator is too interventionist and directive, the settlement may not be completely voluntary or genuine. Andrews provided perhaps one of the most succinct summaries of a mediator's role: 'The mediator's role is to act as an independent and disinterested third party and encourage the parties to talk and to move towards a possible agreed settlement' ${ }^{24}$

Another common trait identified in the comparative survey of Hopt and Steffek was that 'the strength of mediation lies in the very way it primarily targets social conflict, and that the legal resolution merely has an auxiliary function'. ${ }^{25}$ The realization of mediation's strength in resolving social disputes must not, however, overshadow its function in the formal legal order, e.g. alleviating the caseload of the court by channeling disputes.

In addition to the four common core attributes identified by Hopt and Steffek, it is submitted that mediation confidentiality is absolutely essential for upholding the integrity of the process and allowing parties to freely exchange views in a conciliatory setting. The Mediation Directive specifically emphasized the need to provide for a common minimal threshold for mediation confidentiality. ${ }^{26}$ Given the importance of

\footnotetext{
${ }^{17}$ Hopt \& Steffek 2013, p.13.

${ }^{18}$ De Palo \& Keller 2013, p. 673.

${ }^{19}$ Hopt \& Steffek 2013, p. 12.

${ }^{20}$ Hopt \& Steffek 2013, p.13.

${ }^{21}$ Jagtenberg \& de Roo 2011, p. 7.

${ }^{22}$ Hopt \& Steffek 2013, p.12.

${ }^{23}$ Hopt \& Steffek 2013, p.12.

${ }^{24}$ Andrews 2012, para. 9.03, p. 189.

${ }^{25}$ Hopt \& Steffek 2013, p.12.

${ }^{26}$ Para. 23 of the preamble, the Mediation Directive states: 'Confidentiality in the mediation process is important and this Directive should therefore provide for a minimum degree of compatibility of civil
} 
mediation confidentiality, Article 7 of the Mediation Directive is set out below in its entirety:

\section{'Article 7 \\ Confidentiality of mediation}

1. Given that mediation is intended to take place in a manner which respects confidentiality, Member States shall ensure that, unless the parties agree otherwise, neither mediators nor those involved in the administration of the mediation process shall be compelled to give evidence in civil and commercial judicial proceedings or arbitration regarding information arising out of or in connection with a mediation process, except:

(a) where this is necessary for overriding considerations of public policy of the Member State concerned, in particular when required to ensure the protection of the best interests of children or to prevent harm to the physical or psychological integrity of a person; or

(b) where disclosure of the content of the agreement resulting from mediation is necessary in order to implement or enforce that agreement.

2. Nothing in paragraph 1 shall preclude Member States from enacting stricter measures to protect the confidentiality of mediation.'

\subsection{The Hong Kong experience}

Hong Kong inherited its legal system from England. This is the result of over-acentury-long colonial rule by the British from the mid $19^{\text {th }}$ Century to 1997 . There is no court directed mediation procedures (i.e. no judicial mediation, judicial conciliation, or facilitative judging) in Hong Kong, with the exception of some specialist procedures such as family law related proceedings. Mediations in Hong Kong are generally carried out by parties appointing an accredited mediator (an impartial third party) on the panel of the accrediting institution (the four main accrediting entities in Hong Kong have now merged into one unified entity, the Hong Kong Mediation Accreditation Association Limited (HKMAAL)). Mediation practiced by HKMAAL accredited mediators is facilitative in nature. The process neatly fits into the definition of 'modern mediation'.

Drawing inspiration, as well as adopting concrete procedural measures, from the Woolf Reforms, Hong Kong implemented its own Civil Justice Reform in April 2009 (CJR). It is an 'underlying objective' of the CJR to facilitate the settlement of disputes. $^{27}$ The court, as part of its active case management, has the duty to encourage parties to settle using mediatory procedures. It also has the duty to help parties to settle their case. The parties and their legal representatives have the duty of assisting the Court to discharge the duty in question. ${ }^{28}$ Practice Direction 31 (PD 31) was introduced to help the court in discharging this duty. Under PD 31, there will be costs consequences if it can be established by admissible materials that there was any

procedural rules with regard to how to protect the confidentiality of mediation in any subsequent civil and commercial judicial proceedings or arbitration.'

${ }^{27}$ RHC O. 1A, r. 1(e).

${ }^{28}$ PD 31 (para. 1). 
unreasonable failure of a party to engage in mediation. ${ }^{29}$ The court will not make any adverse costs order against a party on the ground of unreasonable failure to engage in mediation where the party has engaged in mediation to the minimum level of participation agreed to by the parties or as directed by the Court prior to the mediation, or where a party has a reasonable explanation for not engaging in mediation. ${ }^{30}$ In exercising its discretion on whether to impose an adverse costs order, the court is guided by PD 31 and case law. The leading case is Halsey v. Milton Keynes General NHS Trust, ${ }^{31}$ in which the English Court of Appeal held:

'In deciding whether to deprive a successful party of some or all of his costs on the grounds that he has refused to agree to ADR, it must be borne in mind that such an order is an exception to the general rule that costs should follow the event. In our view, the burden is on the unsuccessful party to show why there should be a departure from the general rule. The fundamental principle is that such departure is not justified unless it is shown (the burden being on the unsuccessful party) that the successful party acted unreasonably in refusing to agree to ADR ${ }^{32}$

In relation to the relevant factors that the court should take into account when determining whether a refusal to mediate was unreasonable, the court said:

'factors which may be relevant to the question whether a party has unreasonably refused ADR will include (but are not limited to) the following: (a) the nature of the dispute; (b) the merits of the case; (c) the extent to which other settlement methods have been attempted; (d) whether the costs of the ADR would be disproportionately high; (e) whether any delay in setting up and attending the ADR would have been prejudicial; and (f) whether the ADR had a reasonable prospect of success. We shall consider these in turn. We wish to emphasise that in many cases no single factor will be decisive, and that these factors should not be regarded as an exhaustive check-list'. ${ }^{33}$

By way of background, the court will receive a mediation certificate that provides information on (a) whether or not the plaintiff or defendant was willing to attempt mediation with the view of settlement; and (b) if the plaintiff or defendant was unwilling to attempt mediation, the reasons for not willing to do so. ${ }^{34}$

Save for a few exceptions, PD 31 applies to all civil proceedings in the CFI and the DC which have been begun by writ. ${ }^{35}$

Stakeholders generally regard the PD 31 regime as effective. An experienced mediator is of the view that the use of mediation does not prolong delays, especially if the case is suitable for mediation. He is also of the view that the mediators are generally skilful and the parties are willing and committed to resolving their disputes by mediation. ${ }^{36} \mathrm{~A}$ leading litigation practitioner commented that, after the CJR, the court is more successful than before in facilitating settlement. Under the new

\footnotetext{
${ }^{29}$ PD 31 (para. 4).

${ }^{30}$ PD 31 (para. 5).

${ }^{31}$ [2004] 1 WLR 3002.

${ }^{32}$ See [2004] 1 WLR 3002, at 3009.

33 [2004] 1 WLR 3002, at 3009.

34 Appendix B of PD 31.

${ }^{35}$ PD 31 (para. 2).

${ }^{36}$ Chan, Chan \& Chen 2014, p. 114-125.
} 
environment, parties are much more active in considering settlement (usually through mediation) at an early stage of proceedings. This increases the likelihood of settlement. $^{37}$

\subsection{Fundamental conceptual differences between contemporary Chinese mediation and mediation processes in Europe}

This book focuses only on the mediation of civil and commercial disputes in China. The discussion does not cover administrative mediation and settlement processes in criminal proceedings.

The Chinese civil mediation system is complex not only for its structure but also because of its uniqueness. The Chinese definition of 'mediation' is different from the concept of mediation as understood in Europe in the following aspects:

(1) Chinese mediation processes, in its various different forms (with the exception of private mediation of commercial disputes by established institutions) ${ }^{38}$ are in fact conciliation processes. In any event, Chinese mediation processes do not fit into the definition of 'modern mediation'. The Chinese mediator is not restricted to a facilitative role. Among other powers, the mediator could make settlement proposals, assess and comment on the facts of the case, assess and comment on the respective merits of each party's case and give directions on substantive matters where necessary. The mediation process is highly directive and interventionist. In extreme cases, the Chinese mediator would even exert pressure on the parties to accept his settlement proposal, rendering the mediation process very much like adjudication. This is contrasted with the mediation processes common in Europe where the mediator is usually an impartial third party playing predominantly a facilitative role.

(2) While procedural rules now regulate the confidentiality of mediation communications in court mediation, ${ }^{39}$ it is questionable whether judicial conciliators in practice enforce the rules on mediation confidentiality rigorously. It is also unclear whether these procedural rules apply to out-of-court mediation processes. $^{40}$

(3) There is no without prejudice privilege in China. Mediation communications (exchanged during judicial conciliation) are precluded as evidence in subsequent adjudication under Article 67 of the Civil Evidence Rules. However, such restriction is often breached in practice. For instance, the judge when rendering the final judgment is frequently swayed by information revealed in the judicial conciliation process.

(4) While mediation commonly practiced in Europe is based on the principle of voluntariness (or party autonomy), mediation in China is characterized by weak

\footnotetext{
${ }^{37}$ Chan, Chan \& Chen 2014, p. 114-125.

${ }^{38}$ See Chapter 6 of this book for an overview on commercial mediation in China.

${ }^{39}$ It remains to be seen how judges would act given the new obligation to preserve confidentiality under Article 146 of the 2015 Interpretation. Also see Article 67 of the Civil Evidence Rules.

${ }^{40}$ Pissler 2013, p. 978.
} 
party autonomy. Despite statutory protection (e.g. the principle of voluntariness in court mediation), ${ }^{41}$ parties sometimes find themselves pressured or coerced by the mediator into a settlement. The Chinese mediator wields greater power than its European counterpart. Such power commonly includes the authority to make settlement proposals, commenting on the legal issues, fact-finding and 'assisting' the parties to understand their relative positions with the view of reaching settlement.

(5) The European mediator is focused entirely on finding an amicable settlement based on common interests of the parties. While the interests of the parties are an important factor in Chinese mediation, party interests sometimes could not dictate the outcome of the mediation. The reason for this is that Chinese mediation is characterized by the notion that all dispute resolutions must take into account findings of facts and 'substantive justice'.

(6) In Chinese 'judicial mediation', which is an integral part of the wider process of court mediation, the trial judge is empowered to conciliate before, during or after a hearing. The judge assumes a fused role of the conciliator-adjudicator, at one moment examining the witness and at another moment proposes settlement terms to the parties. The Chinese mode of judicial conciliation has characteristics of facilitative judging. ${ }^{42} \mathrm{~A}$ 'mediated settlement' has the legal quality of a civil judgment and, at times, also possesses the substantive quality of a de facto reasoned decision (albeit in an abridged form). Chinese judicial conciliation bears no resemblance to judicial mediation practiced in a number of jurisdictions Europe. $^{43}$

(7) The role of the Chinese courts in pre-action mediation and other conciliatory processes is unique in many ways. Compared to its European counterparts, the Chinese court plays a relatively intrusive role in the private settlement of disputes. The court could interfere with the private negotiations of parties by sending an assistant to 'supervise' the negotiation in a process called 'assisted reconciliation' (xiezhu hejie (协助和解)). Furthermore, under the policy of 'Grand Mediation' (da tiaojie (大调解)), the docketing division of the court is entrusted with the mandate to turn away as many disputes as possible. The practice of pressuring parties to settle by delaying docketing of their case is widespread in some basiclevel courts. ${ }^{44}$

(8) The policy of 'prioritizing mediation' (tiaojie youxian (调解优先)) has been an overriding policy of the Chinese judiciary as early as 2002. It reached its heights during SPC President Wang Shenjun's tenure (March 2008 - March 2013). Although the emphasis was slightly different at every stage, the period between

\footnotetext{
${ }^{41}$ Article 93 of the Code.

${ }^{42}$ Alexander 2009, p. 139.

${ }^{43}$ Consider Roth \& Gherdane 2013, p. 259: in discussing judicial mediation in the context of Austrian civil procedure, the learned contributors said, '[It] is probably correct that attempts at reaching an amicable arrangement in a separate, obligatory conciliation hearing or attempts at reconciliation in divorce proceedings do not fall under the definition of mediation. This follows from the absence of voluntariness in these examples and from the Mediation Act precluding decision-making organs (Entscheidungsorgane) from acting as mediators'.
}

${ }^{44}$ Interview Ref: 2012/3. 
2004 and 2013 can be characterized as the era of mediation. Under the policy of prioritizing mediation, mediation became a political tool in the maintenance of a 'Socialist harmonious society' (shehui zhuyi hexie shehui). Judges were encouraged to settle as many cases as possible by mediation and reduce rendering judgments. At one point, a 'zero judgment' court was considered the role model of Chinese justice. ${ }^{45}$ This political function overshadows the critical functions that adjudication plays in a legal order, e.g. norm declaring and rights enforcement functions.

(9) As a significant proportion of litigants in China are unrepresented, the judge plays a didactic and supervisory role in civil litigation. This role is extended to judicial conciliation. In discharging this duty, the Chinese judge informs the litigants of their respective legal positions, the options available and the possible outcome if the case is not settled. This didactic and supervisory role is alien to a European judge.

\subsection{The Chinese court system}

\subsubsection{Vertical hierarchy of the Chinese judiciary}

The Chinese court system has four levels: the basic-level people's courts at the county level (or municipal districts), the intermediate people's courts at municipality or prefecture level, the high people's courts at provincial level (or autonomous regions/ municipalities directly under the Central People's Government), and the Supreme People's Court (SPC) at the apex of the court system. ${ }^{46}$

The basic-level court adjudicates criminal and civil cases of first instance. When a basic-level court considers that a case it is handling is of major importance and requires trial by a higher level court, it may request that the case be transferred to that court for trial. ${ }^{47}$ The basic-level courts are entrusted with the mandate to direct the work of people's mediation committees. ${ }^{48}$

The intermediate court handles the following cases: (1) cases of first instance assigned by laws and decrees to its jurisdiction; (2) cases of first instance transferred from the basic-level courts; (3) appeals or protests lodged against judgments and rulings of basic-level courts; and (4) cases of protests lodged by the people's procuratorates in accordance with the procedures of adjudication supervision. When an intermediate court considers that a case it is handling is of major importance and requires trial by the a higher level court, it may request that the case be transferred to that court for trial. ${ }^{49}$

The provincial high court handles the following cases: (1) cases of first instance assigned by laws and decrees to its jurisdiction; (2) cases of first instance transferred

\footnotetext{
${ }^{45}$ Peng 2011, p. 52-58.

${ }^{46}$ Chen 2011, p. 182.

${ }^{47}$ Article 20 of the Organic Law.

${ }^{48}$ Article 21 of the Organic Law.

${ }^{49}$ Article 24 of the Organic Law.
} 
from courts at lower levels; (3) appeals and protests lodged against judgments and rulings of courts at lower levels; and (4) cases of protests lodged by people's procuratorates in accordance with the procedure of adjudication supervision. ${ }^{50}$

The civil bench of the Chinese court is divided into a number of divisions, usually four different 'civil divisions'. The Fourth Civil Division is commonly designated as the division that handles exclusively foreign-related civil and commercial disputes. A specific division is designated to handle 'purely civil' cases (e.g. matrimonial disputes, personal injury cases).

\subsubsection{The role of the Supreme People's Court}

The SPC handles the following cases: (1) cases of first instance assigned by laws and decrees to its jurisdiction and which it considers should be tried by itself; (2) appeals and protests lodged against judgments and orders of higher people's courts and special people's courts; and (3) cases of protests lodged by the Supreme People's Procuratorate in accordance with the procedures of judicial supervision. ${ }^{51}$

The SPC supervises the work of lower courts. It also performs a regulatory role in that it gives interpretation on questions concerning specific application of laws and decrees in judicial proceedings. ${ }^{52}$ The judicial opinions and interpretations of the SPC (on matters relating to civil justice and procedure) are de facto 'statutory instruments' in practice. The Civil Procedure Law of the People's Republic of China (Code) must be read in conjunction with these opinions and interpretations. Generally speaking, but in no way being conclusive, 'regulations' (or 'some provisions') (guiding (规定)) are binding judicial interpretations of the SPC, which must be followed by all courts. 'Notices' (tongzhi (通知)) and 'opinions' (yijian (意见)), on the other hand, are policy documents only. They do not acquire the legal status of binding judicial interpretations. $^{53}$

The SPC now issues 'guiding cases' (指导案例) regularly with the aim of providing a more uniform exposition of the jurisprudence. The guiding cases are not meant to be 'case law' (in the common law sense), but courts are expected to follow the principles set out in them. The actual effectiveness of 'guiding cases' remains to be tested. $^{54}$

\footnotetext{
${ }^{50}$ Article 27 of the Organic Law.

${ }^{51}$ Article 31 of the Organic Law.

${ }^{52}$ Article 32 of the Organic Law.

${ }^{53}$ This general principle is subject to a few exceptions, i.e. Notice of the Supreme People's Court on Applying the Provisions on Time Limit for Producing Evidence of the Some Provisions on Evidence in Civil Procedures and the Opinions of the Supreme People's Court on Some Issues Concerning the Application of the Civil Procedure Law of the People's Republic of China.

${ }^{54}$ An intellectual property judge at a basic-level court in a leading commercial city in China believed that the significance of the Guiding Cases system of the SPC has been exaggerated by foreign lawyers and scholars: Interview Ref: 2013/4.
} 


\subsection{Methodology: empirical enquiry}

One of the aims of this work is to explore the various procedural issues of mediation within China's civil justice system. While there are quite a number of articles of the subject from a socio-legal perspective (and there is an abundance of overviews on the subject) ${ }^{55}$ a focused procedural study of this subject in the English language is lacking. The intention of writing this book is therefore to fill a gap in the international literature. For instance, the question of whether access to justice is hampered by the judicial preference for mediation (especially the controversial process of judicial conciliation) in civil lawsuits will be explored in detail. ${ }^{56}$ It is hoped that by drilling into detailed procedural rules and practice, a clear, impartial and holistic view of the contemporary Chinese civil justice landscape could be presented. The proceduralist perspective on China's civil justice under the policy that preferred mediation over adjudication is supplemented by an empirical enquiry into (using the qualitative empirical method) frontline judicial conciliation practice based on two surveys: (a) a survey involving 128 judges from 24 different courts in China (11 intermediate courts and 13 basic-level courts) responding to a questionnaire on judicial conciliation (14 questions); ${ }^{57}$ and (b) a survey involving 15 litigation practitioners based in major commercial cities in China responding to a questionnaire on judicial conciliation (14 questions) ${ }^{58}$ The analysis is supplemented by a number of interviews with judges from three different levels of the Chinese judiciary and practitioners since March $2013^{59}$ and selected primary materials taken from basic-level and intermediate courts, including court internal guidelines and policy papers. Unlike existing empirical studies on Chinese courts that tend to focus only on a few courts, ${ }^{60}$ the empirical study undertaken in this work encompasses 24 courts from a wide geographical spread. The larger scope of the survey strengthens the representativeness of the study. Obviously, the wider scope also limits the depth into which the study could go. But China's geographic diversity in judicial practice calls for a wider sampling. For a detailed description of the empirical methodology, refer to Chapter 5 of this book.

Regarding the interviews, there were in total 29 interviews with civil and commercial judges from three different levels of the Chinese judiciary (basic-level courts, intermediate courts and provincial high courts), litigation practitioners and a former court intern (currently a legal academic in China). ${ }^{61}$ The interviews were conducted on an anonymous basis between May 2012 and February 2015. It was also understood that in using the contents of these interviews, the identity of their

\footnotetext{
${ }^{55} \mathrm{Ng} \&$ He 2014, p. 285-312.

${ }^{56}$ See Chapter 4 of this book.

${ }^{57} 67$ responses were from intermediate court judges and 61 responses were from basic-level court judges. The survey was conducted between May and June 2014 (the first questionnaire response was received on 4 May 2014 and the last was received on 21 June 2014), more than one year since the SPC had a major change in leadership (Zhou Qiang replaced Wang Shengjun as President of the SPC in March 2013).

${ }^{58}$ This survey was conducted from September to November 2014.

${ }^{59}$ Former President of the SPC Wang Shengjun stepped down in March 2013. Hence the period following March 2013 under the SPC's new leadership (with Zhou Qiang as the President of the SPC) is considered the beginning of a new age of reform in Chinese civil justice.

${ }^{60}$ See Ng \& He 2014, p. 288: 'The study is based on detailed, ethnographic observations of more than twenty civil trials we attended in 2011, at a district court in City Z in southern China'.

${ }^{61}$ Note that among the 29 interviews, some of the interviews were with the same interviewee at different points in time, e.g. Interview Ref: 2012/1 and Interview Ref: 2013/13
} 
respective courts would not be disclosed. A brief description of each interviewee can be found in the 'Interview Log' of this book. ${ }^{62}$ Interviews were conducted either by telephone or through face-to-face meetings. Interviews were either tape recorded (if the interviewee agreed) or recorded by way of detailed attendance notes produced by the author right after the interviews.

\subsection{Synthesizing thoughts in previously published articles}

This book synthesizes content from a number of the author's published articles (see Appendix V for a list of these articles). For co-authored articles, only the content of those parts written by the author is featured in this book. While the main arguments in the said articles are repeated in this book, such arguments are further developed and expanded within the overall context of civil mediation in China, providing a more holistic perspective on the subject. For instance, the article 'The Enigma of Civil Justice in Imperial China: A Legal Historical Enquiry ${ }^{63}$ was substantially expanded to take into account the effect of rules and customs that regulated community-based mediation in imperial China, as well as the civil mediation regime of Republican China (1911-1949), the Ma Xiwu adjudication methodology and contemporary trends in the development of mediation institutions in China.

\footnotetext{
${ }^{62}$ See Appendix III.

${ }^{63}$ Maastricht Journal of European and Comparative Law, Vol. 19(2), 2012, p. 317-337.
} 
Chapter 2:

Legal history of civil mediation in China 


\section{LEGAL HISTORY OF CIVIL MEDIATION IN CHINA}

\subsection{Chinese legal culture of wu song}

Confucianism projected the ideal society as one free from litigation (wu song). Disputes should be resolved through mediation to preserve social harmony. This cultural norm is still very much alive today and impacts the conduct of court mediation.

The fundamental principles of party autonomy, the neutrality of the mediator and mediation confidentiality in Western mediation ${ }^{64}$ do not fit well with the Chinese traditional legal culture. Mediation in imperial China had strong didactic functions. Mediators had the inherent mandate to educate the people on Confucian morals and the law. In this regard, traditional Chinese mediation differed from Western mediation in that the Chinese mediator was not an impartial and neutral third party, but rather a conciliator with a quasi-official mandate to advance the objectives of the governing discourse and value system. It remains to be seen how this facet of Chinese legal tradition affects contemporary court mediation. ${ }^{65}$

\subsection{Mediation as a communal disputes resolution mechanism}

\subsubsection{Official recognition of the informal justice system}

Scholars have debated whether community-based mediation had been given some form of official status in China's legal history. In fact mediation was incorporated into the legal system of the Yuan Dynasty (1271-1368 AD) through codification (as $l u$ ( 律)). ${ }^{66}$ Some scholars argue that the Yuan Dynasty was the only time in China's imperial history that mediation was officially codified as $l u$. However, authoritative documents other than $l u$ (such as imperial announcements) also carried the legal effect equivalent or similar to $l u .{ }^{67}$ During the Ming Dynasty (1368-1644 AD), the Ming imperial code recognized the status of community mediation as the 'firstinstance' forum for civil dispute resolution. Disputants were required to go through mediation first before resorting to magisterial adjudication. ${ }^{68}$

Whether officially codified or as customary law, ${ }^{69}$ it is fair to say that communitybased mediation was given some form of recognition by the imperial state as an

\footnotetext{
64 'Western mediation', used generically here, refers to a facilitative process conducted by an impartial and independent third party mediator.

${ }^{65}$ Chan 2012b, p. 252.

${ }^{66}$ Clauses and Paragraphs of the United System of Yuan, Volume Sixteen, 'Edicts on Land' (Tongzhi Tiaoge: Juan Shiliu: Tian Ling), quoted in Zeng 2009, p. 4.

${ }^{67}$ For instance, the Announcement for Civil Education (jiao min bang wen) in the Ming Dynasty had been widely accepted by legal historians to be the most authoritative document that entrenched the societal dispute resolution system at the basic village level. See Han 2000, p. 137.

${ }^{68}$ Lin 2002, p. 310.

${ }^{69}$ Zeng observed, 'In view of its popular use and recognition by the government, instead of referring to mediation as a "system" of regulations, perhaps it is more appropriate to think of mediation as a set of socially accepted customary laws. These customary laws had gained not only popular acceptance but support from the State.' See Zeng 2009, p. 5.
} 
important method for civil disputes resolution. This position is in line with the imperial governing policy of devolving the administration of civil disputes to the local communities. Even magistrates would not take up a lawsuit lightly if they believed that informal channels of justice have not been exhausted. ${ }^{70} \mathrm{~A}$ similar feature can be identified in the magistrate's courts of the Song Dynasty (960-1279 AD). The magistrates demonstrated a strong preference for community mediation where the case involved parties from the same family or clan.

\subsubsection{Special features of the informal justice system}

The informal justice system in imperial China had a number of distinguishing features.

The first feature was the presence of strong local community networks that formed the basis of the system. Community interests and social harmony had priority over individual interests. The typical village community resolved civil disputes through mediation conducted by village leaders. A close resemblance can be found in Tokugawa Japan (1603-1867 AD) where harmony (wa) was the emphasis of society. ${ }^{71}$

The second feature was the didactic function of community mediation. Mediators had the inherent mandate to educate the people on Confucian morals and the law.

Another interesting feature of the informal justice system was its organic connection with the formal justice system. A magistrate, before proceeding to a court hearing (the last stage of a lawsuit), would refer the case to a local quasi-official community leader for mediation. Huang coined the term the 'third realm of justice' to describe this intersection between formal justice and informal justice. ${ }^{72}$

It has been argued that state law played a key role in traditional community mediation. ${ }^{73}$ With reference to a number of societal mediation examples, Huang observed:

'We can see from this example how the triad of state law, the community's sense of right and wrong, and compromise to maintain peace all operated together. Obviously, it would be wrong to assume state law did not matter; once the lawsuit was filed, or even just threatened, the formal system in effect set the negotiating baseline from which the compromise had to be worked out. ${ }^{74}$

Huang advanced three main factors affecting the mediation process: the 'primacy of compromise' (striking a compromise remained the primary goal in mediation), the relevance of state law, and the normative force of common sense right and wrong. ${ }^{75}$

\footnotetext{
${ }^{70}$ Huang 1996, p. 112.

${ }^{71}$ Corne 1990 , p. 349

${ }^{72}$ Huang 1996, p. 110-137.

${ }^{73}$ For instance, Gao argued that (in the context of the Song Dynasty) where there was a clear legal right or wrong in the case, societal mediation settlement could take a form of a 'quasi-judgment' in which the law was simply applied to dictate the result of the settlement: Gao 2005, p. 108.

${ }^{74}$ Huang 1996, p. 68.

${ }^{75}$ Huang 1996, p. 61-68.
} 


\subsubsection{Community mediation in the Song, Yuan, Ming and Qing periods}

As with other periods, societal mediation during the Song Dynasty was conducted by reputable individuals or community leaders. These individuals were familiar with the local customs and community interests. Unlike the Yuan and Ming Dynasties, the local village organizations of the Song Dynasty were conferred less administrative authority. For instance, the extensive quasi-judicial powers conferred to a Yuan she (社) were absent in the Song village organizations. It would be interesting to investigate the extent to which the nature and powers of village organization affected the quality of societal mediation. ${ }^{76}$

The village community (she) was the primary administrative organization in the Yuan Dynasty. ${ }^{77}$ The head of the village community (she zhang) wielded enormous powers. They were not government officials but community leaders with stature. It was argued that the emergence of she mediation was the result of rise of civil disputes particularly in matrimonial and property related matters. Records of cases confirmed that she zhang was conferred official powers to mediate within his she. Another piece of evidence supporting the conferral of such powers was that the prohibition of basic level officials to deal with civil cases did not extend to she zhang. Case forms for filing civil litigation frequently mentioned she zhang performing mediation on the community level. ${ }^{78}$ It was observed that mediation by she zhang was generally highly effective. ${ }^{79}$ It would be very unusual for parties to re-open the dispute once mediation had reached a settlement. In fact under the law, so long as there was no procedural impropriety with the mediation process, parties were forbidden to take the matter to court after a settlement had been reached. This was a unique feature in the Yuan civil justice system and had effectively elevated the status of she mediation to almost the equivalence of judicial mediation. In the Yuan Code (yuan dian zhang), the most important legal text in the period, 'she zhang' appeared 44 times. The critical role of she zhang in the Yuan administrative architecture calls for an in-depth study of the functions performed by she zhang. So important was she zhang's mediation function that the state issued a 'she zhang memorandum' (she zhang shui zhi) as their legal manual for mediation. ${ }^{80}$

The 'statutory basis' of mediation by community elders (li laoren (里老人)) during the Ming period was the Jiao Min Bang Wen, which essentially was an imperial edict relating to the education of the volks on the community level. ${ }^{81}$ The article relating to the mediatory duties and authority of community elders is set out below:

\footnotetext{
${ }^{76} \mathrm{Hu} 2001$, p. 44.

${ }^{77}$ She was formally established under the Yuan Code (yuan dian zhang). Under normal circumstances, a she was comprised of 50 households. For regions with denser population, a she could exceed 100 households: Hu 2001, p. 44.

${ }^{78} \mathrm{Hu} 2001$, p. 44.

${ }^{79}$ She mediation can be distinguished from normal societal mediation in a number of aspects: (i) the codification of mediation revealed the state conscious decision to elevate societal mediation to the centre stage of civil dispute resolution. Hence, she mediation had greater normative force than normal societal mediation; (ii) the she zhang was conferred quasi-judicial powers to mediate by the state unlike normal societal mediation which was purely a matter within the community; and (iii) the de facto legal force given to mediation settlement (transforming it into a quasi-court judgment).

${ }^{80} \mathrm{Hu} 2007$, p. 42-50.

${ }^{81}$ Bang Wen was a special form of law that was the most effective means of communicating the imperial edict in the Ming Dynasty: Han 2000, p. 137-147.
} 
'From now on, the community elders (li laoren) must admonish the people of the li community. Whenever there are minor matters such as matrimony, property and physical conflict, the people should exercise tolerance. If there is an abuse that offends the principles of qing and $l i$, the aggrieved person should approach the community elder, who will consider the matter and make a decision on the appropriate sanction. ${ }^{82}$

From the above article, one can see that the li lao community based mediation had both didactic and disputes resolution functions. It also revealed a consistency in the classification of civil matters as 'minor matters' throughout China's imperial history. From the state's perspective, if possible, these matters were best left to the community elders at first instance, and not to the administrative machinery. Extensive case studies were conducted (mainly by Japanese scholars) on the practice of li lao mediation. Despite these case analyses had shown that the actual operation of this mediation regime was not as effective as what had been contemplated in the Jiao Min Bang Wen (especially in the latter half of the dynasty where disputants were more inclined to have their disputes resolved by magistrates), the system did play an instrumental role in the resolution of civil dispute. The reasons for the entrenchment of this mediation system were (i) the changing social circumstances (including the massive unrest after the first half of the dynasty) created a mismatch between the law as originally enacted and the actual situation; and (ii) the system corresponded with the governing philosophy of the Ming imperial court (e.g. the notion of 'the exemplary subjects governing their fellow volks' (yi liang min zhi min)). ${ }^{83}$ The emergence of private mediation settlement agreements was another defining feature of informal justice system of the Ming period. ${ }^{84}$

Mediation in the Qing Dynasty has always been the prime focus of academic research. Huang's research in this area is groundbreaking not only its conclusion but also the unique methodology adopted. The mediation samples (all from villages of Northern China) concerned inter-village disputes, an area where existing literature is

\footnotetext{
${ }^{82}$ Article 23 of the Jiao Min Bang Wen quoted in Han 2000, p. 142.

${ }^{83}$ Han 2000, p. 146.

${ }^{84}$ Extensive study has been conducted on the practice of community-based mediation in Huizhou (徽 州). The study revealed a wealth of private mediation settlement agreements. These agreements had consistent features: (i) witnessed by a third party; (ii) included the name of the mediator; and (ii) provided for the sanction if the agreement was breached. Sometimes the mediation settlement took the form of a guarantee ( $p i z i$ 批字). It has been argued that these agreements were effective in ensuring that settlements were enforced: See Tian 2009, p.1-10. While the abundance of case examples in the repository of private settlement agreements provided a synopsis of the operation of community based mediation during the Ming Dynasty, one would need to resort to other historical archives to gauge the dynamics of judicial mediation (e.g. private collection of judgments of magistrates). Researching the development of contract law would shed light on the operation of these community-based mediation settlement agreements. Before Ming, the records of mediations settlement had been patchy and incomplete. The emergence of settlement agreements benefited the study of community-based mediation of this period. However, it remains to be seen how helpful these records are in explaining the dynamics of the mediation process and the "reasoning" behind the settlement. It would be interesting to see how courts enforced these settlement agreements. Consistency in enforcement would fortify the normative effect of community-based mediation. Collections of judgments of local officials had limitations. At best they reflect the practice of judicial mediation in certain localities. The extent to which one can rely on these judgments in ascertaining the general norms in judicial mediation during the Ming Dynasty remains a subject to be explored.
} 
the weakest. ${ }^{85}$ Huang distinguished those mediations where a middleman mediator could be identified (usually relating to cases concerning contractual and transactional disputes) from those where no middleman could be summoned as mediator (usually relating to cases concerning family and neighbour disputes) ${ }^{86}$ Unlike mediations conducted by middlemen, kin-group based mediations, especially in relation to household division, often reached definitive results and disputes often end with a settlement without the need to go to court. ${ }^{87}$ As for mediations conducted by middlemen, given the disputes were contractually based there would be greater legal clarity and certainty. Hence disputants were more inclined to resort to formal adjudication should mediation fail to meet their objectives.

\subsection{Magisterial adjudication: the role of mediation in civil dispute resolution in imperial China}

\subsubsection{Introduction}

Confucianism projected the ideal society as one free from litigation (wu song). Disputes should be resolved through mediation to preserve social harmony. On the basis of the Confucian culture, Shiga argued that civil justice in imperial China was a form of 'Kadi' justice in which magistrates would arbitrarily decide cases following Confucian moral principles rather than statutory law. ${ }^{88}$ However, recent literature questioned this view. Based on extensive empirical research, Philip Huang (among others) argued that magisterial adjudication did take place in Qing China and magistrates generally followed the law in determining civil disputes. ${ }^{89}$ Focusing on the Song (960-1279 AD), Yuan (1271-1368 AD), Ming (1368-1644 AD), and Qing (1644-1911 AD) periods, this article investigates the two conflicting lines of argument in search of the true nature of civil justice in imperial China. It is a misconception that imperial China had no consistent statutory framework of civil law. Nor was it true that civil justice was arbitrary and irrational. These misconceptions could be avoided if the historical context of imperial China is carefully considered. In fact, any meaningful research on China's traditional justice system must be premised on a thorough understanding of the governing structure of the empire, the Chinese traditional legal culture and the correlation between the country's legal history and modern legal development. The Chinese traditional legal culture was unique in many ways. The Chinese understanding of law was very different from the West. For instance, drafters of the imperial statutory provisions on civil matters prized practicality much more than logical consistency. ${ }^{90}$ The adjudicative discourse of the magistrates followed a multiple-valued logic that sought to find a balance between

\footnotetext{
${ }^{85}$ Huang 1996, p. 51.

${ }^{86}$ Huang, 1996, p. 52-61.

${ }^{87}$ Huang observed:

'Once agreement was reached and the distribution settled by drawing lots, a formal document was drawn up, spelling out the properties divided, and was signed by the brothers and witnessed by the middlemen. It was a process that left little room for later challenges and disputes. That was why household division, thought he principal source of disputes in the villages, was not a major category of lawsuits.'

Huang, 1996, p. 60-61.

${ }^{88}$ Shiga 1988 , p. 18.

${ }^{89}$ Huang 1996, p. 1-20.

${ }^{90}$ Huang 2010, p. 11.
} 
statutory law and non-statutory norms (including local customs and Confucian values). ${ }^{91}$

The reality was that civil justice in imperial China was much more litigious than the Confucian ideal society. ${ }^{92}$ While lacking jurisprudence in civil law, the 'civil' entitlements of disputants were generally enforced in magisterial lawsuits. ${ }^{93}$

\subsubsection{Understanding China's imperial civil justice within the historical context}

\subsubsection{1. $\quad$ Limitations of the Weberian model}

In the ideal Weberian prototype, law should be formal and rational. As Huang noted, formal-rational law is capable of 'being derived by logical reasoning from [consistent] abstract legal propositions'. ${ }^{94}$ These abstract legal propositions have universal applicability. ${ }^{95}$ At the opposite of formal-rational law is the substantive and irrational category, under which law is derived 'not from logical reasoning based on consistent abstract legal propositions, but from the whims of the ruler. ${ }^{96}$ Weber described this type of substantive and irrational legality as 'Kadi justice', a 'Solomonic justice' based not on rational law but the arbitrary and irrational exercise of the decisionmaker's discretion. ${ }^{97}$

Applying the Weberian straightjacket dichotomy, the imperial Chinese civil legality could not fit into the formal-rational category and therefore is at risk of falling within the substantive irrational category. ${ }^{98}$ Shiga argued that magisterial lawsuits were not adjudication in the Western sense at all as there was an absence of systemic application of statutory law and that no formal procedures were in place. ${ }^{99}$ Decisions were made on the basis of the magistrate's common-sense understanding of righteousness instead of the law. The process by which disputes were resolved was neither formal nor litigious. He argued that magistrates settled disputes by mediation. On this basis, Shiga observed that the imperial civil justice system was a form of mediatory justice (or Kadi justice) that served didactic objectives and detached from the (relatively rational) criminal legality of the imperial state. ${ }^{100}$

\footnotetext{
${ }^{91}$ Lin 2003, p. 93.

${ }^{92}$ Huang 1996, p. 14-15.

${ }^{93}$ Huang 2001, p. 26-27.

${ }^{94}$ Huang 1996, p. 223.

${ }^{95}$ Huang 2010, p. 7.

${ }^{96}$ Huang 1996, p. 224.

${ }^{97}$ See Huang 1996, p. 2. The term 'Kadi justice' was frequently used by Weber to describe a form of justice based not on rational law but on the irrational exercise of ethical judgment. It is a form of justice that is 'individualistic in nature as well as substantive'. The concept is 'central to Weber's sociology of law with its preoccupation with rational versus irrational types of law': see Swedberg 2005, p. 136.

98 Lin 2002, p. 49. Furthermore, consider observations in Peerenboom 2003, p. 39-40: 'magistrates...allegedly determined what was best in a given situation based on their own judgement and interpretation of customary norms (li) rather than by appeal to fixed standards or principles of general applicability, whether legal or non-legal. In Weber's terminology, such a system is nothing more than a kind of arbitrary or irrational Kadi justice.'

${ }^{99}$ Shiga 1988, p. 24.

${ }^{100}$ Shiga distinguished the adjudicative methodologies between civil and criminal cases. In criminal lawsuits, the imperial codes provisions were generally applied and expressly cited in judgments.
} 
As Huang noted, the Weberian 'binary theoretical construction' ignored the space between the extremities of formal-rational justice and Kadi justice. ${ }^{101}$ Shiga's approach of adopting the strict Weberian categorizations in analysing traditional justice is deficient on a number of fronts. Firstly, strict compliance with the statutory law (through the deductive reasoning of the judge) is viewed as the ultimate test of whether a system is formal or not. However, modern common law systems could not fully comply with the test of formalism, ${ }^{102}$ as case law itself was developed through inductive reasoning often in the absence (or through the gaps) of statutory law. Hence, even common law does not fall under the formal-rational category. It shows that more categories need to be devised to explain the systems between the two extremities. Huang observed, 'Weber himself actually moved beyond these simple dichotomies with a tentative formulation that he termed "substantive rationality" (...) [but] he did not elaborate on the concept at any length. ${ }^{103}$ The substantive-rational category illustrates a very important point - a justice system (like the common law system) does not need to attain the purest form of formal-rationality in order to be rational and fair. There is a very wide spectrum between the prototypes of formal-rational justice and Kadi justice. ${ }^{104}$ Common law and traditional Chinese civil justice fall within this spectrum, with the former closer to the formal-rational ideal type and the latter not as close.

Secondly, Shiga overlooked the practical significance of state law in magisterial adjudication. While China never invented a comprehensive and systemic civil code according to Western standards, the imperial codes had detailed and specific provisions that dealt with civil matters. ${ }^{105}$ The traditional civil justice system was founded on statutory law and a complex web of non-statutory norms comprising local customs and Confucian ethics. Only by understanding the interactions among these factors and the magisterial adjudicative discourse could one possibly obtain an unbiased and accurate overview of traditional justice in China.

Thirdly, adopting a strict Weberian approach risks ignoring the political realities of imperial China. Traditionally, the central authority relied heavily on the selfregulation of the local communities. Huang noted that civil matters were considered 'minor matters' in Qing China and were 'supposed to be dealt with mainly by society itself'. ${ }^{106}$ The imperial authority adopted what Huang described as the 'centralized minimalist' approach. ${ }^{107}$ The approach made state interference in civil disputes only necessary (and indeed only appropriate) when the local communities failed to resolve the disputes. Given this governing strategy, it is only reasonable to expect an inherent preference for community-based mediation in traditional Chinese justice. However, from a strict Weberian perspective, a formal-rational legal system cannot tolerate such an inherent preference. Chinese imperial civil justice was not Kadi justice as rational adjudication based on the law existed. Nor does it fall into the formal-rational category. Even if one insists on using the Weberian model, Chinese imperial justice

According to Shiga, in civil lawsuits, statutory provisions were not applied and magistrates generally resorted to personal (Confucian) values to determine the outcome of a case: see Shiga 1988, p. 21-25.

${ }^{101}$ Huang 1996, p. 19.

${ }^{102}$ Huang 2010, p. 7.

${ }^{103}$ Huang 1996, p. 224.

${ }^{104}$ Huang 1996, p. 227.

${ }^{105}$ Huang 1996, p. 6.

${ }^{106}$ Huang 1996, p. 6.

${ }^{107}$ Huang 2010, p. 63-86. 
was a product in between the two categories. Huang argued, 'Qing law was clearly rational in the sense of being consistent and predictable, though not in the sense of being formalist'. ${ }^{108}$

\subsubsection{The nexus between Chinese legal history and China's contemporary legality}

The study of Chinese legal history has long been distorted by the orientalist discourse that considered legal history to be completely irrelevant to China's modern legal development. Interestingly, some crafters of the late Qing and Republican civil codes (during the early 20th century) shared the same paradigm: ${ }^{109}$ the study of Chinese legal history had no practical value if it had nothing to do with the present situation in China. The best rebuttal to the orientalist discourse is by revealing the facts. Examples in the context of civil justice illustrate a clear nexus between legal history and modern legal development.

China today is a strong advocate for court mediation. Despite the move in the 1990s towards constructing a civil justice system that emphasized adjudication, recent reforms have turned the clock back. Since the turn of the century, court mediation has become the officially preferred method for resolving civil disputes, a movement propelled by the policy objective of maintaining 'social harmony'. The concept of promoting non-adversarial resolution of civil disputes in the name of 'social harmony' resonates with the Confucian ideal of a litigation-free society (wu song). The conduct of court mediation, under which the judge would also act as the mediator, also bears close resemblance to the mediatory role magistrates sometimes played in the imperial past. Another example is the transformation of community mediation of the imperial age into countryside mediation by state-approved cadres during the Nationalist period. ${ }^{110}$ It can even be argued that community mediation of the imperial age formed the cultural foundation of people's mediation in contemporary China. Indeed, the prevalent view today is that people's mediation has its roots in traditional Chinese culture. ${ }^{111}$ A further example is the tradition of recognition (or rejection) by state law of local customary rules in imperial China. This tradition survived the demise of the empire as seen in the specific treatment given to local customs by the Republican Civil Code before 1949. ${ }^{12}$

A complete adoption of Western law without due consideration of the special legalhistorical circumstances of China is bound to end in failure. ${ }^{113}$ This is the value of research in Chinese legal history - to investigate the nexus between the past and the present and identify the important traditional underpinnings of law relevant for present day purposes.

\footnotetext{
${ }^{108}$ Huang 1996, p. 226.

${ }^{109}$ Huang 2010, p. 253.

${ }^{110}$ Huang 2010, p. 18.

${ }^{111}$ Mo 2009 , p. 77 and FN 8.

112 Chen L. 2010, p. 173.

${ }^{113}$ Huang 2001, p. 210.
} 


\subsubsection{3.}

To understand China's traditional legal culture, one must pay particular attention to the country's unique historical circumstances. For instance, the magistrate's court which adjudicated on civil disputes could not be simply understood as a judicial body. ${ }^{114}$ The magistrate (zhixian or zhizhou) had multiple roles and exercised administrative as well as judicial powers. While being one of the lowest ranking officials in the imperial power structure, the magistrate was conferred extensive authority at the county level. Liang noted that the magistrate presided over administrative tasks such as 'the maintenance of order, the collection of taxes, the handling of cases, and the promotion of education'. ${ }^{115}$ With such multiplicity of roles, it would be unrealistic to expect a magistrate to discharge his adjudicatory functions with the same devotion (and diligence) as a modern judge. While there was never judicial independence in the Western sense in imperial China, the magistrates were allowed substantial autonomy to handle local civil disputes. Only rarely would a magistrate be asked to report to a superior authority regarding a civil judgment. Despite the lack of an autonomous and sophisticated system of civil procedure, lawsuits brought at the magistrate's court must follow a procedural timetable. In the Qing Dynasty, there were three stages in civil adjudication: the first stage involved the filing of the claim and the magistrate giving initial comments, the second stage was similar to a pre-trial review session and the final stage was the court hearing. ${ }^{116}$ It would therefore be inconsistent with historical reality to criticize the traditional Chinese civil justice system as lacking in any procedural formality.

The law, within the Chinese historical context, was not just concerned with statutory rules. The importance of principles underlying the practice of civil adjudication had been underplayed for many years. The positivist approach turns a blind eye to the rich content of civil law in imperial China embedded in the code provisions dealing with 'minor matters' (civil matters), local customary rules and the norms of practice.

\subsubsection{The need of a paradigm shift: from Weberian formalism to the practice-based legality of China}

Aside from the dogma of orientalism, Weberian formalism (and its emphasis on deductive reasoning) has its limitations when used as a research tool for Chinese legal history. Firstly, the Chinese legal culture emphasized practice rather than abstract legal concepts. ${ }^{117}$ Huang explained, 'a particularly important characteristic of Chinese law is that, with respect to the duality of experience and theory, it privileges experience, but not to the neglect of theory'. ${ }^{118}$ Secondly, adjudication involved an inductive reasoning process (similar to common law) rather than deductive reasoning. Thirdly, statutory law was only a subset of the traditional legal culture. Non-statutory norms (such as local customs) were relevant in civil adjudication. Fourthly, Confucian moral values impacted greatly on the imperial legislative design, making it possible for seemingly contradictory provisions to coexist. ${ }^{119}$ Huang noted that the reason for

\footnotetext{
${ }^{114}$ Liang2007, p. 17.

${ }^{115}$ Liang 2007, p. 17.

${ }^{116}$ Huang 1996, p. 111.

${ }^{117}$ Huang 2010, p. 8.

${ }^{118}$ Huang 2010, p. 8.

${ }^{119}$ Huang 2010, p. 11.
} 
this was that statutory law was not to provide a strictly logical scheme for embedding legal abstractions. It was the state's attempt to codify practices that had proved to work. This practice-based approach in legislation ensured that the reality of practice was fully reflected in the code, even at the risk of logical inconsistency. ${ }^{120}$

Huang's 'history-of-practice' approach ${ }^{121}$ provided a novel approach to studying Chinese legal history. ${ }^{122}$ It embodies a research methodology that fully takes into account the traditional legal culture and the historical context of imperial China. It transcends the limitations of Weberian categorizations, which failed to consider the importance of practice and Confucian moral values in shaping the traditional Chinese legal order.

\subsubsection{The Chinese imperial legal order: a 'thin' version of civil justice}

\subsubsection{The Distinctiveness of Chinese Civil Law and Procedure}

The underdevelopment of civil law in imperial China can be understood on two levels. On the first level, China never developed a rights-based civil law system in the Western sense until the reforms during the late Qing period and early Republican era (during the early 20th century). As a result, the jurisprudence of civil law failed to emerge in imperial China. On the second level, the development of China's civil law lagged behind its criminal and administrative laws. ${ }^{123}$ The governing philosophy of the imperial state was that criminal proceedings concerned the exercise of state authority, while civil matters were to be handled by the local communities with the participation of local authorities where necessary. As a result, criminal and administrative laws featured prominently in the imperial state's codification programme while civil matters were given less attention. ${ }^{124}$

However, it would be inaccurate to view the relative lag in civil law development as an indication that imperial China had no civil law or procedure. Firstly, taking the Qing Code as an example, civil matters were given meticulous treatment in the substatutes of the code despite their relative subservient position (considered as 'trivial matters') vis-à-vis criminal matters. One reason for the relative academic neglect for the codification of civil law is that the provisions on civil law were tucked in the least

\footnotetext{
${ }^{120}$ Huang 2010, p. 11.

${ }^{121}$ Huang 2010, p. 8-11.

${ }^{122}$ Consider Huang 2010, p. 8-9:

'In contrast to the European Continental tradition of formalist law represented by Weber, Chinese law has sought to embed abstract concepts in concrete fact examples, rather than to seek to elevate abstractions into universal principles independent of concrete fact situations...Some scholars (including Weber) have believed therefore that traditional Chinese law attended only to specific concrete situations and lacked abstract concepts and principles, but this belief is based on a misunderstanding. Qing law's difference from modern Western formalist law consists not in its inability to formulate abstract principles about nonconcrete problems, but rather in its different mode of thinking as to how to join experience and theory. Formalism demands that abstract universal principles be created through legal (deductive) logic, while Qing law asks that abstract principles be embedded in concrete examples.'

${ }^{123}$ Chen 1999 , p. 522-523.

${ }^{124}$ Chen 1999, p. 522-523.
} 
prominent layer of the code in the form of sub-statutes. These sub-statutes were added in an adaption to the changing socio-economic circumstances. ${ }^{125}$

Secondly, there was a distinctive locus for the operation of civil law in imperial China. Criminal and civil cases were treated differently in practice. The imperial codes of China were drafted with such a distinction in mind. During the Qing Dynasty, the dichotomy of crime (zui) and non-crime (wu zuiming) in the Qing Code was instrumental in the separation of criminal law from its civil counterpart. ${ }^{126}$ This crime/non-crime distinction in the Qing legal discourse formed the basis of the conceptualization of the criminal/civil distinction in the Republican legal order. ${ }^{127}$

Thirdly, there is evidence that civil and criminal cases were handled under different procedures. In the Song Dynasty, civil procedure was separate from its criminal counterpart. For instance, separate and detailed procedural rules were established for civil appeals. ${ }^{128}$ In the Qing Dynasty, the county magistrate's court was the court of first instance for all civil disputes. This means that civil cases were capable of being appealed to levels above the magistrate's court, and that appeal procedures were available. $^{129}$

Fourthly, civil breaches (represented as 'trivial offences') were not treated as offences at all in practice. Empirical studies of Qing justice have shown that there were clear procedural differences between the handling of civil and criminal matters by magistrates. ${ }^{130}$ Huang's study of the magistrate handbooks in the Qing Dynasty reviewed a striking phenomenon. Despite being couched in penal terms in the imperial code, the approach of magistrates in handling 'trivial matters' (civil matters) was categorically different from the approach in adjudicating criminal matters. Huang observed, 'though the system was ostensibly strictly penal in its approach, the

${ }^{125}$ Huang 1996, p. 105-106.

${ }^{126}$ Consider Liang 2007, p. 13-17:

'Although zui refers either to wrongdoing in general or to named specific crimes, or both, when it is used solely to identify crimes it is combined with another term ming (meaning "name"), forming the phrase "named crime" (zuiming). This is evidence that the crime was a particular category of the law. Where cisong was used, provisions containing this phrase seem to refer to all [civil] law cases, including litigation over land, debt, and marriage matters.'

${ }^{127}$ Huang 1996, p. 219.

${ }^{128} \mathrm{Qu} 2003$, p. 92.

${ }^{129}$ Consider Liang 2007, p. 15 and p. 23:

"The recognition of matters concerning land, debt, and marriage as "non-crimes" was the basis for their different treatment. The procedural rules for trials of both serious crimes and disputes concerning land, debt, and marriage matters were contained in the subsection of the Code entitled "prosecution and litigation (susong)". According to traditional interpretation, the term $s u$ means that the plaintiff petitioned for the prosecution of a crime, whereas the term song means the petition was to institute a (civil) action...Crimes were not allowed to be settled privately through compromise... Offences involving land, debt, or marriage were excluded from its scope. However, disputes over these matters ought still to be clearly judged (Sub-statute 163).'

${ }^{130}$ Based on his empirical study of the Danshui-Xinzhu Archives (also known as the 'Dan-Xin Archives') (the cases in the collection ranged from between 1789 AD to 1895 AD), Allee observed, 'However, many aspects of civil litigation, including formulation of verdicts, as observed in the case records from this local court point to significant differences in practice between civil and criminal procedures...because the stringent application of penal techniques to adjudication produced unacceptably rigid and unjust outcomes, recognizable and distinct "civil" law and "civil" procedure inevitably had begun to develop in late imperial China.' See Allee 1994, p. 141. 
practical instructions took for granted that punishment would seldom be used in civil cases'. ${ }^{131}$ In fact, the 'decriminalization' of civil law happened as early as the Song Dynasty. In adjudicating civil cases, the Song magistrate's courts had reduced the use of measures that would limit the freedom of the parties, such as imprisonment. With regard to the judgment, the Song magistrate's courts introduced various forms of 'civil remedies' (such as compensation or remedies with restitutionary effect) in place of what were essentially criminal punishments. ${ }^{132}$

\subsubsection{2. $\quad$ Adjudicatory Rationality}

Evidence of rationality in magisterial adjudication of civil disputes would serve as a forceful rebuttal to any claim that imperial Chinese justice was nothing but Kadi justice. The 'decriminalization' of the law relating to civil matters (which occurred as early as the Song Dynasty) was evidence that there were de facto 'civil codes' in imperial China much earlier than the late Qing reforms in the early 20th century. ${ }^{133}$ During the Qing Dynasty, the use of magistrate handbooks was a clear sign of entrenchment of adjudicatory rationality. ${ }^{134}$ Huang noted that the handbooks were consistent in stating that a magistrate must adjudicate by the law and must not resort to court mediation if the dispute was not resolved by informal (community-based) mediation. ${ }^{135}$

Adjudicatory rationality was evident in civil lawsuits as early as the Song Dynasty. Magistrates were mostly well informed of the law. Magisterial judgments were generally consistent with the law. ${ }^{136}$ The proliferation of civil lawsuits was the likely result of the rise of trade and commerce during the Song period. There would be a lower chance of appeal if the court decided the case in accordance with the law. Too much reliance on moral values in a decision was almost an invitation for appeal. ${ }^{137}$

Magistrates generally rendered decisions consistent with the law in civil adjudication. ${ }^{138}$ While the degree of compliance was not always to the extent of strictly applying specific code provisions, the principles of the law were generally followed. ${ }^{139}$

\footnotetext{
${ }^{131}$ Huang 1996, p. 220.

132 Zhang W.Y. 2010, p. 137.

${ }^{133}$ For leading scholarship on the historical underdevelopment of civil law in China, see the work of Professor Shiga Shuzo.

${ }^{134}$ Huang noted that the 'magistrate handbooks do not stop with just the moralistic constructs... [but] give concrete and specific instructions about the actual practice of magisterial service.' See Huang 1996, Civil Justice in China: Representation and Practice, p. 201.

${ }^{135}$ Huang 1996, p. 205-206.

${ }^{136}$ Zhang W.Y. 2010, p. 137.

137 Zhang W.Y. 2010, p. 137.

${ }^{138}$ Allee 1994, p. 124-125.

${ }^{139}$ Drawing from his study of the Dan-Xin Archives (on civil lawsuits during the period between 1789AD and 1895AD), Tay-Sheng Wang suggested two approaches for assessing the magistrate's compliance with the law: the 'loose approach of compliance' (only requiring the magistrate to apply the general principles underlying the statutory law) and the 'strict approach of compliance' (requiring the magistrate to follow the strict letter of the statutory law). It appears that Qing magistrates generally complied with the law if the loose approach was adopted, but fell short on compliance if the strict approach was adopted. Wang recalled that one must not neglect the practical difficulty the magistrates faced: the statutory rules lacked the sophistication and specification to cater for different circumstances. As a result, the magistrate would frequently find it impossible to identify the appropriate legal provision applicable to the case even if he was conscious of following the strict letter of the law. See Wang T.S. 1998, p. 45-49.
} 


\subsubsection{Individual entitlements upheld in civil adjudication}

Under the Confucian ethical paradigm, communitarian interests should always take precedence over individual interests and the ideal society should be free from litigation (wu song). However, Huang argued that this 'Confucian representation' was never fully consistent with actual legal practice. ${ }^{140} \mathrm{He}$ noted that 'In Chinese legal reasoning, Confucian moralistic representations are about what ought to be, while the practical provisions and the adjudicatory actions of the judges are about adapting to real-life circumstances that cannot fully accord with moral ideals. ${ }^{141}$ While individual rights were not recognized on a jurisprudential level in imperial China, legal entitlements in relation to civil matters were consistently upheld in practice. ${ }^{142}$

The distinctiveness of 'civil' law and 'civil' procedure, the strong evidence of adjudicatory rationality and the protection of civil entitlements of parties in magisterial adjudication all point to the direction that a 'thin version' of civil justice existed in imperial China. However, Chinese imperial justice could not qualify as a 'thick version' of civil justice as it lacked fundamental attributes of a modern civil justice system such as judicial specialization, an autonomous (and sophisticated) civil procedural regime and a systemic enforcement of civil law based on the jurisprudential understanding of individual rights.

\subsubsection{The magisterial adjudicative philosophy-the application of multiple-valued logic}

\subsubsection{Moral judgment or legal judgment?}

Shiga argued that magisterial lawsuits were predominantly about the exercise of the magistrate's moral judgement, rather than the application of codified law. Following recent empirical findings, the accuracy of Shiga's argument has been queried. ${ }^{143}$ An empirical study on late Qing civil justice based on the Dan-Xin Archives ${ }^{144}$ discovered that three main factors justified magisterial decisions: the statutory law, cultural norms, and local customs. ${ }^{145}$

\footnotetext{
${ }^{140}$ Huang 2010, p. 3-6.

${ }^{141}$ Huang 2010, p. 5.

${ }^{142}$ Consider Huang 2001, p. 26-27: 'In actual legal practice, the courts acted consistently to protect and uphold legitimate ownership, land transactions, lending contracts, marital agreements, and succession and inheritance arrangements. The attitude of the courts, to be sure, was not one of upholding rights but rather one of enforcing regulations.'

${ }^{143}$ Shiga argued that magistrates were (almost) completely unconstrained by codified law in civil cases. Determination of the outcome of a lawsuit depended on qing li, a 'common-sense' understanding of righteousness. See Shiga 1988, p. 24.

${ }^{144}$ The collection of civil cases ranged from between 1789 AD and 1895 AD.

${ }^{145}$ Consider the views in Allee 1994, p. 124-125:

'These categories are analytically distinct but not necessarily antagonistic nor mutually exclusive. Thus when judges elected to respect local custom, they did not do so in preference to or in violation of explicitly codified law or generally accepted Confucian norms. Instead custom was valid when it was not in breach of morality or codified law, or when code and culture were silent or ambiguous. In the same vein, magistrates sometimes issued decisions that were designed to further normative ends not specified in the Qing code. This does not imply an
} 
Empirical research on Qing civil lawsuits revealed that, for most cases, magisterial judgments made no explicit references to the code provisions. One may argue that this is evidence that magisterial judgments were not legal judgments. However, the failure to make an explicit reference to the code did not necessarily mean that a decision had no 'legal basis' under Chinese legal reasoning. ${ }^{146}$ A number of factors explain this view.

Firstly, as discussed above, the imperial code provisions were often not detailed enough to cover the diverse factual situations of the disputes. ${ }^{147}$ For instance, the code provisions were often out of touch with the social realities, in particular during the late Qing Dynasty. The magistrate would not be in a position to adjudicate at all if every decision required the citing of statutory provisions. Hence, the magistrate would need to decide a case on the basis of practical experience and principles developed through time that more specifically addressed the actual situations of society. ${ }^{148}$

Secondly, the code provisions alone did not constitute the entirety of the Chinese imperial legality. In fact, the code provisions were only a 'very limited subset of the vastly larger universe of Chinese cultural principles, doctrines and cannons'. ${ }^{149}$

Thirdly, as empirical studies show, while there might not have been explicit references to the code provisions in most cases, magistrates rarely contradicted the statutes in their ruling. This phenomenon suggested that there must have been 'implicit' references to the code in adjudication. In other words, the magistrates applied the principles of practice developed in coherence with the existing statutory law. ${ }^{150}$

Fourthly, the necessity to provide an explicit citation of code provisions was limited to lawsuits that superior authorities showed an interest in. ${ }^{151}$ It was extremely rare that magistrates would be required to report civil cases to their superiors. While criminal cases must be reported to a higher authority, civil cases were considered minor matters that should be resolved on the local (county) level. The usual targeted audience of a civil judgment were the parties to the lawsuit and not a superior authority. Hence, there was minimal incentive to set out the legal basis of the judgment with reference to the code. ${ }^{152}$ Making explicit references to the statutory law

inherent contradiction between law and culture. The truth is, of course, that the former is largely derived from the latter. Thus magistrates did not pick and choose from among three rigidly defined and exclusive modes of reasoning out their decisions; in good Confucian fashion they probably conceived their task as an attempt to harmonize and reconcile the three perspectives.'

146 Allee 1994, p. 125.

147 Wang T.S. 1998, p. 45-49.

${ }^{148}$ Allee 1994, p. 129.

149 Allee 1994, p. 130.

${ }^{150}$ Allee observed, 'It is undeniable that statutes and sub-statutes functioned as a foundation for the construction of verdicts without the necessity of explicit citation. A decision on any doubtful legal point implicitly relied on an established body of law and precedents that provided a contextual legal framework within which specific questions could be addressed.' See Allee 1994, p. 129.

${ }^{151}$ Allee 1994, p. 128-129.

152 Allee 1994, p. 129. 
and setting out the full legal reasoning could be an onerous task for magistrates given the consistently heavy caseload. ${ }^{153}$

Lastly, as there was usually no pressure to report civil cases to a higher authority, magistrates remained a low ranking bureaucrat in the administrative structure and were subject to scrutiny from superior authorities. Couching civil decisions in congruence with the code and rules of practice was the way to ensure a secured career. ${ }^{154}$ Magistrates were subject to a strict disciplinary system for incorrectly decided cases. ${ }^{155}$ While no explicit references to the code were made in most civil cases, the institutional workings had compelled magistrates to take statutory law seriously in civil adjudication.

\subsubsection{Understanding the concept of 'qing li' and its relationship with statutory law in traditional Chinese legal culture}

Aside from statutory law ( $f a$ (法)), the compound concept of 'qing li' (情理) is commonly known to be the yardstick of magisterial adjudication. The word 'qing' has the literal meaning of 'human compassion'. The word 'li' (literally meaning 'reason'), when used in Chinese traditional scriptures, denoted the Confucian reasoning model (which was commonly captured in the concept of tian-li (天理)).

Shiga argued that reliance on 'qing $l i$ ' in magisterial adjudication obscured the role (and eroded the status) of statutory law. ${ }^{156}$ Following this line of argument, the traditional justice in imperial China was Kadi justice. The magistrate would decide a case simply by exercising his moral judgment based on human compassion and other Confucian values. Legal rules only played a subservient role in the management of civil justice. However, this line of argument overlooked the true nature of the traditional Chinese legal culture.

In fact, qing (情) carried with it much more than human compassion in traditional Chinese legal culture. From the magistrate's perspective, taking qing into consideration meant the working of a combination of factors: the (factual) circumstances of the case, ${ }^{157}$ the prevailing social norms, compassion and other Confucian values, and local customs. The emphasis on 'qing li' in magisterial adjudication was not an attempt to override the statutory law $(f a)$ with ethical norms, but rather to integrate the principles of qing $l i$ with the law. ${ }^{158}$ Chinese legal culture projected a 'multiple-valued logic' under which the integration of qing li and statutory law in litigation demonstrated the Chinese version of balanced justice. ${ }^{159}$ The application of this 'multiple-valued logic' allowed the coexistence of formal

\footnotetext{
${ }^{153}$ Huang mentioned two other possible scenarios that a magistrate would go through the trouble of citing the code. The first situation was when the civil dispute involved more than one county (hence the magistrate was writing the judgment not simply for the parties but also for another magistrate) and the second situation was when a powerful figure of the local community was involved in the lawsuit. See Huang 1994, p. 154-155.

${ }^{154}$ Huang 1996, p. 17.

${ }^{155}$ Minzner 2011a, p. 58-90.

${ }^{156}$ This line of argument was most notably advanced by Shiga. Shiga 1988, p. 18-26.

${ }^{157}$ Lin 2003 , p. 75 and 87.

${ }^{158}$ Lin explained that under the traditional legal understanding, qing $l i$ and the law were not mutually exclusive. Rather, they were mutually inclusive. The reference to qing and $l i$ in civil adjudication was well within the Chinese traditional concept of justice. See Lin 2003, p. 16-17.

${ }^{159}$ Lin 2003, p. 91-92.
} 
parameters (statutory law) and informal parameters (qing $l i$ ) in China's imperial civil justice system with no inherent contradiction. ${ }^{160}$

The application of qing $l i$ by magistrates was not to bypass the law. On the contrary, the application of qing $l i$ had a close connection with the interpretation (and application) of the law. ${ }^{161}$ One possible angle to look at qing $l i$ is that it was an interpretive model employed at various stages of adjudication to derive the principles underlying the law (particularly when the express statutory provisions were unclear or not directly on point) and apply the same on the given facts to achieve a fair result.

\subsubsection{The magistrate's civil adjudicative philosophy}

It is on the basis of this multiple-valued logic that Lin argued that the imperial code (and local statutory provisions) only formed part of the legal foundation of civil adjudication. ${ }^{162}$ Under the influence of Confucianism, the magistrate believed that statutory law could not be detached from 'extra-statutory' norms. In fact, through the use of the qing $l i$ interpretive model, Confucian values and local customs were weaved into a network of extra-statutory norms, which together with statutory law formed the locus of Chinese civil justice. The magistrate's civil adjudicative philosophy (unlike the Weberian approach) did not seek to place the statutory law and the extra-statutory norms opposite to one another. Instead, the two were integrated into one. ${ }^{163}$

On the vertical plane of governance, the central administration respected the 'autonomy' of the local communities in handling civil disputes. Ideally, parties should settle their disputes privately through community-based mediation. The community would avoid, where possible, elevating such disputes to the official level (the magistrate's level). This mutual understanding between the central administration and the local communities allowed the living law and the enacted law to interact in a cooperative and harmonious manner within the civil dispute resolution structure in imperial China. ${ }^{164} \mathrm{~A}$ strict positivist approach would exclude local customs and

\footnotetext{
${ }^{160}$ Lin 2003, p. 91-92. Lin's contextual approach provides perspective on why magistrates might not necessarily simply apply the hard statutory rules in civil adjudication, but rather base their decisions on a much more complex methodology which took into account qing li in addition to statutory law.

${ }^{161}$ Liang observed that qing $l i$ was closely tied with the content of civil law and argued that qing $l i$ was used differently at different stages of civil litigation in the Qing Dynasty. For instance, Liang noted, 'Once the facts had been ascertained, and the magistrate made the decision for the parties, he might use the phrase "zhun/hengqing zhuoli" (consider li on the ground of qing) or "zhunqing yongfa" (apply fa on the ground of qing) in explaining his reasoning. By this he meant that the facts, the whole facts, had been considered in the light of (the real meaning of) the law.' See Liang 2007, p. 244.

${ }^{162}$ Lin 2003, p. 135.

${ }^{163}$ Lin argued that rendering a judgment in accordance with the law should be understood in the context that 'law' was not simply a reference to 'enacted law' (or law in the books) but also 'living law' (or law in action). The imperial code (together with local statutory provisions) formed the body of enacted law. The network of extra-statutory norms was the 'living law'. At the heart of the magistrate's civil adjudicative philosophy was the search for the most appropriate solution that was in harmony with the living law and consistent with the enacted law. This sometimes required the exercise of the magistrate's formal powers (by way of a court hearing), while on other occasions called for less formal means of dispute resolution, for example court mediation. See Lin 2003, p. 79-80 and p. 135-136.

${ }^{164}$ Lin 2002 , p. 310.
} 
Confucian values from the Chinese traditional legal order. But this approach would also skew the true picture of Chinese legal history. ${ }^{165}$

\subsubsection{Understanding Huang's theories of 'centralized minimalism' and the 'third realm of justice'}

\subsubsection{Huang's theory of 'Centralized minimalism'}

The modern state wields enormous 'infrastructural powers' armed with the administrative apparatus that (directly or indirectly) shape the lives of its citizens. ${ }^{166}$ By contrast, the imperial Chinese state had very limited infrastructural powers. ${ }^{167}$ While in theory the emperor was all-powerful, in practice the central authority adopted a 'minimalist approach' to governance. ${ }^{168}$ The imperial outreach stopped at the magistrate's level (or county level). The central authority relied heavily on the 'quasi-official sphere' to bridge the gap between the local village communities and the state administration. The quasi-official sphere comprised of (among others) village leaders, the scholar-gentry class and personal assistants to the magistrate. During the Yuan Dynasty, the 'village community administration' (she) was the quasi-official local administrative organization. ${ }^{169}$ The heads of the village community administration (she zhang) were conferred extensive powers by the state. They were not government officials but community leaders with a quasi-official mandate to 'govern'. During the Ming Dynasty, it was the 'community elders' (li lao) who played this role. In the Qing dynasty, the quasi-official sphere was mainly comprised of the community leaders, local headmen (xiang bao $)^{170}$ and semi-official personnel of the magistrate (such as runners and clerks). ${ }^{171}$

The three constitutive domains of the Chinese imperial structure (the state administration, the quasi-official sphere, and the local village communities) did not operate separately. The local village communities looked to the quasi-official sphere for leadership and organization. The quasi-official sphere defended the interests of (and maintained social harmony within) the local village communities. It also acted as an intermediary between the state administration and the people. The state administration relied heavily on the quasi-official sphere to execute the imperial agenda.

The existence of the quasi-official sphere was reinforced by Terada's in-depth study of the nature of social agreements (yue) in the legal orders of Ming China and Qing China. ${ }^{172}$ The systems established by yue, which operated as village compacts or

\footnotetext{
${ }^{165}$ Lin argued that the Chinese traditional legality embodied a legal pluralism under which state law, local customs and Confucian values interacted and cross-fertilized as a unified system. See Lin 2002, p. $110-112$.

${ }^{166}$ Mann 1984, p. 185-213.

${ }^{167}$ Huang 2010, p. 76.

${ }^{168}$ Huang 2010, p. 76-77.

${ }^{169} \mathrm{Hu} 2001$, p. 44.

${ }^{170}$ Liang 2007, p. 7.

${ }^{171}$ Huang 2010, p. 74.

${ }^{172}$ Consider Terada 2005, p. 315-316:

'Historically speaking, yue is a comprehensive term encompassing various actions undertaken to build up and regulate a shared standard of behavior, as well as the structure and forms of such a
} 
community covenants, regulated not only civil relations but also the moral conduct of its members. ${ }^{173}$ Community compacts date back to the Song Dynasty, but it was not until the middle of the Ming period that they were used widely. ${ }^{174}$ In reality, the network of yue operated as the regulatory regime of the quasi-official sphere in which the community leadership exerted control over the commoners. These regulations were not authoritative in any official sense. However, failure to comply with the regulations would risk the expulsion of the violator from the community. ${ }^{175}$ Under the historical context of yue, the minimalist strategy of governance and the vital role of the quasi-official sphere in filling the gap between the state administration and the people could be clearly articulated.

\subsubsection{Huang's theory of 'The third realm of justice'}

Huang applied the framework of 'centralized minimalism' to the study of the civil justice system in the Qing Dynasty and discovered that there was a 'third realm of justice ${ }^{176}$ in between the formal justice and informal justice systems. ${ }^{177}$ The structure of Qing civil procedure allowed an opportunity for litigants to settle a case by 'quasiofficial extra-judicial mediation' (at the second stage or 'middle stage' of the proceedings) before the commencement of a formal court hearing. ${ }^{178}$ Huang divided Qing magisterial adjudication into three stages. The 'initial stage' involved the filing of the claim (or 'plaint') and the magistrate giving initial comments on the case. In the 'middle stage', which bears some resemblance to a pre-trial review, the magistrate would meet with the parties, preliminarily hear the witnesses and allow an opportunity for the parties to settle the dispute through quasi-official mediation. The mediator was usually the local headman (xiang bao) or a community leader. ${ }^{179}$ If settlement could be reached, the magistrate would give effect to it and the litigation would terminate. If there were no settlement, the dispute would enter the 'final stage' in which there would be a formal court hearing. ${ }^{180}$

standard of behavior. Not only the yue of village communities, but also the "laws" and "contracts/agreements" that appear to be polar opposites in the Ming and Qing legal order, must be re-examined through this historical context...if we turn our attention away from the conceptual level to the reality of the society in Ming and Qing village communities that represented a social sphere larger than the domain of private agreements but smaller than state administrative counties, we discover a vast world of yue that cuts across these two boundaries. What actually went on here provides excellent material for reviewing the conventional polar relationship theory.'

${ }^{173}$ Terada 2005, p. 321.

174 Terada 2005, p. 321.

175 Terada 2005, p. 317.

${ }^{176}$ Consider Huang's synopsis of the operation of the third realm of justice in Huang 2010, p. 15:

'Once a disputant filed a lawsuit, it would trigger an interactive process between the societal system and the official system. On one side were the renewed efforts at community and kin mediation, and on the other, magisterial comments on the plaints, counterplaints, and petitions of the litigants. Those comments were generally either publicly displayed or conveyed to the litigants, or the litigants saw them through other means and channels. These comments would often directly influence the ongoing societal mediation. If the litigants should reach agreement at that point, then they would petition the court to withdraw the case, and the court would almost without exception grant the request. In this way, the dispute would be resolved in this semiformal third sphere through the interaction of the societal and the official systems.'

${ }^{177}$ Huang 1996, p. 110-137.

${ }^{178}$ Zeng 2009, p. 13-14.

${ }^{179}$ Huang 1996, p. 119.

${ }^{180}$ Zeng 2009, p. 13-14; also see Huang 1996, p. 110-114. 
Under the political framework of 'centralized minimalism', the imperial civil justice system was a combination of community mediation, magisterial adjudication and the interaction between the two. The whole system demonstrated a value-based preference for community mediation even though magisterial adjudication was well established as the official civil dispute resolution mechanism. ${ }^{181}$

\subsubsection{Magisterial adjudication in imperial China: Concluding remarks}

Civil justice in imperial China has never been an easy topic for academic research. It is only recently that there have been extensive empirical research outputs. These empirical studies were based on archival records of magisterial lawsuits (mostly focusing on the Qing Dynasty). The relatively subservient role of civil law (vis-à-vis criminal law and administrative law) in China's legal history also explains why civil justice was given less academic attention in the past.

While Huang's contribution in this area has been profound, there is room for his theory to be further developed. For instance, it appears that more can be said on how the principles underlying the law were applied in actual magisterial adjudication. ${ }^{182}$

Empirical studies conducted to date were limited to the civil lawsuits of a few counties during the Qing period. The conclusions may have been different had the sampling been extended to other counties of other provinces. Furthermore, empirical studies that focused only on Qing China cannot be representative of the entire imperial past. For instance, the conclusion that Qing magistrates were judges who applied principles of the law in civil adjudication (instead of resorting to court mediation) may not fully reflect the positions of Song, Yuan and Ming civil justice systems where court mediation was widely practised.

There are a number of areas that require further research. For example, the adjudicative philosophy of the imperial magistrates bears some resemblance to modern common law judging. While common law adjudication depends on the exercise of judicial discretion in interpreting and applying case precedents and statutory law, Chinese magisterial adjudication involved the balancing of the code provisions, customs and social/moral norms. Both systems involved the exercise of inductive reasoning where practice, rather than abstract theorizing, dominates the adjudicatory philosophy. Another example is the extent to which public perception of a case (qun qing (群情)) affected the magistrate's decision. An interesting parallel can be drawn with the public policy consideration of the common law court. ${ }^{183}$ It is hoped

\footnotetext{
${ }^{181}$ Huang 2006, p. 281.

182 See Liang 2007, p. 3:

'Philip Huang in particular wrote a book on Qing civil justice; drawing on 628 cases from Danshui Xinzhu in Taiwan and from Baodi and Ba counties in mainland China, he concluded that in practice the magistrate was a judge who made decisions on civil cases by following the "principles" embedded in the law. However, because Huang makes only very brief references to the law in analysing the decisions, he fails to build up a strong connection between what he sees as the principles and the Code, and between the principles and the magistrate's decisions in the cases.'

${ }^{183}$ Common law jurisprudence evolves not only through the application and development of established principles in case precedents, but also involves the way judges see how the law should
} 
that further empirical findings would open up new paradigms for researching this topic.

Civil justice in imperial China was not Kadi justice. Magisterial adjudication was rational, although perhaps not formal in the Weberian sense. ${ }^{184}$ While rights were not recognized on a jurisprudential level, civil entitlements of disputants were protected in practice. ${ }^{185}$ The Weberian theoretical framework is deficient as it failed to capture the true essence of the Chinese traditional legal culture. On the basis of existing empirical findings, a consistent theoretical framework that takes into account the unique historical circumstances of imperial China is emerging.

\subsection{Court-referred pre-action mediation in the Republican era (1911-1949)}

While the Republican government transplanted a modern procedural code from foreign jurisdictions, the legal tradition of wu song continued to exert its influence over Republican justice.

The court-referred pre-action mediation system was established in 1931. The Legislative Yuan promulgated the Civil Mediation Law with 16 articles. The law became effective in 1931. This was the first attempt in Chinese history to provide a detailed procedural code for pre-action mediation. ${ }^{186}$ According to Hung, the following were key features of the law: (1) the law made it a mandatory requirement that any prospective first-instance lawsuits (with a few exceptions) and cases involving disputes over the legal relationship between individuals must first go through mediation before a lawsuit could be filed (mandatory routine referral regime); (2) for all other cases not subject to the mandatory routine referral regime, the law nevertheless required the parties to go through mediation first (before filing lawsuit) if one of the parties applied for pre-action mediation; (3) mediation was conducted under the supervision of the Court-Annexed Civil Mediation Office (minshi tiaojie chu (民事调解处)) (Mediation Office), which was established at each first-instance court with the objective to manage caseload in the docket; (4) the Mediation Office shall appoint the principal mediator (tiaojie zhuren (调解主任)) (usually a judge of the court) and parties are each allowed to nominate one qualified individual to act as the assistant mediator; (5) the Mediation Office could impose sanction against a party that had failed to appear at a mediation session initiated by the other party; (6) if a settlement was reached, the settlement agreement would be recorded in the court register and become directly enforcement like a civil judgment (7) the Mediation Office was not permitted to charge a fee for any mediation conducted under its supervision. ${ }^{187}$

Xie noted that caseload management had everything to do with the introduction of this mediation system by the Republican authorities (especially the mandatory routine referral regime). Xie quoted statistics of the 1930 s that over $90 \%$ of all first-instance

\footnotetext{
develop given the specific circumstances of society. As such, judges sometimes see fit to take 'public policy' reasons in their consideration in adjudication.

${ }^{184}$ Huang 1996, p. 226.

${ }^{185}$ Huang 2001, p. 26-27.

${ }^{186}$ Hung 2011, p. 32.

${ }^{187}$ Hung 2011, p. 32-33. Also see Li Z.J. 2010, p. 54.
} 
civil cases were heard in basic level courts (e.g. county courts). These basic level courts had to deal with enormous backlogs that could be properly managed by a preaction mediation mechanism. ${ }^{188}$

The Civil Mediation Law was later incorporated into the revised Civil Procedure Law of 1935 (1935 Code). The new mediation provisions under the 1935 Code established key procedures for pre-action mediation, such as the appointment of a mediator and the timing of mediation. Mediation was conducted privately. The procedure provided two tracks: mandatory mediation (routine referral) for certain civil cases (such as divorce); and voluntary mediation by party application. ${ }^{189}$ Under Article 409 of the 1935 Code, any disputes within the remit of Article 402 (of the 1935 Code) were subject to the mandatory mediation track. Article 402 provided a conclusive list of such disputes: (a) any liquidated claim within 800 yuan; ${ }^{190}$ (b) a selected list of actions where the claim was over 800 yuan. Any action that did not fall within the ambit of Article 402 was subject to the voluntary mediation route. There were a list of actions that the 1935 Code specifically provided to be unsuitable for mediation, for example where the prospective defendant had already filed a claim in court against the prospective plaintiff.

\subsection{The shadow of the legendary Ma Xiwu: the legal history of the 'people's judge' and the impact of his adjudicatory approach in Contemporary China}

\subsubsection{The Ma Xiwu model of adjudication}

The magnitude of the impact of the 'Ma Xiwu model of adjudication' (ma xiwu shenpan fangshi (马锡五审判方式)) on contemporary civil justice is significant. Ma Xiwu was a local official and judge in the 1940s in the Communist controlled 'ShanGan-Ning regions' of China (regions in today's Shanxi, Gansu and Ningxia Provinces). His art of fusing the judicial process with local customs and taking the temperament of the masses into account when adjudicating cases made him a towering figure within the Chinese legal community. Ma Xiwu's model was applicable not only to civil cases but also criminal and administrative cases. There is no small proportion of the judiciary today that treats Ma Xiwu as the role model, particularly his 'common touch' and his ability to pacify conflict within the community, something modern judges desperately need given rising tension between the establishment (including the judiciary) and the people. Even within academia, there are voices that call for the revival of Ma's case handling style in less developed areas in China. ${ }^{191}$ The underlying principle of Ma's methodology was that the most appropriate way of resolving disputes among the 'people' is to really get to know their situations and master the local culture (and norms) in the community where the dispute arose. The judge plays multiple roles of the adjudicator, the mediator, the

\footnotetext{
${ }^{188}$ Xie 2009 , p. 89.

${ }^{189}$ Li Z.J 2010, p. 55.

${ }^{190}$ The assessment of the quantum of the liquidated claim rested with the court, which would take into account the amount stated in the claim form as well as market conditions: see Articles 404 to 407 of the 1935 Code.

${ }^{191}$ Jiang 2010, p. 154.
} 
educator of the law, ${ }^{192}$ as well as the vanguard of harmony and stability within the local community. The judge's mandate was to deliver 'substantive justice', an adjudicative principle that survived until today. ${ }^{193}$ It was not the business of the judge to act as an impartial arbiter or to defend an autonomous body of legal rules (something that was non-existent at that time anyway). Under Ma's methodology, procedural justice was counter-intuitive. The result-oriented process necessitated the setting aside of important procedural safeguards in the name of delivering 'real justice'. As such, if a judge were of the view that the claimant was the aggrieved party, he would do whatever it takes (including bending any procedural rule) to ensure that the claimant prevailed.

While Ma's methodology suited the social circumstances of its time (i.e. China was still engulfed in war when this methodology was first put into use), it is highly questionable whether it is of any meaningful reference value today. Having said that, a solid understanding of Ma's methodology is still very important in the study of contemporary Chinese procedure as a good proportion of the stakeholders of the current justice system still hold on to certain fundamental tenets of the methodology. ${ }^{194}$ In other words, the study of contemporary civil justice in practice must be premised on the realization that a certain proportion of judges still think very much like a 'Ma Xiwu judge'. It is fair to say that no matter how much legislators change the procedural rules, the practice of civil litigation today is still greatly influenced by the concept of substantive justice. The relevance of public opinion in the delivery of justice and the paternalistic role of the judge in civil lawsuits (including the didactic function of the bench) are still live issues in contemporary Chinese procedure.

\subsubsection{Characteristics of the Ma Xiwu model of adjudication}

A leading authority on the Ma Xiwu model of adjudication, Zhang Xipo (张希坡), observed that there were four major characteristics with this model of adjudication: (a) a fact-based approach that rejects all forms of subjectivity characterized by an investigative methodology that is comprehensive, objective and in-depth; (b) a massline approach with populist characteristics, an approach that emphasizes the fusion of adjudication and judicial mediation; (c) a principle-centered approach that seeks to establish a judicial culture that promotes a clean bureaucracy and observance of the law; and (d) procedural expedition in the interest of the public. ${ }^{195}$ The mass-line approach is of particular interest as it laid the foundation of the unique role of judicial mediation in China's civil justice system. This approach, as practiced by Ma, distinguishes itself sharply from the modern concept of ADR in the sense that the 'people' (or 'masses') were involved in the process. The judge is in effect using

\footnotetext{
${ }^{192}$ The role of an educator of the law stemmed from the traditional didactic role of Chinese judges. In the Chinese legal tradition, the judge was not an impartial arbiter but an authoritative figure conferred with the mandate to educate the masses on matters relating to the imperial legality (including principles of law and order).

${ }^{193}$ For further discussion on the contemporary adjudicative principle of 'substantive justice', see Chapter 8 of this book.

194 Jiang 2010, p. 154.

${ }^{195}$ Zhang X.P. 1983, p. 41-54.
} 
mediation as a tool to identify the concerns of the parties, understand the sentiments of the community in which the dispute arose such that the judgment can be in line with the interests of the parties as well as the community as a whole. ${ }^{196}$ Technically, although not being a complete match, this kind of adjudicative method can be categorized as facilitative judging. ${ }^{197}$ Ma himself was quite open about the need to tap the wisdom and resources of the people in adjudication. He once said, 'three peasants are better than a local official'. ${ }^{198}$ Zhang describe the intricate techniques that $\mathrm{Ma}$ used in adjudication. He said 'Comrade Ma' adjudicates not by simply rendering a judgment summarily, but tailored his approach to suit the nature of the dispute, and the positions and emotional characteristics of the parties. Ma's approach emphasizes the need to channel away any form of antagonism, speak to the parties so that they understand legal and ethical norms, and the merits of their respective case. Ultimately causing the parties to wholeheartedly accept and endorse the final judgment. ${ }^{199}$

One point to note, however, is that Ma would not 'blindly follow' the views of the masses in adjudication. He would consider and respect such views, yet the ultimate decision must be based on the law and objective fact-finding. Ma observed, 'the masses are no experts in the law...so [their views] will not be unconditionally adopted. He said any decision must be based on policy, legal provisions and evidence. ${ }^{200}$

Judicial mediation in accordance with Ma Xiwu's model of adjudication also focused on the didactic function of the judiciary. For instance, in an appeal case in relation to a matrimonial dispute in Huachi County, Ma condemned the actions of the brothers in the case for harming public order and disturbing the harmony among the families involved (the brothers took the bride by force). Ma also warned the father of the bride that putting one's daughter for sale was not only against marriage laws but also destroys the future of the daughter. ${ }^{201}$ The judiciary playing the role of a social educator was understandable in the early days of the People's Republic. As many communities in China remained backward and agrarian, a dispute that found its way into the courtroom presented the establishment with an excellent opportunity to promote ideologies and policies which otherwise had no way of reaching certain target groups.

From studying Ma Xiwu's style of mediation, one discovers the historical origin of judicial mediation in China. Judicial mediation is more of a medium to prevent disputes within the community from escalating into something that could threaten public order or social harmony; and less of a genuine alternative for parties to exercise their autonomy in resolving the disputes in accordance with their interests. As will be discussed below, this traditional approach has immense impact on contemporary civil justice.

The Ma Xiwu model established a unique type of 'circuit courts' in China where judges would conduct a large portion of the fact-finding exercise through frequent site

\footnotetext{
${ }^{196}$ Zhang X.P. 1983, p. 41-54.

${ }^{197}$ Alexander 2009, p. 139.

${ }^{198}$ Zhang X.P. 1983, p. 46

${ }^{199}$ Zhang X.P. 1983 , p. 46-47.

${ }^{200}$ Zhang X.P. 1983, p. 47.

${ }^{201}$ Zhang X.P. 1983, p. 47.
} 
visits (by virtue of the judge's ex officio power of investigation). During such visits, the judge would seek to understand the nature of the dispute, the views of the community leaders and the 'masses' relating to the matter, and the possibility of settlement. ${ }^{202}$

\subsubsection{Should the Ma Xiwu model be adopted in contemporary China? Why is Ma Xiwu still relevant to today's civil justice landscape in China}

The idea of reintroducing the Ma Xiwu model to contemporary civil justice received support from both academia and the judiciary. ${ }^{203}$ However, Zhang Weiping, a leading proceduralist, has written forcefully against the revival of the Ma Xiwu model based on the fact that socio-economic circumstances have changed so much that the model is inconsistent with contemporary realities of a modernizing China. ${ }^{204}$ The following are difficulties of applying the Ma Xiwu model in today's China. First, from a geographical perspective, the model's intense emphasis on participation of the masses cannot be practically replicated in urban settings. It is at best only suitable for rural China where economic development remains backward. Secondly, from a procedural perspective, the model is at best only suitable for small claims that involve no complex issue of law or fact. This means that the model cannot handle complex commercial cases. Thirdly, from a sociological perspective, the model is suitable only for a closely-knitted village community, but not a modern society where inhabitants are regulated by the law and interact on the basis of contractual relationships. Zhang pointed out that the success of the model relied heavily on the moral character of the judge (人格力量). Litigants in the past were satisfied with this type of justice simply because they trusted the judge, who they saw as the standardbearer of morality rather than an adjudicator who enforced the law. Zhang added that on an institutional level, the Ma Xiwu method requires the deployment of enormous resources by the judiciary for every case as the active judge would be required to shoulder the main responsibility of fact-finding by visiting the community in which the dispute arose and conducting full-fledged investigations on his own. ${ }^{205}$ In a modern society, such labour-intensive and costly use of resources is not only counterutilitarian but also impractical given the substantial caseloads courts are dealing with. Zhang further noted that on a procedural level, re-adopting the Ma Xiwu method would likely result in the deterioration of procedural justice, given the method emphasized on the delivery of substantive justice at the expense of procedure. $\mathrm{He}$ explained that the method worked well with small claims and in backward (rural) regions. However, in a modern economy where predictability and certainty of litigation are paramount to the conduct of business, such disregard for procedural detail would never be able to meet the needs of litigants. ${ }^{206}$

\footnotetext{
${ }^{202}$ Wang L.M. 2010, p. 72.

${ }^{203}$ Interview 2013/7. Some academics are calling for its revival in rural areas. Jiang argued that the Ma Xiwu style of adjudication fits well with the contemporary reality in rural China where parties have very limited resources to conduct fact-finding on their own: Jiang 2010, p. 154.

${ }^{204}$ Zhang W.P. 2009, p. 147.

${ }^{205}$ Zhang W.P. 2009, p. 149.

${ }^{206}$ Zhang W.P. 2009, p. 149-150.
} 


\subsubsection{The reception of the Ma Xiwu adjudicatory philosophy by the contemporary Chinese Judiciary}

The Ma Xiwu mode of adjudication emphasized the importance of substantive justice and the need to leave no stones unturned in civil fact-finding. This fundamental notion of justice survived various legislative policy changes and remains ingrained in the contemporary adjudicatory philosophy of judges in China.

The Vice-President of an intermediate court observed that the 'spirit' of Ma Xiwu should be adopted in civil adjudication, as the judiciary is not just providing a dispute resolution service but also act as the vanguard of social harmony. While noting that it is impossible to fully implement the Ma Xiwu model of adjudication in an increasingly urbanized China (as the model was originally designed for handling disputes within relatively backward rural communities), the pre-eminence of substantive justice under the Ma Xiwu model is a principle that all Chinese judges today should follow (including the extensive use of ex officio investigatory powers in fact-finding). The judge believes that the best measurement for substantive justice under contemporary standards is whether the parties are genuinely satisfied with the outcome of the case (an jie shi liao). ${ }^{207}$ Junior judges with solid legal training who understand the importance of finality are struggling to conform to this wellestablished practice.

A division head of a high court in an in-land province of China (specializing in foreign-related cases) noted that too much emphasis on procedural justice compromises overall justice because only rich litigants can afford going to courts. The division head observed that Chinese courts see themselves as vanguards of substantive justice. Courts are prepared to tolerate even serious procedural breaches if the substantive facts (and truth) are clearly established. He gave a real life example that a plaintiff failed to appear in court at the hearing. The usual procedural consequence is the striking out of the plaintiff's claim. Yet all the evidence had been cross-examined before the actual hearing. In the view of the court, the substantive truth had already been revealed, which favoured the plaintiff. The court gave judgment in favour of the plaintiff despite the procedural breach. ${ }^{208}$

\subsection{Early civil procedural designs on court mediation and regulation of out- of-court mediation in the People's Republic}

\subsubsection{Phase I: 'Mediation as the principal method'}

In the early days of the People's Republic (1950s), court mediation was given a predominant position in civil lawsuits: the so-called policy of 'mediation as the principal [method]' (tiaojie weizhu (调解为主)). The SPC promulgated a guideline that emphasized the active investigatory powers of the judge and the resolution of disputes in the place where the dispute arose using court mediation as the predominant method. It was observed that this policy emphasis was based on the

\footnotetext{
${ }^{207}$ Interview 2013/7.

${ }^{208}$ Interview 2012/2.
} 
theory of mass-line justice propagated by leaders of the Party, most notably Mao. ${ }^{209}$ This stage of development marks the continuation of the Ma Xiwu model of adjudication. ${ }^{210}$

\subsubsection{Phase II: 'Emphasizing Mediation'}

The next stage in the development of court mediation toned down the predominance of mediation in civil justice, but retained its preferential position. The new policy of 'emphasizing mediation' in civil litigation was introduced following the promulgation of the Civil Procedure Law of 1982. Under this policy, courts focused on attaining a high mediation settlement rate. Judges were assessed predominantly on the basis of their ability to facilitate settlements through mediation. However, if mediation was unsuccessful, the court should render a judgment without delay. It is argued that this phase sets the tone for contemporary policies that favoured mediation. ${ }^{211}$

\subsubsection{Phase III: the 'voluntariness and legality' principle}

Since the promulgation of the Civil Procedure Law in 1991 (1991 Code), the previous notion of 'emphasizing mediation' was replaced by the new principle of “voluntariness and legality” (自愿合法原则). Under the new principle, mediation must be voluntary (i.e. parties should not be forced to mediate) and the mediation process must follow procedural rules stipulated in the 1991 Code and other relevant normative instruments. The new principle was given due attention by practitioners and academics alike as it was enshrined under the section of 'general principles' in the 1991 Code, with procedural steps clearly stipulated in the 1991 Code.

While the 1991 Code established the principle of 'voluntariness and legality', the actual operation of mediation depended on the prevailing policy at the material time. For instance, Zhang noted that prior to 2002, courts generally followed the principle, as the prevailing policy was to entrench adjudicatory formalism. This position changed drastically since 2002 given the policy shift that emphasized the importance of mediation in maintaining social harmony. ${ }^{212}$

\subsubsection{Phase IV: 'U-shaped' development - reverting to prioritizing mediation}

Since the turn of the century, through a number of authoritative policy instruments issued by the SPC, mediation was (again) given preferential status (over adjudication) in civil dispute resolution. The underlying objective of this policy change was to use court mediation as a tool to preserve social harmony. The theory was that by emphasizing mediation (and discarding the previous focus on adjudicatory formalism), courts could achieve a resolution without leaving any party discontent with the result. In the view of the policy-makers, a settlement was far better than a judgment as parties under a settlement would not be capable of lodging an appeal and would seldom challenge the result through letters and visits. ${ }^{213}$ Zhang noted that the effect

\footnotetext{
${ }^{209}$ Zhang W.P. 2012, p. 184-185.

${ }^{210}$ Ibidem.

${ }^{211}$ Ibidem

${ }^{212}$ Ibidem.

${ }^{213}$ See Chapter 4 of this book for further discussion on this issue.
} 
of those policy instruments was that the Chinese judiciary had reverted back to the second phase of 'emphasizing mediation'. Zhang observed that the change since the turn of the century was not an autonomous act of individual courts, but rather a centralized effort of the judicial leadership to give preference to mediation. ${ }^{214}$ In 2010 , the SPC promulgated the policy of 'prioritizing mediation, and the fusing of mediation and adjudication' (tiajie you xian, tiaopan jiehe (调解优先, 调判结合)), which effectively placed court mediation as the top priority in judicial work throughout the country. Zhang observed that this move turned China back to Phase II (i.e. emphasizing mediation). ${ }^{215}$

\subsubsection{Phase V: 'Normalization' of court mediation}

With the change in leadership of the Chinese judiciary in March 2013 (in particular, with Zhou Qiang replacing Wang Shengjun as president of the SPC), the policy preference for court mediation has been deliberately watered down. Reform efforts were made to re-establish adjudication as the centrepiece of court work. According to the official line, court mediation, while still being emphasized as a caseload management tool, is no longer given privilege treatment in civil litigation. This change in policy, however, must be critically reviewed with reference to the established judicial culture that favoured mediation and the institutional realities in Chinese courts. This issue will be explored further in Chapter 4, Chapter 5 and the Afterward.

\subsection{Xiao Yang and the rise of formalism in Chinese civil procedure}

Xiao Yang, the former president of the SPC (1998-2008) was praised for his efforts to establish procedural formalism and efficiency, as well as enhancing professionalism within China's judicial system. During his tenure, judges (who were once called adjudication officer (shenpan yuan (审判员)) were given an official (and professional) title of 'judges' (faguan (法官)), a move that has been hailed as a symbolic milestone that distinguished the judiciary from the civil service. What was more important was Xiao Yang's attempt to give formal adjudication its rightful place in a modern justice system. He was responsible for moving courts away from the old policy (in the 1980s) that emphasized mediation and laid the foundation for reforms that sought to promote procedural efficiency and formalism. Fu and Cao described the change of policy as follows:

'As a result of the reform, the position of adjudication was substantially improved when compared with mediation, and procedural justice was widely accepted in the society. As the reform advocated the ideology of procedural justice and open trial, adopting mediation to close the case was regarded as a symbol of "black box" operations and consequently was criticized for its lack of transparency'. ${ }^{216}$

\footnotetext{
${ }^{214}$ Zhang W.P. 2012, p. 184-185.

${ }^{215}$ Zhang W.P. 2012, p. 186.

${ }^{216} \mathrm{Fu} \&$ Cao 2012, p. 503.
} 
The Code, as it currently stands (with two major amendments, one in 2007 and the other in 2012), came into effect in 1991. In the Code, the principle of party voluntariness was introduced to the court mediation system for the first time in the history of the PRC. Adjudicative achievements were taken as the basis for assessing judges. Due to this fundamental change of policy of positioning formal adjudication at the centre of Chinese civil justice, mediation settlement rates (i.e. the number of civil cases disposed through court-mediated settlements multiplied by the overall total number of civil cases disposed) gradually went down in the $1990 \mathrm{~s}^{217}$

\subsection{Wang Shengjun's judicial philosophy}

Former SPC president Wang Shengjun (2008-2013) came from a non-legal educational background (a history graduate). His focus on civil justice was the effectiveness of the system in resolving disputes in such a way that social harmony could best be preserved. The overarching objective to achieve order and harmony overrides all functions a modern judiciary should play, including the vital role of the judiciary in enforcing rights.

Wang's judicial philosophy completely changed the overall landscape of civil justice in China. Under his tenure, judges competed with one another to close as many cases as possible by mediation. Courts throughout the nation actively promoted the goal of social harmony through mediation. It was almost as if the Chinese civil courts had turned into one colossal mediation machinery. Given Wang's policy emphasis, adjudication played at best an ancillary role in civil justice at the heights of this 'mediation frenzy'.

\subsection{Chapter conclusion}

The rich experience in the handling of civil disputes in imperial China was revealed in empirical studies of actual cases, most notably Huang's work on Qing justice. While civil adjudication existed in imperial China (as opposed to the theory that there was only magisterial mediation of disputes), the legal tradition of $w u$ song still has a degree of influence, even today. The culture of face-saving and the maintenance of cordial relations is still a distinctive character of Confucian society. This legal historical background provided the ideological foundation for civil procedural systems during the Republican era and the early days of the People's Republic. Such systems emphasized the use of mediatory means (either by mandatory court-referred mediation or an active mediatory judge) in resolving civil disputes. This traditional predisposition favouring mediation is further strengthened by the need of the contemporary ruling class to engineer a harmonious society. The tasks of maintaining public order and social harmony were partly delegated to the judiciary and grass-root

\footnotetext{
${ }^{217}$ During the period between 1991 and 1998, the national mediation settlement rates for all first instance civil cases are as follow: $59.1 \%$ in $1991,58.3 \%$ in $1992,58.5 \%$ in $1993,58.4 \%$ in 1994 , $56.8 \%$ in $1995,54.07 \%$ in $1996,50.4 \%$ in 1997 , and $45.84 \%$ in 1998 . For further analysis on this trend, see Liu M. 2001, p. 90-95.
} 
organizations (such as people's mediation committees) by way of promoting the policy of 'prioritizing mediation' (tiaojie youxian). 


\section{Chapter 3}

Connecting China's Private and Public Spheres of Civil Disputes Resolution:

Grand Mediation, People's Mediation and Social Engineering 


\section{CONNECTING CHINA'S PRIVATE AND PUBLIC SPHERES OF CIVIL DISPUTES RESOLUTION: GRAND MEDIATION, PEOPLE'S MEDIATION AND SOCIAL ENGINEERING}

\subsection{The ' $\mathrm{Da}$ Tiaojie' (Grand Mediation) system and the ideological basis for the rise of mediation: A bird's eye view of the Chinese mediation regime under Da Tiaojie}

\subsubsection{The concept of social harmony in Chinese politics and law}

In recent years, China experienced unprecedented economic achievements. Despite improvement of per capita income, political reform did not follow the economic miracle. The fabric of Chinese society is not enjoying the kind of stability and true harmony that could provide sustainability in the country's development. A widening wealth gap and the failure of the courts to deliver quality justice on the local level are fuelling an increasing sentiment of discontent. The leaders of China are conscious of this problem, one that could have devastating consequences to their rule and to the fate of the nation. Under the leadership of Hu Jintao, the CCP emphasized the need to maintain a 'socialist harmonious society' (shehui zhuyi hexie shehui) with a view to harness the economic opportunities through a sustainable and low-risk social engineering strategy. The artificiality of the concept of a 'socialist harmonious society' is perhaps best illustrated in the way the leaders of the Chinese judiciary (especially during Wang Shengjun's era) promoted the use of mediation to handle rising conflicts in the country. The rationale behind the policy preference for mediation was that by encouraging mediation as a matter of policy (e.g. by requiring judges to use mediation as the preferred method), parties are more likely to settle their disputes without the need to render a judgment by the court. As a result of increasing the rate of settlement, the disputants are more likely to maintain amicable relations and would not seek to re-open the disputes under the adjudication supervision procedure or by resorting to various means of petitioning (usually by way of xinfang/ shangfang (or letters and visits)).

Although social harmony is no longer the overarching policy motto of the ruling elite (note the change of leadership in the CCP Politburo in 2012, now led by Xi Jinping), the social matrix of China did not change with the leadership reshuffle. The underlying content of the policy of social harmony reincarnates itself in the new policy objective to 'maintain stability' (in the context of public order) (weiwen (维稳 )). Mediation within the judicial process may have lost its predominant position with the change of judicial leadership in March 2013 (the 'official' position is that the policy of preferring mediation is no longer in force), existing institutional build-up and procedural realities dictate the continued preference for mediation by individual judges and courts, especially for purely civil cases or less complex commercial cases. For out-of-court mediation, which is the focus of this chapter, the judiciary's policy that encourages the settling of disputes before the docketing of cases survived the leadership reshuffle. A litigation lawyer (based in a leading commercial city in northern China) expressed the worry that courts are not docketing cases as they should be, as those in control of the docketing divisions are conscious of guarding the court against the influx of cases. He noted that it is not infrequent that parties are left to wait for more than a month when the court is considering whether or not the case 
would be docketed. The delay was a deliberate tactic to push parties to settle out-ofcourt. $^{218}$ Therefore, it would be misinterpreting the situation to say that with the new SPC leadership, mediation is no longer a policy preference.

\title{
3.1.2. Introducing the 'Da Tiaojie' (Grand Mediation) System
}

With this backdrop in mind, it is not difficult to make sense of the ideological underpinning of the institutional built-up of the Da Tiaojie system (大调解格局)(or 'Grand Mediation' system, for want of a better translation). The system institutionalizes an integrated approach in civil, commercial and administrative disputes resolution through linking out-of-court mediation (or other conciliatory processes) with court proceedings. The system supposedly integrates and synergizes the three main modes of mediation in China: administrative mediation, people's mediation and court mediation. The focus of this book is on civil and commercial dispute resolution, hence administrative mediation falls outside of the scope of review. The White Paper on China's Judicial Reform (issued in October 2012) has the following to say about Grand Mediation:

\begin{abstract}
'In response to the frequently occurring conflicts and disputes in a period of rapid social development, in 2010 the legislative organ of China promulgated the Law of the People's Republic of China on Mediation, and relevant department issued Several Opinions on Establishing and Improving Conflict and Dispute Resolution Mechanisms by Linking Litigation and Non-litigation Cases and Guidelines on Encouraging the Use of Mediation to Solve Conflicts and Disputes. They encourage the development and improvement of non-litigation dispute resolution mechanisms, thus establishing multiple dispute resolution mechanisms suited to the national conditions... Strengthening conflict or dispute resolution mechanisms by linking litigation and non-litigation cases. Highlighting the role of people's mediation organizations, social groups, lawyers, experts and arbitration agencies, China endeavors to establish a "grand mediation" work system that integrates people's, administrative and judicial mediation, and improves coordination among the three in terms of procedure linkage, validity confirmation and legal guidance. As for non-litigation dispute resolution mechanisms like arbitration, the people's courts respect their own rules and provide support in such aspects as evidence and property preservation, and compulsory execution. ${ }^{219}$
\end{abstract}

The Grand Mediation system is significant in the following respects: (1) ADR: the system provides multiple ADR avenues for channelling disputes away from the courts (e.g. commissioned mediation (in its various forms); court-annexed mediation programmes (before docketing or soon after docketing); (2) strengthening the nexus between the private and public spheres of disputes resolution by expediting (and formalizing) enforcement of out-of-court settlement through the judicial confirmation procedure; (3) through channelling disputes, courts are reserved for disputes that truly require judicial expertise (e.g. more complex disputes, or disputes involving novel or important legal issues); (4) utilizing resources within the community to mediate disputes that are best resolved informally and locally with the view of maintaining

\footnotetext{
${ }^{218}$ Interview Ref: 2012/3.

${ }^{219}$ White Paper on China's Judicial Reform was issued by the State Council Information Office of the People's Republic of China in October 2012, in Beijing:
}

http://www.scio.gov.cn/zxbd/tt/Document/1226132/1226132.htm (last consulted: 16 July 2015). 
social stability; (5) elevating the importance of people's mediation by regulating it through legislation (thereby enhancing procedural predictability and structure).

\subsubsection{The 2010 SPC Opinion}

It is apt to highlight the significance of the 2010 SPC Opinion in the context of Grand Mediation. As will be discussed in Chapter 4, the opinion reinforces the overarching theme of the judiciary's task of maintaining social harmony with the efficient deployment of mediation tools at its disposal (that court mediation is an 'efficient and effective' mode of civil dispute resolution) and the need for court mediation to coordinate with other modes of mediation (e.g. people's mediation and administrative mediation) within the 'Grand Mediation' scheme (da tiaojie). ${ }^{220}$ The 2010 SPC Opinion effectively calls for the state to intervene in the realm of private justice as part of a greater scheme under which the quelling of social disputes was much more important than recognizing litigants' rights of access to justice.

The essence of 'Grand Mediation' is therefore crystal clear under the 2010 SPC Opinion: the intermingling of populist justice thinking and an out-of-court disputes resolution system that operates under the auspices of the judiciary.

While one might argue that the 2010 SPC Opinion is no longer effective as a policy, the concern for 'social harmony' in the immediate past administration could easily be substituted nowadays by policies that seek to maintain 'social order' (weiwen). As such, the question is not so much whether the 2010 SPC Opinion is followed per se by courts. The question is whether the spirit behind the 2010 SPC Opinion remains intact in China today. The answer, it is submitted, is a resounding 'yes'. ADR is never completely party-driven in China in the sense that the state always has a role to play in disputes resolution given the possibility of an overspill of private contention into a 'dispute involving the masses' (群众事件).

\footnotetext{
${ }^{220}$ The 2010 SPC Opinion contains the following key policies: (1) giving priority to mediation in civil and commercial cases at all stages of proceedings (including but not limited to first instance, second instance, re-adjudication and enforcement); (2) extending the scope of this policy to civil causes of action arising from criminal proceedings (刑事附带民事案件); (3) the aim of the policy being to 'close the case and [truly] resolving the dispute' (案解事了) (courts should monitor closely mediation settlement rates, 'letters and visits' rates (信訪率) and compulsory enforcement rates as they are parameters for measuring the success of the implementation of this policy); (4) judges at all levels of courts should resort to mediation first whenever possible, with special emphasis on the need of basic courts to promote mediation; (5) emphasize the need to strengthen pre-action mediation and developing mediation capabilities at the docketing division of every court (e.g. using 'docket windows' (lian chuangkou) to direct parties to settle the dispute within the docketing division); (6) promotion of pre-hearing mediation (e.g. where possible, courts should establish special teams staffed with judicial assistants to help share the load of pre-hearing mediation); (7) incentivize the use of mediation by introducing mediation settlement/withdrawal rates (调撤率) and other mediation related indices (such as xinfang rates) as key parameters of the case quality evaluation exercise, which is in turn used to assess the work of courts and individual judges; (8) emphasized the need for courts to actively visit parties who have settled the case to supervise on enforcement (调解回访工作); extending the funding of court mediation (e.g. lobbying for mediation related expenditure to be incorporated into the court annual budget); and establishing the court's leading position in the 'Grand Mediation' scheme in every locality (i.e. the court should supervise the scheme as well as acting as the conduit that connects various mediation organizations) and continue to entrench the procedural nexus between out-of-court dispute resolution processes and court procedures (诉讼与非诉讼程序相衔接).
} 


\subsubsection{The Judicial Confirmation Procedure and its significance in the Grand Mediation system}

Among the key SPC interpretations regarding the connecting mechanism between private and public domains of justice, the Several Provisions of the Supreme People's Court on the Judicial Confirmation Procedure for the People's Mediation Agreements $^{221}$ (2011 Judicial Confirmation Rules) is perhaps the most important of all as it formalizes the process by which a private settlement could transform into a type of court order capable of being directly enforced under court-directed mandatory enforcement procedures. The most significant provision is Article 9 of the 2011 Judicial Confirmation Rules: 'Where a party concerned refuses to perform or fails to fully perform a mediation [settlement] agreement confirmed by the decision of the people's court, the other party may apply to the people's court which made the confirmation decision for enforcement'. It is clear from the wording of Article 9 that the effect of judicial confirmation transforms what is simply a contractual settlement into a directly enforceable settlement (i.e. something akin to a consent order under common law). A contractual settlement only gives the non-defaulting party the right to sue for breach of contract, while a settlement confirmed by the court allows the non-defaulting party to enforce the settlement through court-directed mandatory enforcement procedures.

The judicial confirmation procedure is in no way nominal. The court takes into account a number of factors in determining whether an out-of-court settlement should be confirmed. Under Article 7 of the 2011 Judicial Confirmation Rules, the court must not confirm a settlement agreement if the agreement (a) violates mandatory provisions of the law or administrative regulations; (b) infringes upon national interests or public interests; (c) infringes upon the legitimate rights and interests of any non-party; (d) impairs public order; (e) lacks clarity in its contents; and (f) other circumstances under which the agreement must not be confirmed. No judicial guidance is given on the interpretation of Article 7, e.g. whether there is any de minimis principle. The catch-all provision of 'other circumstances' is overly sweeping given there is no guidance on how discretion should be exercised. It creates a loophole for the court to refuse confirmation motivated by ulterior motives (e.g. protection of local business interests). ${ }^{222}$

${ }^{221}$ Judicial Interpretation (fashi) [2011] No. 5, effective since 30 March 2011.

${ }^{222}$ Also see Article 24 of the 2009 SPC Opinion, which states:

'Under any of the following circumstances, the people's court shall not confirm the validity of a mediation agreement:

(1) any mandatory provision of a law or administrative regulation is violated;

(2) the national interests or social and public interests are infringed;

(3) the legitimate rights and interests of non-parties are harmed;

(4) whether a party shall be subject to the criminal liability is involved;

(5) the contents of the mediation agreement are unclear and can not be confirmed and enforced;

(6) the mediation organization or mediator conducts mediation compulsorily or commits any other act in serious violation of professional ethics; or 
The confirmation process is also strictly formal. Article 6 of the 2011 Judicial Confirmation Rules allows the court to call upon the parties, where necessary, to question the parties on the settlement agreement and request for documentary evidence in support of their application for confirmation. In terms of procedural design, Article 23 of the 2009 SPC Opinion states:

'The people's court shall apply by analogy the relevant provisions of the Civil Procedure Law of the People's Republic of China on summary procedure in hearing an application for confirming a mediation agreement. The application shall be heard by a single judge, and both parties shall appear before the court at the same time. The people's court shall ask both parties face to face whether they understand the contents of the settlement agreement, whether they accept the results thereof and whether they allow the people's court to grant enforceability to the [settlement] agreement through the judicial confirmation process.'

Article 33 of the People's Mediation Law provided statutory backing to the judicial confirmation procedure:

'After a mediation [settlement] agreement is reached upon mediation by a people's mediation committee, when necessary, the parties concerned may jointly apply to the people's court for judicial confirmation within 30 days after the mediation [settlement] agreement becomes effective, and the people's court shall examine the [settlement] agreement and confirm its effect in a timely manner. After the people's court confirms the effect of the [settlement] mediation agreement, if one party concerned refuses to perform or fails to fully perform it, the other party may apply to the people's court for enforcement.

If the people's court decides that the mediation [settlement] agreement is invalid, the parties concerned may alter the original agreement or reach a new agreement through people's mediation, or bring a lawsuit to the people's court.'

\subsubsection{Non-political 'sensitive cases'}

The Chinese concept of 'sensitive cases' is not limited to the strictly politically sensitive ones (i.e. cases involving the expression of dissenting political views or actions that challenge the ruling ideology/ establishment). The concept encompasses disputes (be it civil or administrative in nature) that cause mass-scale social unrest or may have significant negative impact on public order. An example of this type of non-political 'sensitive cases' is protests against local authorities or governmentbacked companies in connection with environmental damage. Disputes that have erupted in the form of mass protests, which are frequently seen throughout China today, usually find their way to court. Civil disputes that may threaten public order include mass torts (especially mass-scale medical negligence), land disputes affecting the property rights of a substantial number of citizens (in particular land resumption

(7) other circumstances under which the court shall not make confirmation.

Where the parties enter into a mediation agreement against their true will or the mediation organization or mediator is a party of interest to the case and the mediation apparently lacks fairness, the people's court shall not confirm the validity of the mediation agreement, except when the parties knowing the aforesaid circumstances still insist on applying for confirmation.' 
disputes), and contractual claims relating to the livelihood of the people (especially where there is a gross imbalance of bargaining power in favour of the privileged class). Grievances among the population are unavoidable when a society enters a stage where the wealth gap widens at the expense of the lower-income class and the welfare 'safety net' is underdeveloped. While the Chinese government, as a regulator, is efficient in facilitating economic development, it fails to manage social inequalities and provide the necessary protection for the financially weak. In China, social discontent frequently manifests itself as civil lawsuits.

\subsubsection{Inherent problems of the Grand Mediation System}

The 'Grand Mediation' system has its merits if limited to a purely ADR role and function. However, China's political backdrop dictated the way Grand Mediation is being promoted and implemented. Grand Mediation, as a politically-charged mechanism, has the following inherent problems:

First, the system is operated on the basis of the underlying objective of channelling disputes away from the courts and back to the local community. This, in itself, is unobjectionable if party autonomy is respected. The reality, however, is that courts push away disputes to avoid social discontent entering the court system, at times against the wishes of the parties. ${ }^{223}$ Policy in China has an overriding impact on judicial practices. The way the Grand Mediation system is run is similar to court mediation, in that the overarching policy of the maintenance of social stability (weiwen) trumps party autonomy. A litigator in a leading commercial city in China, for instance, noted that courts are prepared to delay the docketing of a case (which is contrary to the Code $)^{224}$ just to ensure that the dispute in question is given sufficient time to be settled outside of court. ${ }^{225}$ This runs completely contrary to the party's right of access to court. ${ }^{226}$ Even putting aside the docketing issue and focusing only on the out-of-court mediation process itself, one is bound to find problems. As will be illustrated below, people's mediation, by nature, is closely akin to adjudication. In people's mediation, the legal liabilities of parties are taken into account in formulating the settlement agreement. Instead of treating it as a process in which both parties seek to achieve common ground, the people's mediator would frequently steer the process towards a type of result that would be consistent with the substantive law, established government policies and industry customs. This practice infringes party autonomy and diminishes the ADR function of out-of-court mediation.

Second, pushing disputes away from the court system not only infringes the party's right of access to court, it also deprives genuine legal issues that may have 'precedent

\footnotetext{
${ }^{223}$ Pushing cases away from the court system also has a case-management aspect to it. As courts today are dealing with skyrocketing caseloads, channeling disputes back to the community helps manage the docket and avoid over-stretching the court's capacity.

${ }^{224}$ While the Code provides that the court must decide whether or not to docket the case within seven days from the date the claimant files the claim (Article 123 of the Code). But some practitioners confirm that this statutory time limit is not always observed, with some courts refusing to docket a case for 40 days or more: Interview Ref: 2012/3.

${ }^{225}$ It remains to be seen whether this problem would improve with the implementation of the 2015 Registration Rules.

${ }^{226}$ The Grand Mediation system obscures the whole docketing process in that the overriding concern is to settle the dispute without docketing instead if playing by docketing rules.
} 
value' to reach the courtroom. This practice is unfavourable to the development of public interest litigation. It also frustrates China's ability to develop new areas of the law through adjudication. Even with its civilian legal tradition, China is now developing towards a system where court adjudication plays a role in establishing certain legal norms, e.g. the system of 'guiding cases' and the practice that decisions of higher-level courts are highly persuasive for lower-level courts within the same vertical court structure, albeit none of the court decided cases is technically binding,

Third, similar to court mediation, the notion of Anjie shiliao is equally important in out-of-court mediation. The primary objective of the Grand Mediation system is to resolve disputes in a way that social discontent is eradicated once and for all. The collectivist undertone of Grand Mediation places societal interests above individual interests.

Fourth, much more needs to be done in regulating the interaction between out-ofcourt conciliatory processes and formal court procedures. Currently, regulation focuses almost entirely on the judicial confirmation procedure. There is no law or SPC interpretation that establishes procedural safeguards against abuse. For instance, there should be an avenue that allows a party to apply to a higher-level court for an undue delay in docketing. A one-stop complaint procedure (whether managed by a superior court or an administrative authority) is necessary to curb attempts to exert pressure on parties from initiating proceedings.

Fifth, as will be discussed below, the qualification of mediators in people's mediation is questionable. Apart from a vague outline of the requirements of appointment in Article 14 of the People's Mediation Law, ${ }^{227}$ nothing substantial is provided in terms of the professional requirement for people's mediators. Given the expanding scope of people's mediation, an up-to-date accreditation system should be adopted to ensure people's mediators understand and are able to implement the fundamental principles of mediation practice (e.g. the importance confidentiality and party autonomy). This is particularly vital for court-annexed mediation setups as mediation in those situations plays a direct role in pre-litigation dispute resolution. Unless the accreditation of people's mediators reaches the standards of international practice, the quality of private justice in China would continue to lag behind.

Finally, the extensive power of the courts in the judicial confirmation procedure raises the question of whether the state is trespassing into private domains of disputes resolution. As seen under Articles 6 and 7 of the 2011 Judicial Confirmation Rules, the power of the court in reviewing out-of-court settlement agreements is substantive, i.e. the court is capable of striking down settlement agreements on the basis that the content of the agreement falls under any of the situations under Article 7. The concern is that no detailed guidelines are given on what actually constitutes a ground to reject confirmation as the situations set out in Article 7 is ultimately a matter of judicial interpretation. It is suggested that the judicial confirmation procedure should adopt a purely procedural review of the out-of-court settlement, rather then allowing the court the discretion to review the actual content of the substantive settlement.

\footnotetext{
${ }^{227}$ Article 14 of the People's Mediation Law reads, 'People's mediators must be adult citizens who are impartial, decent and dedicated to the people's mediation work, and have a certain level of education, policy understanding and legal knowledge.'
} 


\subsection{People's mediation}

\subsubsection{Legislative scheme: the People's Mediation Law and relevant interpretations}

The enactment of the People's Mediation $\mathrm{Law}^{228}$ was a landmark development in unifying and improving people's mediation institutions, procedures and practices. Prior to the People's Mediation Law, people's mediation was regulated by SPC guidelines and local practices. This law has six chapters: (I) General Provisions; (II) People's Mediation Committees; (III) People's Mediators; (IV) Mediation Proceedings; (V) Mediation Settlement Agreement; and (VI) Supplementary Provisions.

The fundamental objective of the People's Mediation Law is clearly stated in Article 1: 'To improve the people's mediation system, regulate the people's mediation activities, solve disputes among the people in a timely manner and maintain social harmony and stability, this Law is formulated pursuant to the Constitution'. This clear statement indicates that people's mediation is not simply a matter of the community. The state plays a critical role in the operation of people's mediation with the view to maintain social order and political stability. In an authoritative annotation of the People's Mediation Law, it is stated that '[it is an imperative to] uproot disputes when they are at the "sprouting stage", [so as to] avoid simple community disputes from deteriorating into criminal cases, or triggering disputes involving the masses'. ${ }^{22}$ The principle enshrined in Article 1 echoes the traditional social function played by people's mediation committees. The people's mediation system is a network of grassroot organizations established on the basis of the 'mass-line' ideology. ${ }^{230}$ As such, people's mediation is not just about out-of-court disputes resolution among private parties. While playing certain ADR functions, people's mediation network forms part of the local governing structure that exerts control and supervision over the local community through less formal or non-official means.

Article 2 of the People's Mediation Law defines what people's mediation is:

"The term "people's mediation" as mentioned in this Law refers to a process that a people's mediation committee persuades the parties to a dispute into reaching a mediation [settlement] agreement on the basis of equal negotiation and free will and thus resolves the dispute between them.'

Article 2 reveals three important aspects of people's mediation:

(a) The locus of people's mediation must be the people's mediation committee (PMC). Any mediation conducted without the involvement of a PMC is not people's mediation and any settlement resulting from a non-PMC mediation cannot benefit from the procedural advantages (e.g. judicial confirmation) enjoyed under people's mediation.

\footnotetext{
${ }^{228}$ Effective since 1 January 2011.

${ }^{229}$ People's Mediation Law Annotation 2010, p. 13.

${ }^{230} \mathrm{Fu} 1992$, p. 211-216.
} 
(b) People's mediation is a process where the PMC 'persuades' the parties with a view to reach settlement. The word 'persuades' is a less-than-perfect translation of two different terms in Chinese: shuofu (说服) and shudao (疏导). These two Chinese terms, under the People's Mediation Law, are interpreted to mean that the PMC must assist the parties in exchanging views, suggest settlement proposals and guide parties towards the path of settlement. In so doing, the PMC has a duty to explain to the parties what the relevant substantive law and state policies are. ${ }^{231}$

(c) The scope of disputes that are capable of being mediated by PMCs are called 'disputes arising from within the community' (民间纠纷) ${ }^{232}$. These are disputes between individual civilians concerning relatively simply conflicts regarding land, inheritance, child custody and neighbourhood relations, as well as small claims and non-complex torts. But with the advancement of society and economic development, disputants are no longer just individual civilians but also corporates and social organizations. The types of disputes extend to areas of property management, pollution, labour, medical negligence and land ownership and resumption. ${ }^{233}$

According to Article 4 of the People's Mediation Law, people's mediation committees must not charge fees for any mediation of 'disputes arising from within the community'. To date, the no-fee rule is strictly followed by PMCs throughout the country. It remains to be seen if there could be exceptions to the no-fee rule if future disputes become more complex or commercial in nature. This is a reasonable expectation given the state's desire to expand the scope people's mediation to encompass a wider variety of disputes.

As noted earlier, the judicial confirmation procedure is given statutory backing under Article 33 of the People's Mediation Law, ${ }^{234}$ thereby further entrenching the nexus between the private and public spheres of civil dispute resolution.

According to official statistics in 2013, there were altogether 820,025 PMCs and 4,229,061 People's Mediators nationwide. ${ }^{235}$

\footnotetext{
${ }^{231}$ People's Mediation Law Annotation 2010, p. 12.

232 'Disputes arising from within the community' (for want of a better translation), are categorically different from purely commercial disputes or disputes involving the administration.

${ }^{233}$ People's Mediation Law Annotation 2010, p. 13.

${ }^{234}$ Article 33 of the People's Mediation Law states:

'After a mediation agreement is reached upon mediation by a people's mediation commission, when necessary, the parties concerned may jointly apply to the people's court for judicial confirmation within 30 days after the mediation agreement becomes effective, and the people's court shall examine the agreement and confirm its effect in a timely manner.

After the people's court confirms the effect of the mediation agreement, if one party concerned refuses to perform or fails to fully perform it, the other party may apply to the people's court for enforcement.

If the people's court confirms that the mediation agreement is invalid, the parties concerned may alter the original agreement or reach a new agreement through people's mediation, or bring a lawsuit to the people's court.'

${ }^{235}$ Yearbook 2014, p. 226.
} 


\subsubsection{Policy considerations}

People's mediation in China is not just about disputes resolution. PMCs through the country operate under the directions of the administrative bureaux of justice at the same level. ${ }^{236}$ The Ministry of Justice has overall supervisory powers over people's mediation. Any local bureau of justice (at county level or higher) has supervisory powers over PMCs within its jurisdiction. The position of local courts vis-à-vis PMCs is less direct and slightly peculiar in that the People's Mediation Law provided that 'basic-level people's courts shall provide guidance to the people's mediation committees in their mediation of disputes within the community'. ${ }^{237}$ This seems to suggest that while the local administration supervises the institutional aspects of PMCs, local courts have power to give directions on the operational aspects of mediation. It is suggested that local courts should give directions to PMCs through three different channels:

(a) Providing feedback from the judicial confirmation procedure: the courts should take the initiative to provide feedback (or give directions) to the PMC in question if any problems arise from judicial confirmation of the settlement agreement. As the court exercises substantive powers under the judicial confirmation procedure, its views and suggestions would not be taken lightly by the PMCs. ${ }^{238}$

(b) Cooperating with the local justice bureau: the local courts should work with the corresponding local justice bureau to improve the quality of people's mediation. One direct way of influencing PMCs is for the court to get involved in the training of people's mediators. Courts may also weigh in on the formulation of rules and regulations (as well as a code of conduct) for people's mediators. ${ }^{239}$

(c) Influencing people's mediation through strengthening the nexus between private and public spheres of disputes resolution: the court may exert substantial influence over people's mediation by extending and strengthening the organic nexus between private and public spheres of disputes resolution. A common way to achieve this is through establishing 'People's Mediation Windows' (人民调解窗口) within the docketing division of the court. Another way is to strengthen existing schemes of commissioned mediation. ${ }^{240}$

\footnotetext{
${ }^{236}$ Article 5 of the People's Mediation Law sets out the supervisory structure of people's mediation: 'The administrative department of justice under the State Council shall be responsible for guiding the people's mediation work of the whole nation, while the administrative departments of justice of the local people's governments at or above the county level shall be responsible for guiding the people's mediation work within their respective administrative regions. The grassroots people's courts shall provide guidance to the people's mediation commissions in their mediation of disputes among the people.'

${ }^{237}$ Ibidem.

${ }^{238}$ People's Mediation Law Annotation 2010, p. 25.

${ }^{239}$ People's Mediation Law Annotation 2010, p. 25-26.

${ }^{240}$ People's Mediation Law Annotation 2010, p. 26.
} 
The structure of direct administrative control (and judicial supervision) over PMCs suggests that people's mediation serves the purpose of social control in addition to the propagated role of inexpensive alternative dispute resolution. Indeed, the sheer size of the people's mediation network and the pervasiveness of people's mediation on the local level are shocking. The White Paper on China's Judicial Reform states:

'People's mediation is a Chinese way for resolving non-litigation disputes. China has established people's mediation committees in village (residents') committees, townships or towns (urban districts), enterprises and public institutions, as well as industries and sectors with a high frequency of occurrence of disputes. By the end of 2011, China had 811,000 people's mediation organizations and 4.336 million mediators. In 2011, a total of 8.935 million conflicts were resolved through mediation, with a $96.9 \%$ resolution rate. ${ }^{241}$

Politically, the state benefits tremendously if full control over PMCs remains in the hands of the administration and the judiciary. This is why the state is reluctant to grant real autonomy to PMCs despite knowing that there is clear economic need to strengthen and empower the private sphere of disputes resolution.

\subsubsection{General operative principles governing people's mediation}

Article 3 of the People's Mediation Law sets out the general operative principles for people's mediation:

'(1) Mediating on the basis of free will and equality of the parties concerned;

(2) Abiding by laws, regulations and policies of the state; and

(3) Respecting the rights of the parties concerned, and refraining from stopping

the parties concerned from protecting their rights through arbitration, administrative means or judicial means in the name of mediation.'

The high sounding principle of voluntariness does not necessarily resonate with reality, as illustrated in the actual practice of people's mediation. ${ }^{242}$ The people's mediator frequently plays the role of an adjudicator (or quasi-adjudicator) in that he makes determinations on facts as well as what he sees as the law. A people's mediator has the power to make settlement proposals, which is a common feature of conciliation, not facilitative mediation.

The principle of abidance by the law, if over emphasized in practice, could evolve into a rigid exercise of scrutinizing the content of the settlement agreement against the substantive law, rather than giving effect to the will of the parties.

\footnotetext{
${ }^{241}$ White Paper on China's Judicial Reform was issued by the State Council Information Office of the People's Republic of China in October 2012, in Beijing:

http://www.scio.gov.cn/zxbd/tt/Document/1226132/1226132.htm (last consulted: 16 July 2015).

${ }^{242}$ Interview Ref: $2012 / 4$.
} 
The last key principle appears to reinforce the party's right of access to court. Again, in practice, policy constantly dictates what should and should not enter the judicial system, though recent reform efforts are seeking to strengthen the protection of the right of access to court. ${ }^{243}$

\title{
3.3. Origins and ideological underpinnings of people's mediation
}

\subsubsection{From Maoist mass-line ideology to Post-Mao 'social harmony'}

People's mediation went through fundamental changes when Mao's era came to a close. The mass-line ideology of Mao, when applied to civil dispute resolution, saw mediation not as a conciliatory and 'yielding' process where parties come to an amicable settlement, but rather a way to uncover social tensions and conflicts with the view to expose problems, educate the masses and align local interests with the Chinese Communist Party's objectives. ${ }^{244}$ Such deployment of people's mediation by the Chinese Communist Party was consistent with Mao's desire at that time to maintain the momentum of his revolution.

After Mao, however, China took a pragmatic turn to develop its economy. The old mass-line ideology that sought to expose social conflicts for the sake of the 'revolution' was no longer relevant in the context of China's Open Door Policy. People's mediation, therefore, also took a practical turn. Fu observed (back in 1992):

\begin{abstract}
'The diminishing importance of Maoist values led to a spontaneous rejuvenation of suppressed traditional values... Increasingly, people's mediation is identified with the traditional preference for social harmony. It is now claimed that people's mediation is based upon, and developed from, tradition, and the historical and cultural link between the traditional and modern forms of conflict resolution is officially recognized...The emphasis in the new era is no longer on the transformation of disputes and the education of disputants. The government has prioritized dispute prevention. Disputes are regarded as fundamentally disruptive to the modernization program. It is thought that in this new era a chaotic social order would shake people's confidence in the government and endanger the Party's political stability. 245
\end{abstract}

The view that people's mediation was an effective tool to curb social conflicts reached its heights during Wang Shengjun's tenure as president of the SPC (March 2008 - March 2013). People's mediation, being the predominant form of conciliatory process outside of court, plays an important social function within the Party's grand scheme to maintain social stability. Disputes are best uprooted at the place where they emerged by way of mediation to avoid their escalation. Article 21 of the People's Mediation Law states that the mediator should seek to mediate within the locality where the dispute arose in a timely fashion and to avoid intensification of the conflict. The social function of people's mediation is further illustrated in Article 25 of the People's Mediation Law, 'The people's mediators shall take pertinent precautions if a dispute is likely to get intensified in the process of mediation and report to the local public security organ or other competent department in a timely fashion if a dispute is likely to become a public security case or criminal case'.

\footnotetext{
${ }^{243}$ For an overview of recent reforms, see the Afterward of this book.

${ }^{244} \mathrm{Fu} 1992$, p. 212-216.

${ }^{245} \mathrm{Fu} 1992,216-217$.
} 


\subsubsection{Recent developments}

Liu observed that there are four major changes in the people's mediation system in the last decade or so: ${ }^{246}$

(a) In the past, people's mediation organizations were mainly limited to village or neighbourhood PMCs. The current trend is that more and more PMCs are established in different industries, professions and communities. ${ }^{247}$ For instance, medical disputes nowadays usually find their way first to the local medical disputes people's mediation committees, rather than the courtroom. ${ }^{248}$ In fact, the authorities have encouraged the 'professionalization' of people's mediation, making it more industry focused and expert based. ${ }^{249}$ County and district governments established county-level/ district-level PMCs to handle disputes originating from county/ district communities (these PMCs focus mostly on administrative disputes). Courts and police stations have established annexed people's mediation 'work offices' (人民调解工作室) to deal with disputes 'on the spot'. In addition to expanding the size of the people's mediation organization, specialized Centres for Conciliating Social Conflicts and Disputes (社会矛盾纠纷调处中心) were established on the basis of existing PMCs to target specifically disputes that have or could have social ramifications. ${ }^{250}$

(b) In the past, people's mediators were members of village or residents' committees. Nowadays, people's mediators have much wider backgrounds, including retired judges, retired procurators, experts, and volunteers. PMCs are rolling out codes of ethics and operational guidelines for people's mediators in addition to the requirements under the People's Mediation Law. ${ }^{251}$ The People's Mediation Law provides for the establishment of new PMCs, ${ }^{252}$ which means the overall size and reach of the people's mediation organization could further expand in the years to come.

(c) In the past, the legal effect of a PMC-mediated settlement agreement is unclear. Since 2002, the SPC recognized the contractual force of settlement agreements. $^{253}$ This made it possible for the non-defaulting party to sue for

\footnotetext{
${ }^{246}$ Liu M. 2012, p. 59-65.

${ }^{247}$ For further details on the expansion of PMC organizations in China, see Halegua 2005.

${ }^{248}$ Interview Ref: 2012/4.

${ }^{249}$ For instance, see notice promulgated by the Ministry of Justice on 12 May 2011: 《关于加强行业 性，专业性人民调解委员会建设的意见》

${ }^{250}$ Liu M. 2012, p. 60-61.

${ }^{251}$ Liu M. 2012, p. 61.

${ }^{252}$ Article 34 of the People's Mediation Law reads, 'If it is necessary, villages, towns, sub-districts, social organizations and other organizations may form people's mediation commissions under the guidance of this Law to mediate disputes among the people.'

${ }^{253}$ Some Provisions of the Supreme People's Court on Trying Civil Cases Involving the People's Conciliation Agreements, Judicial Interpretation [2002] No. 29, effective since 1 November 2002 [ 《关于审理涉及人民调解协议民事案件的若干规定》]
} 
breach of the settlement agreement as a contractual claim. ${ }^{254}$ Article 10 of the 2009 SPC Opinion made it clear that 'The people's courts shall encourage industrial associations, social organizations, enterprises, public institutions, etc. to establish sound functions and mechanisms for resolving relevant disputes through mediation. A mediation settlement agreement containing civil rights and obligations reached through mediation conducted by a commercial mediation organization, an industrial mediation organization or any other organization with mediation functions shall be of a nature of a civil contract after both parties affix their signatures or seals to it.'

(d) In the past, PMC-mediated settlement agreements are not directly enforceable. With the implementation of the judicial confirmation procedure, the court is given the power to confirm a settlement agreement, which can then be directly enforced under the mandatory enforcement procedures of the Code. ${ }^{255}$

\subsubsection{Special features of people's mediation and procedural issues}

The principle of voluntariness is enshrined in Article 17 of the People's Mediation Law:

'The parties concerned to a dispute may apply to a people's mediation committee for mediation, and a people's mediation committee may also voluntarily offer to mediate. However, no mediation may be made if one party has expressly refused to settle the dispute by mediation.'

Where the people's mediation committee initiates mediation, a party refusing to have the matter mediated must express such refusal either verbally or in writing. Silence is regarded as agreeing to mediate. Even where a party expressed refusal, the people's mediator, as a matter of practice, should try to persuade the party to continue with the mediation, citing the benefits of the process, and 'educating' the party who expressed such refusal. Only when the party still refuses would the mediator terminate mediation. This bizarre practice is rooted in the role and duty of the PMC in Chinese society. While impartiality is emphasized in the mediation process itself, the PMC by no means occupy an impartial position. The PMC is the watchdog for social turbulence and the 'first line of defence' (第一道防线) of social stability in China. It is therefore logical to confer PMCs the power to identify disputes within society and initiate mediation even in the absence of a party request. While on paper parties are given the liberty to opt-out of mediation, in reality, this may not be as easy as it seems. For instance, suppose the work unit of the parties (i.e. both the employer and 'leader' of the parties) reported a dispute to the relevant PMC and the PMC decided to initiate mediation. One could imagine the difficulty the parties face if they flatly refuse to mediate.

Similarly, a court can, before accepting a case, notify the parties concerned that they can apply to the PMC to deal with the dispute. ${ }^{256}$ This can be abused, i.e. hinting that a case cannot be docketed unless the parties go through people's mediation.

\footnotetext{
${ }^{254}$ Liu M., p. 61.

${ }^{255}$ Liu M., p. 61-62.

${ }^{256}$ Article 18 of the People's Mediation Law.
} 
From the PMC's perspective, if the positive social effect could compensate a 'technical' breach of voluntariness, pressuring parties to settle through people's mediation is not only acceptable but also desirable.

A similar problem is found in the PMC's power to designate one or more mediators based on the needs of the case. ${ }^{257}$ It is stated that the nature of the disputes may warrant the appointment of specialists or persons of particular stature in the community as mediators, so much so that it is the duty of the PMC to make that decision on behalf of the parties, subject to the express rejection of parties. Again, on paper, the parties are free to reject the PMC-appointed mediators, but in reality parties are likely to acquiesce, fearing that they may suffer in the mediation by going against the decision the PMC.

The phenomenon of exerting 'soft pressure' on parties is not unique in people's mediation. For as much one desires to see procedural reform, there can be no true procedural justice when the organization that should be delivering justice is there to serve a 'higher social objective' and treats party interests and autonomy as secondary. This is the serious structural problem with justice in China - a failure to establish impartial and independent institutions to defend the fundamental rights of parties, both procedural and substantive. This is particularly true for people's mediation as PMCs are funded by local governments. ${ }^{258}$

Two very interesting procedural points are highlighted in Article 21 of the People's Mediation Law:

'In the process of mediating disputes from within the community, people's mediators shall abide by principles, understand the law and [are able to engage in] legal reasoning, and do justice to the parties concerned. The disputes from within the community shall be mediated in a timely manner and on the spot so as to prevent intensification of the conflict.'

First, the requirement that mediators must 'understand the law and [are able to engage in] legal reasoning' (明法析理) has two levels of interpretation: (a) the mediation is partly a fact-finding process and the settlement must be premised on accurate facts; and (b) the mediator must demonstrate an understanding of the substantive law, so much so that the settlement cannot deviate from the law. ${ }^{259}$ This interpretation is fortified by the wording in Article 22 of the People's Mediation Law, which provides that it is the duty of the mediator to explain the 'relevant law, regulations and state policy' to the parties. 'Relevant law' here encompasses substantive law and not just prohibitive regulations. The net effect of these regulations is that a people's mediator operates not as a facilitative mediator or even an evaluative mediator known to the

\footnotetext{
${ }^{257}$ Article 19 of the People's Mediation Law. Based on the needs of the case, a people's mediator may, subject to the consent of the parties, invite relatives, neighbours or colleagues of the parties concerned, persons with specialized knowledge or experience and persons from the relevant social organization to participate in the mediation process: Article 20 of the People's Mediation Law.

${ }^{258}$ Article 6 of the People's Mediation Law states:

'The state encourages and supports the people's mediation work. The local people's governments at or above the county level shall appropriately guarantee the funds needed for the people's mediation work, and commend and reward people's mediation commissions and people's mediators that make outstanding contributions according to the relevant state provisions.'

${ }^{259}$ People's Mediation Law Annotation 2010, p. 84-85.
} 
West. A people's mediator, by law, acts like a quasi-adjudicator who has the mandate to ensure that any settlement must be based on sound legal reasoning (in the sense that the terms of settlement must be consistent with substantive law) and accurate findings of facts. This is perhaps the most unique feature of people's mediation, distinguishing it from the various forms of mediation in the West. A clear illustration of the factfinding function of people's mediation is that a people's mediator is required to keep a People's Mediation Investigation Record (人民调解调查记录) documenting the factual circumstances surrounding the dispute. ${ }^{260}$

Second, the requirement that a dispute must be 'mediated in a timely manner and on the spot so as to prevent intensification of the conflict' reinforces the earlier argument that the primary objective of people's mediation is to maintain social harmony and stability. It follows that the preoccupation with social stability risks jeopardizing interests of the parties, especially when the two objectives are mutually exclusive in the particular case. This is another distinguishing feature of people's mediation from mediation in the West. The overriding goal of social harmony (or, in the official language of today, the goal of 'maintaining stability and order') is clearly revealed in Article 25 of the People's Mediation Law: 'The people's mediators shall take pertinent precautions if a dispute is likely to get intensified in the process of mediation and report to the local public security authority or other competent authority in a timely fashion if a dispute is likely to become a public security case or criminal case.'

Another key distinction between people's mediation and mediation in the West is the didactic nature of people's mediation. It is suggested that the people's mediation methodology should combine educating the parties on morals on the one hand and imparting knowledge of the relevant law and policies on the other. This methodology is summarized neatly in the slogan 'educating by example, using compassion to influence [the parties], enlightening [the parties] by reason, and explaining [the issues with reference to] the law' ('教之以行，动之以情，晓之以理，喻之以法'). ${ }^{261}$

An interesting feature of people's mediation is that the PMC has the duty to ensure that settlement agreements are honoured. ${ }^{262}$ This is done, in part, by PMC personnel tracking the status of enforcement of settlement agreements through visiting the parties. Every PMC is required to file a People's Mediation Return Visit Record (人 民调解回访记录) to document the status of enforcement of the settlement agreement, whether there is an intensification of the conflict and to record the feedback of the parties on the work of the PMC. ${ }^{263}$

The rights and obligations of the parties are set out under Articles 23 and 24 of the People's Mediation Law:

'Article 23: In the people's mediation of a dispute, the parties concerned are entitled

\footnotetext{
${ }^{260}$ Ding et. al. 2011, p. 35-39.

${ }^{261}$ People's Mediation Law Annotation 2010, p. 96.

${ }^{262}$ Article 31 of the People's Mediation Law reads, 'The people's mediation committee shall oversee the fulfillment of the mediation agreement and urge the parties concerned to honor their obligations as agreed.'

${ }^{263}$ Ding et. al. 2011 , p. 146.
} 
to:

1. Select or accept [the appointment of] the people's mediators;

2. Accept or refuse [to engage in] the mediation, or terminate the mediation;

3 . Require that the mediation be conducted publicly or privately; and

4. Freely express their will and reach a mediation [settlement] agreement on a voluntary basis.

Article 24: In the mediation of a dispute, the parties concerned are obliged to:

1. Truthfully state the facts of the dispute;

2. Abide by the order of the mediation venue and respect the people's mediators; and

3. Respect the other party's exercise of rights.'

While the principle of voluntariness is enshrined in Article 23, the reality is such that social objectives could override voluntariness. Article 24 established the principle of truthfulness, but the law does not state what the consequences are if a party tells only the partial truth, withhold material information or give misleading statements.

\subsubsection{No 'accreditation' of mediators: the issue of lack of professionalism and uniformity}

Articles 13 to 16 provide the procedural details for the appointment of people's mediators. It is apt to set out these provisions here in full:

'Article 13: People's mediators shall be members of and persons appointed by the people's mediation commissions.

Article 14: People's mediators must be adult citizens who are impartial, decent and dedicated to the people's mediation work, and have a certain level of education, policy understanding and legal knowledge. The administrative bureaux of justice of the county people's governments shall provide vocational trainings for the people's mediators on a regular basis.

Article 15: Where a people's mediator commits any of the following acts in his mediation work, the people's mediation commission to which he belongs shall reprimand and educate him and order him to rectify [the mistake]; if the circumstances are serious, the entity which recommends or appoints him shall dismiss him from the position or employment:

(1) Showing favouritism to a party concerned;

(2) Insulting a party concerned;

(3) Asking for or accepting money or goods, or seeking for other illicit benefits; or

(4) Divulging the private [and confidential] information or trade secret of a party concerned.

Article 16: People's mediators shall be properly subsidized for loss of working time. Where a people's mediator gets injured or disabled in the process of conducting the mediation work, the local people's government shall provide necessary assistance for his medical care and livelihood. Where a people's mediator dies on the job, his spouse and children shall receive compensation and preferential treatment according to the relevant state regulations.'

It is clear from the above provisions that there is no uniform system for accreditation for people's mediators. An individual becomes a people's mediator if he or she is a 
member of a PMC or is appointed as such by a PMC. The only guideline, which is vague, is that the appointees must be 'adult citizens who are impartial, decent and dedicated to the people's mediation work, and have a certain level of education, policy understanding and legal knowledge'. While people's mediators are required to go through 'vocational training' on a 'regular basis', training is in no way the same as accreditation.

Given the lack of a uniform system for accreditation, the quality of people's mediators varies greatly. A specialist PMC (e.g. specializing medical disputes) may have more stringent criteria for the selection process, but the majority of PMCs are still appointing mediators on the basis of rather arbitrary criteria. Therefore, the quality of mediation depends very much on the specialization, resources and leadership of the particular PMC.

Without a uniform system of accreditation, it is impossible to establish professionalism in people's mediation. With PMCs expanding their reach and taking on a large variety of disputes, it is questionable whether the existing undisciplined appointment system is sufficient to meet the needs of parties, in particular when the disputes are complex or require special skills. It is recommended that people's mediation should introduce a uniform accreditation system whereby appointment is conditional upon the candidate passing certain tests after having involved in comprehensive and intensive training.

\subsubsection{Caseload management: the channeling of disputes back to the community, keeping them away from the courts}

The tension between the need to channel disputes away from the courts and the risks of 'over outsourcing' of cases that are appropriate for adjudication, and the need to strike a delicate balance, determine the role to which court-annexed or court-referred mediation programmes play in the overall picture of civil justice. Obviously, the realm of private justice can justifiably expand if mediation (and other out-of-court settlement processes) is properly managed under a modern system that respects party autonomy and entrenches fundamental principles (like confidentiality). It is a different story if the sphere of 'private justice' is neither truly private nor properly managed. The people's mediation system on the whole fails to qualify as a properly managed modern system of ADR.

\subsubsection{Limitations of people's mediation}

While being the single most common form of out-of-court mediation process, people's mediation has its limitations in four aspects:

(1) Inability to handle complex cases: People's mediation, ultimately, is a community-based institution with the mandate to secure the peace and stability of the community. It is designed to handle simple cases involving straightforward civil relations. While the scope of people's mediation expanded throughout the years, the quality of the mediators and the procedural deficiencies of the process limit the extent to which people's mediation could 
develop. It is unlikely that PMCs today have the ability, and indeed the mandate, to handle complex cases, especially cases with a commercial dimension involving corporations.

(2) Predominance of social function at the expense of procedural justice: the fundamental objective of the people's mediation regime is to ensure disputes within the community are dealt with in a timely and conciliatory manner. People mediators, therefore, play an important social function - the avoidance of escalation of disputes and the maintenance of social order. The predominance of this social function may infringe parties' right of access to court, in the sense of the mediator steering the mediation towards certain predetermined goal, or the PMC exerting pressure on parties to settle the dispute out-of-court. Ultimately, while people's mediation deals with disputes between private parties, the procedure in itself is not 'private' as such given the underlying political function of PMCs. The non-private nature of people's mediation limits its development, as it causes parties to avoid the PMCs and seek truly private mediation if the dispute concerns highly sensitive and confidential matters.

(3) Resembles a type of quasi-adjudication coupled with conciliation, not a pure form of mediation: the conduct of mediation still very much resembles a summary adjudicatory process coupled with conciliation. ${ }^{264}$ The mediator would frequently take positions (on both legal and factual issues) during mediation and express opinions on matters relating to liability and quantum. ${ }^{265}$ The process has the outlook of a mediation because of its name ('tiaojie' (调 解), Chinese for mediation) and the outcome being crafted in the form of a settlement agreement. The quasi-adjudicatory nature of people's mediation dis-incentivises potential users who are looking for a genuine form of facilitative mediation.

(4) Lacking in procedural safeguards: the people's mediation legislation provides very limited detail on procedural safeguards during and post mediation. An example is the protection of confidentiality. The People's Mediation Law is deficient in that there are no clear rules of confidentiality or 'double confidentiality'. ${ }^{266}$ While without prejudice privilege is alien to Chinese law, the legislation could have provided clear guidance on the circumstances in

\footnotetext{
264 While specialization helps promote the scope of people's mediation (for instance the highly specialized medical disputes mediation processes show the expanding coverage of the people's mediation network), specialization must come hand in hand with the integrity of the process. The lack of independence of PMCs and the interventionist approach of the mediator call into question the fairness of the process. When faced with specialized areas such as medicine, the mediator's own judgment may well become the terms of the settlement. An area of reform is to move the mediator back to his original position (an impartial facilitator) and allow independent experts to assist with the process where necessary.

${ }^{265}$ For instance, the Beijing Municipal Medical Dispute People’s Mediation Committee (北京市医疗 纠纷人民调解委员会) issues a 'Medical Liability Confirmation' (医疗损害责任认定书) at the end of each mediation setting out the points of contention, the treatment process and the mediator's assessment on liability.

266 'Double confidentiality' here means the duty of the mediator to keep information disclosed during a back-to-back session with one party confidential from the other party.
} 
which information disclosed during people's mediation could be used (or is prohibited from being used) in court proceedings.

\subsection{Nexus between private and public spheres of civil disputes resolution}

\subsubsection{Pre-action mediation to be attempted first?}

Article 122 of the Code states, 'If the civil dispute brought before a people's court by a party would be suitable for mediation, mediation shall be attempted first, unless the parties refuse.'

Article 122 applies to two specific stages: the pre-action stage and the stage soon after docketing. This section focuses on the pre-action stage.

Pre-action mediation generally happens when parties choose to resolve their dispute through mediation first before commencing proceedings. On cost-effectiveness and case management grounds, courts generally encourage parties to explore settlement before commencing action. The docketing division of the court would inform parties the availability of various forms of pre-action mediation processes and the advantages of settling disputes out of court. Zhang (et al.) noted that courts must respect the choice of parties if they decide to engage in mediation before commencing action. ${ }^{267}$

There is no procedural regime governing pre-action mediation, save for some guidance in the 2004 Civil Mediation Rules. Also, the scope of disputes that are subject to pre-action mediation is unclear.

An academic view is that given the lack of procedural safeguards in the Chinese preaction mediation regime, strict control on the scope of matters that are suitable for pre-action mediation should be clearly delineated. ${ }^{268}$ For instance, Zhang (et al.) argued that based on a study of judicial practice, the following types of disputes are generally suitable for pre-action mediation: (a) matrimonial disputes; (b) neighbourhood disputes; (c) small claims; (d) personal injury cases; (e) simple cases of debt collection within the community; and (f) any other disputes where the facts are relatively clear and the legal relations are less complex. ${ }^{269}$ This list, of course, is non-exhaustive. With the rapid development of all forms of out-of-court mediation forums (including specialist PMCs), the realm of matters that are suitable for preaction mediation would only expand.

\footnotetext{
${ }^{267}$ Zhang W.P. 2012, p. 181.

${ }^{268}$ Zhang W.P. 2012, p. 181.

${ }^{269}$ Zhang W.P. 2012, p. 181.
} 


\title{
3.4.2. 'Commissioned mediation': the effectiveness of court-referred mediation programmes in China
}

‘Commissioned mediation' (weituo tiaojie (委托调解)), as it is called in China, is essentially a form of court-referred mediation conducted by an independent outside party, usually a PMC. There are three types of commissioned mediation: (a) preaction commissioned mediation; (b) pre-hearing commissioned mediation; and (c) commissioned mediation during the court hearing stage. ${ }^{270}$ This section focuses on pre-action commissioned mediation.

\subsubsection{Pre-action commissioned mediation: the role of the court}

The problem with pre-action commissioned mediation originates from the court's statutory duty to docket a case within the stipulated timeframe:

\begin{abstract}
'Where the conditions for the institution of a legal action are satisfied, the people's court shall place the case on the docket within seven days and notify the parties. If the conditions are not satisfied, the people's court shall render a ruling within seven days and not accept the case. If the plaintiff is dissatisfied with the ruling, he may lodge an appeal. ${ }^{271}$
\end{abstract}

A referral to mediation by the court before a case is docketed could mean that the docketing of the case could be delayed. In fact, prior to the Regulations of the Supreme People's Court on Several Issues Relating to the Docketing Registration of Cases in the People's Courts ${ }^{272}$ (2015 Registration Rules), it is not uncommon for courts to use the referral mechanism as a delaying tactic to avoid docketing new cases and thereby reducing the caseload of the court. ${ }^{273}$

Another problem area is the extent to which the court should be involved when a case is referred to an outside mediator. Academic views tend to favour some form of supervision by the court, ${ }^{274}$ and indeed in practice courts would feel obligated to interfere should there be any complications in the mediation process. This again shows the all-encompassing influence of the court in civil dispute resolution in China. A pre-action mediation conducted out-of-court is ultimately a private matter and should not be subject to court intervention. The fact that it was 'referred' to an outside mediator by the court does not mean the court automatically has jurisdiction over a matter that has not even been docketed. The problem of delay in docketing can simply be avoided by allowing the claimant to apply again for docketing at any time during the mediation. It is said that the extent of court's interference in pre-action commissioned mediation depends on the established 'mediation programme' of the particular court. As identified by Xiao, the Shanghai Pudong District Basic-Level Court adopted a highly interventionist approach in pre-action commissioned mediation. The Suzhou Wuzhong District Basic-Level Court, on the other hand,

\footnotetext{
${ }^{270}$ Xiao 2009, p. 137.

${ }^{271}$ Article 123 of the Code. A judge commented that commissioned mediation during the court hearing stage is underused in China: see Interview Ref: 2012/5.

272 Judicial Interpretation (fashi) [2015] No. 8, effective since 1 May 2015. [最高人民法院关于人民法院登记立案若千问题的规定]

${ }^{273}$ Interview Ref: 2012/3.

${ }^{274}$ Xiao 2009, p. 139.
} 
adopted a pre-action commissioned mediation programme that was independent from the court. The Shanghai Chengling District Basic-Level Court adopted a midway approach with the court supervising the mediating organization where necessary. ${ }^{275}$ Xiao actually advocated the interventionist approach, noting that it is the responsibility of the court to devise the most appropriate dispute resolution mechanism for parties at the pre-action stage. ${ }^{276}$

A further issue, which is most significant of all, is whether the court referral as such constitutes an acceptance of the case (i.e. the de facto docketing of the case). Xiao advocated this interpretation, which entails a failure in the commissioned mediation would automatically allow the claimant to prosecute his case in the court without the need for further consideration by the court's docketing division. ${ }^{277}$ This interpretation has its merits, as it resolves the problem of possible delay in docketing. Xiao further advocated the adoption of the Taiwanese procedure that if commissioned mediation fails, court hearing could commence immediately upon application by any party. ${ }^{278}$

\subsubsection{Court-coordinated 'private' reconciliation: invading the private dispute resolution space?}

It is possible for parties to apply to the court to coordinate private reconciliations or negotiations (和解协调). This usually happens when both parties are willing to explore settlement but due to practical circumstances are unable to reach a settlement. ${ }^{279}$ Under Article 4 of the 2004 Civil Mediation Rules, upon application by the parties, 'the people's court may appoint auxiliary staff of trial or entrust the related entities and individuals to coordinate [with the reconciliation]'. The court's power to 'coordinate' private negotiations is under-regulated with no procedural safeguards whatsoever. While in theory the court's involvement is triggered by way party application, in practice the court may abuse this power by interfering with private reconciliations or negotiations against the wishes of the parties if the dispute in question is one that affects the institutional interests of the judiciary, government authorities or state-owned enterprises. Court-coordinated 'private' reconciliation epitomizes once again the extremely extensive reach of the state machinery in private affairs.

\subsubsection{Outside parties assisting with court mediation (协助调解)}

Under Article 95 of the Code, 'When conducting mediation, a people's court may invite the assistance of relevant entities and individuals. The entities and individuals invited shall assist the people's court in conducting mediation. ${ }^{280}$

\footnotetext{
${ }^{275}$ Xiao 2009, p. 138.

${ }^{276}$ Xiao 2009, p. 139.

${ }^{277}$ Xiao 2009, p. 143.

${ }^{278}$ Xiao 2009, p. 143.

${ }^{279}$ Xiao 2009, p. 136.

${ }^{280}$ C.f. Article 3 of the 2004 Civil Mediation Rules.
} 
'Relevant entities and individuals' are interpreted to mean 'the enterprises and public institutions or social organizations or other organizations, which have special relations with the parties concerned or have some kind of connection with the case, and individuals who possess the professional knowledge, specific social experience and have a special relationship with the parties concerned'.

It is said that by having individuals or representative of organizations at the mediation whom the parties are familiar creates a more amicable environment for settlement. ${ }^{282}$ This view is questionable where the circumstances are complex and involving additional people in the mediation could risk further complicating the matter. Indeed, some judges are sceptical that this mechanism would work effectively, not to mention that the so-called 'relevant entities and individuals' might not be willing to step up and assist. One judge said that the dispute would not have reached the courtroom at all if local stakeholders were able to help resolve it in the first place. ${ }^{283}$

\subsubsection{Judicial confirmation procedure in commissioned mediation: futile or necessary?}

Some argue that since commissioned mediation is in effect a court referral, i.e. a judicial act, settlement agreements arising from the mediation need not go through the judicial confirmation procedure. This view ignored the fact that while it is courtreferred, the very nature of the mediation is an out-of-court mediation, not court mediation. Therefore, while the commissioned people's mediation organization may organically be linked to the court (e.g. as a 'mediation window' of the docketing division), the mediation process is not a judicial process. Any settlement reached is by nature only contractual, not a 'mediation statement' (tiaojie shu). ${ }^{284}$ As Zhou persuasively argued, the view that commissioned mediation could sidestep the judicial confirmation procedure contradicts at least three normative interpretations: Article 3(2) of the 2004 Civil Mediation Rules, Article 21 of the 2009 SPC Opinion and Article 13 of the 2011 Judicial Confirmation Rules. ${ }^{285}$

\subsection{Chapter Conclusion}

With the leadership shuffle in March 2013, mediation settlements are no longer the 'holy grail' of civil justice in China. While unreasonable mediation targets were relics of the past, individual judges today still emphasize mediation as a caseload management tool. In the context of out-of-court mediation, the overarching policy of 'Grand Mediation' (da tiaojie) is still very much intact, as illustrated in this chapter. The deployment of court resources to keep disputes out of the judicial system (chiefly by settling disputes using court-annexed and other out-of-court mediation programmes), has evolved into a type of judicial convention in China. The judiciary's emphasis on settlement is not simply a matter of costs saving or caseload management, it has everything to do with the idea that the stability of the Chinese

\footnotetext{
${ }^{281}$ Article 3 of the 2004 Civil Mediation Rules.

${ }^{282}$ NPCSC Publication 2012, p. 149.

${ }^{283}$ Interview Ref: $2012 / 5$.

${ }^{284}$ Zhou J.H. 2013, p. 123.

${ }^{285}$ Zhou J.H. 2013, p. 123.
} 
social fabric is better maintained when disputes are settled earlier and out-of-court. It is part of a colossal social engineering exercise to weed out sensitive or socially damaging disputes, allowing no or limited recourse for such disputes to reach the courtroom or manifest themselves as 'public spectacles'. 


\section{Chapter 4:}

Court Mediation in the 'Wang Courts' and the impact of Wang Shengjun's policies on future developments 


\section{COURT MEDIATION IN THE 'WANG COURTS' AND THE IMPACT OF WANG SHENGJUN'S POLICIES ON FUTURE DEVELOPMENTS}

\subsection{Introduction - the relevance of a study on the Wang Courts}

It is fair to say that civil justice in China is in a state of flux. On the one hand, the leadership of China's court system emphasized the need to achieve independence of the adjudicative process and establish a culture of rendering correct judgments; on the other hand, the established culture of preferring mediation formulated under the leadership of Wang Shengjun (Wang), former President of the Supreme People's Court (SPC) (hereinafter, the Chinese court system under the presidency of Wang Shengjun (March 2008 - March 2013) is referred to as the Wang Courts), continues to affect the way civil justice is delivered in China.

Under Wang, the civil divisions of the Chinese judiciary turned into state-sponsored mediation centres with the clear mandate to resolve disputes in such a way that 'the case is closed and the dispute is [truly] resolved' (anjie shiliao). The concept of anjie shiliao has social engineering in mind, i.e. the disposal of a lawsuit is insufficient unless it is coupled with the eradication of discontent on the social level in relation to matters arising from the dispute. This concept is consistent with the Chinese government's objective of achieving a 'harmonious society', the ruling ideology at that time. Other functions of the civil court, for instance the important function of declaring legal norms and enforcement of the law, are at best secondary under the overarching policy that favoured mediation.

Settlements reached through court mediation are not appealable and are rarely reopened under the adjudication supervision procedure. ${ }^{286}$ Promoting settlement under the court mediation procedure also minimizes the risk of citizen petitions (xinfang). By actively pushing parties to mediate, the court can avoid the need to deal with thorny legal and factual issues that could potentially come back to haunt it if the judgment is later challenged. The irony of this is obvious: what is supposed to be the vanguard of justice and enforcer of the law became an institution that evades dealing with legal problems and finding truth. The judiciary's attempt to 'gloss things over' (huo xini) using mediation is at the heart of China's failure to establish procedural formalism in civil litigation.

The impetus to prioritize the use of mediation is not lacking for individual judges, thanks to the perverse assessment system that rewards settlements (or withdrawals) and penalizes reversals of judgments. ${ }^{287}$

The chapter seeks to explore the position of court mediation in Chinese civil justice in the Wang Courts and the impact of overusing court mediation on access to justice. The author argues that the deployment of court mediation as the predominant measure of court dispute resolution has one key objective in mind - the strengthening of political control over Chinese society (whether in the name of promoting a 'harmonious society' (hexie shehui) or 'maintaining stability' (weiwen). Such an

\footnotetext{
${ }^{286}$ For a detailed analysis of the civil appeal and re-adjudication procedures in China, see Chapter 7 of this book.

${ }^{287}$ For a detailed analysis of the evaluation system for judges, see Chapter 8 of this book.
} 
objective is contrary to the principle of party autonomy and procedural fairness, as well as hampering access to justice.

The obvious question to ask is this: why are we concerned about the Wang Courts at all when Wang Shengjun is no longer the president of the SPC and the new leadership of the judiciary is trying to move away from Wang's policies that preferred court mediation? The answer is equally obvious for anyone who understands the institutional matrix of China's courts. First, Wang's presidency ended only in March 2013. Judges throughout China are much more familiar with Wang's policies and practices (even if many of them resent such policies and practices) than with the new directives or reform measures of the current judicial administration. Second, Wang's policies had enormous impact on China's judicial culture and affected every facet of a judge's life. From the perspective of the court leadership, the policy objectives of minimizing social unrest arising from civil disputes and avoiding as much as possible letters and visits are paramount and could only practically be achievable by the active deployment of mediation. From the perspective of the individual judge, attaining high mediation rates is about career development. Even at the time this book is written, the appraisal system is partly based on an individual judge's ability to resolve disputes through mediation or facilitating the claimant to withdraw his case. Also, the realities of enormous case backlogs push judges to go back to 'old habits' of steering parties to settle whenever convenient to the judges. Third, Wang's policies were in fact closely linked with the political environment of today where the ruling elites needed an array of different avenues to deal with issues relating to social unrest and public order. Fourth, Wang's policies have practical advantages when it comes to dealing with purely civil cases of a less complex nature from a caseload management perspective. This is particularly true in rural areas where parties are rarely represented and generally less educated (and therefore less knowledgeable about the law). The nature of cases handled on a daily basis by basic level courts (whether in urban or rural areas) also fits well in Wang's litigation model, i.e. one that places a high premium on case processing efficiency rather than the quality of procedural justice. While it is expected that there will be subtle changes to Wang's mediation policy in the near future, one would only expect the change to happen rather slowly, particularly in basic level courts. The judicial culture shaped under Wang's reign is likely to persist for many years.

\subsection{Introducing mediation in the Wang Courts: the judicial responsibility system, case management and social harmony}

\subsubsection{Introduction}

Court mediation in China is a much more complex business than just another form of alternative dispute resolution (ADR). ${ }^{288}$ In fact it is questionable whether this judgeled mediation process is a genuine form of ADR at all. Charged with the responsibility to manage caseload and meet various institutional expectations, leaders of Chinese courts would give administrative directions to individual judges to mediate as many cases as possible, at times disregarding the wishes of the parties or the

\footnotetext{
${ }^{288}$ Minzner 2011b, p. 938.
} 
appropriateness of the case for mediation. In 2007, the SPC issued a policy directive that unequivocally spelt out the organic nexus between the promotion of court mediation and the ruling ideology of building a 'socialist harmonious society' (2007 SPC Opinion). ${ }^{289}$ It was stated in the 2007 SPC Opinion that '[court] mediation is an important part of China's litigation system, an important way for the people's courts to exercise their adjudicative power...[court mediation] embodies the Chinese nation's longing for natural harmony and social harmony'. ${ }^{290}$ Since 2009, China saw a series of local initiatives to make court mediation the primary dispute resolution channel. The courts in Henan Province were the first to take the lead by starting a movement that sought to achieve 'zero judgment' (ling panjue (零判决)), i.e. disposing all court cases through mediation or withdrawal. Following Henan's footsteps, courts in Guangxi, Hebei and Fujian Provinces embraced 'zero judgment' as their objectives. ${ }^{291}$ In 2010 , the SPC issued a policy opinion to implement the principle of 'prioritizing [the use of] mediation, fusing mediation and adjudication' 292 (tiaojie you xian, tiaopan jiehe) (2010 SPC Opinion). ${ }^{293}$ The 2010 SPC Opinion emphasized the imperative to promote court mediation as a means to maintain social harmony. It stated that 'mediation is quality adjudication, mediation is effective adjudication', and that a court's ability to settle as many cases as possible through mediation is a direct indication of its judicial capability. ${ }^{294}$ The notice sets out a comprehensive work-list, requiring courts throughout the country to prioritize the use of mediation in all types of cases (civil, commercial and administrative) and at every stage of litigation, including the use of conciliatory means to resolve disputes arising from enforcement of judgments. The notice specifically called upon basic level courts to mediate cases first before resorting to adjudication. It also specified the types of cases that courts need to focus on in their mediation work: for example, cases that may affect social harmony or stability (cases involving the 'masses') and cases where the relevant law in question is undeveloped or unclear. ${ }^{295}$ This from-cradle-tograve scheme encompasses a complex strategy that seeks to establish mediation as the norm in civil litigation: (1) pre-action stage: the strategy seeks to channel disputes away from the courts by encouraging (which, in practice, could sometimes mean forcing) parties to settle before a case is formally docketed; ${ }^{296}$ (2) docketing stage: the tactic is to settle as many cases as possible within the docketing division of the court; (3) pre-hearing stage: a specialized mediation unit was to be set up with the mandate to mediate as many cases as possible before they enter the hearing stage (usually conducted by judicial personnel other than the trial judge). Pre-hearing mediation is

\footnotetext{
${ }^{289}$ Several Opinions of the Supreme People's Court on Further Displaying the Positive Roles of Court Mediation in the Building of a Socialist Harmonious Society (Judicial Notice ( $f a f a)$ [2007], No. 9; effective since 6 March 2007).

${ }^{290}$ Article 2, 2007 SPC Opinion.

${ }^{291}$ Peng 2011, p. 52-58.

${ }^{292}$ The Chinese word pan, when used in a civil procedural context, could mean adjudication (shenpan) or judgment (panjue). The principle of tiaopan jiehe has the meaning of combining the use of mediation and adjudication in reaching dispute resolution. While 'judgment' is the literal translation, 'adjudication' appears to be a more proper translation, given its context, i.e. the process by which a judgment is made.

${ }^{293}$ Several Opinions of the Supreme People's Court on Furthering the Implementation of the working principle of 'Prioritizing Mediation, Fusing Mediation and Adjudication' (Judicial Notice ( $f a f a)$ [2010], no. 16; effective since 7 July 2010). The principle is sometimes translated as 'giving priority to mediation and combining mediation with judgment'.

${ }^{294}$ Article 2, 2010 SPC Opinion.

${ }^{295}$ Article 4, 2010 SPC Opinion.

${ }^{296}$ Pre-action mediation is given statutory backing in Article 122 of the Code.
} 
given statutory backing in the 2012 amendment of the Code; ${ }^{297}$ (4) hearing stage: judicial conciliation by the trial judge; (5) post-hearing stages: mediation at the appellate, re-adjudication ${ }^{298}$ and enforcement stages.

According to an authoritative annotation of the Code, court mediation serves three main purposes: (1) achieving 'social stability' and 'unity' by 'completely resolving' the disputes between litigants, reaching a mutual understanding and settlement through mediation (this purpose embraces the court's didactic function in 'educating' the litigants and directing them to an amicable settlement consistent with the principle of 'social harmony'); ${ }^{299}$ (2) reducing the case volume of the courts, minimizing overall litigation costs, and enhancing efficiency in case-processing (the benefit of mediation has two levels from an efficiency perspective: as court mediation is usually much quicker than adjudication, parties are able to have their disputes resolved in an expedited fashion; and given that mediated settlements are not subject to appeal, it saves overall judicial costs and enhances efficiency in case-processing by courts); and (3) enhancing the parties' awareness of the law (through court mediation, judges 'educate' the parties on the civil rights and obligations under the law such that the parties will voluntarily enforce whatever the outcome of the lawsuit is). ${ }^{300}$

\subsubsection{Procedural stages of court mediation}

Mediation can happen at any stage of civil proceedings: from commencement to enforcement. ${ }^{301}$ For want of a better system of categorization, court mediation can be divided into docketing mediation (立案调解), pre-hearing mediation (开庭前的调解) and 'judicial conciliation' (庭审中的调解). Docketing mediation happens when a case is docketed at the docketing division (立案庭) and before the case is transferred to the trial division (审判庭). A judge or judicial officer of the docketing division acts as the mediator. Pre-hearing mediation takes place at the trial division after the filing of the defence (i.e. similar to the stage of after the close of pleadings) and before the hearing. It is usually conducted by a judge or judicial officer in the trial division, but rarely by the trial judge himself. 'Judicial conciliation' takes place in the course of the hearing by the trial judge. There are usually four convenient stages during trial to commence judicial conciliation: (1) before the start of the substantive hearing before the bench; (2) after court investigation (法院调查) (and before party debate); (3) after party debate (and before final submissions (最后陈述); and (4) after the hearing (before the rendering of judgment). ${ }^{302}$

\footnotetext{
${ }^{297}$ Article 133(2) of the Code states, 'if the case can be mediated before commencement of the trial, mediation shall be adopted to promptly resolve the dispute'.

${ }^{298}$ For policy guidelines on mediation at the re-adjudication stage, see the Supreme People's Court's Notice on Strengthening the Mediation Work in Re-adjudication (Judicial Notice (fafa) [2005] no. 63; effective since 31 May 2005).

${ }^{299}$ It is noted that usually it is more likely that parties will voluntarily enforce a mediated settlement (as compared with a judgment).

${ }^{300}$ NPCSC Publication 2012, p. 144-145.

${ }^{301}$ Technically speaking, enforcement reconciliation (执行和解) is not part of court mediation. However, in practice, the judge overseeing an enforcement settlement process performs very similar functions to the mediating judge in court mediation: Interview Ref: 2012/3.

${ }^{302}$ NPCSC Publication 2012, p. 146.
} 
Among the various integral processes of court mediation, judicial conciliation proves to be the most problematic and controversial due to its lack of procedural safeguards against the apparent bias of the conciliator who also hears the case.

The civil court performs an important public function, namely the enforcement of rights and the declaration of norms. ${ }^{303}$ Judicial conciliation is designed to settle disputes only and not to enforce rights and declare norms. Overemphasizing judicial conciliation risks the civil court losing its public function. ${ }^{304}$

Proponents argue that judicial conciliation embodies the historical role of the magistrate (who was both a judge and a mediator). It is also argued that the trial judge is in the best position to conduct conciliation given his knowledge about the case. Critics question the voluntariness and genuineness of the conciliation process when the conciliator is so heavily involved in the adjudication of the case. It is almost impossible for a judge-conciliator to act impartially (or at least fairly) given his exposure to the legal and factual arguments of the parties. Critics of judicial conciliation therefore call for a total separation of the adjudication process and court mediation. $^{305}$

\subsubsection{The Policy Preference for Court Mediation in the Wang Courts}

The Chinese Government's promotion of a harmonious society (hexie shehui) since the turn of the century has immense influence over China's civil justice reform. During the tenure of Wang Shengjun as president of the SPC, court mediation was identified by the Chinese judiciary as the preferred method for civil dispute resolution. It was a clear shift away from the old policy of promoting and formalizing civil adjudication in the 1990s. Pressing social circumstances are responsible for the change of policy. Minzner observed, 'Chinese leaders face increasing social unrest generated by civil conflicts between citizens, and between citizens and the state'. ${ }^{306}$ In response to mounting social tension, the state has turned to court mediation as the 'artificial panacea for social stability'. ${ }^{307}$ Furthermore, the way in which the performance of the judge is assessed encourages the judge to resort to court mediation and avoid adjudication.

Court mediation can be an effective alternative dispute resolution method if the decisions to mediate and to settle are made out of the independent will of the parties. But when there is a strong policy preference for court mediation, it will no longer be a genuine 'alternative' dispute resolution method. ${ }^{308}$ Court mediation then loses its original ADR function and creates serious problems for fact-finding. The policy preference creates an artificial settlement culture in the courts. From the judge's perspective, the primary goal in a civil lawsuit is dispute resolution, rather than the

\footnotetext{
${ }^{303}$ Zuckerman observed, 'The civil court provides a law enforcement service. The role of the civil court is not merely to mediate disputes but to give effect to our rights and enforce them'. See Zuckerman 2009 , p. 53.

${ }^{304}$ Overemphasizing court mediation will result in the deterioration of the adjudicatory function of the court (especially in fact-finding) as the focus is shifted from the enforcement of rights to pure dispute resolution. See Wang 2009, p. 72.

${ }^{305}$ Li 2013, p. 5-18.

${ }^{306}$ Minzner 2011b, p. 938.

${ }^{307}$ Minzner 2011b, p. 963.

308 Ibidem.
} 
enforcement of rights. The need to fairly enforce the rights of the parties necessitates a thorough fact-finding process that assists the judge in ascertaining the truth. Overemphasizing court mediation would inevitably result in the lax of the fact-finding process as the focus shifts from the enforcement of rights to pure dispute resolution.

\subsubsection{Legislative scheme and judicial interpretations}

Article 93 of the Code stipulates that court mediation must be conducted on three important bases: (a) parties voluntarily agree to mediate and enter into any settlement reached in the mediation process (voluntary basis); ${ }^{309}$ (b) on the basis of clearly discerned facts (shishi qingchu (事实清楚)) (clear factual basis); and (c) on the basis of correct ascertainment of liability (in Chinese, the phrase 'distinguishing right from wrong' (fenqing shifei (分清是非)) is used) (liability basis). ${ }^{310}$

There is an obvious flaw in this legislative design. By requiring factual and legal correctness of the conciliatory outcome, court mediation is rendered a 'quasiadjudicative' process. While genuine settlement based purely on partisan interests is still possible if the terms of the settlement do not contradict the factual findings of the case and substantive law, this requirement trivializes the principle of voluntariness where the wishes of the parties do not necessarily coincide with the court's factual findings and understanding of the law.

The effect of the clear factual basis and liability basis of Article 93 of the Code reinforces the overarching goal of Chinese civil procedure to achieve substantive justice. Court mediation, while being a conciliatory process, must not compromise the principle that an outcome cannot be 'incorrect'. This concept is difficult to rationalize from a European procedural perspective given the clear distinction of adjudication and mediation in Europe.

The law sought to achieve this by requiring mediation to be conducted in a way where there is clear (and correct) finding of facts and where 'the right is distinguished from the wrong'. This statutory requirement (which was also present in the 2007 amendment version of the Code) came under fire during the consultative stage of the revision of the Code (which culminated in the 2012 version of the Code). Among other critics, Zhang made the following recommendation (Zhang's Recommended Revision Draft $)^{311}$ to the amendment of Article 93 of the Code:

\footnotetext{
${ }^{309}$ For further discussion on the principle of voluntariness in court mediation, refer to Article 9 of the Code. Also see NPCSC Publication 2012, p. 10-11, which discusses the theoretical dimension of the principle (although in practice the situation is very different from theory).

${ }^{310}$ While Article 93 of the Code is not explicit in spelling out the need of determining (and if necessary apportioning) liability, the provision must be read in connection with Article 9 of the Code, which requires that any court mediation must abide by the legality principle. Interpreting the two provisions, the phrase 'distinguishing right from wrong' in fact refers to the requirement that mediation must be conducted in a way that the parties understand their respective liability and obligations in the dispute. It is said that only by correctly discerning liability could the parties be able to voluntarily enforce the mediated settlement: see NPCSC 2012 Publication, p. 145.

${ }^{311}$ Zhang's Recommended Revision Draft (containing article by article revision recommendations) was published in 2011 with the aim to aid the amendment exercise of the Code: see Zhang W.P. 2011.
} 
'The conduct of mediation in the People's Courts must abide by the principle of voluntariness. The content of a mediation statement must not violate the law, mandatory administrative rules and must not harm national interests, collective interests and the interests of third parties. ${ }^{312}$

Zhang raised three reasons for recommending this amendment. First, the ultimate goal of mediation is to reach an amicable settlement of the dispute, which inevitably requires a degree of 'fudging' (模糊性). It is therefore unnecessary to base a settlement on clearly discerned facts. Zhang's recommended amendment effectively eliminates the need of the clear factual basis of court mediation. Second, the emphasis on 'voluntariness' must not be limited only to substantive voluntariness (i.e. that parties voluntarily agreed to the terms of the settlement) but should encompass the concept of procedural voluntariness. The distinction between procedural and substantive voluntariness has not been thoroughly understood by judges in practice. ${ }^{313}$ The spirit of procedural voluntariness is seen in the judge's respect of the parties' will in initiating mediation and their rights to make decisions during the process of mediation (e.g. when to make an offer). This is different from simply ensuring that the parties voluntarily agree to the terms of the settlement at the closure of mediation. Third, Zhang proposes the elimination of the liability basis of court mediation. A settlement agreement may not be consistent with the substantive law of the subject matter in dispute, but could be fully consistent with the 'law'. For instance, assuming the dispute concerns personal injuries sustained in a traffic accident and that a statutory minimum compensation is payable by the defendant should liability be established. The terms of the settlement agreement may not fully reflect the substantive law of the tort of negligence (e.g. the payment by the defendant to the claimant under the settlement is much lower than the statutory minimum compensation should liability be established). While the settlement is clearly inconsistent with the substantive law of the tort of negligence (in this case inconsistent with the hypothetical statutory minimum compensation), the settlement is not contrary to the 'law' in the sense that there is no 'illegality'. Requiring a settlement to be consistent with the substantive law robs the liberty by which the parties could reach an agreement that best reflects their respective interests. It should be enough for the court to recognize and enforce a settlement agreement if it is not illegal. The replacement of the 'liability basis' by this 'illegality test' places court mediation in the right position as an ADR method.

Zhang's recommendation was not accepted in the 2012 amendment exercise. In any event, the recommendation represents a timely academic challenge to the underlying principles of Chinese court mediation that tends to skew the intended purpose of mediation itself.

Mediation is supposed to be an interests-based conciliatory process that seeks to reach common ground between the parties. The requirements under Article 93 of the Code distorts this process and injects an element of uncertainty in that the judicial mediator is in a position to shape the course of mediation and the terms of settlement against

\footnotetext{
${ }^{312}$ Zhang W.P. 2011, p. 238 (Article 198 of Zhang's Recommended Revision Draft).

${ }^{313}$ The principle of voluntariness is already in the relevant provision in the 2007 amendment version of the Code. Yet Zhang's annotation reinforces the need to address the pressing problem of coerced mediation, which could take the form of coercing parties to commence mediation, coercing parties to concede certain points during mediation and coercing parties into a settlement.
} 
the will of parties in the name of upholding Article 93 of the Code. This is one of the reasons why the author argues that court mediation in China is in fact not "modern mediation, 314 at all but a summary judicial process that is capable of providing a 'way out' when formal procedure cannot deliver the result desired.

\subsubsection{The 'new' Article 122 of the Code}

Article 122 of the Code, a provision that is absent in the 2007 amendment version of the Code), reads:

'If the civil dispute brought before a people's court by a party would be suitable for mediation, mediation shall be attempted first, unless the parties refuse mediation.' (emphasis provided)

The word 'shall' in Article 122 imposes a mandatory obligation on the part of the court in all suitable cases to attempt mediation first (xianxing tiaojie (先行调解)) before invoking any formal procedure. While the provision ends with a proviso (i.e. that mediation must be based on the voluntariness of parties), Article 122 denotes a normative standard for courts that mediation remains to be an overriding priority in civil procedure. While it may not be its legislative intention, the practical effect of Article 122 is that it crystallizes and reinforces years of judicial culture that celebrates mediation settlement rates and trivializes adjudication. Courts may also stretch Article 122 to support its continued practice of preferring mediation despite current reform efforts to restore adjudication to its rightful position in civil procedure.

Another problem area is the proviso of Article 122: 'unless the parties refuse mediation'. It is said that so long as the parties do not expressly reject mediation, the court may proceed to mediate the case. In other words, if a party does not air his objection, the court will treat it as implied consent to mediate. ${ }^{315}$ The obvious problem with this interpretation is that courts may take advantage of a party's silence to push for mediation. As the ratio of litigants-in-person is particularly high in China relative to the West, parties may not be properly advised and may be misled to think that mediation is a mandatory requirement before a lawsuit can be docketed or before a case can proceed to trial.

The court has wide discretion to determine what constitutes a 'suitable' case for mediation under Article 122. Generally speaking, purely civil cases (such as matrimonial disputes or neighbor disputes) and less complex civil and commercial cases are typical cases that are suitable for mediation. ${ }^{316}$ Obviously, the court is not restricted to such a generic list of 'suitable' cases and may mediate cases that it deems 'suitable' having considered all the circumstances of the case.

\footnotetext{
${ }^{314}$ For a definition of modern mediation, see Jagtenberg \& de Roo 2011, p. 7:

'[it] makes sense to distinguish between mediation as a generic term and modern mediation. By modern mediation we mean mediation as a professional activity. Mediators need to be able to demonstrate that they have mastered a new body of expert knowledge; they must be certified (at least in some countries); and they are expected to know how to navigate through a negotiation on the basis of their expertise. This sets modern mediation apart from generic or traditional mediation, where anyone could assume a mediatory role as a side-activity, operating on the basis of intuition, authority or one's life experience.'

${ }^{315}$ NPCSC Publication 2012, p. 204.

${ }^{316}$ NCSC Publication 2012, p. 204.
} 
It is said that Article 122 codifies the mechanism set out in Part III of the Several Opinions of the Supreme People's Court on Establishing a Sound Conflict and Dispute Resolution Mechanism that Connects Litigation and Non-litigation (2009 SPC Opinion): $:^{317}$

(a) The pre-docketing stage: the courts, after receiving the written or oral complaint and before formally docketing, may of their own motion (or upon party application), refer the case to an administrative organ, a people's mediation organization, a commercial mediation organization, an industrial mediation organization or any mediation organization to conduct mediation. ${ }^{318}$ The referral is known as 'commissioning' (weituo (委托)) in Chinese procedural language. ${ }^{319}$ Any settlement reached can be given the effect of a civil judgment through the judicial confirmation procedure (i.e. rendering the settlement directly enforceable without the need to commence proceedings for its enforcement). ${ }^{320}$ If no settlement is reached within the agreed or designated time limit, the court must docket the case immediately. ${ }^{321}$

(b) Post-docketing stage: The so-called post-docketing stage in mediation runs from the moment a case is docketed to the pre-hearing stage (right before the actual hearing):

i. Commissioned mediation post-docketing: where both parties consent to mediation or where the court deems necessary, the court may commission an external mediation organization to conduct mediation on the case. If a settlement is reached, the parties may either withdraw the case, apply under the judicial confirmation procedure to give effect to the settlement or apply for a mediation statement. ${ }^{322}$

ii. Assisted mediation post-docketing: ${ }^{323}$ the court may invite a qualified organization or individual to conduct mediation jointly with the court. The mediation shall take place either within the courtroom itself or other venues within the court building. If the parties reach a settlement, they may either withdraw the case or apply for a mediation statement. $^{324}$

As Articles 9 and 93 only govern conciliation during the hearing stage (i.e. judicial conciliation), the addition of Article 122 is useful in clarifying the position of the court in respect of mediation at the pre-docketing stage and at the pre-trial stage (between docketing and hearing). ${ }^{325}$ However, the way Article 122 creates a norm

\footnotetext{
${ }^{317}$ Judicial Notice [2009], No. 45; effective since 24 July 2009. For an analysis of the legislative intent for Article 122 of the Code, see NPCSC Publication 2012, p. 204.

${ }^{318}$ Article 14 of the 2009 SPC Opinion.

${ }^{319}$ See Chapter 3 of this book for an overview of 'commissioned mediation' in China.

${ }^{320}$ For detailed procedures on judicial confirmation, see Part IV of the 2009 SPC Opinion.

${ }^{321}$ In reality, this is not necessarily true. It is suggested that delaying a case from being docketed could compel prospective litigants to settle or pressure the claimant to drop the case altogether. With this method, which clearly contravenes Article 14 of the 2009 SPC Opinion, the court is able to channel disputes away from the judicature, thereby lowering caseloads: Interview Ref: 2012/3. Recently, the SPC promulgated the 2015 Registration Rules. It remains to be seen the extent to which courts would enforce the 2015 Registration Rules. An important pointer indicating courts are enforcing the rules would be to see less delays in formal docketing of cases.

${ }^{322}$ Article 15 of the 2009 SPC Opinion.

${ }^{323}$ Article 16 of the 2009 SPC Opinion.

${ }^{324}$ Article 16 of the 2009 SPC Opinion.

${ }^{325}$ NPCSC Publication 2012, p. 204.
} 
that reinforces the former policy under Wang that preferred mediation and provided the statutory basis for the court to abuse the use of mediation (e.g. forcing parties to settle by delaying docketing of a lawsuit) whenever the situation suits its institutional needs. An improved version of Article 122 should perhaps read like this:

'If the civil dispute brought before a people's court by a party would be suitable for mediation, the people's court shall first encourage the parties to mediate. Mediation shall only be conducted when both (or all) parties provide written consent to mediate.'

At the final stage of the writing of this book (in early 2015), the SPC passed the Interpretation of the Supreme People's Court on the Application of the Civil Procedure Law of the People's Republic of China (2015 Interpretation) ${ }^{326}$. It remains to be seen how courts would implement the 2015 Interpretation. To the extent possible, the chapter takes into account changes made to China's court mediation process under the 2015 Interpretation.

\subsubsection{Judicial policy documents and policy development trend}

The Provisions of the Supreme People's Court about Several Issues Concerning the Civil Mediation Work of the People's Court (2004 Civil Mediation Rules) ${ }^{327}$ provide some structure for judges in mediating civil cases. Article 2 of the 2004 Civil Mediation Rules provides that the court should mediate cases that could possibly be resolved through mediation (although the court should not mediate for certain cases, e.g. winding-up proceedings). The choice of word, 'should', suggests that the court has an obligation to mediate provided there is an opportunity that the case could be settled. In theory, it is obvious that Article 2 should be read in the context of the principle of voluntariness under the Code. However, in practice, given the institutional orientation of China's justice system, it is not uncommon for the court to push for mediation as a matter of administrative obligation in such a way that it infringes the party's right to choose.

Among other important judicial policy instruments, a key instrument that set the tone for reforms in favour of mediation is the 2010 SPC Opinion. The opinion reinforces the overarching theme of the judiciary's task of maintaining social harmony with the efficient deployment of mediation tools at its disposal (that court mediation is an 'efficient and effective' mode of civil dispute resolution) and the need for court mediation to coordinate with other modes of mediation (e.g. people's mediation and administrative mediation) within the 'Grand Mediation' scheme (da tiaojie). ${ }^{328}$ The 2010 SPC Opinion contains the following key policies: (1) giving priority to mediation in civil and commercial cases at all stages of proceedings (including but not limited to first instance, second instance, re-adjudication and enforcement); ${ }^{329}$ (2)

\footnotetext{
${ }^{326}$ Judicial Interpretation (fashi) [2015], No. 5 (Effective since 4 February 2015).

${ }^{327}$ Judicial Interpretation (fashi) [2004], No. 12 (Effective since 1 November 2004).

${ }^{328}$ Articles 1 and 2 of the 2010 SPC Opinion. Article 6 specifically deals with mediation in administrative actions, a topic beyond the scope of this book.

${ }^{329}$ Article 2 of the 2010 SPC Opinion. Technically speaking, there is no such thing as 'enforcement mediation'. The official term is 'enforcement reconciliation process' (执行案件和解). However, Article 8 specifically provides that settlement negotiations should be conducted by way of the court
} 
extending the scope of this policy to civil causes of action arising from criminal proceedings (刑事附带民事案件); ${ }^{330}$ (3) the aim of the policy being to 'close the case and [truly] resolving the dispute' (案解事了) (courts should monitor closely mediation settlement rates, 'letters and visits' rates (信訪率) and compulsory enforcement rates as they are parameters for measuring the success of the implementation of this policy); ${ }^{331}$ (4) judges at all levels of courts should resort to mediation first whenever possible, with special emphasis on the need of basic courts to promote mediation, ${ }^{332}$ (5) emphasize the need to strengthen pre-action mediation and developing mediation capabilities at the docketing division of every court (e.g. using 'docket windows' (lian chuangkou (立案窗口)) to direct parties to settle the dispute within the docketing division) ${ }^{333}$ (6) promotion of pre-hearing mediation (e.g. where possible, courts should establish special teams staffed with judicial assistants to help share the load of pre-hearing mediation) ${ }^{334}$ (7) incentivize the use of mediation by introducing mediation settlement/withdrawal rates (调撤率) and other mediation related indices (such as xinfang rates) as key parameters of the case quality evaluation exercise, which is in turn used to assess the work of courts and individual judges; ${ }^{335}$ (8) emphasized the need for courts to actively visit parties who have settled the case to supervise on enforcement (调解回访工作); ${ }^{336}$ extending the funding of court mediation (e.g. lobbying for mediation related expenditure to be incorporated into the court annual budget) $;{ }^{337}$ and establishing the court's leading position in the 'Grand Mediation' scheme in every locality (i.e. the court should supervise the scheme as well as acting as the conduit that connects various mediation organizations) and continue to entrench the procedural nexus between out-of-court dispute resolution processes and court procedures (诉讼与非诉讼程序相衔接). ${ }^{338}$

Despite confirmation from a number of $\operatorname{sources}^{339}$ that the policies enshrined in directives such as the 2007 SPC Opinion and 2010 SPC Opinion are no longer followed by the courts, question remains as to whether this alleged policy change is implemented in practice. On a grand scale, a leading litigation lawyer based in a leading commercial city in China said that the policy-makers are only saying that they

using mediation techniques. Hence, in practice, the procedure can be understood as court-directed mediation at the enforcement stage.

${ }^{330}$ Articles 2 and 5 of the 2010 SPC Opinion. Under Article 5, courts are entrusted with the responsibility to facilitate a settlement in the concurrent civil case such that the 'conflict' (and personal 'grudges') between the parties can be resolved. The incentive for the defendant in the civil case to settle is the possibility of a reduced sentence in the concurrent criminal proceedings (see below for further discussion). The use of this mechanism to incentivize settlement in the civil action is based on the so-called 'flexible prosecution policy' (宽严相济刑事政策).

${ }^{331}$ Article 3 of the 2010 SPC Opinion.

${ }^{332}$ Article 4 of the 2010 SPC Opinion. In particular, the interpretation referred to Article 14 of the Several Provisions of the Supreme People's Court on the Application of Summary Procedures in Adjudicating Civil Cases (2003) that parties are subject to mandatory mediation before the court hearing for certain types of actions tried under the summary procedures (e.g. labour disputes, personal injury cases arising from traffic accidents, matrimonial disputes).

${ }^{333}$ Article 9 of the 2010 SPC Opinion.

${ }^{334}$ Article 10 of the 2010 SPC Opinion.

${ }^{335}$ Article 22 of the 2010 SPC Opinion.

${ }^{336}$ Article 13 of the 2010 SPC Opinion.

${ }^{337}$ Article 24 of the 2010 SPC Opinion.

${ }^{338}$ Articles $25-29$ of the 2010 SPC Opinion.

${ }^{339}$ E.g. Interview Ref: $2013 / 3$ 
want to establish the rule of law, while in fact the real objective is to preserve stability (wei wen). He noted that there is no substantive difference between the fundamental policies of President Zhou Qiang (current SPC president) and former SPC president Wang Shenjun when it comes to the position of mediation in civil litigation, i.e. both believe that court mediation plays a vital role (and should be the preferred mode) in achieving the real objective of preserving stability. He observed that in practice, the policy preference for mediation has already been entrenched in the system. ${ }^{340}$

\subsubsection{Brief procedural notes on court mediation}

Court mediation may be conducted at various stages of a civil lawsuit (first instance proceedings, appeal or retrial). The procedural rules for court mediation are set out in the 2004 Civil Mediation Rules. Reference should also be made to the 2009 SPC Opinion. The court may invite other entities (or individuals) that have a special relationship with the parties or are connected with the case to assist in court mediation. ${ }^{341}$ The parties as well as the 'presiding staff over the mediation' (i.e. the mediator) may present a settlement proposal. ${ }^{342}$ When a settlement is reached through court mediation, the court shall draw up a written 'mediation statement'. A mediation statement shall clearly set out the claims of the action, the facts of the case, and the result of the mediation. The mediation statement shall then be signed by the judge and the court clerk, sealed by the court and served on both parties. Once the mediation statement is signed and exchanged by both parties, it becomes legally binding. ${ }^{343}$ If either party fails to perform the mediation statement, the other party can apply to the court to enforce the mediation statement. ${ }^{344}$

\subsubsection{Legal effect of a mediation statement}

It is clear that a mediation statement sanctioned by the court has the effect of a civil judgment. A party has the right to apply to the court for compulsory enforcement (强 制执行) if the other party fails to comply with the terms in the mediation statement. ${ }^{345}$ Just like a civil judgment or ruling, a mediation statement is also capable of being reopened under the adjudication supervision procedure.

\footnotetext{
${ }^{340}$ Interview Ref: 2013/6.

341 Art. 3 of the 2004 Civil Mediation Rules. Also see Art. 95 of the Code.

${ }^{342}$ Art. 8 of the 2004 Civil Mediation Rules. Indeed, this particular rule carries an element of conciliation given its directive and interventionist nature (i.e. the mediator may present a settlement proposal).

${ }^{343}$ Art. 97 of the Code.

344 Art. 13 of the 2004 Civil Mediation Rules

${ }^{345}$ There is no right of direct enforcement if the settlement is only a contractual agreement (and not a mediation statement).
} 


\subsection{The position of the individual judge within the Chinese judiciary}

\subsubsection{The position of the courts within the Chinese constitutional structure and the bureaucratic hierarchy of the Chinese Judiciary}

Without an accurate understanding of the realities of civil litigation in China and the power matrix within the judiciary, it is impossible to fully appreciate the role and function of court mediation. This section discusses the relatively weak position of the judiciary within the Chinese constitutional order, the bureaucratic nature of the court structure and the predominance of the court leadership in adjudicatory work, as well as the inferior position of individual judges within the judicial power matrix.

Article 128 of the PRC Constitution reads, 'The Supreme People's Court is responsible to the National People's Congress and its Standing Committee. Local people's courts at different levels are responsible to the organs of state power which created them'. The President of the SPC is selected by the National People's Congress. ${ }^{346}$ Presidents of all other courts at various levels are selected by the people's congresses at corresponding levels. ${ }^{347}$ The direct subordination of the judiciary to the legislature means that there can be no real judicial independence in China unless the constitutional structure is modified. But Chinese constitutional theory specifically rejects the concept of separation of power. ${ }^{348}$ While the legislature has de jure control over the judiciary, real control over the courts is exercised by the administrative organs. The local government still (in principle) controls the court budget (but see recent judicial reforms, summarized in the Afterward of this book). ${ }^{349}$ This fiscal link between the local administration and the courts entrenches local protectionism in civil adjudication. ${ }^{350}$

\footnotetext{
${ }^{346}$ Article 62(7) of the PRC Constitution. Also see Article 17 of the Organic Law (courts at various levels must report on their work to the people's congresses at corresponding levels).

347 Article 35 of the Organic Law.

${ }^{348}$ Throughout China's imperial history, the magistracy (which handled civil cases) had always been part of the bureaucracy rather than a separate and autonomous judicial organ: see Chan 2012a, p. 322323. This tradition has, in principle, survived until today. The contemporary Chinese court system is structured very much like any other government administrative body. Zhong and $\mathrm{Yu}$ provide a succinct overview of the hierarchical arrangement of Chinese courts:

'Like executive agencies, Chinese courts are internally organized according to a strict hierarchy of administrative ranking. Each Chinese court has one president who is at the top of the hierarchy. Next to the president are several vice-presidents, who are in charge of the respective divisions of the court. Chief judges and associate chief judges supervise individual divisions. Court presidents are elected by the People's Congress at the same level, but vice presidents, division chiefs, associate division chiefs and other senior judges are appointed by the corresponding People's Congress Standing Committee.'

See Zhong \& Yu 2004, p. 396-397.

${ }^{349}$ Zhong \& Yu 2004, p. 432. But consider Chen 2011, p. 209:

'Since 2004, the general direction of reform in this regard has been to set minimum standards for the funding of courts and to arrange for the central and provincial governments to contribute partially to the costs of operating local courts... The central government will also provide more financial support for courts in the poorer central-western regions of China.'

${ }^{350}$ Local protectionism remains an important concern for foreign enterprises litigating in China. This problem is particularly acute at the enforcement stage. The government may intervene in favour of the Chinese party (e.g. local businesses or significant state-owned enterprises) if local or national interests are at stake. See Zhang M. 2002, p. 91.
} 


\subsubsection{The lack of adjudicatory independence and the inferior position of the individual judge within the judicial power matrix}

The individual Chinese judge is institutionally weak. There are certain features of the Chinese court system that tend to weaken the adjudicatory independence of the individual judge. ${ }^{351}$ External interference with the adjudicatory process is the norm, rather than the exception. ${ }^{352}$ Wang has warned that the 'bureaucratization of the court' would severely hinder the development of adjudicatory independence in China. Under this bureaucratic culture, the collective decision of the court organization trumps the decision of the individual judge, despite the individual judge having superior knowledge and understanding of the case. ${ }^{353}$

The Chinese judiciary prized discipline over adjudicatory independence of the individual judge. Supervision by the court leadership and higher-level courts forms the fabric of the Chinese adjudicatory system. It is therefore almost impossible to have a truly independent appellate review system under this institutional reality. Minzner offered an excellent observation in the context of advisory requests:

'As Chinese judges themselves note, excessive resort to qingshi [advisory request] practices has many negative effects. It undermines appellate review, because the court or judge that reviews the case on appeal may have responded to the initial qingshi request regarding how to decide the case in the first place. It creates a relatively passive Chinese judiciary reliant on top-down direction. $^{354}$

The institutional weakness of the individual judge is further exacerbated by the fact that the Chinese Judiciary is not independent. While reforms in the past have, to a certain extent, transformed the court from a mere instrument of the ruling elite to a public service that seeks to resolve civil disputes effectively, political forces still shape the appointment of the court leadership, the adjudication of politically sensitive civil lawsuits and other key areas of judicial practice. ${ }^{355}$

Having to navigate their way through the red tape of the judicial bureaucracy, most judges see themselves as civil servants (not very different from a tax officer) rather

\footnotetext{
${ }^{351}$ A noteworthy example is the existence of an adjudicative committee in every court in China: see Article 11 of the Organic Law. Consider the views of Chen 2011, p. 186:

'Before judgment is delivered in certain important and difficult cases heard by a collegiate bench, the cases must first be discussed by the adjudicative committee, and in giving judgment the collegiate bench must implement the decision of the committee.'

Also see Peerenboom 2003, p. 81.

Another example is the system of advisory requests (qingshi). Consider the views of Minzner 2011a, p. 58-59:

'Court responsibility systems that discipline judges for simple legal error also create a perverse set of incentives for Chinese judges. To avoid appellate reversal, lower Chinese courts and judges rely on an ill-defined system of advisory requests (qingshi) to solicit the views of higher courts and judges on how to decide pending cases.'

${ }^{352}$ Chan 2012b, p. 256. Also see Minzner 2011a, p. 58-59.

${ }^{353}$ Wang Y.X. 2011, p. 1

${ }^{354}$ Minzner 2011 a, p. 59.

${ }^{355}$ Liebman 2007, p. 18-21.
} 
than vanguards of justice. ${ }^{356}$ For an average judge, accomplishing his or her assigned tasks without making any mistakes is already a great achievement. Such is the unfortunate reality of Chinese civil justice.

The individual Chinese judge is institutionally weak. External interference with the adjudicatory process is the norm, rather than the exception. ${ }^{357}$ Wang has warned that the 'bureaucratization of the court', a widespread phenomenon in China, has stripped every opportunity to develop adjudicatory independence in China. The collective decision of the court organization trumps the decision of the individual judge, despite the individual judge having superior knowledge and understanding of the case. ${ }^{358}$ The individual judge's deference to the court leadership (coupled with external interferences with adjudication) makes it almost impossible to construct a fair factfinding regime. Factors completely unrelated to the adjudication of the case could affect the fact-finding process. Unfortunately, recent reform efforts in relation to factfinding focused on minor technicalities without due consideration on how to promote fundamental principles in this area. ${ }^{359}$

\subsection{Critical examination of court mediation in the Wang Courts and beyond: procedural problems and solutions}

\subsubsection{Policy preference for mediation: skewing the landscape of civil justice}

An overly strong policy preference for court mediation distorts the original ADR function of mediation ${ }^{360}$ and creates severe problems for fact-finding. A fair judgment is premised on meticulous and accurate fact-finding. But when an artificial settlement culture is created through policy, fact-finding becomes less of a priority.

The Chinese government's emphasis on the need to construct a harmonious society (hexie shehui (和谐社会)) since the turn of the century has immense influence over China's civil justice reform. In response to the proliferation of 'citizens' petitions' (also known as 'letters and visits' (xinfang/ shangfang) ${ }^{361}$ resulting from social

\footnotetext{
${ }^{356}$ This description of the typical Chinese judge is consistently repeated in number of interviews with judges and litigation practitioners conducted by the author, e.g. Interview 2012/3.

${ }^{357}$ A noteworthy example is the existence of an adjudicative committee in every court in China. In certain important and complex cases, the judge must first refer such cases to the adjudicative committee for discussion. The judgment must implement the decision/opinion of the adjudicative committee. See Chen 2011, p. 186.

Another example is the system of advisory requests (qingshi). Consider the views of Minzner 2011a, p. 58-59: 'To avoid appellate reversal, lower Chinese courts and judges rely on an ill-defined system of advisory requests (qingshi) to solicit the views of higher courts and judges on how to decide pending cases.'

358 Wang Y.X. 2011, p. 1.

359 Ibidem.

360 Minzner 2011b, p. 963.

${ }^{361}$ Note Article 2 of the Regulations on Letters and Visits, Decree of the State Council of the People's Republic of China, No. 431 (effective as of 1 May 2005):

"The term "letters and visits" in these Regulations means that citizens, legal persons or other organizations give information, make comments or suggestions or lodge complaints to the people's governments at all levels and the relevant departments of the people's governments at or
} 
discontent, the state has turned to court mediation as the 'artificial panacea for social stability' ${ }^{362}$ In recent years, the old policy to promote and formalize civil adjudication (in the 1990s) ${ }^{363}$ gave way to the momentous rise of court mediation. ${ }^{364}$ In SPC 2010 Opinion, the SPC made it its official position that court mediation is the preferred method for resolving civil and commercial disputes. ${ }^{365}$ Article 2 of the SPC 2010 Notice calls for "Firmly establishing the idea of "mediation first"" and requires courts to 'take mediation as the first choice of handling cases'. Article 2 further notes, 'We shall conduct mediation wherever it works, and shall not miss any opportunity of mediation emerged in litigation and each stage before and after litigation so as to grasp all opportunities of settling a case through mediation as much as possible.'

Minzner explained that the promotion of court mediation had everything to do with curbing social instability in mind:

\begin{abstract}
'Consistent with increased concerns about social instability, central Chinese authorities have ratcheted up pressure on lower-level Party and government officials to prevent instances of citizens petitioning (shangfang) to higher levels of the bureaucracy ... This also extends to the courts. Judges are being held individually liable for decisions they issue that generate petitions by disgruntled litigants to higher officials. Increased mediation targets are simply one component of this broader shift. Party institutions are issuing comprehensive orders to courts and other institutions instructing them to both keep petitioners away from higher authorities at all costs, and to successfully resolve massive percentages of disputes through mediation. ${ }^{366}$
\end{abstract}

Unlike a civil judgment, a court-mediated settlement cannot be challenged by citizens petition. By giving priority to court mediation (and thereby implicitly discouraging adjudication), the state is hoping to lower the overall petitioning rate. The state believes that giving priority to court mediation in civil dispute resolution promotes social harmony. ${ }^{367}$ Scholars, however, have questioned the alleged link between social harmony and the state's policy towards court mediation. ${ }^{368}$ In many Chinese courts today, settling a dispute by court mediation has become an end in itself, rather than a genuine alternative means for resolving disputes. ${ }^{369}$ This phenomenon is worrying as it encroaches upon the litigants' right to be heard.

above the county level through correspondence, E-mails, faxes, phone calls, visits, and so on, which are dealt with by the relevant administrative departments according to law.'

${ }^{362}$ Minzner 2011b, p. 963.

${ }^{363}$ The 1990s saw a decline in the use of court mediation. One of the reasons for this phenomenon was the promotion of adjudication and procedural formalism by the leadership of the Chinese Judiciary at that time, most notably, Xiao Yang, the former president of the SPC.

${ }^{364}$ Legal elites in the 1990 s called for the separation of mediation and adjudication (tiao shen fen li).

${ }^{365}$ The Chinese Judiciary's emphasis on court mediation also has budgetary and case-management reasons. The SPC and the Ministry of Justice were concerned that the proliferation of civil appeals would overburden the courts and add insurmountable cost on China's judicial system. See Peerenboom \& He 2009, p. 26.

${ }^{366}$ Minzner 2011 b, p. 958.

${ }^{367}$ Consider Art. 2 of the 2010 SPC Opinion: 'Mediation is conducive to the elimination of social conflicts and the realization of the resolution of all disputes upon close of a case, conducive to the restoration of the relations among the parties concerned and the realization of harmony.'

${ }^{368}$ Zhang W.P. 2007, p. 24

${ }^{369}$ Minzner 2011b, p. 963. 


\subsubsection{A policy-driven court: parallels with adjudication supervision}

Like court mediation, the adjudication supervision procedure is also a vital measure to guard against social instability resulting from unjust court rulings. The Central People's Government's emphasis on the imperative to build a 'harmonious society' (hexie shehui) has set the tone for China's civil justice reform in the past decade or so. ${ }^{370}$ The pressing need to provide redress for aggrieved litigants far outweighs any reform objectives on the procedural level (such as the need to uphold the finality of judgments). Similar to the promotion of court mediation as the preferred form of civil dispute resolution, ${ }^{371}$ the reform in adjudication supervision has strong underlying policy reasons. Policy-makers have warned of the risks associated with the lack of effective channels for disputants to express their grievances, or in Chinese, the 'difficulty of seeking redress through petition' (shensu nan). ${ }^{372}$ Adjudication supervision provides a convenient avenue to alleviate discontent by correcting 'errors' in civil judgments that may have social ramifications. By stepping up the power of the courts and procuratorates to re-open judgments that could potentially stir up unrest, proponents of the reform argue that conflict within the community can be channeled from the streets to the courtroom where problems can be handled in a much more controlled manner. This is the real incentive for further strengthening the powers of adjudication supervision in the latest amendment of the Code (in 2012). On a more practical level, a court that chooses wisely in re-opening 'sensitive' judgments can avoid the proliferation of citizen petitions ${ }^{373}$ (also known as 'letters and visits' (xinfang and shangfang)). ${ }^{374}$ Consistent with the policy objective of promoting social harmony, leaders of the judiciary would not hesitate to exert pressure on courts to keep petition rates as low as possible. ${ }^{375}$

\footnotetext{
${ }^{370}$ Chan 2012b, p. 250.

${ }^{371}$ Ibidem.

${ }^{372}$ Among other similar views, a leading book series on adjudication supervision authored by policymakers at the SPC described the 'difficulty of seeking redress through petition' as a 'deep-seated problem' and took the view that the recent civil justice reform (leading to the revision of the Code in 2012) had positive effects in tackling this problem and protecting social harmony: see Jiang, Sun \& Wang 2012, p. 7. The 'difficulty of seeking redress through petition' is not a new issue. The SPC has in the past emphasized the imperative of the Chinese Judiciary to improve its adjudication supervision regime so as to deal with this problem: for instance, see the Working Report of the Supreme People's Court (2006) (Zuigao Renmin Fayuan Gongzuo Baogao), delivered on 11 March 2006 before the National People's Congress.

${ }^{373}$ Note that the right to petition (shensu quan) is enshrined in Article 41 of the PRC Constitution. Also note Article 2 of the Regulations on Letters and Visits, Decree of the State Council of the People's Republic of China (No. 431) (Guowu Yuan Xinfang Tiaoli) (effective since 1 May 2005):

"The term "letters and visits" in these Regulations means that citizens, legal persons or other organizations give information, make comments or suggestions or lodge complaints to the people's governments at all levels and the relevant departments of the people's governments at or above the county level through correspondence, E-mails, faxes, phone calls, visits, and so on, which are dealt with by the relevant administrative departments according to law.'

${ }^{374}$ Under the policy of preventing citizen petitions from reaching higher-level authorities, judges throughout China are under tremendous pressure to settle disputes through court mediation. Once a dispute is settled, it is quite unlikely that litigants would resort to petitions. See Minzner 2011b, p. 958. ${ }^{375}$ Ibidem.
}

Each court would usually set up more or less the same mechanism that connects the petitions received with the relevant civil judgments that can be re-opened. For cases of great social significance, the court may form a collegiate bench of five judges to retry the case (as opposed to the norm of three judges): see Yearbook 2009, p. 175. 


\subsubsection{Judicial conciliation? Or facilitative judging? The Chinese spectrum of JDR}

Despite the statutory guarantee for party autonomy, judicial conciliation in China remains highly judge-centered in practice. Under a litigation culture where judges depended on mediation results for career advancement, parties inevitably find themselves second-guessing (to different degrees) what the judge wants instead of holding their interests as the only relevant benchmark in the conciliation process. Drawing insight from the spectrum of Judicial Dispute Resolution (JDR), Chinese judicial conciliation is perhaps a form of 'facilitative judging', rather than simply a type of 'judicial conciliation'. ${ }^{376}$ Given the principles of 'clear factual basis' and 'liability basis', court mediation requires some kind of 'adjudicatory correctness' in the so-called settlement agreement. It is a form of 'judging', despite every effort on the part of the Chinese judiciary to play down this reality. The nature of a mediation statement as a civil judgment also suggests that court mediation is an adjudicatory act the reinforces the state's role and authority in civil justice.

\subsubsection{Judicial preference for mediation/conciliation - a career decision? Assessment of judges and court mediation settlement rate as a key index of performance}

Apart from the top-down policy reasons that gave mediation a predominant position in the Wang Courts, the rise of court mediation is also explainable by the way in which the performance of the individual judge is assessed. The performance of a judge is partly assessed on the basis of his or her ability to avoid mistakes (e.g. minimizing appellate reversals). Adjudication is therefore a 'risky business' for a judge from a career perspective given the possibility of appellate reversals. ${ }^{377}$ Court mediation becomes a very attractive option for judges. ${ }^{378}$ This is because parties cannot appeal against a mediation statement (a settlement sanctioned by the court). ${ }^{379}$ Furthermore, by resorting to court mediation, the judge is absolved from the responsibility to render a fact-finding determination. Issues of facts remain the main ground for appeal in $\mathrm{China}^{380}$ and therefore judges who are uncertain with their factual determinations are exposed to the imminent risk of having their judgments reversed on appeal. ${ }^{381}$

Court mediation also performs case management functions. Writing a judgment can be extremely time consuming. ${ }^{382}$ Given the heavy caseload of a judge, mediation

\footnotetext{
${ }^{376}$ Alexander 2009, p. 139.

${ }^{377}$ Peerenboom and Scanlon noted that judges 'are assessed, in part, on how many of their judgements are overturned on appeal'. See Peerenboom \& Scanlon 2005, p. 40.

${ }^{378}$ While party consent is stipulated to be the prerequisite to court mediation under statute (see Art. 93 of the Code), there is a noticeable discrepancy between the law and actual practice. Parties sometimes find themselves persuaded, induced or pressured into mediation by the judge. A foreign party may find itself engaging in court mediation even if it had no intention to mediate in the first place.

379 Note, however, that parties are allowed to challenge a mediation statement on narrow grounds of coercion or violation of the law.

${ }^{380}$ Zhang \& Walton 2010, p. 110.

${ }^{381}$ The fear of making an improper fact-finding determination is one of the reasons for judicial procrastination and undue delay in many transitional (or ex-socialist) jurisdictions. See Uzelac 2010, p. 392-393.

${ }^{382}$ Interview Ref: 2012/6.
} 
(which only requires the rendering of a simple mediation statement) is much preferred. In a basic-level court of a mid-sized coastal city in China, a judge (on average) handles 280 cases per year. This is reflective of the common saying in China that 'there are too many cases and too few people [judges]' (anduo renshao (案多人少)). Mediation does alleviate the caseload significantly. So in a way court mediation is being used as a case management tool. ${ }^{383}$

Court mediation also has a 'client-satisfaction' advantage over adjudication. The same basic-level judge observed that parties tend to be more satisfied with a mediated settlement as it is usually entered into on a voluntary basis. ${ }^{384}$ However, this view must by caveated by the many instances of coerced mediation in courts. Another basic court judge noted that very rarely would a mediation statement be subject to 'letters and visits' (xinfang/ shangfang) ${ }^{385}$ provided that both parties agree to the settlement.

Since 2011, the Chinese judiciary introduced an elaborate system for trial management. ${ }^{386}$ Each court has its own Trial Management Office (shenpan guanli bangong shi (审判管理办公室)). Judges are assessed, in part, by the number of cases they can settle (or the so-called 'the mediation rate' (tiaojie lu (调解率))). A judge that could demonstrate an effective use of mediation in handling cases is more likely to be promoted and/or receive monetary incentives. The linking of judicial merit with the prioritization of mediation has a number of serious repercussions. Firstly, judges treat mediation as a guarantee for career success, rather than looking at it as a genuine ADR method. This hampers the ADR function of court mediation. The net effect is that court mediation becomes the 'normative expedited procedure' that takes precedence over the adjudicative procedures. Secondly, the principle of penalizing reversal of judgments encouraged judges to push parties to settle, since a settlement cannot be appealed (and hence cannot be reversed). Thirdly, due process suffers when the judge forces parties to mediate and settle. Mediation should be a consensual process, whether one looks at international practice or Chinese statutory law. ${ }^{387}$ Party consent is paramount in initiating mediation and reaching settlement. The institutional drive to attain high mediation rates inevitably means that judges would sometimes have to bend the wishes of the parties. A litigation practitioner commented that a judge would leave the parties outside the courtroom and wait for them to negotiate with one another, deliberately dragging the lawsuit to exert indirect pressure on the parties to settle. ${ }^{388}$

\footnotetext{
${ }^{383}$ Interview Ref: $2012 / 7$.

${ }^{384}$ Interview Ref: $2012 / 7$.

${ }^{385}$ Note Article 2 of the Regulations on Letters and Visits, Decree of the State Council of the People's Republic of China, No. 431 (effective as of 1 May 2005):

"The term "letters and visits" in these Regulations means that citizens, legal persons or other organizations give information, make comments or suggestions or lodge complaints to the people's governments at all levels and the relevant departments of the people's governments at or above the county level through correspondence, E-mails, faxes, phone calls, visits, and so on, which are dealt with by the relevant administrative departments according to law.'

${ }^{386}$ See Chapter 8 of this book for a detailed analysis of the 'trial management' system.

${ }^{387}$ Article 93 of the Code.

${ }^{388}$ Interview Ref: 2012/3.
} 


\subsubsection{Judicial conciliation at the appellate stage}

A court may mediate a civil dispute at any stage of proceedings, including at the appellate stage and the re-adjudication stage. ${ }^{389}$

A special feature of the Chinese appellate system is the active encouragement of court mediation at the appellate stage. If a settlement is reached through court mediation, a mediation statement shall be made. ${ }^{390}$ The mediation statement must then be signed by the adjudicating judges and the court clerk, and affixed with the seal of the appellate court. When the mediation statement is served on both parties, the first instance judgment is deemed to have been set aside and the mediation statement becomes directly enforceable (just like any civil judgment). ${ }^{391}$

The role of the appellate court is to review the lower court's decision, not to mediate. The appellate court performs an important function of declaring what it sees to be the correct norms through the various possible outcomes of appellate review. This function promotes consistency in adjudication and uniformity in statutory interpretation. Recklessly promoting court mediation at the appellate stage as a matter of policy weakens this function and distorts the real purpose of an appeal. ${ }^{392}$

\subsubsection{Coerced conciliation: a brief qualitative empirical analysis}

The policy preference for judicial conciliation sometimes leads to the use of coercive practices by judges where parties are forced to have their case conciliated or become 'victims' of a compelled settlement.

It is against the well-established principle of voluntariness for judges to use coercion in conciliation (yatiao (压调)). ${ }^{393}$ Given the possibility of petition and revocation of the mediation statement, ${ }^{394}$ judges are generally careful not to violate of the principle of voluntariness in a blatant way. ${ }^{395}$ However, some judges are fairly comfortable

\footnotetext{
${ }^{389}$ The court may invite other entities (or individuals) that have a special relationship with the parties or are connected with the case to assist in court mediation (Article 3 of the SPC 2004 Provisions; Article 95 of the Code). The parties as well as the mediator may present a mediation proposal (Article 8 of the SPC 2004 Provisions). When a settlement is reached through court mediation, the court shall draw up a written 'mediation statement'. A mediation statement shall clearly set out the claim in the lawsuit, the facts of the case, and the result of the mediation. The mediation statement shall then be signed by the judge and the court clerk, sealed by the court and served on both parties. Once the mediation statement is signed and exchanged by both parties, it becomes legally binding (Article 97 of the Code). If either party fails to perform the mediation statement, the other party can apply to the court to enforce the agreement (Article 13 of the SPC 2004 Provisions).

${ }^{390}$ Article 172 of the Code.

${ }^{391}$ Ibidem. For an explanation of the deeming provision (i.e. the first instance judgment is deemed to have been set aside upon service of the mediation statement), see Zhang \& Li 2012, p. 324.

${ }^{392}$ For a summary of the policy reasons behind the promotion of court mediation in China, see Chan 2012 b, p. $250-252$.

${ }^{393}$ Article 93 of the Code.

${ }^{394}$ Article 201 of the Code.

${ }^{395}$ A basic-level court judge noted that blatant violation of the principle of voluntariness by the judge in court mediations is less likely to occur in the economically advanced regions. The overt use of coercion in court mediation is generally seen in less developed inland regions: Interview Ref: 2012/7.
} 
with the idea of hinting to parties what their preliminary judgments are as a tactic to secure settlements. A senior judge, based on his extensive experience, described a hypothetical case that illustrates this practice. A simple breach of contract case went to conciliation:

The responsible judge of the collegiate bench (Judge X) was the sole conciliator. ${ }^{396}$ The plaintiff offered to settle the case if the defendant were to pay him RMB500,000. When conciliating the case, Judge $\mathrm{X}$ already made up his mind that the defendant should lose if the conciliation failed (with damages amounting to RMB800,000). He met with the defendant at a back-to-back session and hinted that the judgment would be against the defendant. Judge $\mathrm{X}$ further hinted that the defendant was likely to pay more if the case were not settled. As a result, the defendant agreed to settle. ${ }^{397}$

The senior judge was of the view that Judge X's practice (which according to him is very common) does not amount to coerced conciliation. ${ }^{398}$ He noted that this method is very effective in that it allows parties to appreciate what the consequences are should conciliation fail. The art of this method, he said, is how to communicate the preliminary judgment in a subtle manner. ${ }^{399}$ But the senior judge did raise the problems associated with 'hinting' the direction of judgment (these are at least factors the judge needs to assess before hinting): (a) how much should the judge tell the parties; (b) in what way should the judge hint; (c) would the party feel oppressed; (d) as the case is usually tried by a collegial bench, the conciliator's view (usually the Responsible Judge (chengban faguan (承办法官))) regarding the final judgment may not necessarily reflect the ultimate view of the collegial bench (hence the hint may turn out to be wrong, and the party may feel being cheated). ${ }^{400}$

Another judge commented that this method helps the parties understand the legal positions they are in. As many litigants are unrepresented, the judge plays a didactic and supervisory function in conciliation - almost like putting on the hat of a legal advisor. $^{401}$

Violation of the principle of voluntariness also occurs when parties are pressured into participating in judicial conciliation. Even where a party has successfully resisted participating in conciliation, it is possible that a refusal to conciliate without good cause would be viewed unfavourably by the court. ${ }^{402}$ While whether or not to resort

\footnotetext{
${ }^{396}$ Under Article 94 of the Code, a single judge or the whole collegiate bench may conduct the mediation.

${ }^{397}$ Interview Ref: 2012/2.

${ }^{398}$ Based on the high court judge's personal experience, only about $3-5 \%$ of judicial conciliation cases were subject to 'coercive practices' of the court. He clarified that this approximate figure relates to those cases where the judge blatantly and 'maliciously' coerced a party into mediation or a settlement. He added that most of such cases involve executive intervention because local interests were at stake. Where the local government-backed party has a weak case, a judge may use mediation to force the private party to settle with the local government-backed party.

${ }^{399}$ Interview Ref: $2012 / 2$.

${ }^{400}$ Interview Ref: $2012 / 2$

${ }^{401}$ Interview Ref: $2012 / 7$.

${ }^{402}$ Interview Ref: $2012 / 2$.
}

A basic court judge observed that where the court believes that a claimant has a better case but the evidence available does not support a ruling in the claimant's favour, the court may push for mediation so that the claimant may recover some compensation. Obviously, the mediation will be steered towards this adjudicative agenda: Interview Ref: 2012/6. 
to judicial conciliation is stated to be completely voluntary under the Code, ${ }^{403}$ an intermediate court judge observed that a party risks offending the judge if he refuses to submit to judicial conciliation despite multiple attempts on the part of the court to recommend conciliation. ${ }^{404}$ This view was echoed by a high court judge. Speaking from his personal practice, the high court judge said that he is likely to impose procedural hurdles against a party who refuses to mediate despite being asked to do so by the court. However, the party's refusal to conciliate should not affect the substantive outcome of the case. ${ }^{405}$ A leading litigation lawyer observed that judges would 'lose face' if lawyers advise their clients to reject a conciliation recommendation by the judge, resulting in some form of 'retaliatory' response from the court. While the party rejecting the conciliation recommendation may not eventually lose the case, lawyers tend to advise clients to go with the court's recommendation to avoid unnecessary procedural difficulties. ${ }^{406}$

A settlement under the pressure of the court is not a genuine settlement. ${ }^{407}$ Unfortunately, with the policy incentive to settle civil disputes, it is very difficult to eradicate this kind of 'subtle' coercive conciliation practices by judges. Enforcement statistics show that a rising number of settlements fail to conclusively resolve disputes. This may be an indicator that at least some settlements are affected by this kind of coercive practices. ${ }^{408}$ The observation that Chinese judges frequently use subtle ways to exert pressure on parties to settle by conciliation is confirmed by academics from Mainland China ${ }^{409}$

\subsubsection{Circumstances under which the conciliating judge would communicate to the parties the outcome of the case should conciliation fails}

A basic-level court judge from a leading commercial city in northern China explained two common situations under which the judge would have to communicate to the parties the possible outcome of the case should conciliation fail (either by hinting what the judgment is likely to be or simply by informing the parties the outcome in an explicit manner).

\footnotetext{
${ }^{403}$ Article 93 of the Code.

${ }^{404}$ Interview Ref: $2012 / 8$.

${ }^{405}$ Interview Ref: $2012 / 2$.

${ }^{406}$ Interview Ref: 2012/3.

${ }^{407}$ As any mediation statement reached at second instance trumps the first instance judgment, coerced settlements at the appellate level threaten the normative effect of first instance decisions. Obviously, such practices also infringe the party's right of appeal.

${ }^{408}$ While court mediation settlement rate has risen during the period between 2002 and 2009, court enforcement rate of mediation statements during the same period also skyrocketed. This suggests that a considerable number of mediated settlements did not conclusively resolve disputes and parties had to resort to the court for enforcement. The situation is particularly serious in basic-level courts: see Pan \& Liu 2010, p. 75-76. This trend is confirmed by a civil judge at a basic-level court in a leading commercial city in Northern China: Interview Ref: 2012/9.

${ }^{409}$ Consider Cai 2014, p. 46: 'To avoid being criticised, judges usually do not use explicit mandatory language, but use implicit terminology having a mandatory meaning to exert pressure on the parties. The parties that understand the judge's language are forced to cooperate with him and to accept mediation. However, this usually gives rise to the parties later regretting having cooperated in mediation.'
} 
First situation: Where the law imposes an obligation on the court to provide clarification (richterliche Aufklärung), ${ }^{410}$ the conciliating judge must explain to the party in question the legal consequences of failure to produce certain evidence. Technically speaking, this can be seen as disclosure of the possible outcome to the parties (assuming conciliation should fail). For instance, under Article 76 of the Code, if a case concerns factual issues of a specialist nature, the party may apply to the court for a forensic analysis (司法鉴定). For instance, in a medical negligence case, given the specialist nature of the matter, the judge needs to explain to the claimant (as per the obligation of judicial clarification) that the claimant bears the risk of failing to establish the facts of his case (and hence the risk of losing the lawsuit) if a forensic analysis is not requested. The judge is obligated to do this even where the parties are in conciliation. This is effectively informing the claimant the possible outcome of the case. ${ }^{411}$

Second situation: Where the concilaiting judge is of the view that disclosure of the possible outcome of the case could help the parties make an informed decision while deciding on the terms of settlement (and where such disclosure could limit the negative effects of parties being taken by surprise with the outcome when conciliation fails), the judge should not hesitate to hint the outcome by sharing his thoughts with the parties on the merits of the case, the decision on possible quantum and his interpretation of the law. ${ }^{412}$

The problem with disclosure of outcome to parties in conciliation is that the disclosure itself would constitute a pivotal factor in the parties' consideration for settlement. It therefore obscures the voluntary nature of the process and derails what is supposed to be an interest-based negotiation between the parties. In the first situation, despite clear requirement under the law for judicial clarification, the conciliating judge could have refrained from discussing the issue of evidence during mediation, and only address any evidential difficulties when the parties cannot continue with the conciliation. Using the same example above, the clarification of the consequences of not obtaining a forensic analysis (which is almost the same as telling the claimant that his case would definitely fail without the forensic analysis) seems to suggest that the claimant is at fault for not producing vital evidence. But the production of evidence should not be a consideration at all in conciliation. Interpreting the statutory provision that there is the need to provide clarification during conciliation would turn what is supposed to be an interest-based facilitative process into a fact-finding mission with the conciliating judge as the arbiter, not the conciliator.

The reasoning behind the second situation where the judge would feel obligated to disclose the possible outcome of the case is even more puzzling. A party is taken by surprise by procedural ambushes from the other side. This can be fully prevented by drafting clear and comprehensive procedural rules on due notice (and enforcing those rules). The court has no duty to ensure that a party is given due notice with regards to

\footnotetext{
${ }^{410}$ Article 3 of the Civil Evidence Rules provides, 'The People's court shall inform the parties concerned of the requirements for producing evidences and of the corresponding legal liabilities so that the parties concerned may produce evidence actively, completely, correctly and honestly within the reasonable time period'.

${ }^{411}$ Interview Ref: $2014 / 2$.

${ }^{412}$ Interview Ref: 2014/2.
} 
the outcome of the case. On the other hand, disclosure of the outcome does not necessarily cause the parties to make an informed decision on settlement, as conciliation should be about striking an agreement based on common interests. If a party needs to know what his legal liabilities are (so to effectively assess their Best Alternative to a Negotiated Agreement (BATNA)), the best person to turn to is his lawyer and not the judge. It appears that the so-called need to manage expectation of the litigation outcome or to help parties make an informed settlement decision could be a handy excuse for the court to interfere with the conciliation process and result in such a way that best suits the agenda of the court (whether the agenda is policydriven, efficiency-drive or of other natures). This tendency to disclose the potential outcome with the view of 'advising' (or 'mentoring') the parties is also rooted in the judicial culture that in-court mediation is not just about parties reaching an amicable resolution but also about the delivery of substantive justice in the sense that the settlement cannot be too far off the standards and remedies under the substantive law (see discussion above on the problems associated with Article 93 of the Code).

\subsubsection{The virtues of synthesizing adjudication and judicial conciliation: a Chinese perspective}

Court mediation is said to be at the 'centre' of 'Grand Mediation' (datiao jie). ${ }^{413}$ An intermediate court judge commented on the virtues of combing judicial conciliation and adjudication. First, parties tend to respect a judge by virtue of the judge's authority to decide the outcome of the case. Unlike a facilitative mediator, the Chinese judge-conciliator is empowered to sanction the parties and (usually by the time of the conciliation) has a rough idea of where the liability lies. It is therefore much easier for the judge-conciliator to 'push for a settlement'. Parties are 'scared' of the judge and 'have to listen'. Second, a fused role also ensures that the conciliator knows everything about the case. ${ }^{414}$

An experienced intermediate court judge said that judicial conciliation could occur on a rolling basis (i.e. attempt conciliation at different stages of the trial), which would be more in line with the development of the dispute. From his experience, it is only until halfway through the trial would the parties really appreciate the merits of their respective cases as the facts gradually reveal themselves. ${ }^{415}$

Some judges interviewed expressed skepticism about the idea of separating the mediatory and adjudicatory processes at trial (i.e. a total abolition of judicial conciliation and replace it with a pre-hearing mediation by a mediator who does not hear the case). Among other reasons, such separation would make the mediatory process very inefficient as (a) the mediator (who does not also hear the case) is unlikely to know much about the case; (b) the judiciary has insufficient resources to sustain a standalone team of 'pure' mediators; (c) the mediator (who is not the adjudicator) does not posses the kind of authority of a trial judge, thereby lowering the efficiency of the process (i.e. parties are unlikely to submit to a 'pure' mediator who does not hold their futures in his hands); and (d) the case has not developed at the pre-hearing stage of the proceeding to such an extent that the parties are in an

\footnotetext{
413 Interview Ref: 2012/1.

${ }^{414}$ Interview Ref: 2012/1.

415 Interview Ref: 2012/1.
} 
appropriate position to settle (for instance, the facts have not been sufficiently revealed for the parties to appreciate their respective positions). ${ }^{416}$

\subsubsection{Didactic and supervisory function of judicial conciliation}

As compared with common law jurisdictions, the proportion of litigants-in-person is much greater in China. As such, Chinese courts frequently find themselves dealing with parties who are ignorant of the civil process and the substantive law. A basic court judge of a leading Chinese city accounted that judges are forced to play the role of a 'quasi legal advisor' educating the litigants-in-person on legal as well as factual matters, although the court has no strict statutory basis to do so. A court mediation setting provides the best theatre to perform this special role. ${ }^{417}$ Another basic-level court judge is of the view that this practice helps the parties understand the legal positions they are in. As many litigants are unrepresented, the judge plays a didactic function in court mediation. ${ }^{418}$ In fact, the didactic function of judges finds its roots in China's legal history, where the magistrates took onto themselves the role to educate the parties on matters of law as well as morality. ${ }^{419}$

An authoritative annotation of the Code stated that the court mediation process is a vital process for educating the public on the law and reinforcing the concept of the rule by law. It is said that the judicial mediator educates the parties on the importance of respecting the rights of one another, their respective legal liability and how to distinguish right from wrong (fenqing shifei). ${ }^{420}$

\subsubsection{Civil justice without 'without prejudice privilege'}

Although expressly prohibited in Article 67 of the Civil Evidence Rules, in practice information disclosed in the judicial conciliation process is frequently used at trial and sometimes influences the final judgment (assuming mediation failed and adjudication resumed). It remains to be seen how judges would act given the new obligation to preserve confidentiality under Article 146 of the 2015 Interpretation.

According to a basic court judge, any disclosure during mediation is likely to have a bearing on the way a judge exercises his discretion in the fact-finding process. Furthermore, the proposals with regards to monetary payment during mediation would frequently affect the assessment of quantum in the ensuing adjudication. ${ }^{421}$

\footnotetext{
416 Interview Ref: 2012/1.

${ }^{417}$ Interview Ref: $2013 / 2$.

${ }^{418}$ Interview Ref: $2012 / 8$.

${ }^{419}$ See Chapter 2 of this book on the didactic role of magistrates in civil litigation in imperial China.

${ }^{420}$ NPCSC Publication 2012, p. 145.

${ }^{421}$ Interview Ref: $2014 / 2$.
} 


\subsubsection{Court mediation as a caseload management tool}

Chinese judges are under tremendous pressure to handle an enormous caseload within statutory deadlines. In an ordinary procedure, the judge must conclude the case within 6 months; in a summary procedure, within 3 months. Strict observance of the deadline is paramount as a matter of discipline. The assessment of judges, in part, is based on whether judges are able to handle cases as expeditiously as possible. Failure to meet these statutory deadlines could be devastating to a judge's career. Settlement generally saves time and allows the judge to manage his caseload efficiently. Backlogs are best handled by judicial conciliation. To avoid the stigma of delay, judges are incentivized to push for conciliation in view of having the case settled as soon as possible. It is reasonable to expect that, under extreme time pressure, a judges would not hesitate to thrust his own will upon parties to come to settlement which otherwise may never materialize. Procedural expediency then overrides any concerns for the interests of the parties or party autonomy, elements which are important in a genuine ADR process.

A basic court judge explained that by settling a case through conciliation, the dispute is unlikely to be re-opened again, thereby achieve the goal of Anjie shiliao ('the case is closed and the dispute is [truly] resolved'). This result, from an overall perspective, is arguably more 'economical' than rendering a judgment. Compared to a judgment, the judge argues that a settlement is usually enforced voluntarily (a view the author disputes), has 'better social impact' (jiaohao shehui xiaoguo (较好社会效果)) and substantially reduces the ensuing administrative work of court clerks. ${ }^{422}$

\subsubsection{Court-sanctioned settlement at the enforcement stage: abusing the system in the name of 'social harmony'}

A peculiar feature in Chinese civil procedure is the possibility for parties to enter into a 'settlement' (which can later be sanctioned by the court) in relation to the judgment debt at the enforcement stage. This process is also known as enforcement reconciliation. A simple example would illustrate the absurdity of this procedure:

Party X (the claimant) won the case and was awarded RMB 200,000 in damages. Party Y (the defendant) was unable to pay. Party X applied to the court for compulsory enforcement of the judgment. Party Y indicated it lacked the means to pay for the amount in full but was willing paying half of the damages (i.e. RMB 100,000). Knowing that he might get nothing if he did not take the offer, Party X accepted Party Y's offer and entered into a 'settlement'. The court sanctioned the settlement agreement and Party $\mathrm{X}$ withdrew his enforcement application.

The glaring flaw of this procedure is that it could easily be abused by the losing party, resulting in grave injustice. While the rules stated that all enforcement settlements

\footnotetext{
${ }^{422}$ Interview 2014/2. The judge admits that for certain cases, mediation could take more time (and judicial effort) than adjudication.
} 
must be based on the voluntary decisions of the parties, ${ }^{423}$ in reality the court has ample avenues to manipulate the process and steer the parties onto the path of settlement. ${ }^{424}$ In the name of 'social harmony' (or 'social stability' in today's jargon), a successful party could be deprived of his rightful fruits of litigation in a Chinese court.

\subsubsection{How judicial conciliation negatively affects fact-finding}

The policy of giving priority to court mediation detrimentally affects the fairness of civil fact-finding. The situation is particularly serious in the case of judicial conciliation, as the judge wears the hats of both conciliator and adjudicator. There are at least three problem areas that deserve attention.

The policy preference for judicial conciliation creates an artificial settlement culture in the courts. From the judge's perspective, the primary goal in a civil lawsuit is dispute resolution, rather than the enforcement of rights. The need to fairly enforce the rights of the parties necessitates a thorough fact-finding process that assists the judge in ascertaining the truth (whether legal or objective truth). Overemphasising judicial conciliation will inevitably result in the lax of the fact-finding process as the focus shifts from the enforcement of rights to pure dispute resolution. The lax in factfinding deteriorates the public function of the court, which involves the delivery of justice to parties, both in the form of rights enforcement, as well as in the form of ascertaining the truth. The search for the truth through fact-finding is a core and indispensable component of public justice. Overemphasizing judicial conciliation (at the expense of adjudication) compromises this core value of public justice.

Apart from being an integral part of adjudication, the fact-finding process also assists parties in assessing their positions in settlement negotiations (ADR function of factfinding). For instance, when parties reach a stage at which they have obtained enough facts that reflect their relative positions, they would be more likely to engage in settlement negotiations. This is only possible if the principle of voluntariness is strictly observed (i.e. parties genuinely consent to conciliate and may terminate the conciliation process at anytime). As judicial conciliation is given priority as a matter of policy, the principle of voluntariness is endangered. As a result, the parties may be induced or pressured into judicial conciliation without sufficient facts on which to base their settlement process. Even where the parties agree to conciliate, it is possible that the decision is made on the basis of what they believe the judge prefers, rather than on the basis of their genuine interests. This obscures the ADR function of factfinding. A policy-driven settlement culture endangers the deliberative process in which parties are free to assess the facts and evidence in considering their ADR options.

When judicial conciliation fails and adjudication resumes, there is always the risk of the judge inappropriately utilizing the facts ascertained in the conciliation process for adjudicative purposes. In the ensuing adjudication, the judge may be swayed or

\footnotetext{
${ }^{423}$ Articles 86 and 87 of the Regulations of the Supreme People's Court on Several Issues Relating to the Enforcement Work of the People's Courts (For Trial Implementation), Judicial Interpretation (fashi), [1998] No. 15, effective since 8 July 1998.

${ }^{424}$ Interview Ref: 2012/3.
} 
affected by the facts revealed in the conciliation process. This gives rise to an apparent bias on the part of the judge and in turn affects the quality of justice. ${ }^{425}$

Proper fact-finding is the basis for the fair disposal of a lawsuit. The court, through fact-finding determinations, performs an important norm-declaring function. ${ }^{426}$ The institutional bias in favour of court mediation creates a policy-driven settlement culture that reduces the court's norm-declaring function.

\subsubsection{Judicial conciliation in civil cases connected with criminal proceedings (minshi fudai xingshi anjian): when justice completely fails}

A deeply disturbing aspect of judicial conciliation is when a conciliated settlement in a civil action connected with a criminal case could influence the outcome of the criminal case. An experienced practitioner in a leading commercial city confirmed that criminal courts frequently take settlement in the connected civil case into account when deciding on the outcome (and/or sentencing) of the criminal case in question. ${ }^{427}$

One obvious danger of this practice is that the defendant in the criminal case could partially exonerate himself by paying for a civil settlement. This practice creates unimaginable injustice in the criminal process and distorts the function of the civil process. With considerable wealth, a murderer could escape the punishment he deserves if he has deeper pockets than the other side. Even where the parties enjoy economic parity, a judge handling a controversial criminal case may be tempted to adopt this practice to keep people quiet. This again confirms the dire consequences when the bench is assessed not on substantive merit, but rather on the basis of misguided notions of efficiency and 'social effects' of the outcome.

A basic-level court judge commented that it is very common to have civil claims attached to criminal proceedings (minshi fudai xingshi anjian) (民事附带刑事案 件). ${ }^{428}$ A conciliated settlement in the attached civil case is evidence of 'remorse' ( kui jiu) on the part of the defendant in the criminal case and could reduce sentence in the criminal case (see criminal procedure law, which also provides low risk of repeating the offence as another sentencing reduction factor - i.e. civil settlement may also mean that the likelihood of the offence committed again is low). ${ }^{429}$ The usual practice is that the defendant's lawyer would secure a 'conciliatory memorandum'

\footnotetext{
${ }^{425}$ Consider Fu \& Cao 2012, p. 518: '[it] is unacceptable for judges to go back into the courtroom after mediation (being privy to the confidential information disclosed during the mediation) and act as if they were "impartial" judges, as clearly there is unavoidable bias involved in such a practice.'

${ }^{426}$ In theory, court mediation must be conducted on the basis of clear and accurate facts (see Article 85 of the Code). However, there are simply no procedural rules to ensure the facts established in court mediation are clear and accurate. Settlement, unlike adjudication, is based on the interests of the parties and not entirely on facts. Overemphasizing court mediation as a matter of policy diminishes the functional role of fact-finding in civil justice. While China does not embrace the principle of stare decisis, the SPC publishes 'guiding cases' to provide direction to lower courts. While not being binding, the guiding cases are expected to be referred to by lower courts. The guiding cases are (supposedly) based on sound fact-finding. As such fact-finding determinations in guiding cases possess enormous normative force. See <http://news.stanford.edu/news/2012/february/china-guiding-cases020612.html>, last consulted in July 2012.

${ }^{427}$ Interview Ref: 2012/10.

${ }^{428}$ Interview Ref: 2013/2.

${ }^{429}$ Interview Ref: 2013/2.
} 
(xieyi shu) from the victim or his relatives indicating the civil settlement and that the victim or his family accept this gesture as an indication of 'remorse'. This practice has been criticized as 'using money to buy sentence reduction' (yiqian maixing), or in murder cases, 'using money to buy life' (yiqian meiming).

\subsubsection{Judicial populism and social harmony: A grand retreat from constructing a formalist legality?}

A leading Chinese procedural scholar, Zhang Weiping, commented that there is no necessary nexus between social harmony and the policy of promoting court mediation as the preferred form of civil dispute resolution. ${ }^{430}$ In fact, such a policy may prove to be counterproductive. Social cohesion is at its strongest when justice is done. When parties are subject to a coerced settlement, grave injustice is done. Party autonomy is infringed and the principle of party disposition is at stake. Policy preference for court mediation could have the effect of distorting the rightful entitlements of parties and their right to be heard in a trial. If one party has a clear case claiming RMB1000 and should have easily won if given the opportunity to be heard, it would be unjust to thrust mediation on the party to settle for RMB500. Such grave injustice cannot be excused on the basis of utilitarian justifications ('social harmony' being the ultimate utilitarian argument).

The phenomenon of trading the very essence of access to justice for an ill-defined notion of social harmony has its roots in the socialist legal culture that treats law as an instrument for social engineering. Under Marxist-Leninist legal doctrine, the law serves the interests of the party-state. This entrenched legal instrumentalism, coupled with Maoist conception of a populist legality made court mediation all the more attractive to policy makers in the Chinese judiciary.

\subsection{Settlement rate in appellate review and re-adjudication}

A troubling trend during Wang Shengjun's tenure was the rise of mediation rate in second-instance and re-adjudication cases. An appeal or a re-adjudication usually concerns more complex issues, which should be best resolved through adjudication. The high mediation rates at appellate and re-adjudication stages are also inexplicable from the perspective of parties' free will as no party is prepared to lodge an appeal or apply for re-adjudication if it does not believe it has a genuine case (and the will to prevail by so doing), at least most of the time.

\subsection{Chapter conclusion: Reforming court mediation in China by separating conciliation from adjudication}

The fused role of the judge-conciliator in judicial conciliation creates far too many procedural pitfalls that it threatens the very legitimacy of the civil process. As such, separation of the roles of trial judge and judicial conciliator is a key imperative in the modernization of China's courts. Among other scholars, Li Hao (a prominent

${ }^{430}$ Zhang W.P. 2007, p. 18-27. 
procedural expert in Mainland China) has been very persistent in arguing for the separation of the adjudicatory and conciliatory processes in civil litigation. ${ }^{431}$ In his recent work, $\mathrm{Li}$ argues that the nature and procedure of conciliation and adjudication are so different that separating the two processes is the best way forward. ${ }^{432}$ As argued earlier, the fused role of the adjudicator and the conciliator creates apparent bias on the part of the judge in both the conciliation and adjudication processes. A judge who conducts conciliation cannot completely prevent the process being affected by his position as the adjudicator of the case. Impartiality of the conciliator can only be fully secured if the conciliator is insulated from the litigation procedure. In common law jurisdictions, for instance, the mediator must be someone who has no conflict of interests with the parties. While the adjudicator has no conflict of 'interests' per se, there is a conflict of roles that is likely to give rise to partiality and unfairness. Li argues that separation of the processes can put a stop to the infringement of the principle of voluntariness in judicial conciliation. He argues that the adjudicatory power of the conciliating judge has the potential of distorting the conciliatory process in that parties may not be genuine in giving consent. ${ }^{43}$ Indeed, as revealed in the empirical findings in Chapter 5, undue influences by the judge in judicial conciliation are not uncommon. Therefore, separating the two processes can ensure that no adjudicator could use its judicial powers to coerce any party to engage in (to settle following) a conciliation process. As rightly pointed out by $\mathrm{Li}$, separation not only protects voluntariness in conciliation (and hence enhances the sanctity of the process), but also helps promote access to justice as parties are given a genuine choice whether to litigate. ${ }^{434}$ As determined as the SPC leaders are to rejuvenate the normdeclaring and rights enforcement functions of courts, the incompatibility of Chinesestyle judicial conciliation with modern values of civil justice calls for a completely revision of China's court mediation regime.

There are positive developments in judicial conciliation with the promulgation of the 2015 Interpretation. The 2015 Interpretation strengthened procedural safeguards and reinforced the importance of the principle of voluntariness in judicial conciliation. ${ }^{435}$

Regarding the reinforcement of the principle of voluntariness, the court is now required to rule on the case in a timely fashion if one party or both parties insists on refusing conciliation. ${ }^{436}$ For matrimonial disputes, the court is explicitly prohibited from dragging its feet with conciliation. If no settlement can be reached, the court must immediately rule on the matter. ${ }^{437}$

The measures set out in the 2015 Interpretation demonstrate the heightening of procedural safeguards. The mediation statement must now only be personally served on the party (no other service would suffice). ${ }^{438}$ The 2015 Interpretation also

\footnotetext{
${ }^{431}$ Some scholars (e.g. Hao Li, see Li 2013) call for an appropriate level of separation between trial and judicial conciliation (tiaoshen shidu fenli)(调审适度分离)], which on the one hand retains the trial judge's power to conciliate, but on the other hand structures the process in such a way that possible settlements are reached at the pre-trial stage.

${ }^{432}$ Li 2013, p. 5-9.

${ }^{433}$ Li 2013, p. 9-10.

${ }^{434}$ Ibidem.

${ }^{435}$ Interview Ref: 2015/1.

${ }^{436}$ Article 145 of the 2015 Interpretation.

${ }^{437}$ Ibidem.

${ }^{438}$ Article 133 of the 2015 Interpretation.
} 
provided by far the most detailed procedural guidelines on mediation confidentiality: (a) the conciliation process is by default private and subject to confidentiality; only when both parties agree would a conciliation process; (b) the mediation statement is protected by confidentiality and only in exceptional circumstances would confidentiality be set aside (e.g. when national interests are at stake); and (c) specific requirement on the part of the conciliator to keep all communications revealed during conciliation confidential. ${ }^{439}$ The issue of when and how the mediation statement becomes effective is given clear guidance. ${ }^{440}$ While there is no without prejudice privilege in China, the court is now explicitly prohibited, in rendering a final judgment, to rely on factual admissions during the conciliation process. ${ }^{441}$

The 2015 Interpretation also 'codified' certain existing practices, e.g. it is expressly stated that mediation can take place during pre-trial conference (庭前会议). ${ }^{442}$ The 2015 Interpretation also established new procedures, e.g. the subject of mediation in public interest litigation is finally given explicit procedural guidance for the first time. $^{443}$

\footnotetext{
${ }^{439}$ Article 146 of the 2015 Interpretation.

${ }^{440}$ Articles 149 and 151 of the Interpretation.

${ }^{441}$ Article 107 of the Interpretation.

${ }^{442}$ Article 225 of the 2015 Interpretation.

443 Article 289 of the 2015 Interpretation.
} 


\section{Chapter 5:}

An Empirical Analysis of

Judicial Conciliation in China 


\section{AN EMPIRICAL ANALYSIS OF JUDICIAL CONCILIATION IN CHINA}

\subsection{Judicial perception is reality: the value of qualitative empirical research on Chinese law and procedure}

In any jurisdiction, there is bound to be discrepancies between the black-letter law and actual practice. The gap between law and practice, particularly in the context of civil litigation, is especially wide in China. ${ }^{444}$ It is therefore important to capture the actual dynamics of the law in a systematic way. Empirical work on Chinese courts written for an international audience emerged not so long ago. ${ }^{445}$ Ethnographic research helped reveal what really happens in Chinese courtrooms. A number of these studies helped dispel certain generalizations or misconceptions arising from official representation of the judicial process. ${ }^{446}$ The value of qualitative empirical work is obvious: the judiciary tends to be highly secretive when it comes to sharing what really happens in the courtrooms and qualitative empirical research helps pierce the mystical veil of Chinese courts. In essence, the law is real only to the extent of how judges interpret and enforce it. For instance, if a judge views strict procedural rules as an obstacle to delivering what he believed to be substantive justice (shiti zhengyi), those rules lose their normative effect. Litigants can seek as much advice as they like from their legal representatives. But the redress is determined by the judge. It is therefore fair to say judicial perception of what the law embodies $i s$ the reality. Judicial perception is qualitative. Interviewing individual judges free from bureaucratic constraints and collecting their views by way of questionnaires could help flesh out what the general perceptions of Chinese judges are. While some judges are bound to differ on certain issues (perhaps due to their diverse backgrounds or institutional differentiations), a common pattern of thinking usually emerges. For instance, the concept of Anjie shiliao is considered to be 'very important' (as a goal of civil justice) by a predominant proportion of respondents in the surveys conducted in this chapter.

There are limitations in the qualitative empirical method in Chinese legal research. Court practices diverge depending on the geographical location of the court (for instance, courts in large commercial cities tend to be better at following procedures than courts in the countryside), the personal qualities of the court leadership, the level of the court, the nature of supervision from the superior court, the severity of social unrest within the region where the court is situated and local policies. A study focusing on a few courts is hardly representative of the whole Chinese judiciary.

\footnotetext{
${ }^{444}$ Clarke 1996, p. 81.

${ }^{445}$ See generally the works of Xin He, Benjamin L. Liebman and Carl Minzner.

${ }^{446}$ He 2009, p. 419-457.
} 


\subsection{Methodology}

\subsubsection{Limitations of this study}

It is important to begin by stating the limitations of this study. Surveys and interviews that form the basis of this chapter were conducted within a circle of judges and litigation practitioners who were either directly associated with the author or associated with someone who knows the author personally through tertiary institutional networks or legal professional networks. These networks obviously are not representative of the whole judiciary and legal profession in China. Given the direct contacts of the author are mostly from a highly educated background (generally with undergraduate degree or above), it is possible that the study has its bias, tilting towards the intellectual strata of the judiciary and the profession. There were obviously exceptions, i.e. the author personally knows a number of judges who are seasoned adjudicators but have not necessarily received a university education.

Another limitation is that this study does not intend to act as an ethnographic enquiry. The scope of the surveys and interviews covers numerous courts and judges of divergent specializations, so much so that a focused ethnographic study (which usually focuses only on a few courts with a very focused research agenda) is not possible.

As stated earlier, no study could claim full representativeness given the divergent modes of practices within the Chinese judiciary. While already being an extensive study (e.g. Survey A encompasses a total of 24 courts), it must be emphasized here that the analysis covers only a fraction of what really goes on in Chinese judicial conciliation.

\subsubsection{Strengths of this study}

Knowing the bureaucratic tendency of the judiciary in China, any attempt to contact judges through the official channel for research purposes would either result in a flat rejection or responses that 'toe the line'. This study therefore bypasses the official structure of the courts by contacting judges on a personal basis and conduct interviews informally (e.g. over a casual lunch or dinner). The questionnaires were sent to judges on the same basis, i.e. either the respondents were personal contacts of the author or their personal friends. This methodology has a better chance of revealing the truth free from institutional constraints. ${ }^{447}$

This study seeks to challenge common contemporary representations on Chinese civil procedure. For instance, it is said that following recent reforms to reconstruct procedural formalism, courts are no longer used as policy tools to serve administrative objectives and conciliation is no longer emphasized by courts. The empirical data reveals a very different picture. Not only the majority of respondents in the surveys claim that Anjie shiliao is still very much a central goal of civil justice, a significant

\footnotetext{
${ }^{447}$ In fact, there were multiple attempts to collect data, interview judges and observe actual judicial conciliation sessions through official channels. None of them were successful. The common response is since the author is from outside of Mainland China, and the research topic is a sensitive one, the court in question could not proceed with such requests.
} 
proportion of judges indicate that conciliation is still very much emphasized as the preferred method of dispute resolution by courts.

\subsubsection{The Surveys}

This chapter adopts the qualitative empirical method to reveal the realities of frontline judicial conciliation based on two surveys: (a) a survey involving 128 judges from 24 different courts in China (11 intermediate courts and 13 basic-level courts) responding to a questionnaire on judicial conciliation (14 questions) (Survey A); and (b) a survey involving 15 litigation practitioners based in major commercial cities in China responding to a questionnaire on judicial conciliation (14 questions) (Survey B). Within Survey A, 67 responses were from intermediate court judges (Survey A1) and 61 responses were from basic-level court judges (Survey A2). The analysis is supplemented by a number of interviews with judges from all levels of the Chinese judiciary since March $2013^{448}$ and selected primary materials taken from basic-level and intermediate courts, including court internal guidelines on trial management and internal policy documents on conciliation.

Survey A encompasses courts from a wide geographical span: 5 intermediate courts and 6 basic-level courts are located in first-tier coastal cities, 3 intermediate courts and 4 basic-level courts are located in second-tier costal cities or mid-sized coastal counties, 3 intermediate courts and 3 basic-level courts are located in inland cities or counties. $^{449}$ The wide scope enhances the representativeness of the survey, as judicial practices could differ markedly with geography. There are a number of ways to make sense of such divergences caused by geography: (a) the very well known urban-rural divide; (b) divergent policies of local authorities; and (c) commercialization of the region where the court is located (e.g. an intermediate court in cosmopolitan Shanghai would operate very differently when compared to an intermediate court in Nanning (capital of Guangxi Province), which is a much smaller and much less commercialized city).

Survey A differentiates responses from intermediate court and basic-level court judges. This is necessary for a number of reasons: (a) as first instance courts, basiclevel courts are likely to handle a larger number of purely civil cases (e.g. matrimonial cases or simple land disputes within the community) as opposed to intermediate courts; (b) the case-processing function of basic-level courts is more significant than intermediate courts; and (c) intermediate courts have regulatory functions (in terms of enforcing SPC and provincial high court policies within its jurisdiction) that basic-level courts do not have. Survey A deliberately leaves out provincial high courts as the bulk of first instance cases are disposed of at basic-level and intermediate courts.

\footnotetext{
${ }^{448}$ Former President of the SPC Wang Shengjun stepped down in March 2013. Hence the period following March 2013 under the SPC's new leadership (with Zhou Qiang as the President of the SPC) is considered the beginning of a new age of reform in Chinese civil justice.

${ }^{449}$ Needless the say, the first-tier coastal cities are wealthier and more densely populated than the second-tier/ mid-sized coastal cities. Comparatively, inland cities or counties tend to be less developed than coastal cities in China.
} 
The questionnaire in Survey A sets a broad framework for respondents to comment on the general practice of judicial conciliation in Chinese civil litigation. It does not seek to explore the intricate procedural detail of conciliation at appellate, re-adjudication and enforcement stages of proceedings.

The study based on Survey A is partly functional, requiring the respondent to identify his usual practice in judicial conciliation and elaborate on such practice. For instance, Question 1 asks the judge whether it is more time consuming to mediate or to adjudicate in the disposal of a case. The question provides four choices as the answer, 'disposal of case by conciliation', 'disposal of case by adjudication [i.e. by way of rendering a judgment]', 'depending on the circumstances, cannot conclusively comment [whether it is conciliation or adjudication]', and 'others/ difficult to determine'. However, there are also questions that are less functional in nature. For instance, Question 10 asks the respondent to comment on whether the policy of 'prioritizing conciliation' had changed in recent times. Such questions ask for the judge's personal perspective on the general nature and conduct of civil litigation as influenced by policy, ideology and other factors.

Unlike existing empirical studies on Chinese courts that tend to focus only on a few courts, ${ }^{450}$ Survey A encompasses 24 courts from a wide geographical spread. The larger scope of the survey strengthens the representativeness of the study. ${ }^{451}$ Obviously, the wider scope also limits the depth into which the study could go. But China's geographic diversity in judicial practice calls for a wider sampling.

All 128 questionnaire responses in Survey A are identified, i.e. the name of the court in which the respondent is based is provided in each response. Those questionnaire responses that fail to identify the court are excluded from the survey.

Survey B is very small in terms of sampling (only 15 responses). This is because the purpose of Survey B is simply to supplement findings in Survey A from a different perspective. Survey A on its own, despite its wide scope, is limited only to the views of judges. Survey B performs the function of testing the findings of Survey A through the lens of experienced litigation practitioners. As civil litigation is not only about the judge, but also the legal representatives and the parties, collecting data and comments from litigation lawyers is a logical next step (considering the enormous difficulty in China to interview litigants themselves).

It is obvious that the timing of the survey is important. It directly shows the relevance of the data collected. Survey A was conducted between May and June 2014 (the first questionnaire response was received on 4 May 2014 and the last was received on 21 June 2014), more than one year since the SPC had a major change in leadership (e.g. Zhou Qiang replaced Wang Shengjun as President of the SPC in March 2013). Survey B was conducted from September to November 2014.

\footnotetext{
${ }^{450}$ For example, Woo \& Wang 2005, p. 911-940.

${ }^{451}$ The study benefits from the fact that certain personal details of the respondent (e.g. seniority as a judge, average number of cases handled annually, specialization) were provided in the questionnaire responses, allowing a more focused analysis that compares and contrasts views of the respondents according to their respective backgrounds.
} 


\subsubsection{Interviews conducted since March 2013}

In order to capture the alleged policy shift on mediation brought about by the change of SPC leadership, signified by the stepping down of Wang Shengjun in March 2013, the surveys are supplemented by 16 interviews conducted between March 2013 and February $2015 .{ }^{452}$ Out of the 16 interviews, 9 were with judges from basic-level, intermediate and provincial high courts (with one judge being interviewed twice ${ }^{453}$ and another judge being interviewed three times ${ }^{454}$ ), 2 were with practicing litigation lawyers, ${ }^{455}$ and 1 was with a former court intern (currently a legal academic in Mainland China) who was interviewed twice. ${ }^{456}$

These interviews were conducted with the goal to reveal what the actual changes were and depict the delicate details of court mediation practice since March 2013.

\subsubsection{An anecdotal note on conducting empirical work in Chinese courts}

\subsubsection{Getting started}

As a general principle, judges are not allowed to disclose information or make comments that may reflect negatively on the Chinese judiciary. It is best not to disclose the research questions before the interview (or even hint what areas will be covered), otherwise the interviewee may back out. The most honest opinions are gathered on the individual and informal level without any pretext. Research questionnaires circulated to judges must be kept as simple as possible. The questions should focus on procedural matters. Court visits must be approved by the leadership of the court. It is very difficult to obtain clearance unless one knows someone influential within the system. The author tried to conduct interviews with judges in the format of a discussion group (or seminar). These judges have at first refused to be interviewed individually, but later agreed to participate in a discussion group (or seminar) held by a neutral third party on a university campus. The interview and data-collection are much more likely to be successful if the researcher first becomes acquainted with the judge.

\subsubsection{What to ask and what not to ask}

Chinese judges are highly politically sensitive. Even the slightest hint that one is trying to discover a problem within their system deters them from answering. The best way is to adopt a more diplomatic approach without asking direct questions that might upset them. For instance, keep the questions technical (or at least having the appearance of being technical). Instead of asking them directly whether 'forced conciliation' (压调) is prevalent in their courts, ask them to elaborate on methods they would usually employ to ensure that parties mediate effectively. Highlight the fact that it is understood that things are done a little differently in China. Chinese

\footnotetext{
${ }^{452}$ See Part B of Appendix III.

${ }^{453}$ Interview Ref: 2013/11; and Interview Ref: $2014 / 3$

${ }^{454}$ Interview Ref: 2013/4; Interview Ref: 2013/5; and Interview Ref: 2013/9.

${ }^{455}$ Interview Ref: 2013/6; and Interview Ref: 2014/1.

${ }^{456}$ Interview Ref: 2013/3; and Interview Ref: 2015/1.
} 
exceptionalism is something widely accepted (and at times celebrated) within judiciary.

\subsection{Social Effect vs. Procedural Justice: Is Anjie shiliao still a paramount goal in Chinese civil justice?}

\subsubsection{Overview}

The concept of 'substantive justice' is paramount in Chinese judicial thinking. ${ }^{457}$ From numerous interviews, the author was told that Chinese judges are prepared to bend the rules if by so doing substantive justice could be achieved. ${ }^{458}$ Interviewees emphasized repeatedly the importance of the 'social effect' (社会效果) of a judgment, i.e. the belief that the 'quality' of justice is measured by the positive social impact a court decision has, rather than the strict legal correctness of the judgment. ${ }^{459}$ Recent reform efforts call for a revamp of the adjudicatory machinery with the view of promoting the 'rule by law' (依法治国). ${ }^{460}$ The question, obviously, is how far did these reform efforts (or policy changes) promote procedural formalism in China's civil courts. Are judges now less concerned with the 'social effect' of their decisions? The following data would undoubtedly shed some light on the subject.

\subsubsection{The Judges' Survey}

Out of the 128 respondents in Survey A (i.e. the judges' survey): ${ }^{461}$

a) 90 were of the view that the principle of Anjie shiliao (案结事了) ${ }^{462}$ is 'still very important' (仍然非常重要)as a goal of Chinese civil justice;

b) 22 were of the view that the principle of Anjie shiliao is 'still important', but 'not as important as before’ (仍然重要, 但没有已往那么重要);

c) 10 were of the view that the principle is 'no longer important' (已不再重要); and

d) 6 chose neither the above (i.e. selecting the fourth option, 'others/ difficult to determine' (其他/很难判断)).

\footnotetext{
${ }^{457}$ See Chapter 7 of this book for an in-depth analysis on the concept of 'substantive justice' in Chinese judicial thinking.

${ }^{458}$ E.g. Interview Ref: $2012 / 2$.

${ }^{459}$ E.g. Interview Ref: 2012/2, Interview Ref: 2012/3 and Interview Ref: 2012/5.

${ }^{460}$ For an overview of the recent reforms, refer to the Afterward of this book.

${ }^{461}$ Percentages set out in this chapter are rounded off to two decimal places.

462 The handling of a case in such a way that 'the case is closed and the dispute is [truly] resolved'. For a detailed description of the principle of Anjie shiliao, see [Chapter 4 - cross reference]
} 
In other words, $70.31 \%$ of the respondents considered the principle of Anjie shiliao 'still very important', ${ }^{463}$ and $17.19 \%$ of the respondents considered the principle as 'still important, but not as important as before'. ${ }^{464}$

This is to say that $87.50 \%$ of the respondents either believed that Anjie shiliao is either 'still very important' or 'still important' at the time of the survey. ${ }^{465}$

Only $7.81 \%$ of the respondents believed that Anjie shiliao is 'no longer important'. The percentage is still only $12.50 \%$ even if one adds the 6 respondents who selected the fourth option (i.e. 'others/ difficult to determine').

It is interesting to note that among the 10 respondents who believed that Anjie shiliao is 'no longer important', 6 came from the same court (a basic-level court). It is possible that this particular court views this issue from an unconventional approach.

\subsubsection{The Litigation Practitioners' Survey}

Out of the 14 respondents who answered the relevant question in Survey B (i.e. the litigation practitioners' survey): ${ }^{.46}$

a) 7 were of the view that the principle of Anjie shiliao is 'still very important' as a goal of Chinese civil justice from the judiciary's perspective (as understood by them);

b) 5 were of the view that the principle of Anjie shiliao is 'still important', but 'not as important as before'; and

c) 2 were of the view that the principle is 'no longer important'.

While the sampling in Survey B is much smaller in size, the figures are still of some reference value.

$50 \%$ of the respondents believe that Anjie shiliao is 'still very important', while $35.71 \%$ were of the view that Anjie shiliao is 'still important', but 'not as important as before'.

This is to say that $85.71 \%$ of the respondents believed that Anjie shiliao is either 'still very important' or 'still important' at the time of the survey. The percentage is close to that in Survey A $(87.5 \%)$.

Only $14.29 \%$ of the respondents believed that Anjie shiliao is 'no longer important'.

\footnotetext{
${ }^{463}$ The breakdown is that around $68.66 \%$ of the respondents in Survey A1 (intermediate courts only) and around $72.13 \%$ of the respondents in Survey A2 (basic-level courts only) believed that Anjie shiliao is 'still very important'.

${ }^{464}$ The breakdown is that around $20.90 \%$ of the respondents in Survey A1 (intermediate courts only) and around $13.11 \%$ of the respondents in Survey A2 (basic-level courts only) believed that Anjie shiliao is 'still important, but not as important as before'.

${ }^{465}$ The breakdown is that around $89.55 \%$ of the respondents in Survey A1 (intermediate courts only) and around $85.25 \%$ of the respondents in Survey A2 (basic-level courts only) believed that Anjie shiliao is either 'still very important' or 'still important'.

${ }^{466}$ There were 15 respondents in Survey B. However, one respondent was unable to answer the question on Anjie shiliao as (s)he was unfamiliar with the concept.
} 


\subsubsection{Analysis}

The overwhelming majority of respondents in both Survey A and Survey B taking the view that the principle of Anjie shiliao is 'still very important' as a goal of Chinese civil justice is revealing. First, it shows that judges generally see themselves shouldering a social responsibility beyond the usual job description of a judge as understood in the West. One respondent commented that Anjie shiliao is the 'accomplishment and honour' of a judge, it is the judge's 'contribution to society' in his own subtle way. ${ }^{467}$ Second, the continuing emphasis on Anjie shiliao in part reflects the practical concerns of judges. A respondent commented that due to the Xinfang system (i.e. the citizens' petition system, or 'letters and visits'), it is unavoidable that judges need to achieve Anjie shiliao to avoid the escalation of Xinfang rates. The respondent noted further that if the Xinfang system continues without reform and the job security of judges remains uncertain, Anjie shiliao would continue to remain as a very important objective in civil adjudication. ${ }^{468}$ Another respondent highlighted the tedious and exhausting work a judge needs to take up (e.g. reporting to the Xinfang authority and answer questions from the authority) after the closing of a lawsuit if the litigant files a citizen's petition. Post-lawsuit follow-up duties of a judge in Xinfang cases are likely to be long-term obligations, thereby adding further workload onto the judge. ${ }^{469}$ One respondent even went as far as saying that without Anjie shiliao, a court decision has 'no practical meaning' (没有实际意 义). ${ }^{470}$ Third, the phenomenon is, in part, the product of top-down directions. One respondent said, '[In] fact we ourselves are relaxed [about this], but the "head office" promotes it this way, as if it is still very important'. ${ }^{471}$ The respondent is referring how the court leadership's active promotion of Anjie shiliao affects the decision of individual judges in adjudication. Another respondent kept it direct and concise: Anjie shiliao is 'the ultimate goal of [the judiciary's] current policy'. ${ }^{472}$ Fourth, some judges believe that Anjie shiliao is what litigants are truly looking for. ${ }^{473}$ This 'clientorientated' emphasis on the principle of Anjie shiliao reveals that disputants in China lacked ADR channels to resolve disputes and rely heavily on courts to resolve their disputes by way of conciliation.

\footnotetext{
${ }^{467}$ Questionnaire No. 9, Basic-Level Court File (x). This respondent was of the view that Anjie shiliao is 'still very important'.

${ }^{468}$ Questionnaire of Basic-Level Court File (ix). This respondent was of the view that Anjie shiliao is 'still very important'.

${ }^{469}$ Questionnaire No. 7, Basic-Level Court File (iii). This respondent was of the view that Anjie shiliao is 'still very important'.

${ }^{470}$ Questionnaire No. 1, Basic-Level Court File (ii). This respondent was of the view that Anjie shiliao is 'still very important'.

${ }^{471}$ Questionnaire of Basic-Level Court File (viii). This respondent was of the view that Anjie shiliao is 'still important'.

${ }^{472}$ Questionnaire No. 4, Basic-Level Court File (ii). This respondent was of the view that Anjie shiliao is 'still very important'.

${ }^{473}$ Questionnaire No. 2, Basic-Level Court File (ii). This respondent was of the view that Anjie shiliao is 'still very important'.
} 


\subsection{Is the policy of 'prioritizing conciliation' still in effect? What is its impact on adjudication?}

\subsubsection{Is the policy of 'prioritizing conciliation' still in effect?}

The policy of 'prioritizing conciliation' (调解优先) is documented in a number of SPC judicial notices. ${ }^{474}$ While technically these judicial notices are not repealed, many believe that with the recent reform the policy of 'prioritizing conciliation' has become a relic of the past. ${ }^{475}$ The policy also sits uncomfortably with the statutory requirement under Article 99 of the Code, i.e. if no settlement is reached through conciliation, the court must render a judgment in a timely manner.

Empirical data, however, reveal a different picture.

In Survey A, out of 128 respondents, 73 indicated that the policy of 'prioritizing conciliation' is still in force and emphasized by courts. Given $57.03 \%$ of all respondents believe that conciliation has priority over adjudication, it is questionable whether the statement that the recent reforms have 'normalized conciliation' (调解常 规化) is a valid one. This percentage appears to be consistent at both levels of courts. $^{476}$

48 respondents (or $37.5 \%$ of all respondents) took the view that the policy of 'prioritizing conciliation' has undergone 'some changes', i.e. that it is not abolished but is no longer emphasized by the court. 7 respondents (or 5.47\%) indicated that it is difficult to comment on this issue or provided other answers. No respondent believed that the policy has been abolished.

Survey B reveals a similar pattern. A substantial proportion of respondents (7 out of 15 ) indicated that the policy of 'prioritizing conciliation' is still in force and emphasized by courts. 6 out of 15 respondents took the view that the policy of 'prioritizing conciliation' has undergone 'some changes', i.e. that it is not abolished but is no longer emphasized. 2 out of 15 respondents indicated that it is difficult to comment on this issue or provided other answers. No respondent believed that the policy has been abolished.

\subsubsection{Does the policy of 'prioritizing conciliation' affect the total number of judgments rendered by individual judges and the freedom of parties in selecting conciliation?}

The issue of whether the policy of 'prioritizing conciliation' is still in effect is closely connected to another critical issue - i.e. whether the policy affected the total number of judgments rendered by individual judges and the freedom of parties in selecting conciliation.

\footnotetext{
${ }^{474}$ For a discussion these SPC judicial notices, see Chapter 4 of this book.

${ }^{475}$ The policy of 'prioritizing conciliation' must be distinguished from the pre-action mediation procedure under Article 122 of the Code: 'If the civil dispute brought before a people's court by a party would be suitable for mediation, mediation shall be attempted first, unless the parties refuse mediation.'

${ }^{476}$ The percentage of respondents confirming that the policy of 'prioritizing conciliation' is still in force is $55.74 \%$ at basic-level courts and $58.21 \%$ at intermediate courts respectively.
} 
In Survey A, only $14.06 \%$ of all respondents indicated that the policy significantly lowered the total number of judgments rendered. Almost half of all respondents (49.22\%) indicated that the policy has some effect (though not significant) on the total number of judgments rendered. This indicates that the majority of respondents believe that the policy of 'prioritizing conciliation' has different degrees of impact on their ability to adjudicate cases in a manner free from policy influences that preferred conciliation over adjudication.

A brief, yet very informative, comment from one of the respondents in a basic-level court attributes the significant decrease in judgments rendered not to the policy of 'prioritizing conciliation' itself, but to the practical reality that judgments are 'too hard to write' and 'could give rise to xinfang (letters and visits)'. ${ }^{477}$ It follows that even if the policy is abolished, the real-life constraints of a judge sometimes dictate the preference for conciliation over adjudication.

In Survey B, the pattern differed in that no respondent indicated that the policy of prioritizing conciliation' significantly affected the freedom of their clients in choosing conciliation or mediation. Out of the 15 respondents, 6 indicated that the freedom of their clients in choosing conciliation or adjudication was affected (though not significant). 8 respondents indicated that the policy has absolutely no effect on the freedom of parties in choosing conciliation or adjudication. 1 respondent selected the option 'others/ difficult to determine'.

\subsection{Coerced conciliation and undue influence from the bench}

Article 96 of the Code made it clear that 'A mediation [settlement] agreement must be reached by the parties voluntarily, and may not be coerced. The contents of a mediation statement may not violate the law.' The reality may not necessarily correspond to this statutory requirement. As discussed in Chapter 4, some judges are fairly comfortable with the idea of disclosing to parties what their preliminary judgments are as a tactic to secure settlements.

In Survey A, only $24.22 \%$ of all respondents clearly indicated that they would absolutely not disclose their preliminary judgment to parties at a judicial conciliation session. $24.22 \%$ of respondents indicated that they would hint to parties what their preliminary judgments are. $3.91 \%$ of the respondents indicated that they would blatantly tell the parties what their preliminary judgments are. $46.09 \%$ of all respondents said whether or not they would disclose their preliminary judgment in a conciliation session depends on the circumstances (要看情况而定) and that there can be no generalized answer to this question (不能一概而论). In other words, the overwhelming majority of respondents have had disclosed preliminary judgments to parties at conciliations in the past in one way or another.

\footnotetext{
${ }^{477}$ Questionnaire No. 1, Basic-Level Court File (xii).
} 
The findings in Survey B were even more one-sided. Out of the 15 respondents, 7 respondents indicated that they came across instances where judges hinted to parties what their preliminary judgments were, while 5 respondents indicated that they came across instances where judges blatantly tell the parties what their preliminary judgments would be. Only 2 respondents indicated that they have never come across judges disclosing their preliminary judgment to parties at a judicial conciliation session. 1 respondent selected the option 'others/ difficult to determine'.

These findings reinforced the general perception among judges as revealed in the interviews, i.e. that disclosure of a judge's inclination on the merits and quantum of a case is not only acceptable but also desirable given the institutional need to achieve timely closure of cases. ${ }^{478}$

\subsection{Effect of judicial conciliation on ultimate judgment should there be no settlement}

\subsubsection{Conciliation as a fact-finding tool and its influence on ultimate judgment}

In the Survey A questionnaire, respondent judges were asked the question whether they would use the conciliation process to assist with the fact-finding in the ensuing proceedings should the case fail to settle. In other words, the question is about the extent to which the ultimate ruling relies on facts gathered during judicial conciliation. The majority of respondents $(63 \%)$ in Survey A indicated that they would not use conciliation for fact-finding. Only $15.75 \%$ of the respondents indicated that they would rely on the facts gathered during conciliation. $20.50 \%$ of the respondents were of the view that the answer to the question depends on the circumstances.

Survey B did not cover this question as the respondents were litigators, not judges.

\subsubsection{Effect of party statements made during judicial conciliation on the ultimate judgment}

In Survey A, 71 out of 128 respondents (55.47\%) indicated that party statements made during conciliation would not in any way affect the ultimate judgment should settlement fails. 11 respondents $(8.59 \%)$ indicated that party statements would definitely affect the ultimate judgment. 46 respondents $(35.94 \%)$ were of the view that the effect of party statements made during conciliation on the ultimate judgment depends on the circumstances of each case.

As discussed, there is no without prejudice privilege under Chinese law. The very nature of judicial conciliation (i.e. where the trial judge also conciliates the case) makes it impossible to insulate communications in the conciliation sessions from the adjudication process. While the survey reveals clearly that the majority of judges subjectively believe that representations of parties made during conciliation have no effect on their determination of the merits and quantum of the case, it is doubted

${ }^{478}$ E.g. Interview Ref: 2012/2. 
whether the total separation of the two processes by the same judge is humanly possible.

While those (in Survey A) who believe that party statements made during conciliation have different degrees of effect on the ultimate judgment is in the minority, the proportion is in no way insignificant (57 out of 128 respondents, i.e. $44.53 \%$ ). These respondents were asked a follow-up question of how party communications (statements made and information disclosed) during the conciliation process affected the judge's ultimate judgment. Four options were given: [that the communications during conciliation] (a) affected the ultimate decision on liability; (b) affected the ultimate decision on quantum; (c) affected the ultimate decision on both liability and quantum; and (d) others/ difficult to determine (Follow-up Question). Out of the 57 respondents who believe that party communications during conciliation have different degrees of effect on the ultimate judgment, 55 responded to the Follow-up Question. ${ }^{479}$ The distribution of responses (55 respondents in total) for the Follow-up Question is as follows: 8 respondents were of the view that party communications during conciliation affected the judge's decision on liability only $(14.55 \%$ of the respondents of the Follow-up Question); 17 respondents were of the view that party communications during conciliation affected the judge's decision on quantum only (30.90\% of the respondents of the Follow-up Question); 14 respondents were of the view that party communications during conciliation affected the judge's decision on both liability and quantum (25.45\% of the respondents of the Follow-up Question); and 16 respondents chose the option 'others/ difficult to determine' $(29.10 \%$ of the respondents of the Follow-up Question).

Article 107 of the 2015 Interpretation clearly provides that, except otherwise provided by the law or if the parties themselves give consent, factual affirmations made by a party with the view to reach a compromise (whether in connection with the agreement to conciliate or the settlement agreement) must not be used to that party's disadvantage in ensuing proceedings (assuming conciliation fails). As China has not entrenched the principle of without prejudice privilege in its general law, Article 107 of the 2015 Interpretation can be considered an indirect confirmation of the principle in judicial conciliation. However, the empirical evidence suggests that Article 107 is not necessarily enforced in real life practice, as 57 out of 128 respondents (i.e. $44.53 \%$ ) in Survey A indicated that party statements made during conciliation have different degrees of effect on the ultimate judgment

The proportion of respondents in Survey B believing that party statements would definitely affect the ultimate judgment is significantly higher than that in Survey A (40\% in Survey B vis-à-vis $8.59 \%$ in Survey A). In Survey B, 6 out of 15 respondents indicated that party statements would definitely affect the ultimate judgment. Only 3 out of 15 respondents indicated that party statements made during conciliation would not in any way affect the ultimate judgment should settlement fail. 5 out of 15 respondents were of the view that the effect of party statements made during conciliation on the ultimate judgment depends on the circumstances of each case. 1 respondent selected the option 'others/ difficult to determine'. 12 respondents in Survey B responded to the Follow-up Question. The distribution of responses (12

\footnotetext{
${ }^{479}$ The two respondents who did not answer the Follow-up Question did not provide any reason for the failure.
} 
respondents in total) for the Follow-up Question is as follows: no respondent was of the view that party communications during conciliation affected the judge's decision on liability only; 5 respondents were of the view that party communications during conciliation affected the judge's decision on quantum only; 5 respondents were of the view that party communications during conciliation affected the judge's decision on both liability and quantum; and 2 respondents chose the option 'others/ difficult to determine'.

\subsection{The position of substantive law in judicial conciliation}

As discussed in Chapter 4, the liability basis is a fundamental pillar in deciding how a case is settled in judicial conciliation. The empirical evidence confirms this position. In Survey A, out of 127 respondents, 77 (60.63\%) indicated that the respective legal liability of parties in the case would definitely affect the outcome of the conciliation. Only 21 respondents have indicated unequivocally that liability has no impact on a conciliated settlement (16.54\%). The remaining respondents either said it depends on the circumstances of the case or are unable to determine $(22.83 \%)$. These findings are reinforced in Survey B in that 14 out of 15 respondents were of the view that the respective legal liability of parties in the case would definitely affect the outcome of the conciliation. 1 respondent said it depends on the circumstances of the case.

The predominant position of legal liability in judicial conciliation (in the sense that a conciliated settlement must be consistent with the substantive law in issue) reveals that the principle of substantive justice is still very much ingrained in Chinese adjudication culture. What is supposed to be an interest-based conciliatory process is skewed to accommodate the principle of substantive justice (i.e. any court-sanctioned outcome must be 'legally correct' in the substantive sense). Such a belief frustrates the ADR function of judicial conciliation and runs counter to the SPC's desire to construct a modern civil justice system based on procedural formalism and the respect for party autonomy.

\subsection{Trial management, case quality evaluation and settlement rate}

The 'Trial Management' system (审判管理) measures the procedural efficacy and social effect of court work and processes by meticulously collecting and analyzing data on case processing. Among other benchmarks, trial management takes indices such as 'conciliation settlement rate', 'withdrawal rate', 'actual enforcement rate' and 'the rate of reversal and new trial by remittal of first instance decisions (decisions in error)' into account in its assessment of judicial merit. These benchmarks feature in a scoring matrix (generally known as 'Case Quality Evaluation') that measures the level of fairness (公正指标), efficiency (效率指标) and effectiveness (效果指标) in the handling of cases by the court under review.

In Survey A, respondents were asked whether their decisions on choosing conciliation or adjudication were affected by the encouragement of settling cases through conciliation under the performance evaluation of individual judges and the Case Quality Evaluation. Four options were given: (a) significantly affected (would place great emphasis on conciliation); (b) somewhat affected (would place relative emphasis on conciliation; (c) not affected at all; and (d) others/ difficult to determine. 
Out of 128 respondents, the majority (66 respondents, i.e. $51.56 \%$ ) indicated that the performance evaluation matrix that encouraged conciliation had somewhat affected their decisions on choosing conciliation or adjudication and, as a result, they would place relative emphasis on conciliation. 22 respondents $(17.19 \%)$ indicated that the performance evaluation matrix significantly affected their decisions and, as a result, they would place great emphasis on conciliation. 35 respondents $(27.34 \%)$ were of the view that the performance evaluation matrix has no effect on their decision at all. 5 respondents (3.91\%) selected the last option (others/ difficult to determine).

Survey B generally echoed Survey A, in that 7 out of 15 respondents were of the view that the performance evaluation matrix had somewhat affected judges' decision; 5 out of 15 respondents were of the view that the performance evaluation matrix had significantly affected the judges' decisions. Only one litigator was of the view that the performance evaluation matrix has no effect on judges' decisions. 6 out of 15 respondents selected the last option (others/ difficult to determine).

From the empirical findings, it appears that the majority of judges and litigators alike agree that the encouragement of settlement through conciliation under the performance evaluation matrix and Case Quality Evaluation system have affected judges' decisions in choosing conciliation or adjudication. In other words, because of the institutional emphasis on conciliation in evaluating judicial performance, judges find themselves giving preference to conciliation in handling civil and commercial cases. This has a significant ramification: in order to 'prop up' their settlement rates, judges have a tendency to push for conciliation (in some cases even against the will of parties) and unduly influence the process leading up to settlement. This tendency infringes party autonomy and other rights of the parties.

\subsection{Practical aspects of judicial conciliation as revealed in the surveys}

\subsubsection{Common phases of judicial conciliation}

As discussed in Chapter 4, there are usually four convenient stages during trial to commence judicial conciliation: (1) right before the start of the substantive hearing; (2) after court investigation (法院调查) (and before party debate); (3) after party debate (and before final submissions (最后陈述); and (4) after the hearing (before the rendering of judgment). ${ }^{480}$

Judges in practice would ask parties whether they are willing to commence conciliation at any stage of the hearing. A provincial high court judge observed that most judicial conciliation occurs after the court hearing (and before the rendering of judgment). The rationale for this is that since the facts would have been established by the conclusion of the hearing, it is much easier for parties to appraise their relative positions in negotiating a settlement. ${ }^{481}$ This view is put in doubt when one looks at the empirical findings.

\footnotetext{
${ }^{480}$ NPCSC Publication 2012, p. 146.

${ }^{481}$ Based on an interview with a deputy division head of the high court of an inland province in China (on 14 May 2012). The senior judge specialises in handling foreign-related civil and commercial disputes.
} 
In Survey A, out of 128 respondents, only 29 (22.66\%) indicated that they usually conduct conciliation after the court hearing and before the rendering of judgment. 30 respondents (23.44\%) indicated that they usually conduct conciliation before the court hearing. 5 respondents $(3.91 \%)$ said conciliation usually takes place after court investigation (and before party debate). 11 respondents $(8.59 \%)$ said conciliation usually takes place after party debate (and before final submissions). 3 respondents $(2.34 \%)$ indicated that conciliation usually takes place in none of the above stages. The largest proportion of respondents (50 out of 128 , i.e. $39.06 \%$ ), however, said the stage at which conciliation would take place depends on the circumstances.

In Survey B, out of the 15 respondents, 3 indicated that judges usually conduct conciliation before the court hearing. 2 respondents said conciliation usually takes place after party debate (and before final submissions). 5 respondents indicated that conciliation usually takes place after the court hearing and before the rendering of judgment. 5 respondents said the stage at which conciliation would usually take place depends on the circumstances.

\subsubsection{Efficiency in Judicial Dispute Resolution: adjudication vs. conciliation}

The general view (especially during Wang Shengjun's era) is that settling a case through judicial conciliation is much more efficient than rendering a judgment from a caseload management perspective. Empirical findings in Survey A does not, however, provide any conclusive indication that this generally held view is accurate. Out of the 128 respondents in Survey A, 21 (16.41\%) indicated unequivocally that conciliation is more time consuming than adjudication. 28 respondents indicated unequivocally that adjudication is more time consuming $(21.88 \%)$. The great majority of respondents ( 79 out of 128 , i.e. $61.72 \%$ ) indicated that the matter is complicated and which process is quicker depends on the circumstances of the case.

The finding in Survey B seems to confirm the generally held view in that 10 out of 15 respondents found adjudication to be more time consuming than conciliation. Only 1 out of 15 respondents believed that conciliation is more time consuming. The remaining respondents indicated that it depends on the circumstances which method is more efficient.

\subsubsection{Cases suitable for conciliation}

Respondents were asked the question whether purely civil cases are more suitable for judicial conciliation than commercial cases. Purely civil cases encompass matrimonial disputes, simple tort actions (including personal injury cases) and simple contractual disputes that do not involve corporates (e.g. uncollected debts of a family loan). The contemporary view is that purely civil cases are more suitable for conciliation as such cases arise out of the community in which the parties know one another very well (either as family, neighbours or friends). Commercial disputes on the other hand require a more predictable outcome and formalistic procedures. The question is significant in two respects: (a) basic level courts tend to handle much more purely civil cases than intermediate courts; and (b) courts in rural regions (of whatever level) tends to handle much more purely civil cases than courts based in urban regions. By testing this contemporary view, one can predict with greater 
certainty in which types of courts judicial conciliation would continue to play a significant role in dispute resolution.

The empirical evidence, however, sheds doubt on this contemporary view. In Survey A, out of 128 respondents, 34 (26.56\%) agreed unequivocally with the statement that purely civil cases are more suitable for judicial conciliation than commercial cases; 21 (16.41\%) disagreed with the statement unequivocally. The majority of the respondents $(57.03 \%)$ indicated that the matter is by no means a clear-cut one (63 respondents indicated that it depends on the circumstances of the case and 10 indicated that it is difficult to form a view either way).

In Survey B, only 2 out of 15 respondents agreed that purely civil cases are more suitable for judicial conciliation than complex commercial cases; 6 out of 15 respondents disagreed. 7 out of 15 respondents indicated that the matter is by no means a clear-cut one.

\subsubsection{To conciliate or not to conciliate}

Chinese judges are familiar with the slogan 'conciliate whenever possible, but render a judgment if [the case is] suitable for adjudication' (能调则调, 当判则判). While the principle of voluntariness is central to conciliation as a matter of statutory construction, the will of the judge in practice plays an important role in deciding whether or not conciliation is commenced. The question of how a judge determines whether a case should be conciliated is therefore critical in understanding the actual practice of judicial conciliation. In the study, the respondents were asked what factors determine their choice of conciliation or adjudication. The options are: (a) the type and nature of the case (Option A); (b) the relationship between the parties (Option B); (c) the prevailing policy of the court (Option C); (d) all of the above (Option D); (e) other factors/ difficult to determine (Option E). In Survey A, out of 128 respondents, 36 chose Option A $(28.13 \%) ; 10$ chose Option B $(7.81 \%) ; 4$ chose Option C (3.13\%); 61 chose Option D (47.66\%); and 17 chose Option E (13.28\%). In other words, almost half of the respondents believe that all three factors (court policy, type/nature of the case and relationship between the parties) play an important role in the decision-making.

In Survey B, out of 15 respondents, 1 selected Option C, 10 selected Option D and 4 selected Option E.

\subsubsection{Court enforcement rate of mediation statements}

In Survey A, respondents were asked to comment on the overall rate of mandatory enforcement of mediation statements in their respective courts (as opposed to the enforcement rate of mediation statements sanctioned by the individual respondent judge). The choices were: (a) very high; (b) on the high side; (c) moderate; (d) on the low side; and (e) very low. Out of those 103 respondents who answered this question, ${ }^{482} 6$ selected 'very high' $(5.83 \%), 17$ selected 'on the high side' $(16.50 \%)$, 31 selected 'moderate' $(30.10 \%), 37$ selected 'on the low side' $(35.92 \%)$, and 12

\footnotetext{
${ }^{482}$ Out of the 128 respondents, only 103 answered this question concerning the rate of mandatory enforcement of mediation statements.
} 
selected 'very low' (11.65\%). In Survey B, respondents were asked to comment on the overall rate of mandatory enforcement of mediation statements for cases that they have personally handled in the past three years. The choices of answers are the same. Out of 14 respondents, 6 indicated that the overall rate was 'very low', 4 responded 'on the low side', 1 responded 'moderate', 2 responded 'on the high side, and 1 responded 'very high'.

The figures show that the overall rates of mandatory enforcement of mediation statements have clearly dropped after Wang Shengjun had stepped down.

\subsection{Chapter conclusion: the position on judicial conciliation since March 2013 as revealed in the latest interviews}

Interviews conducted after March 2013 reveal an interesting phenomenon. ${ }^{483}$ Senior judges tend to 'toe the party line', insisting that the policy of prioritizing conciliation has been, de facto, revoked. Junior judges, however, confirmed that it is basically 'business as usual', i.e. judicial conciliation still plays a dominant role in civil disputes resolution. It may be the case that higher up in the judicial hierarchy, senior judges are not hard pressed with insurmountable caseload and deadlines, hence the consensus among senior judges that the policy preference for conciliation as seen in Wang's era is no longer effective. Buried in hundreds of cases per year, junior judges or judges hearing first instance cases at lower level courts (in particular basic level courts) have very little choice but to make good use of judicial conciliation as a caseload management tool. The parameters for evaluating case quality could also have contributed to the insistence on the policy preferring conciliation at lower courts. Leaders of basic level courts (and to a certain extent intermediate courts) may find conciliated settlement rates the easiest way to demonstrate to their superiors that Anjie shiliao has been achieved in their courts. It is fair to say that, in principle, the interviews have confirmed the results of the surveys regarding the notion of Anjie shiliao, i.e. that the vast majority of judges still believe that Anjie shiliao to be a significant objective of Chinese civil justice. Obviously there are differences in opinion as to how the court can achieve Anjie shiliao, with some insisting that mediation is still the only efficient and practical way to achieve Anjie shiliao and others believing that there are other ways to do it.

${ }^{483}$ See Part B of Appendix III. 
Chapter 6:

Commercial Mediation in China:

A Guide for Foreign Enterprises 


\section{COMMERCIAL MEDIATION IN CHINA: A GUIDE FOR FOREIGN ENTERPRISES}

\subsection{Chapter Introduction}

\subsubsection{Mediation options for resolving commercial disputes involving foreign enterprises in China}

There are in general three mediation options for resolving commercial disputes in China: court mediation, mediation conducted in the course of arbitration proceedings (commonly known as "med-arb"), and private mediation through professional thirdparty mediation institutions (hereafter institutional commercial mediation). Institutional commercial mediation is highly professionalized. There are established rules and a code of conduct for mediators. Mediators are well trained and equipped with the relevant knowledge and experience. Fundamental principles of modern commercial mediation (such as without prejudice privilege and the impartiality of the mediator) are entrenched in the mediation rules and procedure. Despite some individual lapses, med-arb processes conducted by the China International Economic and Trade Arbitration Commission (CIETAC) and leading local arbitration commissions are generally in line with international practice. The problem area is judicial conciliation (which is a type of court mediation). There are concerns with regards to the impartiality of the trial judge who acts as both the adjudicator and conciliator. The confidentiality of without prejudice information disclosed during the conciliation process is also at risk if the conciliation failed and the court hearing resumes under the same judge.

The relevance of these mediation options to foreign enterprises

Institutional commercial mediation provides a cost-effective avenue for foreign enterprises to resolve commercial disputes without having to resort to litigation or arbitration. ${ }^{484}$ Mediators on the penal are generally professional and experienced. A mediated settlement agreement may be transformed into an arbitral award that can be directly enforced in a Chinese court. The majority of cases referred to institutional commercial mediation are settled. To date, institutional commercial mediation is underutilized by foreign enterprises. This is partly due to a common misconception that Chinese mediation (given its dispute resolution tradition) lacks fairness and party autonomy. ${ }^{485}$ The reality for institutional commercial mediation is quite the opposite. Institutional commercial mediation is generally reliable and in line with the principles of modern commercial mediation. Work must be done to dispel such misconception and promote institutional commercial mediation as a viable ADR option for foreign enterprises.

Court mediation is an integral part of contemporary Chinese civil procedure. Court mediation is almost unavoidable if a foreign enterprise litigates in a Chinese court. In the Notice of the Supreme People's Court on Issuing Several Opinions on Further Implementing the Work Principle of 'Giving Priority to Mediation and Combining

\footnotetext{
${ }^{484}$ See http://adr.ccpit.org/typeinfo.aspx?t1=15\&t2=39 (last visited: 3 March 2015)

${ }^{485}$ Peerenboom \& Scanlon 2005, p. 41.
} 
Mediation with Judgment' (SPC 2010 Notice), ${ }^{486}$ the Supreme People's Court made it its official position that court mediation is the preferred method for resolving civil and commercial disputes. Although arguably the policy of prioritizing court mediation is technically no longer effective since the introduction of the judicial reform measures in $2015,{ }^{487}$ judges (especially judges at basic level courts) still prefer court mediation for a number of different reasons. ${ }^{488}$ While party consent is stipulated to be the prerequisite to court mediation under statute (i.e. the principle of party voluntariness), ${ }^{489}$ there is a noticeable discrepancy between the law and actual practice. ${ }^{490}$ Parties sometimes find themselves persuaded, induced or pressured into a mediated settlement by the judge. A foreign enterprise may find itself settling even if it had no intention to mediate in the first place. An underlying reason for the judge's preference for court mediation is the way in which the performance of the judge is assessed. The work of the judge is assessed with reference to his or her ability to avoid mistakes and minimise reversals of judgments on appeal. Adjudication (which involves the rendering of a decision) is 'risky' for a judge given the possibility of a reversal of the decision on appeal or being accused outright of applying the wrong law. Mediation becomes a very attractive alternative. While party autonomy is emphasized under the law, the court often dominates the mediation process and steers the settlement negotiation along its adjudicative agenda. ${ }^{491}$

Mediation conducted in the course of arbitration proceedings (med-arb) is an integral component of CIETAC arbitration and arbitration conducted at local arbitration commissions (such as the Beijing Arbitration Commission (BAC)). Kaufmann-Kohler and Fan observed, 'it already appears that objections to such a combined approach [med-arb] raised elsewhere are less strong now, and that the opponents are beginning to see that the combination may have some merits'. ${ }^{492}$ Arbitration has become increasingly popular among foreign enterprises. Given the general scepticism of the Chinese civil justice system (for instance, the lack of impartiality of the court resulting from local protectionism), foreign enterprises find arbitration an attractive alternative to litigation. Arbitral commissions are promoting med-arb as an effective settlement route within arbitration. A foreign enterprise involved in arbitration proceedings in China must be familiar with the med-arb process, including the potential pitfalls. Despite individual lapses, med-arb in China is generally in line with international practice. CIETAC and leading local arbitration commissions (in particular the BAC) have been taking active measures to enhance procedural justice within the med-arb process. ${ }^{493}$

\footnotetext{
${ }^{486}$ No.16 [2010] of the SPC (effective since 7 June 2010).

${ }^{487}$ For an overview of recent reform efforts, see the Afterward of this book.

${ }^{488}$ Court mediation is an attractive option for judges in China given the fact that a mediation statement is not appealable. By resorting to court mediation, the judge can avoid appellate reversal of his judgment, thereby giving him a relatively 'clean record' on this front when it comes to assessment of his work.

${ }^{489}$ Article 93 of the Code.

${ }^{490}$ Clarke 1996, p. 81.

${ }^{491}$ Fu \& Cullen 2011, p. 51.

${ }^{492}$ Kaufmann-Kohler \& Fan 2008, p. 492.

${ }^{493}$ See, for instance, Article 58(2) of the Beijing Arbitration Commission Arbitration Rules.
} 


\subsubsection{A brief overview of the disputes resolution system involving foreign enterprises in China}

Foreign enterprises involved in commercial mediation in China are encouraged to acquire a basic contextual understanding of the country's disputes resolution system. The following is a brief overview of the Chinese court system and arbitration regime.

\subsubsection{The Chinese court system}

There is no separate commercial court in China. All commercial litigation proceedings follow the Code. Commercial disputes involving foreign parties are handled by the Fourth Civil Division of the court. ${ }^{494}$ Foreign enterprises may commence commercial proceedings at any court level, although it is generally advisable to commence proceedings at a higher-level court. ${ }^{495}$ The Chinese court system has four levels: the basic-level people's courts (usually at the county level), the intermediate people's courts (usually at city or prefecture level), the high people's courts at provincial level, and the SPC at the apex of the court system. ${ }^{496}$ The SPC supervises the work of lower courts. It also performs a regulatory role in that the judicial opinions and interpretations of the SPC (on matters relating to civil justice and procedure) are de facto 'statutory instruments'. The Code must be read in conjunction with these opinions and interpretations.

Under the Chinese appellate system, a decision at second instance is final (liangshen zhongshen zhi (两审终审制)). ${ }^{497}$ Critics question whether a second instance judgment is really final and conclusive given the ease to re-open second instance judgments under the adjudication supervision procedure. ${ }^{498}$ The lack of true finality in a civil judgment will remain one of the greatest uncertainties for foreign enterprises litigating in a Chinese court. ${ }^{499}$

There are certain features of the Chinese court system that may seem peculiar from the perspective of foreign enterprises. A noteworthy example is the existence of an adjudicative committee in every court in China. Chen noted, 'Before judgment is delivered in certain important and difficult cases heard by a collegiate bench, the cases must first be discussed by the adjudicative committee, and in giving judgment the collegiate bench must implement the decision of the committee. ${ }^{500}$ Another example is the system of advisory requests (qingshi). As Minzner noted, 'Court responsibility systems that discipline judges for simple legal error also create a perverse set of incentives for Chinese judges. To avoid appellate reversal, lower

\footnotetext{
${ }^{494}$ Chen 2011, p. 180-183.

${ }^{495}$ Zhang 2002, p. 61-64.

Also see Articles 18, 19 and 20 of the Code; also see Notice on Taking of Cases Concerning Civil and Commercial Disputes at Higher Court of Provinces for the Trial of First Instance issued by the SPC in 1999.

${ }^{496}$ Chen 2011, p. 182.

${ }^{497}$ For discussion on the lack of finality in Chinese civil judgments, see Liu 1999, p. 35.

${ }^{498}$ Liu 1999, p. 36; Zhong \& Yu 2004, p. 422.

${ }^{499}$ For further discussion on the lack of finality in Chinese civil judgments, see Chapter 7 of this book, which outlines the fundamental theoretical tenets of Chinese civil justice.

${ }^{500}$ Chen 2011, p. 186. Also see Peerenboom 2003, p. 81.
} 
Chinese courts and judges rely on an ill-defined system of advisory requests (qingshi) to solicit the views of higher courts and judges on how to decide pending cases. ${ }^{, 501}$

Local protectionism remains an important concern for foreign enterprises litigating in China. This problem is particularly acute at the enforcement stage. The government may intervene in favour of the Chinese party (e.g. local businesses or significant stateowned enterprises) if local or national interests are at stake. ${ }^{502}$

There is no judicial independence in China. The concept of separation of powers is expressly rejected as incompatible with the political reality of China. Throughout the country's imperial history, the magistrate's court had always been part of the bureaucracy rather than a separate and autonomous judicial organ. This tradition has survived until today. The people's courts are accountable to the people's congresses at the same level. The local government still exerts fiscal influence over the courts. ${ }^{503}$ This further entrenches local protectionism. However, the fiscal influence is likely to diminish significantly with the recent reform of the judicial system.

\subsubsection{Understanding the arbitration regime in China-recent reform and limitations}

The Chinese arbitration system consists of CIETAC, the China Maritime Arbitration Commission and approximately 200 local arbitration commissions established throughout the nation. CIETAC remains the most important arbitration commission for foreign enterprises, despite local arbitration commissions may now also take up foreign-related arbitration cases. ${ }^{504}$ Peerenboom and He observed, 'CIETAC arbitrations are generally considered to be substantively fair'. They referred to a survey conducted by the American Chamber of Commerce that showed up to ' $75 \%$ of respondents who had actual experience with CIETAC arbitration believed CIETAC measured up favorably to arbitration at other major international centers'. ${ }^{505}$

Recent reform has enhanced party autonomy in arbitration. These reform efforts help promote CIETAC arbitration as an attractive disputes resolution avenue for foreign enterprises. Under the new Arbitration Rules of CIETAC (2015) (CIETAC Rules), ${ }^{506}$ parties are permitted to appoint individuals from outside the CIETAC's Panel of Arbitrators. The parties may each recommend one to three arbitrators as candidates for the presiding arbitrator and shall submit the list of recommended candidates to the CIETAC. Where there is only one common candidate in the lists, such candidate shall be the presiding arbitrator jointly appointed by the parties. All arbitrator appointments, however, must be confirmed by the Chairman of CIETAC. ${ }^{507}$ As the CIETAC's Panel of Arbitrators comprises mainly of arbitrators who are Chinese nationals, the revised rules have made it much easier for foreign enterprises to appoint foreign arbitrators. ${ }^{508}$

\footnotetext{
${ }^{501}$ Minzner 2011a, p. 58-59.

502 Zhang 2002, p. 91.

${ }^{503}$ Zhong \& Yu 2004, p. 432; but see Chen 2011, p. 209.

${ }^{504}$ Peerenboom \& He 2009, p. 28.

${ }^{505}$ Peerenboom \& He 2009, p. 29.

${ }^{506}$ Revised and adopted by CIETAC on 4 November 2014. Effective as from 1 January 2015.

${ }^{507} \mathrm{Gu} 2011$, p. 273 . Also see Article 76 of the CIETAC Rules.

${ }^{508} \mathrm{Gu} 2011$, p. 273.
} 
Despite real efforts to improve the arbitration rules and procedure, certain weaknesses persisted. Under the Arbitration Law of the People's Republic of China (Arbitration Law), ad hoc arbitration is prohibited in China, as arbitration must be conduced under the rules of properly constituted arbitration commissions. ${ }^{509}$ This is far from satisfactory given, as Gu noted, 'almost all countries permit ad hoc arbitration in their national arbitration legislation'. ${ }^{5}$

Arbitration is seen as a better alternative to litigation because foreign enterprises generally lack confidence in Chinese courts. However, it would be a misconception that a foreign enterprise could by-pass the court system altogether by resorting to arbitration. The foreign enterprise must enforce an arbitral award in a Chinese court if the other party (having assets in China) does not honour the award. The same problems of local protectionism and corruption within the judiciary are likely to haunt a foreign enterprise at the enforcement stage. ${ }^{511}$ The cost issue is also frequently overlooked for those foreign enterprises that prefer arbitration. CIETAC arbitration is more expensive (and sometimes substantially more expensive) than court litigation.

The main problem with arbitration in China remains the enforcement of arbitral awards. The law provides for different enforcement regimes for foreign-related awards and domestic awards, ${ }^{512}$ the regime governing foreign-related awards being more favourable.

Until recently, it is much more difficult for the court to refuse enforcement of foreignrelated awards. Any refusal to enforce must be on strict procedural grounds only (e.g. the formation of the tribunal or the arbitration proceedings do not conform to the rules of arbitration). ${ }^{513}$ In the past, under the 2007 amended version of the Code, the court could refuse to enforce a domestic award on both procedural and substantive grounds. For instance, insufficiency of the main evidence and error in the application of the law by the tribunal were valid grounds for refusing enforcement. ${ }^{514}$ This preferential treatment has been fiercely criticized for its unfairness and the consequence of discouraging domestic arbitration. In view of such critique, following the amendments to the Code in 2012, the court can no longer refuse enforcement of a domestic award on substantive grounds. ${ }^{515}$

Despite reform efforts outlined above, other preferential measures remain. For instance, foreign-related awards can benefit from the reporting mechanism under which a decision by a lower court to refuse recognition or enforcement of an award

\footnotetext{
${ }^{509}$ The Arbitration Law has been effective since 1 September 1995 and revised on 27 August 2009. See particularly Articles 11 and 16 of the Arbitration Law.

${ }^{510} \mathrm{Gu} 2011$, p. 276.

${ }^{511} \mathrm{Gu} 2011$, p. 279.

${ }^{512}$ Peerenboom 2000, p. p. 11.

${ }^{513}$ Article 258 of the Code (2007 amended version).

${ }^{514}$ Article 213 of the Code (2007 amended version).

${ }^{515}$ Article 213 of the Code (2007 amended version) has been amended by the Decision of the Standing Committee of the National People's Congress on Amending the Civil Procedure Law of the People's Republic of China (2012). Under Article 237 of the latest version of the Code, the substantive grounds for refusing enforcement (i.e. insufficiency of the main evidence and error in the application of the law) have now been repealed and replaced with two non-substantive grounds (i.e. where the award was rendered on the basis of forged evidence and where a party has concealed from the tribunal evidence that could affect the fairness of the decision).
} 
must be approved by the SPC ${ }^{516}$ This reporting mechanism is not applicable to domestic awards. ${ }^{517}$

Foreign enterprises conducting arbitration within Mainland China would obtain either a foreign-related award or a domestic award, depending on whether a "foreign element" exists. $^{518}$ If the foreign enterprise were the party to the arbitration, the award rendered would be considered a foreign-related award (because a foreign element is present by virtue of the foreign enterprise being a party to the arbitration). However, if a foreign investment company (a Chinese corporate vehicle invested by the foreign enterprise, e.g. a Sino-foreign equity joint venture) were the party to the arbitration, it is likely that the award rendered would be considered a domestic award, unless it can be shown that a foreign element exists. The reason for this is that the foreign investment company is considered a Chinese legal person. Hence, it is a domestic party and not a foreign party to the arbitration. ${ }^{519}$

\subsection{Institutional commercial mediation - the Mediation Centre of the China Council for the Promotion of International Trade/China Chamber of International Commerce}

\subsubsection{Overview}

There are institutions in China established for resolving commercial disputes by private mediation charging an administrative fee. The most influential institution is the China Council for the Promotion of International Trade/China Chamber of International Commerce (CCPIT/CCOIC), which operates a mediation centre with national coverage (Mediation Centre). Established in 1987, the Mediation Centre maintains a nationwide network of over 40 sub-council (local) mediation centres in provinces, municipalities and autonomous regions. CCPIT/CCOIC has an enormous presence in China. According to official statistics, over $80 \%$ of the cases that underwent mediation by the Mediation Centre have been successfully settled. ${ }^{520}$ The reason for this high rate of success is unclear. There is virtually no independent empirical research on institutional commercial mediation. Norton noted, 'Reliable statistics on the caseload of these mediation centres are unavailable'. ${ }^{521}$ This is possibly due to the difficulty in convincing parties to disclose the results of the mediation for the purpose of research. While far from being satisfactory, existing literature simply relies on the official statistics released by the Mediation Centre. Provided the official statistics are accurate, a review of sample mediation cases suggests that the professionalism of the mediator is a contributing factor to the high rate of success. The mediator is usually able to apply his or her expert knowledge and adopt flexible mediation strategies in bringing the parties closer to settlement. ${ }^{522}$ Peerenboom and Scanlon observed that the majority of cases successfully settled are

\footnotetext{
${ }^{516}$ Peerenboom 2000, p. 28-29. Also see Notice on Courts' Handling of Issues in Relation to Matters of Foreign-related Arbitration and Foreign Arbitration issued by the Supreme People's Court in 1995.

${ }^{517}$ See criticism of the reporting mechanism in Gu 2012, p. 164

${ }^{518}$ Peerenboom 2000, p. 11 . Also see Article 304 of the Some Opinions Concerning Implementation of the Civil Procedure Law (1991) issued by the SPC.

${ }^{519}$ Peerenboom 2000, p. 11.

${ }^{520}$ See brief overview of the Mediation Centre at: http://lad.ccpit.org/second/index.aspx?nodeid=3 (last visited: 3 March 2015).

${ }^{521}$ Norton 2007, p. 38.

522 http://adr.ccpit.org/typelist2.aspx?t1=19\&t2=56 (last visited: 3 March 2015)
} 
domestic in nature and do not involve cross-border elements. Foreign enterprises in China generally preferred arbitration or litigation in resolving their commercial disputes than relying on private mediation centres. ${ }^{523}$ As noted above, a possible reason for the underutilization is that foreign enterprises fear that Chinese mediation (given its dispute resolution tradition) lacks fairness and party autonomy. ${ }^{524}$ This is a misconception as mediation practised by the Mediation Centre is generally in line with international practice. The mediator is regulated by a code of professional conduct and parties are free to decline any settlement proposed by a mediator. ${ }^{525}$ With China's rapid economic development and the proliferation of lawsuits, private mediation by professional institutions provides an attractive form of ADR for foreign businesses.

The Mediation Centre maintains a panel of mediators selected from Chinese and foreign individuals with professional knowledge or practical experience in commerce or the law. The Mediation Centre provides a model mediation clause for easy adoption into commercial agreements. As there is no legislation in China detailing the procedures for private mediation conducted by a mediation institution, the mediation agreement of parties and the rules of the mediation institution are vital in regulating the conduct of mediation. ${ }^{526}$

\subsubsection{Mediation Rules and Code of Conduct - entrenching principles of modern mediation}

The Mediation Centre adopts a set of uniform mediation rules (Mediation Rules). All sub-council mediation centers must uniformly apply the Mediation Rules. ${ }^{527}$ The uniformity of rules provides procedural consistency and predictability for private commercial mediation throughout China. Parties may modify the Mediation Rules (or selectively apply them) so long as such selective application or modification does not conflict with the law. ${ }^{528}$ The Mediation Rules, together with the Code of Conduct for Mediators of the Mediation Centre (Code of Conduct) ${ }^{529}$, entrenched fundamental principles of modern commercial mediation. Cao observed that although Chinese law does not recognize the privilege between a mediator and parties to the mediation, ${ }^{530}$ the principles of impartiality and independence of the mediator are emphasized under the Mediation Rules and the Code of Conduct. ${ }^{531}$ In addition, a mediator must keep confidential all information arising out of or in connection with the mediation (both factual and procedural in nature). ${ }^{532}$ While there is no statutory provision for without

\footnotetext{
${ }^{523}$ Peerenboom \& Scanlon 2005, p. 37-38.

${ }^{524}$ Peerenboom \& Scanlon 2005, p. 41.

${ }^{525}$ Peerenboom \& Scanlon 2005, p. 41. Also see Cao 2006, p. 85; Alexander 2009, p. 16-17.

${ }^{526}$ Cao 2006, p. 86.

${ }^{527}$ Mediation Centre of the China Council for the Promotion of International Trade \& China Chamber of International Commerce, Mediation Rules (2012) (effective since 1 May 2012).

${ }^{528}$ Article 3 of the Mediation Rules. Also see Article 96 of the Code. The requirements set out in Article 96 cannot be contracted away.

${ }^{529}$ The Code of Conduct came into effect on 1 July 2005.

${ }^{530}$ Cao 2006, p. 87.

${ }^{531}$ See Articles 2, 7, 9 and 10 of the Code of Conduct. Also see Articles 18 and 30 of the Mediation Rules.

${ }^{532}$ Article 8 of the Code of Conduct.
} 
prejudice privilege in China, the rules provide that settlement plans or proposals disclosed in the mediation must not be invoked in subsequent proceedings. ${ }^{533}$

\subsubsection{The mediation procedure and methodology}

The Mediation Centre accepts cases based on the mediation agreement between the parties concluded either before or after the occurrence of the dispute. Where there is no mediation agreement, the Mediation Centre may still accept the case upon application by one party with the consent of the other party. ${ }^{534}$ Articles 9 and 11 of the Mediation Rules detail the documentation required in an application to mediate and the registration fee payable. ${ }^{535}$ After receiving the Application for Mediation, the Mediation Centre shall deliver to both parties the Notification of Mediation, the Mediation Rules and the Panel of Mediators. ${ }^{536}$ The respondent has 5 days from the date of the receipt of the Notification of Mediation to confirm (by way of submitting a written opinion) whether or not he agrees to submit the dispute to the Mediation Centre for mediation. ${ }^{537}$ If the respondent does not confirm its agreement to mediation within the time limit, it shall be deemed that it has rejected mediation. ${ }^{538}$ Under usual circumstances, mediation is conducted by one mediator, unless the parties agree otherwise. ${ }^{539}$ The parties would jointly select one mediator or jointly authorize the Mediation Centre to appoint one mediator within 10 days of the receipt of the Notice for Fee Collection. If the parties fail to jointly appoint or jointly authorize the Mediation Centre to appoint the mediator within the prescribed time limit, the Mediation Centre shall appoint the mediator. ${ }^{540}$ While the Mediation Centre maintains a Panel of Mediators for the parties to choose from, the parties could choose mediators from outside the Panel of Mediators. ${ }^{541}$ The mediator may adopt the mediation method that is deemed appropriate for the parties to reach a settlement: e.g. with the parties' approval to engage relevant experts ${ }^{542}$ While commercial mediation administered by the Mediation Centre gives the appearance of a purely facilitative mode of mediation, the reality is that the process can be rather evaluative. In fact, the Mediation Rules give the mediator the power to offer parties a settlement proposal or suggestion, which makes the process more like conciliation than facilitative mediation. ${ }^{543}$

\subsubsection{Enforcement of a mediated settlement agreement}

A mediated settlement agreement is only a private contract. Unlike an arbitral award or court judgment, the settlement agreement cannot be directly enforced. ${ }^{544}$ If a party

\footnotetext{
${ }^{533}$ Article 30 of the Mediation Rules. Also see Cao 2006, p. 87.

${ }^{534}$ Article 8 of the Mediation Rules.

${ }^{535}$ See Mediation Fee Schedule at http://adr.ccpit.org/english/typeinfo.aspx?t1=119\&t2=131 (last visited: 28 June 2014). The minimum fee is RMB1,500.

${ }^{536}$ Article 11 of the Mediation Rules.

${ }^{537}$ See Article 12 of the Mediation Rules; but this article does not apply to cases where both parties submitted the Application for Mediation jointly.

${ }^{538}$ Article 14 of the Mediation Rules.

${ }^{539}$ Article 16 of the Mediation Rules.

${ }^{540}$ Article 17 of the Mediation Rules.

${ }^{541}$ Article 16 of the Mediation Rules.

${ }^{542}$ Article 20 of the Mediation Rules.

${ }^{543}$ Article 20 of the Mediation Rules.

${ }^{544}$ Liang J.Q. 2008, p. 490.
} 
fails to comply with the settlement agreement, the other party seeking to enforce the agreement must first seek a judgment from the court (by way of a contractual claim) and then enforce the judgment. This situation is far from satisfactory given the unpredictability and costs involved in the litigation.

To prevent delay and excessive costs in enforcement, an effective mechanism was established to link up the CCPIT/CCOIC mediation regime with the CIETAC arbitration regime to allow a settlement agreement to be transformed into an arbitral award, which is directly enforceable. This mechanism is entrenched in both the Mediation Rules and the CIETAC Rules. ${ }^{545}$ The parties have the option to insert an arbitration clause in the settlement agreement resulting from mediation by the Mediation Centre. When a settlement agreement is entered into, any of the parties may apply to CIETAC for arbitration. CIETAC then appoints a sole arbitrator to examine the case on the basis of documents only. As Hilmer noted, the sole arbitrator may issue a consent award following the terms of the settlement agreement and 'the arbitration fees may be reduced in consideration of the quantity of the work involved and the actual expenses incurred by CIETAC'. ${ }^{546}$ The consent award is enforceable like any other awards.

Noting the difficulties of enforcement of a mediated settlement agreement, the SPC issued the Several Opinions of the Supreme People's Court on Establishing a Sound Conflict and Dispute Resolution Mechanism that Connects Litigation and Nonlitigation (SPC 2009 Opinion) to expedite the process. ${ }^{547}$ For a mediated settlement agreement that involves only a monetary payment, the parties may secure enforcement through notarization or by applying to the basic people's court having jurisdiction for a payment order. ${ }^{548}$ For more complex settlement agreements (involving obligations other than monetary payment), the SPC 2009 Opinion introduces a standardized and expedited judicial confirmation procedure. Under such a procedure, the parties shall jointly apply to the court having jurisdiction and submit the mediated settlement agreement and a letter of commitment signed by both parties. ${ }^{549}$ The court shall apply by analogy the relevant provisions of the Code on summary procedure in confirming the settlement agreement. The case shall be handled by a single judge. Both parties shall appear before the court at the same time. The court will ask both parties face to face whether they understand the contents of the agreement, whether they accept the results thereof and allow the court to grant enforceability to the agreement through the judicial confirmation procedure. ${ }^{550}$ The court will decide, upon examination of the case, whether to confirm the agreement. A confirmed agreement is enforceable once it is served on both parties. ${ }^{551}$ There are situations where the court must refuse confirming an agreement. ${ }^{552}$

\subsubsection{Joint mediation centers}

Article 6 of the Mediation Rules allows the Mediation Centre to conduct mediation jointly with other dispute resolution institutions or accept the invitation by other

\footnotetext{
${ }^{545}$ Article 28 of the Mediation Rules.

Also see Article 47(10) of the CIETAC Rules.

${ }^{546}$ Hilmer 2009, p. 102-103.

${ }^{547}$ The 2009 SPC Opinion has been in force since 24 July 2009.

${ }^{548}$ Articles 12 and 13 of the 2009 SPC Opinion.

${ }^{549}$ Article 22 of the 2009 SPC Opinion.

${ }^{550}$ Article 23 of the 2009 SPC Opinion.

${ }^{551}$ Article 25 of the 2009 SPC Opinion.

${ }^{552}$ Article 24 of the 2009 SPC Opinion.
} 
institutions to mediate disputes jointly or solely. On such a basis, the Mediation Centre has set up a number of mediation centers with international counterparts (e.g. from Germany, the United States, the United Kingdom and Italy) with an objective to promote the resolution of foreign-related disputes through private mediation. ${ }^{553}$ Norton observed that joint mediation centres have been underutilized in China. The reason for this is 'not entirely clear'. 554

\subsubsection{Non-institutional commercial mediation}

Non-institutional commercial mediation refers to private commercial mediation conducted by an impartial third-party mediator outside the CCPIT/CCOIC regime. There is no comprehensive study or a repository of statistics on the subject of noninstitutional mediation. As with institutional mediation, parties that have entered into a settlement agreement by non-institutional mediation may rely on Article 40.1 of the CIETAC Rules (on the basis of an arbitration agreement) to secure a consent award.

\subsection{Court mediation and its impact on commercial disputes resolution involving foreign enterprises}

Foreign-related commercial disputes that made their way to the people's courts may be settled by court mediation. Court mediation is an integral part of contemporary Chinese civil procedure. ${ }^{555}$ Two basic principles underscore court mediation in China: legality and voluntariness (of the parties). ${ }^{556}$ Respecting voluntariness of the parties in court mediation is an observance of the principle of party disposition. It also promotes the enforcement of a mediated settlement. ${ }^{557}$ Unfortunately, voluntariness in court mediation is under siege as a result of a number of factors.

Court mediation may be conducted at various stages of a civil lawsuit (first instance proceedings, appeal or retrial). The procedural rules for court mediation are set out in the 2004 Civil Mediation Rules. The court may invite other entities (or individuals) that have a special relationship with the parties or are connected with the case to assist in court mediation. ${ }^{558}$ The parties as well as the presiding staff over the mediation may present a mediation proposal. ${ }^{559}$ When a settlement is reached through court mediation, the court shall draw up a written 'mediation statement'. A mediation statement shall clearly set out the claims of the action, the facts of the case, and the result of the mediation. The mediation statement shall then be signed by the judge and the court clerk, sealed by the court and served on both parties. Once the mediation statement is signed and exchanged by both parties, it becomes legally

\footnotetext{
${ }^{553}$ Norton 2007, p. 39.

Also see http://www.cpradr.org/Resources/ALLCPRArticles/tabid/265/ID/625/The-CPRCCPITMediation-Procedure-for-Disputes-Submitted-to-the-US-China-Business-Mediation-Center.aspx (last visited: 3 March 2015)

${ }_{554}^{55}$ Norton 2007, p. 40.

${ }_{555}^{5}$ Alexander 2009, p. 139.

${ }^{556}$ Article 9 of the Code. Also see Articles 93 and 96 of the Code.

${ }^{557}$ NPCSC Publication 2007, p. 155.

${ }^{558}$ Article 3 of the 2004 Civil Mediation Rules. Also see Article 95 of the Code.

${ }^{559}$ Article 8 of the 2004 Civil Mediation Rules.
} 
binding. ${ }^{560}$ If either party fails to perform the mediation statement, the other party can apply to the court to enforce the mediation statement. ${ }^{561}$

Court mediation generally includes two distinct procedures: pre-trial mediation and judicial conciliation. Pre-trial mediation takes place at the docketing stage and other pre-hearing procedural stages. It is usually conducted by a judge or judicial officer. ${ }^{562}$ The judge conducting the mediation must be different from the trial judge. ${ }^{563}$ Judicial conciliation takes place after the case is transferred from the docketing court to the trial court. In judicial conciliation, the trial judge acts as the conciliator. If conciliation failed, the same judge will continue with the adjudication of the case. This practice is likely to threaten the without prejudice nature of the conciliation process (particularly given the judge is allowed to meet ex parte with parties) ${ }^{564}$ and the judge's impartiality in the adjudication that follows. Judicial conciliation may occur at the closing phase of the trial right before the rendering of a judgment so long as parties consent to conciliation. ${ }^{565}$

After a decline in the court mediation settlement rate in the $1990 \mathrm{~s}$, court mediation has re-emerged as the preferred dispute resolution tool of the people's courts since 2002. There are strong policy reasons behind this. ${ }^{566}$ The judiciary's emphasis on court mediation has budgetary and caseload management reasons. Peerenboom and He observed that the SPC and the Ministry of Justice were concerned that the proliferation of civil appeals would overburden the courts and add insurmountable cost on China's judicial system. ${ }^{567}$ Another reason for the judicial preference for mediation, as Peerenboom and Scanlon noted, is that judges 'are assessed, in part, on how many of their judgements are overturned on appeal'. ${ }^{568}$ Unlike judgments, meditation agreements are neither subject to appeal (although parties are allowed to challenge the agreement on narrow grounds of coercion or violation of the law) nor citizens petition (xinfang). As a result of the policy and judicial bias in favour of court mediation, parties of a commercial dispute may be forced to mediate their case and become 'victims' of a compelled settlement. ${ }^{569}$ When a party enters into a settlement against its will, it is more likely that it will not honour the settlement agreement. This leads to enforcement problems.

It will be fallacious to conclude that court mediation of commercial disputes in China has been successful simply looking at the court mediation settlement rate. If mediated settlements are frequently subject to mandatory court enforcement, the necessary conclusion must be that the mediation in the first place was not effective. ${ }^{570}$ The enforcement of settlement agreements reached by court mediation has been increasingly problematic. ${ }^{571}$ While the court mediation settlement rate has arisen

\footnotetext{
${ }^{560}$ Article 97 of the Code.

${ }^{561}$ Article 13 of the 2004 Civil Mediation Rules.

${ }^{562}$ Also see Article 15 of the 2009 SPC Opinion.

${ }^{563}$ Article 16 of the 2009 SPC Opinion.

${ }^{564}$ Article 7 of the 2004 Civil Mediation Rules.

${ }^{565}$ Article 1 of the 2004 Civil Mediation Rules.

${ }^{566}$ Article 1 of the 2010 SPC Notice.

${ }^{567}$ Peerenboom \& He 2009, p. 26.

${ }^{568}$ Peerenboom \& Scanlon 2005, p. 40.

${ }^{569}$ Wang 2009, p. 71-73.

${ }^{570}$ Pan \& Liu 2010, p. 75.

${ }^{571}$ Peerenboom \& He 2009, p. 25-26.
} 
during the period between 2002 and 2009, mandatory court enforcement rate of the same period also skyrocketed. ${ }^{572}$ This suggests that a considerable number of mediated settlements did not conclusively resolve disputes and parties had to resort to the court for enforcement. The situation is particularly serious in basic-level people's courts. ${ }^{573}$

Court mediation has its merits. ${ }^{574}$ It may expedite the resolution of commercial disputes and save costs. It may also bring about final resolution of the dispute (as a settlement cannot be appealed). But, as Wang warned, court mediation must not be overemphasised. ${ }^{575}$ Overemphasis on court mediation will result in the deterioration of the adjudicatory function of the court (especially in fact-finding) given the focus has been shifted from the enforcement of rights to pure dispute resolution.

\subsection{Med-Arb: Mediation in CIETAC Arbitration}

Whether the arbitral tribunal should be allowed to mediate during the course of arbitration has attracted international debate. ${ }^{576}$ Both the CIETAC Rules and the Arbitration Law allowed the arbitral tribunal to also act as the mediator in the course of arbitration. ${ }^{577}$ This mediation procedure is known as 'med-arb'. Med-arb can either be invoked when both parties have the desire for mediation or if one party so desires and the other party agrees when approached by the arbitral tribunal. The arbitral tribunal may mediate a case in the manner it considers appropriate. The tribunal shall terminate the mediation and resume the arbitration proceedings if one of the parties requests a termination of mediation or if the arbitral tribunal believes that further efforts to mediate will be futile. ${ }^{578}$ Where mediation fails, any opinion, view or statement and any proposal or proposition expressing acceptance or opposition by either party or by the tribunal in the mediation process must not be invoked as grounds for any claim, defence or counterclaim in the subsequent arbitration or litigation proceedings. ${ }^{579}$ Cao observed that mediation typically 'takes place after the parties' arguments and the examination of evidence in an oral hearing'. The tribunal will proceed to mediation with the parties' consent 'when it perceives a possibility for settlement'. ${ }^{580}$ Cao further observed that the mediation techniques used in med-arb include the 'face to face' approach (where mediation is conducted in the presence of all parties) and the 'back to back' approach (where the mediator caucuses with the parties separately). ${ }^{581}$ If a settlement is reached through mediation by the arbitral tribunal, the parties shall sign a written settlement agreement. Unless otherwise agreed by the parties, the arbitral tribunal will close the case and render an award on the terms set out in the settlement agreement. A settlement agreement reached by the parties themselves during the course of med-arb without the involvement of the

\footnotetext{
${ }^{572}$ Pan \& Liu 2010, p. 75.

${ }^{573}$ Pan \& Liu 2010, p. 76.

${ }^{574}$ Wang 2009, p. 69-71.

${ }^{575}$ Wang 2009, p. 72.

${ }^{576}$ Cao 2006, p. 89.

577 Article 47 of the CIETAC Rules and Article 51 of the Arbitration Law.

${ }^{578}$ Articles 47(3) of the CIETAC Rules.

${ }^{579}$ Article 47(9) of the CIETAC Rules. Also see Zimmerman 2010, p. 967.

${ }^{580}$ Cao 2006, p. 90.

${ }^{581}$ Cao 2006, p. 90.
} 
arbitral tribunal is deemed to be a settlement reached through the mediation by the tribunal. ${ }^{582}$

According to Wang, 'three fundamental principles' underscore med-arb in CIETAC arbitration proceedings. First, mediation is "an option for the parties and not a required mandatory procedure of arbitration". ${ }^{583}$ Second, party autonomy must be respected. On a substantive level, any settlement must be reached on the basis of 'the absolute free will of the parties'. On a procedural level, the parties have the absolute power to determine whether to initiate or terminate the mediation process. ${ }^{584}$ Third, following a core principle in court mediation, ${ }^{585}$ CIETAC med-arb should be conducted with the objective of distinguishing between right and wrong based on clear facts. ${ }^{586}$

While the principle of party autonomy is paramount, the arbitral tribunal is given powers to facilitate a compromise (including the power to propose the terms for settlement). The arbitral tribunal must be very careful in exercising these powers and avoid the appearance of bias. For instance, if there is a risk that the tribunal is favouring one party over another in presenting a settlement proposal, the court is likely to set aside the award on the basis that the arbitration process is tainted by apparent bias. ${ }^{587}$ In practice, Peerenboom and Scanlon observed that 'arbitrators may be inclined to push mediation to avoid having to decide a case where the facts or law are unclear, to save time and effort, [or] to reduce the potential for problems at the enforcement phase'. They further noted that some foreign parties have 'reportedly felt pressured to mediate and accept a settlement'. ${ }^{588}$ Foreign enterprises are also concerned that arbitrators may misuse confidential information obtained during caucusing that they are otherwise not privy to in the course of the usual arbitration hearing. ${ }^{589}$

\subsection{Chapter Conclusion}

Apart from saving costs, time and business relationships, mediation has a unique advantage in China. Enforcement of arbitral awards and court judgments is particularly difficult in China. Parties are more likely to comply with a voluntary settlement agreement (reached through mediation) than an award or judgment. ${ }^{590}$ However, this advantage can only be enjoyed if the mediation process is based on the voluntary deliberations of the parties free from external interference. Institutional commercial mediation upholds international standards. Mediators are professional and impartial. It allows parties flexibility in choosing the procedures for mediation. Medarb conducted by CIETAC and leading local arbitration commissions is generally in line with international practice. Court mediation remains particularly problematic,

\footnotetext{
${ }^{582}$ Article 47 of the CIETAC Rules.

${ }^{583}$ Wang, see $n 53$ above, p. 441.

${ }^{584}$ Cao, see $\mathrm{n} 40$ above, p. 90.

${ }^{585}$ Article 93 of the Civil Procedure Law.

${ }^{586}$ Wang, see n 53 above, p. 441.

${ }^{587}$ See Gao Haiyan v Keeneye Holdings Ltd (HCCT 41/2010 (12 April 2011)).

${ }^{588}$ Peerenboom \& Scanlon, see $\mathrm{n} 2$ above, p. 40.

${ }^{589}$ Ibid., p. 40.

${ }^{590}$ Ibid., p. 41.
} 
however, as voluntariness of the parties is under siege in an institutionalized settlement culture. Reforming court mediation in China is an absolute imperative. 


\section{Chapter 7:}

Fundamental Tenets of Contemporary Chinese Civil Justice:

Substantive Justice, Material Truth and the Chinese Judicial Mind-set 


\section{FUNDAMENTAL TENETS OF CONTEMPORARY CHINESE CIVIL JUSTICE: SUBSTANTIVE JUSTICE, MATERIAL TRUTH AND THE CHINESE JUDICIAL MIND-SET}

\subsection{Chapter Introduction: The underlying philosophy of contemporary Chinese civil adjudication}

Contrary to the modern emphasis on procedural justice (in common law jurisdictions and many of the continental European jurisdictions), the Chinese judiciary focuses on substantive justice while deliberately downplaying the importance of procedural formalism. ${ }^{591}$ The common Chinese judicial notion that an adjudicator must 'distinguish right from wrong' (分清是非), a notion embedded in court mediation as well, embodies this philosophy at work. While lip service is given to the importance of following procedural rules in adjudication (especially following a new wave of reforms since 2013 that sought to fortify the 'rule of law' in China), judges of the people's courts are much more interested in seeing the final resolution of a dispute where parties are satisfied with the outcome. The goal of 'anjie shiliao' (案结事了) (i.e. the case is closed and the dispute is [truly] resolved) remains an overriding objective in Chinese civil justice. ${ }^{592}$ Apart from cultural reasons, ${ }^{593}$ there are strong institutional reasons for the emphasis on substantive justice: the absence of finality in Chinese procedure means that judges' focus in adjudication is not the delivery of justice by defending the sanctity of procedure, but to reach a judgment where the losing party is least likely to re-open the case on appeal or by way of re-adjudication. Furthermore, judges are assessed on the basis of, among other parameters, their ability to avoid citizens petition (xinfang) and appellate reversal. The populist undertone is obvious: courts must do whatever it takes to help maintain social stability and public order. These are institutional defects that no single reform attempt could rectify.

Another key guiding concept in Chinese civil adjudication is that it is the duty of the judge to find the 'material truth' in every case. The fact-finding process is still in practice dominated by judges despite efforts in civil procedural rule-making that entrust parties with greater fact-finding responsibilities. A Chinese judge reserves the residual right to actively investigate into a factual matter. While Article 63 of the Civil Evidence Rules is said to have repealed the doctrine of factuality, ${ }^{594}$ the traditional preference for material truth and the retention of the judge's ex officio powers of investigation and evidence collection suggest that the doctrine of factuality still exerts considerable influence over contemporary civil adjudication in China.

In China, it is a statutory requirement that court mediation must be conducted on the basis of accurate fact-finding and a proper determination of liability (i.e. the notion of the need to 'distinguish right from wrong'). ${ }^{59}$ As such, a proper investigation on

\footnotetext{
${ }^{591}$ A basic-level court judge commented that Chinese judges are generally willing to sacrifice procedural justice if doing so could achieve substantive justice: Interview Ref: 2012/6.

${ }^{592}$ See empirical findings in Chapter 5 of this book on the notion of Anjie shiliao and its influence on civil adjudication.

${ }^{593}$ See Chapter 2 of this book for an overview of China's traditional legal culture regarding civil litigation.

${ }_{594}$ Zhang \& Zwier 2003, p. 451.

${ }^{595}$ Article 93 of the Code.
} 
Chinese court mediation must be premised on clear and comprehensive understanding of these two fundamental tenets in Chinese civil adjudicatory conduct.

This chapter critically reviews the first fundamental tenet (substantive justice) in the context of the appellate and re-adjudication systems and the second fundamental tenet (material truth) in the context of the recent developments in the Chinese civil factfinding regime (drawing comparative insights from Hong Kong civil litigation practice). At the final stage of the writing of this book (in early 2015), the SPC passed the Interpretation of the Supreme People's Court on the Application of the Civil Procedure Law of the People's Republic of China (2015 Interpretation) ${ }^{596}$. It remains to be seen how courts would implement the 2015 Interpretation. To the extent possible, the chapter takes into account changes made to China's civil procedure under the 2015 Interpretation.

\subsection{The Pre-eminence of Substantive Justice in Chinese Civil Adjudication: using civil appeals in China as illustration}

\subsubsection{An outline of the appellate procedures}

An appeal against a first instance judgment lies as of right to the second instance court. $^{597}$ An appeal must be lodged within 15 days from the date when the written judgment is served. ${ }^{598}$ A party may also appeal against a first instance ruling so long as the appeal is lodged within 10 days from the date when the written ruling is served. ${ }^{599}$ A 'judgment' is a determination on substantive issues of the lawsuit while a 'ruling' is a decision on procedural issues. ${ }^{600}$ The time limits for appeal are strict and no extension of time is allowed. ${ }^{601}$ Leave is not required to appeal against a judgment or ruling in Mainland China. This is contrasted with the position in Hong Kong where an appeal against an interlocutory judgment or order of the Court of First Instance must obtain leave. ${ }^{602}$

An appellant must submit a written 'notice of appeal' (shangsu zhuang). ${ }^{603}$ Among other things, ${ }^{604}$ the notice of appeal must include a 'request for appeal' (shangsu

\footnotetext{
${ }^{596}$ Judicial Interpretation (fashi) No. 5 [2015] (Effective since 4 February 2015).

${ }^{597}$ The second instance court (i.e. appellate court) is the court at the next higher level of the trial court. For instance, if the first instance judgment was rendered by an intermediate court within Province X, the appellate court is the High Court of Province X.

${ }^{598}$ Article 164 of the Code.

${ }^{599}$ Ibidem.
}

Given a ruling only concerns procedural matters, the time limit to appeal against a ruling is shorter than the time limit to appeal against a judgment: see NPCSC Publication 2007, p. 296.

${ }^{600}$ See Section 5 of Chapter 12 of the Code.

The content of a written judgment must include all the elements set out in Article 152 of the Code.

There are eleven types of rulings (including the catch-all category, 'other issues to be resolved by a ruling'), but only three types are appealable: (a) refusal to accept an action; (b) objection to jurisdiction; and (c) dismissal of an action: see Article 154 of the Code.

${ }^{601}$ A judgment or ruling that have not been appealed within the prescribed time limits will become 'legally effective': see Article 155 of the Code. A 'legally effective' judgment can be enforced. It is regarded as 'final' in the Chinese procedural sense. The time limit for appeal is imposed with procedural efficiency in mind: see NPCSC Publication 2007, p. 296.

${ }^{602}$ Section 14AA(1) of the High Court Ordinance reads, 'Except as provided by rules of court, no appeal lies to the Court of Appeal from an interlocutory judgment or order of the Court of First Instance in any civil cause or matter unless leave to appeal has been granted by the Court of First Instance or the Court of Appeal.'

${ }^{603}$ Article 165 of the Code. 
qingqiu $)^{605}$ and the 'grounds of appeal' (shangsu liyou). Regarding the 'request for appeal', the appellant must indicate whether he is seeking to set aside (chexiao) ${ }^{606}$ or reverse (gaipan) the first instance decision. Essentially, the request for appeal sets out the scope of the appeal as envisaged by the appellant. With regards the 'grounds of appeal', the appellant must indicate whether he is challenging the factual or legal findings of the first instance decision, or both. The appellant may raise new legal or factual issues (and submit new evidence) at the time of submitting the notice of appeal. ${ }^{607}$ The appellant may submit the notice of appeal either to the first instance court or to the appellate court (although the usual practice is to file the appeal with the first instance court). ${ }^{608}$ The first instance court has five days to deliver the notice of appeal to the respondent upon receiving the same. Upon receiving the notice of appeal, the respondent has 15 days within which to submit a written response (dabian zhuang). Failure to submit a written response would not prevent the appeal from going forward. ${ }^{609}$ The appellate court must review all the relevant facts and applicable law pertaining to the request for appeal. ${ }^{610}$ The appellate court must form a collegiate bench to adjudicate the case. ${ }^{611}$ After verifying the facts of the case, ${ }^{612}$ the collegiate bench shall decide whether it is necessary to hold a court hearing. ${ }^{613}$ If it is unnecessary, the collegiate bench will render a decision without a hearing. ${ }^{614}$ Under Article 37 of Some Provisions of the Supreme People's Court on Reforming the Civil

\footnotetext{
${ }^{604}$ Such as the names of the parties, the name of the first instance court, the docket number, and the cause of action: see Article 165 of the Code.

${ }^{605} \mathrm{~A}$ 'request for appeal' is sometimes translated as a 'claim of appeal'.

${ }^{606}$ Chexiao ('to set aside') is sometimes translated as 'to revoke'.

${ }^{607}$ NPCSC Publication 2012, p. 276-277.

${ }^{608}$ Article 166 of the Code.
}

If the notice of appeal is submitted to the appellate court, the appellate court must (within five days) transfer the notice of appeal to the first instance court, which will then handle procedural matters relating to the appeal, i.e. whether the time limit has expired and whether the notice of appeal has complied with the formalities. The option to submit the notice of appeal directly to the appellate court at least gives the appellant some comfort of impartiality. See NPCSC Publication 2012, p. 277-288.

${ }^{609}$ Article 167 of the Code. Upon receiving the notice of appeal, the written response, all relevant evidence and the case file, the first instance court must within five days forward the same to the appellate court.

${ }^{610}$ Article 168 of the Code. Under certain circumstances, the appellate court is not bound by the scope of the request for appeal in its review of the case: see Zhang \& Li 2012, p. 323.

${ }^{611}$ A collegiate bench consists of three judges. The presiding judge heads the bench, while the 'responsible judge' (chengban faguan) takes care of the administrative aspects of the case. Court mediation is usually conducted by the responsible judge (acting as the mediator).

${ }^{612}$ Under Article 169 of the Code, the collegiate bench may verify the case by consulting the first instance case files, making its own investigations and questioning the parties. Nothing in the Code restricts the scope of the court's investigation in the verification process. So arguably, the court may probe into matters beyond the scope of the request for appeal even at this verification stage.

${ }^{613}$ Where no new facts, evidence or grounds are submitted by the parties, and the collegiate bench takes the view that no court hearing is necessary, the appeal may proceed without a hearing: see Article 169 of the Code. The decision that the appeal should proceed without a hearing must be unanimous: see Fu 2005, p. 44.

In some translations of Article 169 of the Code, the word 'trial' is used to describe an appellate hearing (kaiting shenli). However, 'court hearing' is a better translation, as it avoids any possible confusion (a trial commonly refers to the first instance hearing).

${ }^{614}$ If the appeal proceeded without a court hearing, the collegiate bench would make a decision on the basis of a paper review and its own investigations (the bench has the benefit of questioning the parties and making its own investigations under Article 169 of the Code). It is therefore argued that an appellate review without a hearing is not a mere paper review as the court may supplement its decision with evidence gathered from its own investigations: see Zhang \& Li 2012, p. 324. 
and Economic Adjudication Method (1998 Provisions), ${ }^{615}$ a court hearing is required if the collegiate bench believes that there is a need to re-examine the evidence on which the first instance fact-finding was based, or if new evidence has been presented on appeal. The collegiate bench may render a judgment or ruling without a hearing under four circumstances: (a) where the first instance ruling concerns a refusal to accept an action, an objection to jurisdiction, or a dismissal of an action, (b) where the request for appeal is clearly unsustainable, (c) where there is a legal error in the first instance judgment (but no factual error); or (d) where the first instance judgment is tainted by procedural violation (and should be remitted to the original court for a new trial). ${ }^{616}$

There are five possible outcomes in a civil appeal: ${ }^{617}$

(1) dismissing the appeal (i.e. affirming the first instance judgment or ruling) on the basis that the first instance judgment or ruling applied the correct law and was based on 'a clear finding of facts' (rending shishi qingchu) ${ }^{618}$ (Outcome (1)); ${ }^{619}$

(2) overruling (i.e. reversing, modifying or setting aside) ${ }^{620}$ the first instance judgment or ruling on the basis that the decision is tainted by factual or legal error (Outcome (2)); ${ }^{621}$

(3) (i) where the first instance judgment is based on 'an unclear finding of basic facts' (rending jiben shishi buqing), ${ }^{622}$ the appellate court may set aside the judgment and

${ }^{615}$ In Chinese: Zuigao Renmin Fayuan Guanyu Minshi Jingji Shenpan Fangshi Gaige Wenti Ruogan Guiding. Effective since 11 July 1998 (Judicial Interpretation (fashi) No. 14 [1998]).

${ }^{616}$ Article 333 of the 2015 Interpretation.

${ }^{617}$ Article 170 of the Code.

${ }^{618}$ The Code is silent on what 'a clear finding of facts' means. Presumably, based on a reading of the whole Article 170 of the Code, an appellate decision that there was a clear finding of facts at first instance implies that the first instance decision (a) contains no factual error within the meaning of Article 170(2); and (b) was based on a clear finding of 'basic facts' (as well as non-basic facts) within the meaning of Article 170(3). Ultimately, it is a judgment call for the appellate court to decide whether the facts established at first instance are accurate and sufficiently support the decision rendered.

${ }^{619}$ Article 170(1) of the Code.

${ }^{620}$ Reversing, modifying and setting aside a first instance decision (or parts of the decision) are different levels or methods of overruling the first instance decision (or parts of the decision). 'Reversing a decision' (gaipan) means the appellate court replaces the first instance decision with its own decision. 'Modifying a decision' (biangeng) means the appellate court makes changes to the first instance decision. 'Setting aside a decision' (chexiao) means the appellate court revokes the first instance decision (i.e. the decision would lose its legal effect). These methods of overruling first instance decisions are not specifically defined in the Code. The above analysis is based only on the author's review of sample second instance judgments.

${ }^{621}$ Article 170(2) of the Code applies when the decision has been tainted by factual error, legal error or both: see NPCSC Publication 2012, p. 283. If the decision is only tainted by legal error, the appellate court will only rectify the legal error without disturbing the fact-finding determinations of the first instance court: see NPCSC Publication 2007, p. 308.

${ }^{622}$ Note that Outcome (3)(i) refers to an unclear finding of 'basic facts'. A 'basic fact' is not defined in the Code. According to an authoritative annotation of the Code, a basic fact is a material fact that may determine the outcome of the case: see NPCSC Publication 2012, p. 283-284. 
remit the case to the first instance court for a new trial (Outcome (3)(i)); ${ }^{623}$ or (ii) where the first instance judgment is based on 'an unclear finding of (non-basic) facts', ${ }^{624}$ the appellate court should reverse the judgment after ascertaining the facts on its own (Outcome (3)(ii))(together Outcome (3)); ${ }^{625}$

(4) setting aside the first instance judgment and remitting the case to the first instance court for a new trial on the basis of serious procedural violation (such as unlawfully entering a default judgment or omission of a party in the first instance judgment (Outcome (4)); ${ }^{626}$ or

(5) setting aside the first instance judgment and dismissing the action if the appellate court finds that the court should not have accepted the case in the first place (Outcome (5)). ${ }^{627}$

An appeal against a ruling would only result in Outcomes (1) and (2), while an appeal against a judgment may result in Outcomes (1) to (5). ${ }^{628}$

In relation to Outcome (3)(ii), where there is 'an unclear finding of (non-basic) facts', the court should ascertain the facts on its own and reverse the first instance judgment (without the need to remit the case to the original court). It is only where the first instance judgment is based on an unclear finding of 'basic facts' (Outcome (3)(i)) that

\footnotetext{
${ }^{623}$ A remittal of a case by the appellate court to the first instance court for a 'new trial' (chongshen) is distinguished from the re-opening of a final decision for 're-adjudication' (zaishen) (under the adjudication supervision procedure).

${ }^{624}$ The Code did not specify that Outcome 3(ii) is in relation to 'non-basic' facts. But such an inference can be drawn by reading Article 170(3) in its entirety. The provision essentially provides two ways for handling situations of unclear fact-finding: if the facts involved are basic facts, then given the severity of the factual irregularity, the case should be remitted to the original court for a new trial; but if the facts involved are not basic facts, the factual irregularity is less severe and therefore the appellate court should (for procedural efficiency reason) handle the matter on its own. See NPCSC Publication 2012, p. 283-284,

${ }^{625}$ Article 170(3) of the Code.

${ }^{626}$ Article 170(4) of the Code. This provision has been revised in the 2012 Amendment Version of the Code. In the 2007 Amendment Version of the Code, any procedural violation that may affect the correctness of the outcome is arguably a ground for setting aside the first instance decision. In the 2012 Amendment Version of the Code, only serious procedural violation (the new provision also expressly provided examples of serious procedural violations: i.e. omission of a party in the first instance judgment or a default judgment being rendered in violation of the law) could constitute a ground for setting aside a first instance decision. The revision avoids the situation where a judgment is set aside for technical procedural violations. A list of serious procedural violations is provided in an SPC judicial interpretation: see Article 325 of the 2015 Interpretation.

${ }^{627}$ Article 330 of the 2015 Interpretation; also see Zhang \& Li 2012, p. 326. Where the appellate court is of the view that a case should not have been accepted by the people's court at all, it may dismiss the action altogether when setting aside the first instance decision. Normally, a decision to dismiss an action is made by the first instance court by way of a ruling. The court may dismiss an action if the case is found (in the process of adjudication) to fall outside the accepted scope of civil proceedings: see NPCSC Publication 2012, p. 253. Article 330 of the 2015 Interpretation gives a special power to the appellate court to dismiss an action in appellate proceedings.

${ }^{628}$ In the 2007 Amendment Version of the Code, the possible outcomes of an appeal against a ruling are not specified. Judges handling appeals against rulings need to infer from the old provision that refers only to judgments. The 2012 Amendment Version rectified this problem by making express provision for the possible outcomes of an appeal against a ruling in Article 170(1) and Article 170(2) of the Code: see NPCSC Publication 2012, p. 284. A 'ruling' in China, by nature, is similar to a 'Beschluß' under German procedure.
} 
the appellate court should remit the case to the original court for a new trial. This arrangement is designed with procedural efficiency in mind. ${ }^{629}$

Confusion may arise as the Code fails to define 'factual error' (see Outcome (2)) and 'an unclear finding of facts' (see Outcome (3)) and explain the differences between the two concepts. 'Factual error' and 'an unclear finding of facts' are two different types of irregularities in fact-finding. A 'factual error' arises when facts established are based on false or fabricated evidence, rendering the facts inaccurate. 'An unclear finding of facts' refers primarily to the situation where the facts established are based on insufficient evidence (and the judgment is rendered prematurely without thorough investigation). ${ }^{630}$

A new trial by remittal (see Outcomes (3)(i) and (4)) follows the procedural rules of first instance proceedings and a decision rendered in the new trial is a first instance decision, ${ }^{631}$ which may be appealed under the same appellate procedures. ${ }^{632}$ In the past, endless rounds of remittals have made civil appeal in China unpredictable and caused undue delay. The phenomenon was consistent with the socialist characteristic of civil procedure. ${ }^{633}$ This problem has been rectified in the 2012 Amendment Version of the Code by limiting a case to one remittal only in the context of civil appeal. $^{634}$

The appellate court renders a ruling to determine an appeal against a first instance ruling. ${ }^{635}$ It is unnecessary for the appellate court to hear the case as a ruling concerns only procedural matters. ${ }^{636}$

Under the Chinese appellate system, before a decision is rendered, an appellant may only withdraw his appeal with the approval of the court. ${ }^{637}$ The rationale behind this rule is that the court must be able to step in to protect the interests of third parties (as well as state interest and public interest) and uphold substantive justice (e.g. where

\footnotetext{
${ }^{629}$ NPCSC Publication 2012, p. 283-284.

${ }^{630}$ NPCSC Publication 2007, p. 309.

Based on a review of a number of sample appellate cases reported in the Gazette of the Supreme People's Court of the People's Republic of China [Zuigao Renmin Fayuan Gongbao] and the old provision of the Code that dealt with factual issues in an appeal (Article 153(3) of the 2007 Amendment Version of the Code), 'factual error' simply means an inaccurate finding of facts; while 'an unclear finding of facts' generally means that the fact-finding of the first instance judgment is either incomplete, inconsistent (or contradictory), contains a factual error, or the supporting evidence is inconclusive (or any combination of the above).

${ }^{631}$ The appellate court renders a 'ruling' (i.e. a procedural decision) to set aside a first instance judgment and remitting the case for a new trial. It is a demonstration of the powers of a higher court to supervise the lower court. See NPCSC Publication 2007, p. 310.

${ }^{632}$ Article 170 of the Code.

${ }^{633}$ Uzelac 2010, p. 390.

${ }^{634}$ Article 170 of the Code. In fact, Article 170 incorporated an earlier judicial interpretation restricting the number of remittals to one: see Article 1, Provisions of the Supreme People's Court on the Relevant Issues of Remanding for a New Trial and Ordering for a Retrial of a Civil Case [Zuigao Renmin Fayuan Guanyu Renmin Fayuan Dui Minshi Anjian Fahui Chongshen He Zhiling Zaishen Youguan Wenti De Guiding] (2002 Provisions), effective since 15 August 2002 (Judicial Interpretation (fashi) No. 24 [2002]).

${ }^{635}$ Article 171 of the Code.

${ }^{636}$ No court hearing is necessary for appeals against rulings: see NPCSC Publication 2012, p. 286.

${ }^{637}$ Article 173 of the Code.
} 
there is a serious error in the first instance decision) by disallowing a withdrawal if these other interests are at stake. ${ }^{638}$

Chapter 14 of the Code deals exclusively with the appellate procedures but it only covers parts of an appeal. It must be read in conjunction with Chapter 12 of the Code (Ordinary Procedure at First Instance), which deals with, for instance, the conduct of court hearings. ${ }^{639}$

The time limit for rendering an appellate judgment is three months from the docketing of the case. This is contrasted with the much shorter time limit of 30 days for the rendering of an appellate ruling. ${ }^{640}$ The reason for the difference is that a judgment concerns the disposition of substantive rights while a ruling is purely procedural in nature.

It is not necessary to stay the enforcement of the first instance decision on appeal, as an appeal lodged within the prescribed time limit means that the first instance decision would not become a legally effective decision. Only legally effective decisions can be enforced. ${ }^{641}$

A second instance decision is said to be 'final'. ${ }^{642}$ However, as will be discussed, the Chinese concept of 'finality' is nebulous and shaky. A second instance decision may be re-opened under the adjudication supervision procedure.

\subsubsection{The nature of Chinese appellate review - real appeal or de novo hearing?}

$\mathrm{Fu}$ observed that the Chinese appellate review system has five defining characteristics: ${ }^{643}(1)$ the court reviews both legal and factual findings of the first instance court; (2) the court may review matters outside the scope of the appellant's request for appeal; ${ }^{644}$ (3) the court may entertain new evidence and new points of law; (4) appellate review is conducted by way of a court hearing. ${ }^{645}$ and (5) the court may overrule the first instance decision or remit the case to the first instance court for a new trial. ${ }^{646}$

\footnotetext{
${ }^{638}$ NPCSC Publication 2012, p. 288. It is arguable, in line with the principle of party disposition, that the court should not retain the substantive power to disallow a withdrawal of an appeal (particularly when there is no cross appeal). But it is unlikely that the Chinese court would give up this power.

${ }^{639}$ Article 174 of the Code.

${ }^{640}$ Article 176 of the Code.

The time limit may be extended under special circumstances with the approval of the court president.

${ }^{641}$ Art 236 of the Code.

${ }^{642}$ Article 175 of the Code; Article 12 of the Organic Law.

${ }^{643} \mathrm{Fu} 2005$, p. 40-41. This section discusses characteristics (1)-(3). Characteristics (4) and (5) are explained above.

${ }^{644}$ The court's power to review matters outside the scope of the request for appeal is subject to certain restrictions: see Article 35 of the 1998 Provisions.

${ }^{645}$ Records of the first instance proceedings should still be the basis of the review, but should not limit the scope of the review. In principle, the norm is still for the appellate court to hold a hearing. In practice, however, judges burdened by heavy caseloads are more inclined to do away with hearings (under Article 169 of the Code): see Fu 2005, p. 40-41.

${ }^{646} \mathrm{Fu} 2005$, p. 40-41.
} 
The Chinese appellate court has the power to review any finding of the first instance court (both legal and factual). ${ }^{647}$ Article 168 of the Code reads, 'A people's court of second instance shall review the relevant facts and the applicable law pertaining to the request for appeal'. The Chinese appellate court has unrestricted powers to examine the factual findings of the first instance court that is within the scope of the request for appeal. ${ }^{648}$ In theory, such examination involves a qualitative assessment of the accuracy and adequacy of the lower court's factual findings. If the request for appeal encompasses every factual finding of the first instance decision, then it is the appellate court's duty to review every factual aspect of the case. ${ }^{649}$ In practice, the review goes beyond simply reviewing the overall merits of first instance fact-finding and rectifying obvious errors. It is often a repetition of the fact-finding exercise as if the appellate court were a trial court. ${ }^{650}$ This is contrasted with the common law position where the appellate court gives much more deference to the factual findings of the lower court and will only disturb a primary finding of fact if there is a plain error. ${ }^{651}$ This deference in common law appellate review is partly due to the fact that the appellate court 'does not enjoy the advantages enjoyed by the trial judge who received the evidence at first hand' ${ }^{652}$ The Chinese appellate court is not subject to this kind of restriction. Even at the stage of verifying the case to determine whether a court hearing is necessary, the Chinese appellate court may conduct its own investigations and question parties to obtain first hand evidence on the case. ${ }^{653}$ The power of the Chinese appellate court to repeat the fact-finding exercise is consistent with the notion that substantive justice has preeminence in Chinese civil adjudication.

\subsubsection{2.}

\section{Power of the appellate court to review beyond the remit of the request for appeal}

With regards to the scope of an appellate review, Article 168 of the Code seems to suggest that the appellate court is limited to review only legal and factual matters set out in the appellant's 'request for appeal'. Article 168 of the Code must be read in conjunction with Article 323 of the 2015 Interpretation, which provides that the appellate court may go beyond the scope of the request for appeal if the first instance judgment violates prohibitive regulations (of the law), harms public interest or

\footnotetext{
${ }^{647}$ Ibidem.

${ }^{648}$ As argued below, the appellate court is at liberty to move beyond the scope of the appellant's 'request for appeal' under certain circumstances.

${ }^{649}$ NPCSC Publication 2012, p. 279.

${ }^{650}$ Zhang \& Li 2012, p. 320.

${ }^{651}$ Consider Wilkinson, Cheung \& Booth 2011, p. 1061-1063:

'The question for the Court of Appeal in an appeal where it is asked to disturb a primary finding of fact is whether, even though it does not enjoy the advantages enjoyed by the trial judge who received the evidence at first hand, it is nevertheless satisfied that his conclusion on the facts is plainly wrong. The Court of Appeal should intervene if so satisfied and should defer to the trial judge's conclusion even if in some doubt as to its correctness.'

${ }^{652}$ Ibidem.

${ }^{653}$ Under Article 169 of the Code, the appellate court may decide whether a court hearing is necessary after verifying the facts of the case by consulting the first instance case files, making necessary investigations, and questioning the parties. If the court believes that it is not necessary to have a hearing, it may make a judgment or ruling without a hearing. For further discussion of the appellate court making a judgment or ruling without a hearing, see Liu 1999, p. 49.
} 
violates the interests (and rights) of another party. This echoes Article 35 of the 1998 Provisions.

However, what constitutes a violation of the interests (and rights) of another party is not defined in the 2015 Interpretation, the 1998 Provisions or any other normative instrument. Presumably, 'another party' encompasses the respondent in the appeal and third parties, and a broad meaning would be given to 'interests' (and rights).

While Article 323 of the 2015 Interpretation is deliberately made to be more restrictive than Article 180 of the Opinions of the Supreme People's Court on Some Issues Concerning the Application of the Civil Procedure Law of the People's Republic of China ${ }^{654}$ in limiting the power of the appellate court to review matters beyond the scope of a request for appeal, in practice, the appellate court may not see itself bound by Article 323 of the 2015 Interpretation when there is an obvious error in the first instance judgment that has not been highlighted in the request for appeal. In any event, as long as overall substantive justice is served, courts are likely to interpret Article 323 of the 2015 Interpretation flexibly so as to allow itself to venture beyond the scope of the request for appeal. Hence, by appealing, an appellant may end up in a worse position than before if the appellate court decides to review beyond the request for appeal to rectify an injustice in the first instance judgment. ${ }^{655}$ Such a result is clearly undesirable from the perspective of procedural justice and constitutes a blatant violation of the principle of party disposition. ${ }^{656}$ From a policy perspective, it is argued that the court needs to balance the right of the appellant to limit the scope of the appeal against the imperative to ensure that the first instance judgment does not harm another party's interests (or public interest) as a result of any judicial error or misfeasance. It is further argued that this is only possible if the court has the discretion to extend the scope of review beyond the request for appeal. ${ }^{657}$

\subsubsection{3. $\quad$ Entertaining new evidence at the appellate level}

In the past, the appellate court could entertain new evidence without any restrictions. Under Article 139 of the Code, parties could present new evidence during trial (first instance hearing) or on appeal (second instance hearing). This rule has been criticised for causing undue delay. ${ }^{658}$ This position has changed with the introduction of Some Provisions of the Supreme People's Court on Evidence in Civil Procedure (Civil Evidence Rules). ${ }^{659}$ Article 139 of the Code now has to be viewed in conjunction with Articles 40 to 45 of the Civil Evidence Rules, i.e. that the parties' right to present

\footnotetext{
${ }^{654}$ Judicial Interpretation No. 22 [1992] (effective from 14 July 1992 to 3 February 2015; repealed by the 2015 Interpretation on 4 February 2015).

${ }^{655}$ Zhang \& Li 2012, p. 320.

${ }^{656}$ Zhang \& Li 2012, p. 320-321.

${ }^{657}$ NPCSC Publication 2012, p. 279-280.

${ }^{658}$ Zhang and Zwier noted, 'It is very common that a party refuses to produce or exchange evidence before the trial, but presents the evidence to the court during the trial by surprise, or even on appeal. Even where a party has presented no evidence during the trial, he could present to the appellate court “new” evidence in his favour.' See Zhang \& Zwier 2003, p. 430-431; also see Uzelac 2010, p. 392.

${ }^{659}$ In Chinese: Zuigao Renmin Fayuan Guanyu Minshi Susong Zhengju de Ruogan Guiding. Effective since 1 April 2002 (Judicial Interpretation (fashi) No. 33 [2001]). Note that there are some discrepancies in the English translation of the rules. It is sometimes translated as Specific Provisions on Evidence in Civil Actions of the Supreme People's Court or Several Rules of Evidence Concerning Civil Litigation. The Civil Evidence Rules consist of 83 articles and remain the most comprehensive legal instrument regulating civil fact-finding to date.
} 
new evidence is not unrestricted. ${ }^{660}$ In the case of Guo Chun Xuan v Liu Zong Lai ${ }^{661}$ (a first instance decision), the plaintiff applied to the Zhengzhou City Intermediate Court to produce supplemental evidence. The court rejected the application on the basis that the supplemental evidence was not 'new evidence', as it is already in 'objective existence' (and in the custody of the plaintiff) during the time period for producing evidence. ${ }^{662}$ Similarly, in a second instance decision, the appellate court rejected the appellant's application to adduce a fresh piece of evidence on two grounds: (a) the evidence was already in existence before the first instance hearing (hence it is not 'new evidence' within the meaning of Article 41 of the Civil Evidence Rules); and (b) unless it is new evidence, the appellate court must not accept any evidence after the expiration of the time-limit for producing evidence (see Article 43 of the Civil Evidence Rules). ${ }^{63}$ The 'objective existence' test ${ }^{664}$ is contrasted with the more sophisticated test in Hong Kong for adducing new evidence on appeal pursuant to the principles in Ladd v Marshall. ${ }^{665}$

\subsubsection{Entertaining new points of law at the appellate level}

There seems to be no restriction on raising new points of law on appeal. ${ }^{666}$ This is contrasted with the position under common law where the introduction of new legal issues on appeal is the exception rather than the norm. ${ }^{667}$

The Chinese appellate court's power to review beyond the request for appeal extends to legal issues (i.e. not limited to factual issues) so long as it is consistent with Article 323 of the 2015 Interpretation. Hence, even where the appellant raised no new points

\footnotetext{
660 'New evidence' is clearly defined. In relation to first instance proceedings, Article 41 of the Civil Evidence Rules states: 'New evidence of first instance proceedings include: evidence newly discovered by the parties concerned after the expiration of the time period for producing evidence in first instance proceedings; evidence which the parties concerned cannot provide during the time period for producing evidence due to objective reasons and still cannot provide during the extended time period approved by the People's court.'

In relation to second instance proceedings, 'new evidence' refers to any evidence discovered after the completion of the first instance hearing, or evidence collected by the appellate court pursuant to an application from the party (where the same application was not approved by the first instance court under Article 64 of the Code).

${ }^{661}$ [(2008) zhengmin sanchu zi (No. 99)] (reported civil judgment of the Zhengzhou Intermediate People's Court, Henan Province).

${ }^{662}$ Ibidem.

${ }^{663}$ Xin Lian Hua $v$ Bank of Tianjin (Xingang Office of the Tanggu Branch) (second instance civil judgment of the Tianjin Second Intermediate People's Court. Delivered on 23 February 2004; reported in the Gazette of the Supreme People's Court of the People's Republic of China).

${ }^{664}$ Article X of the Notice of the Supreme People's Court on Applying the Provisions on Time Limits for Producing Evidence of the Some Provisions on Evidence in Civil Procedures. In Chinese: Zuigao Renmin Fayuan Guanyu Shiyong Guanyu Minshi Susong Zhengju de Ruogan Guiding Zhong Youguan Juzheng Shixian de Tongzhi. Effective since 11 December 2008 (Judicial Interpretation (fafa) No. 42 [2008])

${ }^{665}$ [1954] 1 WLR 1489, 1491 (per Denning L.J. (as he then was)):

'To justify the reception of fresh evidence or a new trial, three conditions must be fulfilled: first, it must be shown that the evidence could not have been obtained with reasonable diligence for use at the trial; secondly, the evidence must be such that, if given, it would probably have an important influence on the result of the case, though it need not be decisive; thirdly, the evidence must be such as is presumably to be believed, or in other words, it must be apparently credible, though it need not be incontrovertible.'

${ }^{666}$ Liu 1999, p. 50

${ }^{667}$ For instance, for the position in Hong Kong, see Flywin Co Ltd v Associates [2002] 2 HKLRD 485, 495.
} 
of law, the appellate court could arguably examine legal issues that have not been considered at first instance if so doing could help rectify irregularities contemplated under Article 323 of the 2015 Interpretation.

\subsubsection{A complete review system with Chinese characteristics}

One may argue that China has moved from a 'complete review' system to a 'limited review' system as Article 168 of the Code specifically provides that appellate review should be within the scope of the 'request for appeal'. ${ }^{668}$ However, the defining characteristics of the Chinese appellate review system ${ }^{669}$ suggest that a 'complete review' system is still in place. The appellate court has almost unlimited authority (save for some minor restrictions) to redefine the remit of the appeal, entertain new evidence and legal issues, actively probe into the merits of the first instance court's factual and legal findings, and even repeat the whole fact-finding exercise altogether. Liu attribute this practice to the Chinese judicial notion of 'base the decision on facts and take the law as the criterion (ye shenshi wei genju yi falu wei zhunsheng)', which means that the appellate court has an obligation to rectify any error identified in the first instance decision. ${ }^{670}$ In other words, substantive justice (in the pure sense) is still the top priority of Chinese civil justice. A limited review would not serve the purpose of defending this kind of substantive justice.

The official position is that Chinese appellate review is a genuine appeal and not a trial de novo. However, based on the above analysis, an appellate review in China can actually operate very much like a trial de novo in practice. Some critics even

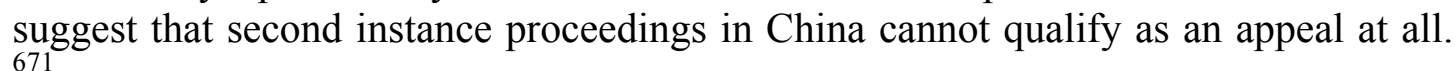

${ }^{668}$ See Liu 1999 , p. 51, note particularly the following observation:

'The point this author wants to emphasize is that so-called limited review by the court of second instance is not limited to the issues that have been argued and decided by the court of first instance, but is limited to the issues that have been presented to the court of second instance. To put it another way, an appellant is free to present an issue or issues for review, regardless of whether those issues have been argued in or decided by the court of first instance.'

${ }^{669} \mathrm{Fu} 2005$, p. 40.

${ }^{670}$ Liu 1999, p. 51-52.

${ }^{671}$ Zhang and Li observed that the Chinese appellate procedure is unique and does not fall into the usual theoretical categories of appellate systems: see Zhang \& Li 2012, p. 320.

$\mathrm{Fu}$ argued that China's appellate system embraces the socialist model of complete review coupled with the principle that the appellate court has the obligation to 'supervise' and 'direct' the first instance court through the appellate procedure: see Fu 2005, p. 40-41.

Also consider Liu 1999, p. 48:

"In the regular Chinese trial system, the term "appeal" (shang shu) is used to describe the proceedings of the court of second instance, and a decision made in such proceedings is said to be final. So it could be assumed that the proceedings in the court of second instance are an appeal instead of a new trial. However, this is a serious misconception. As a matter of fact, the proceedings in the court of second instance are more like a new trial rather than an appeal from a common law perspective. There are two general rules differentiating an appeal from a trial in the common law system: exclusion of new evidence and exclusion of new issues on appeal. These rules do not exist in China.' 


\subsection{The Pre-eminence of Substantive Justice in Chinese Civil Adjudication: Using the Adjudication Supervision Procedure as illustration}

\subsubsection{The nature of adjudication supervision and its underlying policy considerations}

Chapter 16 of the Code sets out the key procedural rules for adjudication supervision (shanpan jiandu). ${ }^{672}$ The adjudication supervision procedure allows a legally effective judgment or ruling (or mediation statement) ${ }^{673}$ to be re-opened for readjudication ${ }^{674}$ on the basis that the decision has been tainted by error. ${ }^{675}$ It is a core principle in Chinese civil justice that 'errors, when identified, must be corrected' (youсио bijiu). ${ }^{676}$ Adjudication supervision is a discretionary procedure and should only be used sparingly (i.e. only when a definite error has been identified in the final judgment). ${ }^{677}$

The adjudication supervision procedure can be distinguished from the appellate procedure on a number of levels: ${ }^{.78}$

First, unlike an appeal (which, at least in theory, is a complete review in China), a readjudication triggered by the adjudication supervision procedure is a trial de novo. From a comparative perspective, re-adjudication in China bears no resemblance to the final appellate procedure in common law jurisdictions, ${ }^{679}$ or the Revision procedure in civilian jurisdictions.

Second, while a case can only be appealed once (second instance being the 'final' instance), ${ }^{680}$ there is no legislative or other limitation on the number of times a case could be reopened under the adjudication supervision procedure. ${ }^{681}$ The adjudication

\footnotetext{
${ }^{672}$ A special division in each court deals specifically with matters of adjudication supervision and conducts re-adjudication.

${ }^{673}$ A 'mediation statement' (tiaojie shu) is a written court-sanctioned settlement agreement reached through court mediation. It has the same legal effect as a civil court judgment and can be enforced directly by the parties. It is sometimes translated as a 'consent order' or a 'written mediation statement'. For an overview of court mediation in China, see Chan 2012b, p. 250-256.

674 'Re-adjudication' (zaishen) (sometimes translated as 'retrial'), is a key component of the adjudication supervision procedure. A 're-adjudication' must be distinguished from a 'new trial' (chongshen) triggered by the remittal of a case from the appellate court to the first instance court in the appellate procedure.

${ }^{675}$ The threshold for re-opening a legally effective decision varies with the entity initiating the adjudication supervision process. For instance, if a party applies for re-adjudication, the legally effective decision must fall under any of the circumstances set out in Article 200 of the Code. If the adjudicative committee of the court that rendered the legally effective judgment sought to re-open the case, a finding of 'definite error' in the judgment is required (see Article 198 of the Code).

${ }^{676}$ Zhang \& Li 2012, p. 332.

${ }^{677}$ Adjudication supervision is a special procedure, which should be distinguished from the day-to-day adjudicatory work of the courts: see Zhang \& Li 2012, p. 333.

Woo noted, 'Adjudication supervision ("shenpan jiandu"), or supervisory review, is a procedure for additional, but discretionary, reviews of final judgments': see Woo 1991, p. 97

${ }^{678}$ Woo 1991, p.100-101.

${ }^{679}$ For instance, the leave stage for re-adjudication in China does not involve a quantum threshold (as found in the final appellate review procedure in some common law jurisdictions, such as Hong Kong).

${ }^{680}$ This position is subject to the situation where the appellate court remits the case to the first instance court for a new trial. The judgment rendered in the new trial (which is a first instance judgment) can be appealed only once: see Article 170 of the Code.

${ }^{681}$ Consistent with the Chinese concept that substantive justice must prevail over procedural justice, a re-adjudicated case can still be re-opened if a 'definite error' is identified. While the same court should
} 
supervision procedure can potentially make litigation an endless exercise in China. As promoting 'substantive justice' is a fundamental objective of judicial undertaking, ${ }^{682}$ a case must be re-opened if any definite error is found in a legally effective judgment, no matter how high the procedural cost is.

Third, unlike in the appellate procedure where an appeal must be lodged within a strict time limit (i.e. within 15 days from the date when the written judgment is served), there is no time limit on the court's exercise of its ex officio power of adjudication supervision under Article 198 of the Code.

Fourth, while an appeal is a procedure exclusive to the parties (and initiated by the parties), the adjudication supervision procedure can be triggered by non-party entities, such as the adjudicative committee of the court that rendered the legally effective judgment, a higher-level court (and the SPC), a higher-level procuratorate and the people's congresses.

A 'final judgment' in China is not truly final. ${ }^{683}$ The lack of finality encroaches on the procedural rights of litigants and throws the overall reliability of the system into doubt.

Different reasons were advanced seeking to justify the system of adjudication supervision. The most significant one is that since there are only two instances in any civil lawsuit, adjudication supervision becomes an indispensible recourse for litigants against judgments, as re-adjudication can ensure that a legally effective decision is fair, accurate and just. ${ }^{64}$ Another argument is that the re-adjudication process promotes uniformity in the application of law, since any erroneous application of law

not re-try a case that it has re-adjudicated before, it does not prevent further re-adjudication by a different court (for instance, a higher-level court): see Article 2 of the 2002 Provisions. However, see the Circular of the Supreme People's Court on Correctly Applying the 'Provisions on the Relevant Issues of Remanding for a New Trial and Ordering for a Retrial of Civil Cases' (Zuigao Renmin Fayuan Guanyu Zhengque Shiyong 'Guanyu Renmin Fayuan Dui Minshi Anjian Fahui Chongshen He Zhiling Zaishen Youguan Wenti De Guiding' De Tongzhi), effective since 13 November 2003 (Judicial Interpretation No. 169 [2003]), which elaborated that the same court should only be allowed to readjudicate the case once under 'normal circumstances'. It appears that this clarification leaves the door open for the same court to retry a case more than once under special circumstances. Also see Liu 1999, p. 36 .

${ }^{682}$ The author conducted interviews with judges at different levels of the Chinese Judiciary. The message has been consistent: if substantive justice could only be achieved by bending certain procedural rules, the judge would be inclined to do so. The philosophy of promoting substantive justice at the expense of procedural fairness could be witnessed at different stages of the civil process. For instance, while Article 64 of the Code only allows the court to investigate and collect evidence ex officio upon an application by the parties (when the parties cannot independently obtain the evidence for some realistic or objective reasons), in practice it is not unusual for the judge to 'direct' parties to make an application under Article 64 of the Code (thereby in violation of this procedural requirement): based on an interview (in May 2012) with a basic court judge who specializes in intellectual property adjudication in a leading commercial city in China.

${ }^{683}$ Consider the following view arguing that Chinese legal tradition and the political system play an important role in determining the 'meaning of finality' in China: see Liu 1999, p. 36:

"As a matter of fact, "judicial finality" itself is a complicated or even misleading term under the Chinese legal system. In determining the meaning of finality, one has to take into account the actual operation of the entire Chinese system instead of perceiving it narrowly based on the written law. Most importantly, particular attention should be paid to those factors affecting the implementation of law, such as Chinese legal culture and the political structure.'

${ }^{684}$ NPCSC Publication 2007, p. 346. 
in a legally effective judgment is a ground for its re-opening under Article 200 of the Code (i.e. under the party application regime). ${ }^{685}$

The adjudication supervision procedure is also a vital measure to guard against social instability resulting from unjust court rulings. The Central People's Government's emphasis on the imperative to build a 'harmonious society' (hexie shehui) has set the tone for China's civil justice reform in the past decade or so. ${ }^{686}$ The pressing need to provide redress for aggrieved litigants far outweighs any reform objectives on the procedural level (such as the need to uphold the finality of judgments). Similar to the promotion of court mediation as the preferred form of civil dispute resolution, ${ }^{67}$ the reform in adjudication supervision has strong underlying policy reasons. Policymakers have warned of the risks associated with the lack of effective channels for disputants to express their grievances, or in Chinese, the 'difficulty of seeking redress through petition' (shensu nan). ${ }^{688}$ Adjudication supervision provides a convenient avenue to alleviate discontent by correcting 'errors' in civil judgments that may have social ramifications. By stepping up the power of the courts and procuratorates to reopen judgments that could potentially stir up unrest, proponents of the reform argue that conflict within the community can be channeled from the streets to the courtroom where problems can be handled in a much more controlled manner. This is the real incentive for further strengthening the powers of adjudication supervision in the latest amendment of the Code (in 2012). On a more practical level, a court that chooses wisely in re-opening 'sensitive' judgments can avoid the proliferation of citizen petitions $^{689}$ (also known as 'letters and visits' (xinfang and shangfang)). ${ }^{690}$ Consistent with the policy objective of promoting social harmony, leaders of the judiciary would not hesitate to exert pressure on courts to keep petition rates as low as possible. ${ }^{691}$

\footnotetext{
${ }^{685}$ Jin 2012 , p. 38.

${ }^{686}$ Chan 2012b, p. 250.

${ }^{687}$ Ibidem.

${ }^{688}$ Among other similar views, a leading book series on adjudication supervision authored by policymakers at the SPC described the 'difficulty of seeking redress through petition' as a 'deep-seated problem' and took the view that the recent civil justice reform (leading to the revision of the Code in 2012) had positive effects in tackling this problem and protecting social harmony: see Jiang, Sun \& Wang 2012, p. 7. The 'difficulty of seeking redress through petition' is not a new issue. The SPC has in the past emphasized the imperative of the Chinese Judiciary to improve its adjudication supervision regime so as to deal with this problem: for instance, see the Working Report of the Supreme People's Court (2006) (Zuigao Renmin Fayuan Gongzuo Baogao), delivered on 11 March 2006 before the National People's Congress.

${ }^{689}$ Note that the right to petition (shensu quan) is enshrined in Article 41 of the PRC Constitution. Also note Article 2 of the Regulations on Letters and Visits, Decree of the State Council of the People's Republic of China (No. 431) (Guowu Yuan Xinfang Tiaoli) (effective since 1 May 2005):

"The term "letters and visits" in these Regulations means that citizens, legal persons or other organizations give information, make comments or suggestions or lodge complaints to the people's governments at all levels and the relevant departments of the people's governments at or above the county level through correspondence, E-mails, faxes, phone calls, visits, and so on, which are dealt with by the relevant administrative departments according to law.'

${ }^{690}$ Under the policy of preventing citizen petitions from reaching higher-level authorities, judges throughout China are under tremendous pressure to settle disputes through court mediation. Once a dispute is settled, it is quite unlikely that litigants would resort to petitions. See Minzner 2011b, p. 958. ${ }^{691}$ Ibidem.
}

Each court would usually set up more or less the same mechanism that connects the petitions received with the relevant civil judgments that can be re-opened. For cases of great social significance, the court may form a collegiate bench of five judges to retry the case (as opposed to the norm of three judges): see Yearbook 2009, p. 175. 


\subsubsection{Adjudication supervision: a critical review of the procedural issues}

There are generally four avenues to re-open a legally effective decision under the adjudication supervision procedure: (1) by the adjudicative committee of the same court that rendered the decision upon referral by the president of that court; ${ }^{62}$ (2) by the next higher-level court (or the SPC) exercising its adjudicative supervisory jurisdiction; ${ }^{693}$ (3) by a party applying to the next higher-level court for readjudication (zaishen shenqing) (party application), ${ }^{694}$ and (4) by a 'protest' (kangsu) from the next higher-level procuratorate (or the Supreme People's Procuratorate) (procuratorial protest). ${ }^{695}$

\subsubsection{Adjudication supervision through party application}

A party may apply to the court for re-adjudication. ${ }^{696}$ Article 199 of the Code reads:

'If a party is of the opinion that a legally effective judgment or ruling is erroneous, that party may file an application for re-adjudication with the court at the next higher level. If the persons constituting a party are numerous or both parties are citizens, the parties may apply for re-adjudication with the original court that rendered the judgment or ruling. Where a party applies for re-adjudication, the execution of the judgment or ruling shall not be suspended.'

Two prerequisites must exist before a party can apply for re-adjudication: (a) the judgment or ruling must be legally effective; and (b) the judgment or ruling must contain an error. ${ }^{697}$ The default position is for a party to apply to the court at the next higher level, although it is possible (in special circumstances) ${ }^{698}$ to apply to the same court that rendered the original judgment.

The court must grant leave for re-adjudication if the party application falls under any of the 13 circumstances set out in Article 200 of the Code. ${ }^{699}$ The circumstances in

\footnotetext{
${ }^{692}$ Article 198(1) of the Code; also see Article 14 of the Organic Law.

${ }^{693}$ Article 198(2) of the Code; also see Article 14 of the Organic Law.

${ }^{694}$ Article 199 of the Code. For a party applying to re-open a mediation statement, see Article 201 of the Code.

${ }^{695}$ Article 208 of the Code; also see Article 14 of the Organic Law. A judgment can also be re-opened by the court on a discretionary basis when it receives a procuratorial recommendation from the same level procuratorate.

${ }^{696}$ A party's right to 'apply' (shenqing) for re-adjudication is sometimes translated as a party's right to 'petition' for re-adjudication. As the word 'petition' is frequently used to refer to the right to petition against state authorities (under Article 41 of the PRC Constitution), to avoid confusion this article uses 'party application' (instead of 'party petition') to describe the regime under which the party initiates the re-adjudication procedure.

${ }^{697}$ NPCSC Publication 2012, p. 323. 'Error' in a legally effective judgment or ruling is explained in Article 200 of the Code. If the case falls under any of the circumstances set out in Article 200, it is deemed that the judgment or ruling is tainted by error.

${ }^{698}$ Such circumstances are stated in Article 199 of the Code. The rationale is that if both parties are citizens, seeking relief from the original trial court would save traveling time and cost. If the parties on one side are numerous, it is more conducive for fact-finding if the original court re-adjudicates the case: see NPCSC Publication 2012, p. 323.

${ }^{699}$ Article 200 of the Code reads:
}

'If the party's application satisfies any of the following circumstances, the people's court shall retry the case: 
Article 200 are commonly known as the 'causes of re-adjudication' (zaishen shiyou). The following is an overview of the causes of re-adjudication:

(1) Legal errors: whether a judgment applied the wrong law is to be determined by the court at the leave stage of re-adjudication. ${ }^{700}$ Possible scenarios of erroneous application of the law include where (a) the law applied is clearly inconsistent with the nature of the claim; (b) the law applied has been repealed or has not come into force; and (c) the way the law has been applied clearly contradicts its legislative intent. ${ }^{701}$ It has been argued that re-opening judgments by the SPC and courts at higher levels on the basis of legal error has the positive effect of ensuring

(1) there is new evidence sufficient to overturn the original judgment or ruling;

(2) there is a lack of evidence supporting the basic facts established in the original judgment or ruling;

(3) the principal evidence supporting the facts established in the original judgment or ruling was fabricated;

(4) the principal evidence supporting the facts established in the original judgment or ruling was not cross-examined;

(5) the concerned party, not being able to gather the principal evidence required in the trial of the case itself due to objective reasons, applied to the people's court in writing to investigate and gather evidence, but the people's court did not do so;

(6) there was a definite error in the application of the law in the original judgment or ruling;

(7) the composition of the trial organization was unlawful or a member of the adjudication personnel who, in accordance with law, ought to have recused himself/herself, did not do so;

(8) a person with no capacity to engage in litigation was not represented by a statutory agent or a person that ought to have participated in the action did not do so due to a reason not attributable to himself/herself/itself or his/her/its agent ad litem ;

(9) a party's right to defend himself/herself/itself was denied in violation of the law;

(10) a default judgment was rendered without a summons having been issued;

(11) the original judgment or ruling omitted claims or exceeded the claims;

(12) the legal document on the basis of which the original judgment or ruling was rendered has been vacated or modified; or

(13) a member of the adjudication personnel, in the trial of the case, accepted a bribe, practised favouritism by committing fraud or made a judgment that perverted the law.'

See http://www.chinalawandpractice.com/Article/3110946/PRC-Civil-Procedure-Law-2ndRevision.html (last visited: 4 March 2015)

${ }^{700}$ The leave stage of re-adjudication under the party application regime is set out in Article 204 of the Code.

${ }^{701}$ NPCSC Publication 2012, p. 326. Obviously, there cannot be an exhaustive list of all the possible scenarios of erroneous application of the law. Hence, the question of legal error must be left to the professional judgment of the court handling the application. 
uniformity in statutory interpretation. ${ }^{702}$ However, given that lower-level courts could also re-adjudicate cases (especially since the 2012 amendment of the Code), this argument is only partially accurate.

(2) Factual errors: Article 200 of the Code listed four irregularities in the fact-finding process as causes of re-adjudication: (a) new evidence has emerged that is sufficient to overturn the original judgment; (b) the findings of basic facts in the original judgment lack evidential support; (c) the primary evidence supporting the original judgment's fact-finding is fabricated; and (d) the primary evidence supporting the original judgment's fact-finding has not been cross-examined. ${ }^{703}$ It is quite troubling to see that any new evidence crucial to the case, if uncovered after a judgment becomes legally effective, could be used as a ground to nullify the judgment. While a limited avenue to introduce new evidence is well justified at the appellate level, allowing any fresh evidence to overturn a final judgment completely defeats finality. Note particularly that the 6-month time limit for lodging an application for re-adjudication when new evidence emerges is calculated from the date when the party knew (or should have known) about the new evidence, not from the date when the judgment came into effect. ${ }^{704}$ A judge could only determine a lawsuit on the basis of evidence presented by the parties. This is so even for a Chinese judge as the fact-finding regime is premised on a party responsibility system. ${ }^{705}$ Only in exceptional circumstances should a Chinese court exercise its ex officio power of investigation and evidence collection. $^{706}$ It is indeed absurd that a final decision that contained no actual error could be re-opened 20 years later just because a party uncovered new evidence that could overturn the decision.

(3) Procedural irregularities: such as illegally denying a party the right to engage in debate; irregularity in the formation of the 'trial organization' (shenpan zuzhi); a default judgment being entered against a party who has not been summoned. While a serious procedural irregularity that infringes basic rights of the party would justify the re-examination of a case, any procedural problems at trial should have been dealt with conclusively at the appellate stage.

(4) Other irregularities: for instance, where the judgment is tainted by judicial corruption (e.g. acceptance of bribes).

\footnotetext{
702 Jin 2012, p. 38.

${ }^{703}$ Article 68 of the Code regulates the cross-examination of evidence (zhizheng) in court. Note that cross-examination in the Chinese fact-finding context is a procedure to ensure the reliability and authenticity of evidence. It gives parties an opportunity to question one another on the evidence adduced and allows the court to investigate further if parties object to the admission of certain evidence: see NPCSC Publication 2012, p. 106. Cross-examination of evidence under Chinese civil procedure must not be confused with cross-examination of witnesses under common law civil procedure. Consider Schmidt 2003, p. 309-311:

'However, zhizheng is much broader than simply questioning a witness about his or her testimony. Both witness testimony and written and physical evidence can be zhizheng-ed. To zhizheng evidence means to examine and confront it, and only part of that process includes cross-examining witnesses.'

${ }^{704}$ Article 205 of the Code.

${ }^{705}$ Chan 2012b, p. 233-243.

${ }^{706}$ Chan 2012b, p. 234-237.
} 
Two causes of re-adjudication have been removed in the 2012 Amendment Version of the Code: (a) jurisdictional error (i.e. the judgment should be set aside for want of jurisdiction); and (b) any procedural irregularity that could affect the correctness of the judgment or ruling (i.e. a catch-all provision for procedural irregularity). ${ }^{707}$ The real reason for their removal is unclear. While hardly convincing, the reasons given in an authoritative annotation of the Code were that jurisdictional errors are already capable of being rectified under Article 200(6) of the Code (i.e. within the meaning of a legal error) and there is no need for a catch-all provision for procedural irregularity as the list of causes of re-adjudication in Article 200 is already 'relatively comprehensive'. ${ }^{708}$

As a matter of policy, the party application regime for re-adjudication was introduced to rectify the so-called 'difficulty in commencing the re-adjudication procedure' (zaishen nan). Jin noted that the party application regime 'transformed the retrial procedure into a more appeal-like procedure'. ${ }^{709}$ There is some truth in this view. First, the court is obligated to re-open a case if the application raises a valid cause of re-adjudication. So the list in Article 200 of the Code, in some way, operates like a plethora of grounds for appeal. ${ }^{710}$ Second, as an appeal (where a court hearing is held) in practice can look very much like a trial de novo, the de facto procedural characteristics of an appeal and a re-adjudication can be similar.

An encouraging amendment in 2012 is the shortening of the time limit for a party to apply for re-adjudication from 2 years ${ }^{711}$ to 6 months ${ }^{712}$ from the effective date of the judgment or ruling. ${ }^{713}$ The stricter timeframe gives more certainty to a final judgment. However, the real effect of this amendment is limited as nothing could stop the court from re-opening final judgments through exercising its ex officio power of adjudication supervision after the expiry of the 6-month deadline. ${ }^{714}$

A party applying for re-adjudication must submit a 'written application for readjudication' (zaishen shenqing shu). The court should, within five days after receiving the written application, serve copies of the written application on the opposing parties. The opposing parties have the opportunity to respond to the written application by serving a 'written opinion' (shumian yijian). The court may require the applicant and the opposing parties to provide supplemental information and question them on relevant matters. ${ }^{715}$ The court may either question the parties together or ex parte. ${ }^{716}$

\footnotetext{
${ }^{707}$ These two causes of re-adjudication were provided under Article 179 of the Code (2007 Amendment Version). Also see NPCSC Publication 2007, p. 350-360.

${ }^{708}$ NPCSC Publication 2012, p. 330.

${ }^{709}$ Jin 2012, p. 37.

${ }^{710}$ Ibidem.

${ }^{711}$ Article 184 of the Code (2007 Amendment Version).

${ }^{712}$ Article 205 of the Code (2012 Amendment Version).

${ }^{713}$ For circumstances set out in subsections (1), (3), (12) and (13) of Article 200 of the Code, the party must file an application within 6 months from the date when the party knows or should have known about the relevant circumstance(s).

${ }^{714}$ Article 198 of the Code.

715 Article 203 of the Code. Note that failure to submit a 'written opinion' by the opposing party does not prevent the court from examining the written application for re-adjudication and determining whether or not to grant leave.

${ }^{716}$ NPCSC Publication 2012, p. 333.
} 
The court has the discretion to determine whether or not to re-open a judgment upon receiving an application from the party. This in effect is the leave stage of the readjudication procedure. The court must, within three months after receiving a written application for re-adjudication, examine the application and, if the application complies with the Code (i.e. falls within any of the circumstances in Article 200), issue a ruling to retry the case (i.e. granting leave). If the application fails to comply with the Code, the court should issue a ruling to dismiss the application (i.e. refusing leave). Under special circumstances, the president of the court may grant an extension of time beyond three months. ${ }^{717}$

Once the court grants leave to re-adjudicate the case, execution of the original judgment would be stayed by a court order. ${ }^{718}$

There is no separate set of procedural rules for re-adjudication. Depending on the situation, the court retrying the case either follows the first-instance procedure or second-instance procedure. ${ }^{719}$ A court must form a collegiate bench to retry a case. ${ }^{720}$ A party may apply to the court to re-open a mediation statement if evidence can be adduced to show that the mediation violated the principle of voluntariness or if the content of the settlement has violated the law. The court, upon reviewing the application and confirming such irregularity, should order a retrial of the case. ${ }^{721}$

\subsubsection{Adjudication supervision: ex officio power of the court to re- open final judgments}

Under Article 198(1) of the Code, if any 'definite error' is discovered in a legally effective judgment, ruling or mediation statement and the president of the court that rendered the decision believes that a re-adjudication is necessary, the president must submit the case to the adjudicative committee of the court, ${ }^{722}$ which in turn would decide whether the case should undergo the re-adjudication process. ${ }^{723}$

\footnotetext{
${ }^{717}$ Article 204 of the Code.

${ }^{718}$ According to Article 206 of the Code, the stay of execution does not apply to claims relating to child support, medical expenses etc.

${ }^{719}$ Article 207 of the Code. A number of scenarios are possible when it comes to which type of procedure to adopt in re-adjudication triggered by party application: (a) where a party applies to the court at the next higher level for re-adjudication (which is the default position under Article 199), and the re-adjudication is conducted by that court, second-instance procedure should apply; (b) if a party applies to the same court that rendered the original judgment for retrial (which is the exceptional position under Article 199), first-instance procedure should apply if the original judgment was a firstinstance judgment, or second-instance procedure should apply if the original judgment was a secondinstance judgment; and (c) where pursuant to a party application, the SPC or a high court (provincial level) refers the case back to the original court (or a court of the same level of the original court) for readjudication, the applicable procedure would depend on whether the original judgment was a firstinstance or second-instance judgment: see NPCSC Publication 2012, p. 338.

${ }^{720}$ Article 207 of the Code.

${ }^{721}$ Article 201 of the Code. Note that the principle of voluntariness applies to both the initiation of mediation and the settlement itself. If the court forces a party to mediate or imposes settlement terms on a party against its will, the mediation statement could be set aside under Article 201. The issue of re-opening a mediation statement will be further explored below in the context of the court exercising ex officio power of adjudication supervision.

${ }^{722}$ For a succinct summary of the role and responsibilities of the adjudicative committee, see Woo 1991, p. 102-103; also see Chen 2011, p. 186-188.

${ }^{723}$ This internal mechanism to re-open a legally effective judgment by the adjudicative committee (upon the initiation of the court president) is also stipulated under Article 14(1) of the Organic Law.
} 
Under Article 198(2) of the Code:

'Where the Supreme People's Court discovers any definite error in a legally effective judgment, ruling or mediation statement rendered by a local people's court at any level; or where a people's court at a higher level discovers any definite error in a legally effective judgment, ruling or mediation statement rendered by a people's court at a lower level, the Supreme People's Court or the court at a higher level shall have the power to directly retry the case or direct a people's court at a lower level to retry the case.'

Article 198(2) encapsulates the power of a higher-level court to supervise the adjudicative activities of a lower-level court (and the SPC's powers to supervise the adjudicative activities of all courts in China). ${ }^{724}$

It is important to note that the power of adjudication supervision set out in Article 198 of the Code is free-standing, which means that even where the parties have not applied for re-adjudication, the same court (through its adjudicative committee) or a higher-level court (or the SPC) may initiate the process on its own.

While noting the need to maintain quality and consistency in civil adjudication in a system that lacked more sophisticated mechanisms, the court's ex officio power to reopen a 'final' judgment can be criticized on a number of levels: (a) the arbitrariness in the court's exercise of this power (due to an ill-defined threshold for re-opening judgments); (b) the free-standing nature of such power is inconsistent with the system of appellate review (e.g. an appeal must be initiated by the party); (c) the lack of procedural safeguards (e.g. time limits) against the abuse of this power; and (d) the intrusion of the court into the realm of private justice by the recent extension of the court's ex officio power to re-open mediation statement. The retention of the court's ex officio power under Article 198 not only complicates the normal course of adjudication, but also infringes adjudicatory autonomy, ${ }^{725}$ assaults the principle of party disposition and takes away the normative force of 'final' judgments and rulings re-opened under the procedure.

First, the triggering threshold for re-opening a legally effective decision or a mediation statement is the finding of any ' definite error' (queyou cuowu) in the decision or mediation statement. ${ }^{726}$ The term 'definite error', however, is not defined in the Code or any judicial interpretation. One widely accepted view is that a legally effective decision (or mediation statement) is generally tainted by 'definite error' if any of the circumstances set out in Articles 200 and 201 of the Code are present. ${ }^{727}$ However, nothing in the Code or any other normative instrument prohibits the

\footnotetext{
${ }^{724}$ When the higher-level court decides to re-open a case, it may either re-adjudicate the case by itself (tishen), which is the norm, or (where necessary) remit the case to the lower level court for retrial: see Article 27 of the 2008 Interpretation; also see Article 27 of the 2009 SPC Opinion. As for the SPC or a high court (provincial level), the common practice is to direct the original court that rendered the legally effective judgment or any court of the same level as the original court to retry the case: see Article 27 of the 2008 Interpretation.

${ }^{725}$ Conferring on the court ex officio power to re-open final judgments presumes that judges who are higher up in the judicial hierarchy possess greater judicial competence than the adjudicator(s) who directly handled the lawsuits (at trial and appeal). It is questionable whether this presumption is always accurate given the way to move up the Chinese judicial ladder is not necessarily through adjudicative excellence.

${ }^{726}$ Articles 198 of the Code.

${ }^{727}$ NPCSC Publication 2012, p. 321.
} 
adjudicative committee of the same court or a court at a higher level (or the SPC) to go beyond the scopes in Articles 200 and 201 in determining what 'definite error' means. ${ }^{728}$ Article 200 of the Code is expressed to apply only to situations where there is a party application ${ }^{729}$ or a procuratorial protest (or procuratorial recommendation). ${ }^{730}$ Article 201 of the Code is expressed to apply only to the situation of party application. Therefore, the threshold of 'definite error' remains undefined. The lack of a definition for this monumentally important threshold is troubling as the test for determining whether or not to re-open a legally effective judgment could well be arbitrary, potentially allowing extraneous factors to affect its outcome. A basic court judge observed that the Code simply failed to provide sufficient procedural guidance on the operation of the Article 198 regime. As a result, the court is left with enormous discretion to interpret the threshold of 'definite error'. 731

Second, a procedure that allows courts to re-open final decisions ex officio does not fit in at all with the theory underlying an appellate system. Under the appellate procedure, a party must lodge the appeal. The court cannot in any way force the appellate review procedure on the parties. The literature in Mainland China struggled to find a consistent theory that justifies the retention of the court's ex officio power to re-open judgments. Some simply stop at saying that this is a 'unique feature' of the Chinese civil justice system. ${ }^{732}$

Third, the Article 198 regime has no detailed procedural arrangement. Under the party application regime, three distinct stages are stipulated in the Code: (a) the initiation stage where the party submits an application; (b) the leave stage where the court determines whether an effective judgment should be re-opened; and (c) the actual re-adjudication stage. Under Article 198, however, no such arrangement is provided as though the court would simply operate behind closed doors with no procedural restrictions at all. The lack of a clear procedural arrangement under Article 198 has serious implications, most notably the absence of any time limit for the re-opening of judgments. Under the party application regime, the party must file an application for re-adjudication within 6 months from the effective date of the judgment or ruling, ${ }^{733}$ and upon receiving the party application, the court must decide whether or not to allow leave within 3 months. ${ }^{734}$ The Article 198 regime imposes no

\footnotetext{
${ }^{728}$ One possible restriction on the court's ex officio power can be found in a judicial interpretation (Article 30 of the 2008 Interpretation) which provides that where the parties have not applied for a retrial and the procuratorate has not presented a protest, the court should re-open a legally effective judgment/ruling or mediation statement under Article 198 if the judgment/ruling or mediation statement harms national interest or public interest (i.e. tainted by definite error): see Zhu, J.G., 'Zaishen Shiyou de Yizhong Jiedu' [One Approach to Interpreting the Causes of Re-adjudication], research paper presented at the 2012 Civil Procedure Law Research Conference [minshi susong faxue yanjiu hui 2012 nian nianhui] (http://www.civilprocedurelaw.cn/html/spcx 1179 3095.html).

However, Article 30 of the 2008 Interpretation looks more like a provision requiring the court to step in where the error in the judgment or mediation statement would give rise to concerns of national interest or public interest, rather than a restriction on the court's ex officio power under Article 198 of the Code.

${ }^{729}$ Article 199 of the Code.

${ }^{730}$ Article 208 of the Code.

${ }^{731}$ Interview Ref: 2012/6.

732 Zhang \& Li 2012, p. 333

${ }^{733}$ Article 205 of the Code.

${ }^{734}$ Article 204 of the Code.
} 
such time limits on the court. It is difficult to defend a system that is both opaque and lacking in the necessary procedural safeguards.

Fourth, a glaring shortcoming of the 2012 revision to Article 198 of the Code is the extension of the court's ex officio power to re-open a case settled by court mediation. If a mediation statement is found to contain any 'definite error', it should be reopened like any legally effective judgment or ruling. 'Definite error' in the context of mediation statement is not defined in the Code, although some guidance is provided in Article 201 of the Code: ${ }^{735}$

'A party may apply for retrial against a legally effective mediation statement if he can adduce any evidence that the mediation violated the principle of voluntariness or any content of the mediated settlement violated the law. If the people's court finds the evidence to be true upon examination, it shall conduct a retrial.'

Allowing the court to set aside a private settlement arrangement ex officio and to order a retrial of the case opens the door for unwarranted judicial intervention of private justice. While it may be a panacea for the problem of coercive practices in court mediation, its remedial effect fails to outweigh the harm it creates. The problem of coercive mediation practices should be tackled not by giving more power to the court to intervene, but by reforming the crippled court mediation system in China. ${ }^{736}$ If the mediation statement violated the law, the most straightforward remedy is to disallow enforcement. ${ }^{737}$ It would be much more consistent with the principle of party disposition to leave the parties themselves to decide what to do next if enforcement is refused, ${ }^{738}$ rather than to allow the court to re-open an otherwise settled dispute. Of course, proponents of this amendment would argue that a mediation statement is not purely a private settlement under Chinese procedural theory, as the court's authority to sanction the settlement is a manifestation of its adjudicatory power. ${ }^{739}$

Some academics in Mainland China have questioned the need to retain the court's $e x$ officio power of adjudication supervision. Tang, for instance, calls for the abolition of such a system. By removing its ex officio power to re-open final judgments, the judiciary would be able to focus on improving the quality of its adjudicatory work (and would thereby become more confident with its own decisions), instead of having to rely on the re-adjudication mechanism to correct errors. ${ }^{740}$

\footnotetext{
${ }^{735}$ NPCSC Publication 2012, p. 321

${ }^{736}$ Chan 2012b, p. 249-256.

${ }^{737}$ As a mediation statement must be sanctioned by the court before it becomes binding, the judge should reject a mediation statement that contains illegal terms in the first place, rather than waiting until the enforcement stage to rectify the problem.

${ }^{738}$ For instance, the parties may decide to apply to re-open the mediation statement under Article 201 of the Code.

${ }^{739}$ Zhang W.P. 2012, p. 21.

${ }^{740}$ Tang, W.J., 'Minsu Fa Xiugai Zhong Jiancha Jiandu Quan De Wanshan' [Perfecting the Supervisory Powers of the Procuratorate in the Revision of the Civil Procedure Law], Procuratorial Daily, 23 May 2011. However, Tang is in favour of retaining the supervisory power of the procuratorate over civil adjudication.
} 


\subsubsection{Procuratorial supervision: enhancing accountability or violation of adjudicatory autonomy?}

The Chinese procuratorates exercise enormous powers in adjudication supervision.

\subsection{Procuratorial protest:}

Article 208 of the Code confers (a) the power on the Supreme People's Procuratorate (SPP) to protest (kangsu) against a legally effective judgment or ruling of any court in China; and (b) the power on a higher level procuratorate to protest against a legally effective judgment or ruling of a lower level court, if the judgment or ruling falls under any of the circumstances set out in Article 200 of the Code. A procuratorate may lodge a protest ex officio, i.e. without the need of a 'request for protest' from the party. ${ }^{741}$ While the court may reject a party application for re-adjudication, ${ }^{742}$ it must re-open an effective judgment upon receiving a procuratorial protest. ${ }^{743}$ There is no apparent time limit for lodging procuratorial protests when the procuratorate exercises this power ex officio. ${ }^{744}$

Article 208 of the Code also confers the power on procuratorates (the SPP or a higher level procuratorate) to protest against a mediation statement of a lower level court if the mediation statement causes any damage to 'national interest' or 'public interest'.

Article 209 of the Code allows parties to file a 'request for protest' (kangsu shenqing) with a procuratorate. ${ }^{745}$ This mechanism can only be used when the party has exhausted its rights under the party application regime: i.e. when (a) the court rejects the party's application for retrial; (b) the court fails to grant leave for retrial within the prescribed time limit; or (c) there is a 'clear error' (mingxian cuowu) in the judgment or ruling entered after the retrial. ${ }^{746}$ 'Clear error' is not defined in the Code or any judicial interpretation, but presumably it has the same meaning as 'define error'.

The procuratorate must determine whether or not to lodge a protest within three months upon receiving a request for protest. ${ }^{747}$ The procuratorate may investigate the matter and request for information from the parties (or non-parties) for verification purposes. ${ }^{748}$ The procuratorate deciding to proceed with a protest must produce a 'written protest' (kangsu shu), and the court accepting the protest ${ }^{749}$ must set the case

\footnotetext{
${ }^{741}$ NPCSC Publication 2012, p. 339-340.

${ }^{742}$ Article 204 of the Code.

${ }^{743}$ Article 211 of the Code; also see NPCSC Publication 2007, p. 343.

${ }^{744}$ Article 208 of the Code provides no time limit for procuratorial protest; also see Liu 1999, p. 40. But there is a time limit for protest triggered by a 'request for protest': see Article 209 of the Code.

${ }^{745}$ A party is only allowed to request for procuratorial protest once: see Article 209 of the Code.

${ }^{746}$ The requirement to exhaust all avenues under the party application regime first before seeking redress from the procuratorate was absent in the 2007 Amendment Version of the Code. Commentators describe this new requirement as allowing 'the court to rectify any error first, to be followed by procuratorial supervision [if the error is still not rectified] at a later stage' (fayuan jiucuo xianxing, jiancha jiandu duanhou): see Jiang, Sun \& Wang 2012, p. 10. This arrangement prevents the duplication of work by the court and the procuratorate. A party that sought redress under the party application regime and from the procuratorate should not be allowed another bite of the cherry. This is a limited attempt on the part of the policy makers to ensure some stability in the system: see NPCSC Publication 2012, p. 342. However, nothing stops multiple re-opening of a judgment by the court or procuratorate exercising its ex officio power.

${ }^{747}$ Article 209 of the Code.

${ }^{748}$ Article 210 of the Code.

${ }^{749}$ The court receiving a procuratorial protest must be the next higher-level court of the court that rendered the original judgment.
} 
down for retrial within 30 days from receiving the written protest. As a general rule, the court receiving the protest should transfer the case to a lower-level court for retrial if the case is re-opened pursuant to any of the causes of re-adjudication set out in Article 200(1) to (5) of the Code. However, if the case has already been retried earlier by a lower-level court, the court receiving the protest should retry the case on its own. ${ }^{750}$

The procuratorate may send a representative to be present at a retrial hearing initiated by procuratorial protest. ${ }^{751}$

\subsubsection{2. $\quad$ Procuratorial recommendation}

An additional supervisory power has been conferred on the procuratorate in the 2012 Amendment Version of the Code. A procuratorate at the same level as the court that rendered the legally effective judgment may issue a 'procuratorial recommendation' (jiancha jianyi) in relation to the judgment if any of the circumstances in Article 200 of the Code is present. ${ }^{752}$ This is contrasted with a procuratorial protest, which can only be lodged by a higher-level procuratorate. The scope of a procuratorial recommendation is much wider than that of a procuratorial protest, ${ }^{753}$ i.e. a protest is only limited to 'civil adjudicatory activities' (minshi shenpan huodong) while a recommendation may cover any matter relating to 'civil litigation' (minshi susong). ${ }^{754}$ The 2012 Amendment Version of the Code also confers the power on procuratorates to recommend the re-opening of mediation statements sanctioned by same-level courts if the mediation statements cause any damage to 'national interest' or 'public interest'. 755

While being called a 'recommendation', the normative effect of a procuratorial recommendation could well be very similar to that of a procuratorial protest. ${ }^{756}$ Given the legal tradition that the judiciary is under the supervision of the procuratorate, courts are likely to re-open judgments upon receiving procuratorial recommendations unless there are compelling reasons not to do so.

With the promulgation of the 2015 Interpretation, it appears that the normative force of procuratorial recommendation has become clear.

\footnotetext{
${ }^{750}$ Article 211 of the Code.

751 Article 213 of the Code.

752 Article 208 of the Code. Alternatively, the procuratorate may request a higher-level procuratorate to lodge a protest against the judgment.

A procuratorial recommendation can be issued either upon party request or by the procuratorate $e x$ officio. The procedure for party request for procuratorial recommendation is almost identical to that for procuratorial protest, except (in theory) that there is no obligation for the court to re-open a judgment upon receiving a recommendation.

${ }^{753}$ A procuratorial recommendation is not limited to the adjudication supervision procedure. For instance, a recommendation may cover matters relating to judicial conduct in first-instance proceedings: see Article 208(3) of the Code.

${ }^{754}$ Note the amendment made to Article 14 of the Code (2012 Amendment Version of the Code).

755 Article 208 of the Code.

${ }^{756}$ Zhang W.P. 2012, p. 19
} 
Under Article 415 of the 2015 Interpretation, the court 'should accept' (应予受理) a procuratorial recommendation to re-open a 're-adjudicated judgment' tainted by 'clear error' (明显错误). ${ }^{757}$

Where a court has dismissed a party's application for re-adjudication or the court has failed to render a ruling in respect of a party's application for re-adjudication by the prescribed deadline, the party may apply to the same level people's procuratorate for a procuratorial recommendation under Article 209 of the Code. The people's procuratorate shall then conduct a review of the party's application and render its decision on whether to lodge a procuratorial recommendation or not within three months. If the people's procuratorate decides to lodge a procuratorial recommendation (recommending re-adjudication) and all the procedural requirements under Article 416 of the 2015 Interpretation are satisfied, the court in question 'shall accept' the procuratorial recommendation.

\subsubsection{Adjudication supervision through non-party application}

A non-party has a limited right to apply to a higher-level court for re-adjudication upon showing that his property rights are affected by the enforcement of the judgment and it is not possible to seek redress by initiating fresh proceedings. ${ }^{758}$ The non-party may apply for a stay of execution of the judgment in connection with the property in question. $^{759}$

\subsubsection{Issues with enforcement of an effective judgment challenged under the adjudication supervision procedure}

A party application for re-adjudication cannot act as an automatic stay of execution of the original judgment. Execution will only be stayed upon the court granting leave for re-adjudication (i.e. setting aside the original judgment). ${ }^{760}$ It is therefore possible for the original judgment to be executed before leave for re-adjudication is granted. ${ }^{761}$ Under normal circumstances, and consistent with the principle of finality, a successful party should not be prevented from executing an effective judgment. However, in order to ensure that the re-adjudication procedure works, the rules should cater for special circumstances, for instance, where without a stay of execution of the original judgment, the new judgment rendered at retrial would become nugatory. To deal with these special circumstances, a party should be able to apply for a stay of execution of the original judgment at the same time when an application for re-adjudication is made. The court, in deciding whether to grant a stay, would need to consider whether there is a prima facie case for re-adjudication based on the test in Article 200 of the Code and whether the special circumstances identified in the application justify a stay

\footnotetext{
${ }^{757}$ Also see Article 413 of the 2015 Interpretation, i.e. the court 'shall accept' a procuratorial recommendation for re-adjudication if the legally effective judgment/ ruling/ mediation statement in question harms national interest or public interest.

${ }^{758}$ See Article 5 of the 2008 Interpretation, note particularly the strict time limits on applying for a retrial.

${ }^{759}$ Article 227 of the Code.

${ }^{760}$ Article 206 of the Code.

The ruling to stay execution must be signed by the president of the court and affixed with the seal of the court.

${ }^{761}$ Note the three-month statutory period designated to the leave stage of the re-adjudication process: see Article 204 of the Code.
} 
of execution. ${ }^{762}$ Obviously, the court should not grant a stay unless there are compelling reasons. In structuring the test for granting a stay of execution, useful insight can be drawn from the Hong Kong case Star Play Development Ltd v Bess Fashion Management Co Ltd ${ }^{763}$ which deals with the granting of a stay of execution pending appeal. ${ }^{764}$ As the condition of a stay of execution, the court may require the applicant to provide security in the same manner as stipulated under Article 100 of the Code.

The longer one waits before a case is retried, the riskier it is that any decision of the retrial, no matter how just, could no longer be enforced. ${ }^{765}$ This problem epitomizes the uncertain nature of the adjudication supervision process: on the one hand, a successful party can never be sure when an effective judgment would be overturned on retrial; on the other hand, the party seeking to re-open the judgment can never be certain whether any favourable result at retrial could be enforced. ${ }^{766}$

\subsubsection{Critical examination of the new powers of the Chinese procuratorate}

The power of the procuratorate to interfere with civil adjudication has been substantially expanded as a result of the 2012 revision of the Code.

First, the ambit of procuratorial supervision has been extended. In the past, the procuratorate could only exercise supervisory power over 'civil adjudicatory activities'. ${ }^{767}$ After the 2012 amendment, the procuratorate may exercise supervision over all matters relating to 'civil litigation'. ${ }^{768}$ With such an extended ambit, the procuratorate may now exercise oversight on enforcement actions and court mediation. ${ }^{769}$ This marks a doctrinal shift in the approach of procuratorial supervision over the Chinese civil justice system.

Second, a new interventionist measure has been introduced - procuratorial recommendation. ${ }^{770}$

\footnotetext{
${ }^{762}$ Article 225 of the Code (where a party may object to illegal enforcement conduct) would not help an applicant for re-adjudication seeking to stay the execution of a judgment on an urgent basis.

763 [2007] 5 HKC 84.

${ }^{764}$ While not directly on point, the test for granting a stay of execution pending appeal in Hong Kong could be adopted by analogy (or at least referred to for guidance), as the procedural characteristics are similar. For instance, under some circumstances, the new judgment may become nugatory if a stay of execution of the original judgment is not granted. For a discussion of Star Play Development Limited and the principles governing the grant of a stay of execution pending appeal in Hong Kong, see Wilkinson, Cheung \& Booth 2011 (Chapter 21).

${ }^{765}$ This risk becomes even more apparent when the court re-opens a case ex officio without any statutory time limit (e.g. years after the original judgment has been rendered).

${ }^{766}$ This enforcement problem indirectly encourages the successful party to execute the original judgment as soon as possible and dissipate all assets (e.g. through transferring the assets to an innocent third party).

${ }^{767}$ Article 14 of the 2007 Amendment Version of the Code.

768 Article 14 of the Code.

769 The expansion of the realm of supervision was partially motivated by the policy need to combat illegal actions taken during enforcement actions and mediation processes designed to harm national interest or public interest. See NPCSC 2012, p. 19:

${ }^{770}$ Articles 208 to 210 of the Code.

A procuratorial recommendation is different from a procuratorial protest in three important aspects: (a) unlike a protest, a recommendation in theory cannot force a retrial of the case (see Article 208 of the Code); (b) unlike a protest which must be presented by a higher-level procuratorate, a recommendation
} 
Third, the procuratorate has been conferred investigatory powers to (where necessary) verify relevant information from litigants and non-parties when it performs its duties under the adjudication supervision procedure. ${ }^{771}$

Among the many justifications for expanding procuratorial powers advanced by policy-makers, two are particularly important: (a) to address the difficulty of seeking redress through petition (shensu nan) ${ }^{772}$ and (b) to address the problem of judicial corruption (especially at the enforcement stage) ${ }^{773}$ However, none of these factors seems sufficient to justify the new procuratorial powers. Procuratorial intervention with civil adjudication has its origin in the Soviet legal tradition. ${ }^{774}$ The dominant role of the procuratorate in Chinese civil justice is easily noticeable. For instance, the court receiving a procuratorial protest is under an obligation to re-open the case for retrial. $^{775}$

There is nothing that prevents a procuratorate from exercising its ex officio power to lodge a protest. In theory no protest should be lodged unless a cause of readjudication (as set out in Article 200 of the Code) is present. ${ }^{776}$ However, in practice, the procuratorate has unchecked power to interpret Article 200 as an effective judgment must be re-opened pursuant to a protest.

The more troubling issue is the extension of procuratorial power to re-open a mediation statement if it causes any damage to 'national interest' or 'public interest'. ${ }^{777}$ The procuratorate did not have this power until the 2012 amendment of the Code. Neither 'national interest' nor 'public interest' was defined in the Code, leaving the procuratorates ample discretion to determine their meaning. ${ }^{778}$ Given the private nature of a mediated settlement, it is questionable whether the best way to deal with irregularities in a mediation statement is through a non-judicial public body, especially when power can possibly be exercised by that body arbitrarily. Under Chinese civil procedure, parties are entitled to settle a lawsuit voluntarily and free from any form of intervention. The principle of voluntariness in court mediation, which is a core principle in Chinese civil procedure, is enshrined in Article 9 of the Code. The extension of procuratorial power to re-open mediation statements contradicts the spirit of Article 9. A better option is to simply refuse enforcement of a mediation statement if it is found to be contrary to the law. The proposed 'illegality'

is presented to the court by the same-level procuratorate; and (c) a protest is only concerned with the adjudication supervision procedure, but a recommendation may cover any aspect of civil litigation (i.e. not limited to adjudication supervision). See NPCSC Publication 2012, p. 340-341.

${ }^{771}$ Article 210 of the Code.

${ }^{772}$ Note that the right to petition (shensu quan) is enshrined in Article 41 of the PRC Constitution.

${ }^{773}$ Apart from these two factors, there is another reason for the extension of procuratorial powers. Basic-level procuratorates were essentially left dormant in the past when it came to adjudication supervision, given it took a higher-level procuratorate to lodge a protest. With the 2012 revision of the Code, basic-level procuratorates would see a drastic increase in workload, as now they have the power to present procuratorial recommendations. See Zhang W.P. 2012, p. 14:

${ }^{774}$ Zhang W.P. 2012, p. 14.

${ }^{775}$ For an overview of the dominant role of procurators in Romanian civil justice during the Socialist era, see Spinei 2011, p. 46-47.

${ }^{776}$ Article 208 of the Code.

777 Ibidem.

${ }^{778}$ Some academics in Mainland China have called for clearer guidance from the SPC and SPP on the test of 'national/ public interest' through the issuance of a judicial interpretation that regulates the reopening of mediation statements by procuratorates: for instance, see Zhang W.P. 2012, p. 22. 
test is superior to the current 'national interest/public interest' test as the proposed test is far more precise and predictable. The proposed test also echoes the principle of legality in court mediation under Article 9 of the Code. ${ }^{779}$ Treating irregular mediation statements at the enforcement stage allows the court to deal with the matter within its own domain, without the need for an intruding procurator. ${ }^{780}$

While procuratorial oversight on certain judicial issues (such as judicial corruption and serious dereliction of judicial duty) is justified in the context of China's legal tradition, the procuratorial portfolio should not include intervening with individual civil lawsuits. China can never develop a stable and predictable civil justice system if procuratorates are given overriding powers to re-open legally effective civil decisions and interfere with private mediation settlements. Some Mainland Chinese scholars noted the problem with over-empowering procurators and called for the abolition of procuratorial supervision over civil adjudication in the long run. ${ }^{781}$ Unfortunately, this view seems to contradict the contemporary policy to extend procuratorial powers even further (as witnessed in the latest amendment of the Code). Such a trend is indeed worrying as the procuratorate may now interfere with processes that are traditionally within the domain of the parties (such as the appellate procedure and court mediation). The reform in effect creates an overriding procuratorial privilege that trumps adjudicatory autonomy and the principle of party disposition.

\subsubsection{Interference from other institutions}

In addition to the ex officio powers of the court and the procuratorate to re-open final judgments, the principle of party disposition is further infringed by interferences from the Chinese legislature (i.e. the people's congresses). The Standing Committee of the National People's Congress supervises the SPC and standing committees of people's congresses at different levels supervise courts at the corresponding levels. ${ }^{782}$ While the people's congresses cannot directly re-open a final judgment, it may exert considerable influence over lawsuits by urging the court to re-adjudicate or the procuratorate to lodge a protest. As a matter of policy, courts and procuratorates do take re-adjudication recommendations from people's congresses seriously. ${ }^{783}$

Being in an inferior position vis-à-vis stronger state organs and the ruling Chinese Communist Party within the Chinese constitutional order, courts frequently find

\footnotetext{
${ }^{779}$ Under Article 9 of the Code, the procedure and method for court mediation must be legal, and so must the content of the mediation statement: see NPCSC Publication 2012, p. 11.

${ }^{780}$ In fact, the judges should be entrusted with the duty to ensure that any mediated settlement sanctioned by the court should not be illegal and hence avoid as much as possible the need to deal with this matter at the enforcement stage.

${ }^{781}$ Zhang W.P. 2012, p. 18-21.

${ }^{782}$ Article 67(6) of the PRC Constitution. Also see Liu 1999, p. 84.

The National People's Congress (and its standing committee) appoints the leaders of the SPC. The National People's Congress selects the President of the SPC: see Article 62(7) of the PRC Constitution. The Standing Committee of the National People's Congress has the power to appoint and remove members of the Adjudicative Committee of the SPC: see Article 11 of the Organic Law.

${ }^{783}$ For a case example of the National People's Congress interfering with civil adjudication, see Liu 1999, p. 86-88.

When considering re-adjudication, special preference is given to cases referred to the courts by deputies of the people's congresses: see Yearbook 2010, p. 175.
} 
themselves subject to external interferences, both within and outside the regime of established rules. ${ }^{784}$

\subsection{5. $\quad$ Recent trends in civil appeals and re-adjudication}

Based on official statistics available for the past four years (from 2009 to 2012, with the exception of 2012 where official statistics are only available for the first nine months), less than $10 \%$ of the total number of civil cases disposed of by the courts at all instances (which include first instance, appellate and re-adjudication cases) each year were appellate cases.

Less than $1 \%$ of the total number of civil cases disposed by the courts at all instances each year was re-adjudication cases. This shows that re-adjudication remains a discretionary procedure only to be invoked under special circumstances. ${ }^{785}$

\footnotetext{
${ }^{784}$ For an analysis of how the Chinese Communist Party supervises the work of the courts, see Zhu 2010; also see Liu 1999, p. 88-90.

The issue of external interference should also be examined in the context of local protectionism, where local government intervenes with adjudication (sometimes in the form of forcing courts to re-open final judgments that are unfavourable to entrenched local interests). Chen summarized this problem well:

'Local protectionism is a structural problem because the local judiciary is dependent on the local government in terms of funding, and personnel decisions relating to the local judiciary are also in the hands of the local party committees and local people's congresses. Many leaders of local government view the local courts as subordinate departments of the local government, and sometimes express to judges their views on individual cases pending before the courts. Judges who without fear or favour apply the law to the detriment of local interests may therefore suffer in terms of their career prospects or their employment benefits. Reduction of funding for the local court is also a threat that its members have to live with.'
}

See Chen 2011, p. 203-204.

${ }^{785}$ In the first nine months of 2012, a total of 5,199,111 civil cases at all instances were disposed of by the courts. 4,789,647 civil cases were disposed of at first instance. 389,237 civil cases were disposed of at second instance. 20,227 civil cases were disposed of through re-adjudication. For an update of the latest statistics on civil litigation in China, see http:/www.court.gov.cn/qwfb/sfsj/index.html (last visited: 4 March 2015). Appellate cases account for approximately $7.49 \%$ of the total number of civil cases disposed of during this period. Re-adjudication cases account for approximately $0.39 \%$ of the total number of civil cases disposed of during this period.

In 2011 , a total of 7,168,992 civil cases at all instances were disposed of by the courts. $6,558,621$ civil cases were disposed of at first instance. 571,762 civil cases were disposed of at second instance: Yearbook 2012, p. 1066-1067.38,609 civil cases were disposed of through re-adjudication, out of which 8,074 cases were initiated by procuratorial protest: Yearbook 2012, p. 1071. In 2011, approximately $20.91 \%$ of re-adjudication cases were initiated by procuratorial protest. Appellate cases account for approximately $7.98 \%$ of the total number of civil cases disposed of during this period. Readjudication cases account for approximately $0.54 \%$ of the total number of civil cases disposed of during this period.

In 2010, a total of 6,747,399 civil cases at all instances were disposed of by the courts. $6,112,695$ civil cases were disposed of at first instance. 593,373 civil cases were disposed of at second instance: Yearbook 2011, p. 1052-1053. 41,331 civil cases were disposed of through re-adjudication, out of which 9,485 cases were initiated by procuratorial protest: Yearbook 2011, p. 1057 . In 2010, approximately $22.95 \%$ of re-adjudication cases were initiated by procuratorial protest. Appellate cases account for approximately $8.79 \%$ of the total number of civil cases disposed of during this period. Readjudication cases account for approximately $0.61 \%$ of the total number of civil cases disposed of during this period.

In 2009 , a total of $6,433,585$ civil cases at all instances were disposed of by the courts. $5,797,160$ civil cases were disposed of at first instance. 598,355 civil cases were disposed of at second 
Between 2009 and 2011, approximately 20\% of re-adjudication cases were initiated by procuratorial protest each year. This shows that procuratorial protest remains an important avenue for re-opening effective judgments.

\subsubsection{Recommendations for reform in China's civil appellate system: establishing the principle of finality in Chinese civil justice}

The Chinese approach of complete review frustrates the true nature of civil appeals. The appellate court is too powerful: save for a few minor restrictions, the appellate court may redefine the remit of the appeal, entertain new evidence and legal issues, and review the merits of every factual and legal finding of the first instance court. In practice, factual review takes the form of a fresh fact-finding exercise. This approach makes second instance procedure in China more like a trial de novo than a genuine appellate review. To move forward, China needs to consider adopting a limited review of appeals. Consistent with the principle of party presentation, the scope of review should be limited to the request for appeal only. The purpose of an appeal is not to retry the case. The appellate court should not reinvent the wheel by repeating the fact-finding exercise and should not disturb first instance findings of facts unless there are plain errors. ${ }^{786} \mathrm{New}$ evidence should not be accepted on appeal unless there are good reasons. The test in Ladd v Marshall ${ }^{787}$ may offer some useful guidance in formulating the future test for admission of new evidence in appellate review. From the perspective of procedural efficiency, remittals should be avoided as much as possible. $^{788}$

However, reforming the appellate system itself is insufficient. The adjudication supervision procedure continues to be the greatest hurdle for constructing a reliable and effective appellate system. Adjudication supervision creates unpredictability in access to justice in China. When finality cannot be guaranteed, justice cannot be secured. The prevailing judicial culture that views finality as an obstacle thwarts any genuine reform effort to develop the rule of law in civil procedure. Populist manipulation of the adjudication supervision procedure further complicates the matter. When effective judgments can be revoked on populist policy grounds cloaked in the name of adjudication supervision, procedural safeguards (no matter how well designed) would become superfluous. Paradoxically, allowing populist objectives to sway determinations in adjudication supervision indirectly encourage litigants to petition even more fiercely, as doing so their grievances are most likely to be heard and taken seriously by the courts. Litigants who are less vocal before would follow suit. Adjudication supervision triggered by extraneous factors is bound to backfire. No judge would ever be sure what would happen next in a culture where social

instance: Yearbook 2010, p. 920-921. 38,070 civil cases were disposed of through re-adjudication, out of which 7,469 cases were initiated by procuratorial protest: Yearbook 2010, p. 925. In 2009, approximately $19.62 \%$ of re-adjudication cases were initiated by procuratorial protest. ${ }^{785}$ Appellate cases account for approximately $9.30 \%$ of the total number of civil cases disposed of during this period. Re-adjudication cases account for approximately $0.59 \%$ of the total number of civil cases disposed of during this period.

${ }^{786} \mathrm{Fu}$ noted that the role of the appellate court is to assess whether the factual findings at first instance were accurate, not to conduct a retrial of the facts. See Fu 2005, p. 43.

${ }^{787}$ [1954] 1 WLR 1489, 1491.

${ }^{788} \mathrm{Fu} 2005$, p. 43 . Even if a remittal cannot be avoided, the appellate judgment should clearly indicate the reasons for the remittal. 
sentiments dictate the daily schedules of courts. It shows that the best way to deliver justice is through upholding the rule of law, not by chasing populist goals.

On a procedural level, the principle of party disposition can only be upheld when courts are banned from exercising their ex officio power of adjudication supervision. This can simply be done through amending the Code. Such an amendment would at least put the parties in the driver's seat and prevent situations where the court forces its will on the parties by re-opening judgments. It would also avoid the abuse of such power, e.g. the court re-opening judgments ex officio that are unfavourable to local authorities or vested interests. The regime of party application for re-adjudication can be improved by providing detailed practice directions on the standards for triggering re-adjudication. For instance, the definition of legal error under Article 200(6) of the Code remains vague. If an overly wide interpretation is adopted, even trivial errors of law could disturb the finality of judgments, which is clearly unwarranted. Ideally, adjudication supervision should only be triggered when there is a serious procedural violation (e.g. the violation resulted in the denial of a fair trial). If the substantive causes of re-adjudication are to be retained (e.g. the re-opening of a judgment tainted by factual error), it is advisable that Article 200 should at least specify that a final judgment should not be re-opened unless the substantive error is sufficiently serious that the judgment would have been materially different but for the error. Procuratorial supervision of civil litigation threatens adjudicatory autonomy and infringes the principle of party disposition. While procuratorial oversight on certain judicial issues (such as judicial corruption and serious dereliction of judicial duty) is justified in the context of China's legal tradition, the procuratorial portfolio should not include intervening with individual civil lawsuits. Unfortunately, a converse trend has been witnessed in the latest reform where policy makers expanded the supervisory powers of the procuratorate to cover all matters relating to civil litigation. This trend is indeed worrying.

The notion that uniformity of the law can be achieved through adjudication supervision may be sound in theory. In practice, however, retrial decisions (especially retrial decisions of lower-level courts) can be just as inconsistent as first or second instance decisions. The rules of adjudication supervision are primarily catered for correcting errors identified in effective judgments, not for achieving consistency in jurisprudence. To achieve uniformity, the highest level of courts must be in a position to declare universal norms. This cannot be achieved unless policy makers are willing to fundamentally reform the current system in China. Some Chinese academics are in favour of revoking the current two-instance system ${ }^{789}$ in the long run, to be replaced by a three-tier system with a third level Revision to the SPC. ${ }^{790}$ Zhang and Li highlighted a number of weaknesses of the two-instance system. ${ }^{791}$ Civil appeals today are mostly heard by intermediate courts, which are relatively low ranking (only one level higher than the basic-level courts). There are in total 409 intermediate courts in China. ${ }^{792}$ It is difficult to manage the quality of appellate review and avoid discrepancies in application of the law when appeals are heard by

\footnotetext{
${ }^{789}$ Under the current Chinese appellate system, a second instance decision is said to be 'final': Article 175 of the Code and Article 12 of the Organic Law.

${ }^{790}$ For an overview of discretionary review appeal in the German context, see Murray \& Sturner 2004, p. 386-399.

${ }^{791}$ Zhang \& Li 2012, p. 50.

792 See http://www.court.gov.cn/jgsz/rmfyjj/
} 
such a vast number of (relatively) low-ranking courts. ${ }^{793}$ Since an intermediate court that hears an appeal usually has its seat within or near the community where the dispute arose, the court is much more prone to influence from stakeholders within that community, including interference motivated by local protectionism. Furthermore, given the traditionally close connections between intermediate courts and basic-level courts of any given region (in terms of administrative link, adjudication supervision and personnel), it is questionable whether appellate judges of the intermediate courts are impartial enough to review decisions made by their brethren at basic-level courts whom they are closely associated with. ${ }^{794}$ Under the three-tier system, the SPC should abandon adjudication supervision and focus on clarifying the law with the view of achieving uniformity (through Revision). ${ }^{795}$ Guided by norms declared by the SPC, greater consistency (as well as accuracy) in application of the law can be expected at second instance even where the bulk of appeals are still handled by intermediate courts. ${ }^{796}$ Adopting the three-tier system would inevitably make adjudication supervision redundant. Given the judiciary's obsession with material truth and substantive justice, it is unsurprising that leaders of China's courts are generally not keen with the idea of establishing a Chinese court of Revision ${ }^{797}$ and would prefer to retain the adjudication supervision procedure. ${ }^{798}$ The adjudication supervision system is not just about correcting errors in effective judgments. It is the cement of a power matrix that regulates activities within the judicial bureaucracy in China. As long as the beneficiaries of adjudication supervision can still exert influence over policy-making, the two-instance system is expected to remain. ${ }^{799}$

Ultimately, Chinese courts must embrace finality as a fundamental principle of civil adjudication. The absence of finality in China affects not only the rights of individual litigants but also the country as a whole, as investors cannot trust a system in which the fruits of their legal battles could be set aside in the name of substantive justice. China is at the crossroads of modernization. To match the aspirations of a true market

\footnotetext{
${ }^{793}$ Zhang \& Li 2012, p. 50.

794 Ibidem.

${ }^{795}$ Currently, the SPC hears second-instance appeals just like an intermediate or high court. With the proposed reform, it would no longer be appropriate for the SPC to continue with this role. Such a change would require a reconfiguration of the appellate system such that the high courts would become the highest-level courts that handle second-instance appeals.

${ }^{796} \mathrm{Fu} 2005$, p. 43-44.

${ }^{797}$ As Murray and Sturner noted, 'The purpose of such [discretionary] review appeal is not primarily to obtain correct justice in the individual case. More important to the court's willingness to decide any given review appeal is the significance of the issue presented to the system of justice as a whole. The decisions of the Federal Supreme Court of Justice serve to unify and rationalize Germany's entire system of civil justice.' See Murray \& Sturner 2004, p. 386. The purpose of Revision is clearly different from the core objective of the Chinese Judiciary to achieve substantive justice in the individual case. This is one of the reasons why leaders of the judiciary are not particularly keen with the idea of adopting the three-tier system.

${ }^{798}$ Another possible hurdle in eliminating adjudication supervision is the inevitable objection from vested interests (e.g. from the powerful members of the adjudicative committees of all levels of courts in China).

${ }^{799}$ While reluctant to pursue any structural changes to the appellate system, the SPC has made a modest attempt to enhance uniformity in the application of law through publishing 'guiding cases' (zhidao anli). Courts of all levels should refer to these guiding cases when adjudicating similar cases: see Article 7 of the Provisions of the Supreme People's Court on Case Guidance (Zuigao Renmin Fayuan Guanyu Anli Zhidao Gongzuo De Guiding), effective since 26 November 2010 (Judicial Interpretation ( $f a f a)$ No. 51 [2010]). For an overview of the system of guiding cases, see Jin 2012, p. 29-60.
} 
economy, China needs to build a stable and predictable legal system. Finality of judgment is at the heart of a stable and predictable legal system. Supervision in any organisation is important from an accountability perspective. But any supervision would be counterproductive if there is no empowerment of the individual. The Chinese individual judge is simply not trusted with the task of adjudication. Collective wisdom of the court organization therefore takes precedence over the professional judgment of the adjudicator. Without empowering individual judges and fundamentally changing the judicial culture, any procedural reform would be futile.

\subsection{Civil Fact-finding in China - the search for material truth}

\subsubsection{Efficiency and Fact-finding}

Fairness in adjudication is premised on accurate facts. Constructing a sophisticated and efficient regime for fact-finding is therefore an imperative for civil justice.

China's attempt to enhance efficiency was mainly effected by devolving the responsibilities of fact-finding from the judge to the parties and strengthening the adversarial principle in its civil procedure ${ }^{800}$ Parties are playing an increasingly crucial role in fact-finding. As a general duty, a party is required to produce evidence in support of the facts on which the party's allegations are based. However, it would be a misconception to view fact-finding in China as purely a party driven exercise. In fact, the judge retains extensive powers in shaping the landscape of fact-finding. ${ }^{801}$ The extent to which the judge should be allowed to participate in the fact-finding process is worth close academic scrutiny, particularly given that procedural reforms in China are intended to confer greater autonomy to parties in proceedings.

In Hong Kong, a converse development has been witnessed. The Civil Justice Reform substantially expanded the court's powers in case-management. The court is now equipped with greater discretionary powers to enforce procedural deadlines, limit discovery and administer the litigation timetable. These powers have immense implications for the fact-finding process in Hong Kong, particularly in enhancing efficiency in fact-finding.

\subsubsection{The Evolving Role of the Judge in Civil Fact-Finding}

\subsubsection{Background}

In the past, the Chinese judge wielded monolithic powers in civil litigation. The Ma Xiwu style of adjudication in the past (which emerged in communist controlled areas

800 In this regard, China is not alone given similar experiences of transitional (or former socialist) legal systems. Uzelac described the strengthening of the adversarial principle as 'an attempt to empower judges to use the right to decide on the basis of burden of proof rules, instead of allowing endless, unsuccessful attempts to find certainty based on the evidence that is taken sua sponte'. See Uzelac 2010, p. 392.

801 The judge is empowered to look beyond the pleadings in determining the material facts of the case. The court has the power to investigate and collect evidence on its own account. The judge is also given extensive discretion to determine the burden of proof in cases where the evidentiary rules are silent on the subject. See Zhong \& Yu 2004, p. 401. 
in China before 1949) required the judge to be extremely active in the fact-finding process. The judge would visit the community in which the dispute arose, ascertain the actual situation by interviewing the persons involved in the dispute and actively collect evidence, and reach a decision in the best interest of the community and in line with government policy. ${ }^{802}$ Judicial mediation was the main method for dispute resolution. ${ }^{803}$ The Ma Xiwu style of adjudication greatly influenced the construction of China's modern civil justice system. Although it is no longer the adjudicatory approach in China, some academics are calling for its revival in rural areas. Jiang argued that the Ma Xiwu style of adjudication fits well with the contemporary reality in rural China where parties have very limited resources to conduct fact-finding on their own. ${ }^{804}$

A ground-breaking development in Chinese civil fact-finding was the promulgation by the SPC of Some Provisions of the Supreme People's Court on Evidence in Civil Procedure (Civil Evidence Rules). ${ }^{805}$ The Civil Evidence Rules consist of 83 articles and remain the most comprehensive legal instrument regulating civil fact-finding to date. It is important to read the Code in conjunction with the Civil Evidence Rules in order to fully understand Chinese civil fact-finding. ${ }^{806}$

There is clear devolution of fact-finding responsibilities from the judge to the parties since the Code and the Civil Evidence Rules came into force. ${ }^{807}$ The fact-finding function of the judge has (in principle) turned from collecting evidence to reviewing and checking evidence. ${ }^{808}$

However, commentators have warned that the enhanced role of the parties in factfinding must not be interpreted to mean that the inquisitorial nature of civil adjudication has changed once and for all. ${ }^{809}$ The principle of party presentation does not apply and the judge still retains extensive discretionary powers in fact-finding. ${ }^{810}$

\footnotetext{
802 Huang 2010, p. 115.

803 Consider Huang's summary of the fundamental principles of the Ma Xiwu style of adjudication: "The entire process was summed up in a three-clause formula: "rely on the masses" (yikao qunzhong), "investigate and do research" (diaocha yanjiu), and "mainly use mediation" (tiaojie weizhu)'. See Huang 2010, p. 115.

804 Jiang 2010, p. 154.

805 Note that there are some discrepancies in the English translation of the rules. It is sometimes translated as Specific Provisions on Evidence in Civil Actions of the Supreme People's Court or Several Rules of Evidence Concerning Civil Litigation.

806 The Code must be read in conjunction with the judicial opinions and interpretations of the SPC. The SPC is at the apex of the Chinese court system. The SPC supervises the work of lower courts. It also performs a regulatory role in that the judicial opinions and interpretations of the SPC (on matters relating to civil justice and procedure) are de facto 'statutory instruments'. From the judge's perspective, these opinions and interpretations are as important as the Code, as they provide concrete operational rules and guidance. Simply referring to the Code without understanding the SPC's opinions and interpretations is seriously inadequate. to 46 of the Civil Evidence Rules), and the cross-examination of evidence and witnesses (Art. 66 of the Code; Arts. 47-62 of the Civil Evidence Rules).

808 Fu \& Cao 2010, p. 12.

809 See Zhang \& Zwier 2003, p. 455. It is fair to say that fact-finding under Chinese civil procedure has moved from a strict inquisitorial system to a mixed regime with inquisitorial and adversarial traits.

810 Consider the views of Zhong \& Yu 2004, p. 401:
} 
On a general procedural level, efforts were made to promote the principle of party disposition. However, as Fu argued, the court still retains the authority to decide certain adversarial matters ex parte (e.g. the filing of additional claims). ${ }^{811}$ This remains a major obstacle for China to fully entrench the principle of party disposition.

\subsubsection{Evidence Collection: Party Responsibility System and Judicial Intervention}

Article 64 of the Code provides, 'A party shall have the responsibility to provide evidence in support of its own propositions'. Article 2 of the Civil Evidence Rules provides, 'The parties concerned shall be responsible for producing evidences to prove the facts on which their own allegations are based or the facts on which the allegations of the other party are refuted'. The Code establishes a party responsibility system under which the parties have the primary role of evidence collection while the judge's role becomes secondary. ${ }^{812}$ However, Article 64 of the Code retained the judge's ex officio powers of investigation and evidence collection in two situations: ${ }^{813}$ (1) when the parties cannot independently obtain the evidence for some realistic or objective reasons (the parties may request the court to collect the evidence); and (2) when the court considers the evidence necessary for adjudicating the case. ${ }^{814}$ For the first situation, an example is where the evidence is archived at a public security authority (or when the evidence relates to land or bank deposits) ${ }^{815}$ it is impossible (or very difficult) for parties to collect such evidence on their own accord. Upon application from the party, the court may collect the evidence on the party's behalf. ${ }^{816}$ In the second situation, 'necessity' is elaborated in Article 15 of the Civil Evidence Rules, which tends to give it a restrictive definition, limiting the exercise of the court's ex officio power of investigation and evidence collection to matters relating to state/public interests and non-substantive disputes only. ${ }^{817}$ It is further stated in the

'Chinese judges have more extensive powers than their US counterparts. In common law jurisdictions, judges will only consider the issues raised, the objections mentioned, and the points made in the pleadings. The issues that the parties do not raise are usually waived. Therefore, the judge's determination is limited to the pleadings the parties have filed. As the judge "sits solely to decide" the dispute, she will not make an independent inquiry into the merits of the case, let alone independent investigation. Under the Chinese system, however, a judge's adjudication is not limited to the pleadings and arguments, but focuses on actual investigation and study. The adjudication system and the style of work of Chinese courts are intended to be convenient to, maintain close ties with, and serve the masses. Only after the court has discovered the whole truth of the case and collected sufficient evidence can it make its judgment.'

Fu \& Cao 2010, p. 11.

812 Woo \& Wang 2005, p. 932.

813 Zhang and Zwier argued that the Civil Evidence Rules gave Art. 64 of the Code a narrow interpretation with the view of weakening the ex officio powers of the court in evidence collection. See Zhang \& Zwier 2003, p. 441.

814 Art. 64 of the Code provides, 'For the evidence that cannot be obtained by any parties or their litigation representatives because of some realistic reasons or for the evidence that the people's court considers necessary for adjudicating the case, the people's court shall investigate and collect such evidence'; Art. 3 of the Civil Evidence Rules provides, 'Any party who cannot independently collect evidence due to objective reasons may request the People's court to collect after investigations'.

815 NPCSC Publication 2007, p. 219.

816 Art. 17 of the Civil Evidence Rules sets out three circumstances under which the parties concerned may request the court to investigate or collect evidence on their behalf.

817 Art. 15 of the Civil Evidence Rules reads, 'The "evidences deemed as necessary by the People's court for hearing the case" as mentioned in Article 64 of the Civil Procedure Law of the People's Republic of China shall refer to the following: (1) The facts that may injure the interest of the 
rules that, unless provided in Article 15 of the Civil Evidence Rules, 'the investigation upon and collection of evidences by the People's court shall be based on the application of the parties concerned' ${ }^{818}$ However, in practice, 'necessity' has sometimes been interpreted widely to encompass any matters that the court in its discretion believes to be necessary for the adjudication of the case. An example is where the case involves complex issues such that the parties are unlikely to be able to provide adequate evidence. Under these circumstances, the court will collect evidence on its own initiative to obtain first-hand knowledge of the relevant facts. ${ }^{819} \mathrm{~A}$ discrepancy between the legislative intent and actual practice seems to arise here. On the one hand, it has been argued that the Civil Evidence Rules were intended to give Article 64 of the Code a narrow interpretation with the view of weakening the ex officio power of the court in evidence collection. ${ }^{820}$ On the other hand, as a matter of practice, a wide interpretation can be given to the concept of 'necessity'. 821

As a general principle of fact-finding, the parties and the court are positioned to work hand in hand to discharge the evidentiary responsibilities in a civil action. ${ }^{822} \mathrm{~A}$ possible reason for the retention of the judge's ex officio powers of investigation and evidence collection is the parties' relative lack of resources to conduct fact-finding (as compared with litigants in Western jurisdictions). ${ }^{823}$ With the exception of large commercial cases, an average Chinese party may not have the economic resources to conduct a comprehensive evidence collection exercise. Another hurdle of implementing a full party-driven evidence collection regime is the administrative red tape in China. Nothing really gets done without good connections. Again, an average party may find it very difficult to collect evidence when the source is a government body, a state-owned enterprise or entities backed by powerful individuals. The judge's intervention in the evidence collection exercise does sometimes alleviate these difficulties.

In addition to its investigatory powers, the court retains extensive authority in a number of other areas relating to evidence collection and preservation. ${ }^{824}$

state, the public interest of the society or the lawful interest of other people; (2) The procedural matters that have nothing to do with the substantial dispute, such as adding parties concerned, suspending the litigation, ending the litigation, withdrawing, etc. on the basis of authority of the courts.'

818 Art. 16 of the Civil Evidence Rules.

819 NPCSC Publication 2007, p. 112.

820 Zhang \& Zwier 2003, p. 441.

$821 \quad$ NPCSC Publication 2007, p. 112.

822 Ibidem.

823 Jiang 2010, p. 153-155.

824 The following are a few examples of these powers (as provided in the Code):

Art. 65 states that the court has the authority to obtain evidence from any relevant units or individuals, and such units and individuals may not refuse to provide evidence. The court shall then verify and determine the validity of documentary evidence provided by the relevant unit.

Art. 69 states that the court shall authenticate audio and visual materials and decide whether they can be admitted as a basis for finding the facts after examining them and comparing them with other evidence of the same case.

Art. 71 states that the court has the authority to examine the statements of the parties in connection with other evidence of the case to decide whether such statements can be taken as a basis for finding the facts. The refusal of a party to make a statement shall not prevent the court from finding the facts of a case based on other evidence.

Art. 74 states that the court may preserve evidence on its own initiative where there is a likelihood that the evidence may be destroyed or become too difficult to obtain later on. 
Despite the retention of the court's ex officio powers to intervene, the attempt to move to a party responsibility system in evidence collection is already a significant step forward in promoting greater judicial impartiality in fact-finding (it is at least arguably successful as a legislative design). ${ }^{825}$ The past practice of collecting evidence sua sponte by judges (without any restrictions) bears the danger of the judge forming premature views on the merits of the case (e.g. favouring one side over the other) during the process of evidence collection, thereby negatively affecting the impartiality of the court. ${ }^{826}$ However, the ease with which judges may intervene with evidence collection today (even in the absence of application from the parties) suggests that the same danger is still very much present under the current fact-finding regime. ${ }^{827}$ An inappropriate exercise of judicial activism will result in unwarranted encroachment on what is supposed to be a party responsibility system of evidence collection.

The way in which the court exercises its powers of investigation and evidence collection also deserves attention. Under the current evidence collection regime, judges are still allowed to contact the parties and witnesses individually without a formal hearing or without the participation of the opposing party. This practice contradicts the principle of open trial, potentially taints the reliability of evidence (as a witness testimony may be influenced by the exchange between the judge and the witness) and assaults judicial impartiality. ${ }^{828}$ Another concern is the power of the Chinese judge to take both real and documentary evidence ex officio. ${ }^{829}$ As Zhong and $\mathrm{Yu}$ argued, an arbitrary exercise of judicial powers of investigation and evidence collection negatively affects the reliability of evidence gathered and places 'extraevidentiary influences on judgments'. ${ }^{830}$

Empirical research shows that judges still exercise their powers of investigation and evidence collection to 'varying degrees, depending on judicial temperament, philosophy and ability'. ${ }^{831}$ Another factor that determines the degree of judicial evidence collection is the caseload of the court. A court struggling with a heavy

825 Woo \& Wang 2005, p. 932.

826 Zhang \& Zwier 2003, p. 430.

827 Fu \& Cao 2010, p. 12-13.

828 Fu \& Cao 2010, p. 11.

829 This is contrasted with the judges in certain continental European jurisdictions (e.g. Austria) who are only able to take real evidence ex officio. In these jurisdictions, documentary evidence is only admissible if at least one of the parties has referred to the document in question. See Oberhammer \& Domej 2005, p. 304.

The extent to which the court uses its investigatory power also varies with jurisdictions. For example, in France, the preparatory judge (le juge de la mise en état) 'in practice seldom uses the statutory powers to investigate, and so controls more than directs factual investigation in the pretrial phase'. See Clermont \& Sherwin 2002, p. 248.

830 Consider the views of Zhong \& Yu 2004, p. 436:

'Formal procedure is often perfunctorily applied. Because the judge conducts an extensive investigation and collects evidence before he hears the case, he has an understanding of the likely result of the litigation before adjudication commences. In some instances, the judge will make a decision about the outcome of a case before hearing any argument, making the trial essentially a "show trial". Further, in the course of investigation, the judge inevitably has frequent, often ex parte, contacts with both litigants. All of these extra-evidentiary influences on judgments are problematic. Frequent contacts between the judge and litigants facilitate judicial corruption because they are not subject to any procedural requirements.'

831 Woo \& Wang 2005, p. 933. 
caseload usually has no time to actively investigate, thus allowing greater party autonomy in evidence collection. ${ }^{832}$

\subsubsection{Civil Burdens of Proof - A Big Step Forward?}

The issue of civil burdens of proof is closely intertwined with the devolution of evidence collection responsibilities to the parties. These elements form the building blocks of the party responsibility system in Chinese civil fact-finding. The foundational provision for civil burdens of proof is Article 2 of the Civil Evidence Rules:

'The parties concerned shall be responsible for producing evidences to prove the facts on which their own allegations are based or the facts on which the allegations of the other party are refuted.

Where any party cannot produce evidence or the evidences produced cannot support the facts on which the allegations are based, the party concerned that bears the burden of proof shall undertake unfavourable consequences.'

Articles 4, 5 and 6 of the Civil Evidence Rules allocate specific burdens of proof in tortuous, contractual and other forms of disputes. Under Article 7 of the Civil Evidence Rules, where specific burdens of proof are not explicitly provided and it is not possible to define who shall be responsible for producing evidence according to the Civil Evidence Rules or other judicial interpretations, the court may determine the burden of proof in accordance with the principle of fairness and the principle of honesty and credit, and taking factors such as the ability to produce evidence into consideration. ${ }^{833}$

There are obvious gaps in the current rules governing burden of proof. Firstly, the standard of proof has not been expressly delineated. Secondly, there is no provision governing the shifting of the burden of proof in specific situations. Thirdly, greater procedural guidance is warranted when the court exercises its wide discretion in determining the burdens of proof when encountered with the situation under Article 7 of the Civil Evidence Rules. Fourthly, some commentators have criticised the overly serious consequence when a party fails to provide adequate evidence in support of its allegations, which usually results in the party losing the case. Jiang observed that China should develop its own evidence production regime based on the joint effort of the parties and the judge (inferring that the second paragraph of Article 2 of the Civil Evidence Rule should be repealed). ${ }^{834}$

The first two problems have been partially addressed in Articles 133 to 142 of the Uniform Provisions of Evidence of the People's Court: Proposal for Judicial Interpretations (Proposal). ${ }^{835}$

\section{Ibidem.}

Art. 7 of the Civil Evidence Rules.

Jiang 2010, p. 154-155.

Zhang B.S. 2008, p. 94-100. The Proposal was adopted in pilot programmes of a number of local courts in China. The main objective of the Proposal is to construct a uniform set of rules of evidence that applies to all cases (civil, criminal and administrative). However, this objective was not widely accepted within the legal field. It is unclear whether the Proposal would be considered again in future legislative exercises. 
In practice, the question is whether the courts truly subscribe to the burdens of proof requirements as a fundamental premise for decision-making. An empirical study shows that judges generally view burdens of proof as relevant in the decision-making process. Burdens of proof tend to be 'decisive in close decisions' ${ }^{836}$

\subsubsection{The Paradox of Party Responsibility in the Absence of the Principle of Party Presentation}

Paradoxically, the devolution of fact-finding responsibilities to the parties and the introduction of adversarial elements to the fact-finding regime proceeded without implementing the principle of party presentation (Verhandlungsmaxime). ${ }^{837}$ The follow-up question must be whether the reform to enhance party participation in factfinding was intended only to achieve efficiency rather than promoting overall justice through true party empowerment. ${ }^{838}$

Examples that demonstrate the operation of this paradoxical fact-finding philosophy are numerous. Firstly, statements made by parties are a specific class of evidence. ${ }^{839}$ While performing a similar function as pleadings (i.e. setting out the party's claim), the status of party statements is nothing close to that of common law pleadings. Article 71 of the Code provides that the court shall examine the statements of the parties in connection with other evidence of the case to decide whether such statements can be taken as a basis for finding the facts. The refusal of a party to make a statement shall not prevent the court from finding the facts of the case based on other evidence. In other words, party statements may not be taken as a basis for factfinding if the judge decides it is inappropriate to do so (having also considered other evidence). In any event, party statements may only form part of the basis for factfinding and the court is at liberty to depart from the remits of the statements. ${ }^{840} \mathrm{In}$ case a party refuses to make a statement, the court can do away with the party statement requirement altogether and rely on other evidence as the basis for factfinding. ${ }^{841}$ Secondly, while parties are entitled to engage in debate in a court session, ${ }^{842}$ the debate only serves as a fraction of the fact-finding procedure. As with party statements, the court has no obligation to render judgment on the basis of party debates. This is known as the non-binding principle of debate. ${ }^{843}$ Thirdly, judicial evidence collection may go well beyond the factual remits set out by the parties under circumstances explained above.

\footnotetext{
836 Woo \& Wang 2005, p. 933-934.

837 Lenhoff observed (when discussing the principle of party presentation), 'Since it is for the parties to initiate the proceedings, it is left to them to present the facts in support of their demands and defences'. See Lenhoff 1954, p. 313.

838 The Proposal still retained the ex officio powers of the judge to collect evidence under certain circumstances (e.g. facts involving a person's identity and relationships) or where it is 'necessary to collect evidence...to verify evidence of significant importance to a case or evidence having material doubts'. See Article 110 of the Proposal.

839 Art. 63 of the Code.

840 Fu \& Cao 2010, p. 13; also see Zhong \& Yu 2004, p. 401: 'Under the Chinese system, however, a judge's adjudication is not limited to the pleadings and arguments, but focuses on actual investigation and study.'

841 Fu \& Cao 2010, p. 13.

842 Under Arts. 12 and 50 of the Code, parties are entitled to engage in debate. Arts. 127 and 128 of the Civil Evidence Rules set out the procedures for court debate.

843 Fu \& Cao 2010, p. 7.
} 
Without entrenching the principle of party presentation, the remit of fact-finding becomes nebulous. Despite positive developments in the Civil Evidence Rules ${ }^{844}$ in the direction of abandoning the doctrine of factuality, ${ }^{845}$ the backdoor for active judicial investigation invites the reincarnation of the doctrine. If determined to be 'necessary for adjudicating the case', ${ }^{846}$ the judge may go beyond the evidence presented by the parties and engage in his own train of evidential enquiry ex officio, causing delay and other problems. ${ }^{847}$ Without the entrenchment of the principle of party presentation, party participation in fact-finding may reduce (in the extreme case) to a mere nominal exercise under which parties spend considerable time delineating the facts, producing evidence and debating the facts only to find that their participation had very limited influence over the court's ultimate fact-finding determination. Paradoxically, as a result of the absence of the principle of party presentation, the increased adversarial elements in Chinese civil procedure (which were introduced partly to achieve procedural efficacy) have the potential of causing greater delay due to the formal requirements of party participation. On a substantive level, the lack of entrenchment of the principle of party presentation is contrary to the objective of party empowerment, which is supposed to be one of the main themes in the Chinese civil justice reform.

There are two main reasons for the continued rejection of the principle of party presentation in Chinese civil procedure. Firstly, the Chinese legal historical experience in civil litigation was about the empowerment of the magistrate (or the judge) and not the parties. In magisterial civil adjudication in imperial China, unrestrained fact-finding powers were conferred to the magistrate. ${ }^{848}$ While parties were allowed to be involved in presenting evidence, the magistrate was the ultimate arbiter in determining the factual scope of the case. The Ma Xiwu style of adjudication was also premised on the notion of an all-powerful investigatory judge. Secondly, the obsession for material truth in Chinese legal culture nurtured an adjudicative philosophy that is hostile to the principle of party presentation. ${ }^{849}$ Under this jurisprudential view, which in some ways is revealed in the Code, ${ }^{850}$ partypresented facts can only form the legal truth of a case. The partisan predispositions of the litigants almost certainly cannot ensure that a fact-finding process premised on the principle of party presentation can ever reveal the material truth. This view necessitates the court to go one step further to ascertain the material truth. The Maoist instrumentalist approach to legal procedure (which focuses on material truth) still has a lingering effect on the contemporary civil justice system. ${ }^{851}$ Indeed, the obsession with material truth has been identified as a characteristic feature of former socialist or transitional civil justice systems. ${ }^{852}$ While Article 63 of the Civil Evidence Rules is

\footnotetext{
844 Art. 63 of the Civil Evidence Rules.

845 Zhang \& Zwier 2003, p. 451. The doctrine of factuality concerns the judicial pursuit of the material truth.

846 Art. 64 of the Code.

847 Fu \& Cao 2010, p. 13.

848 Zhong \& Yu 2004, p. 433.

849 For academic support of the doctrine of factuality, see Jiang 2010, p. 155. For criticism of the judicial preference for material truth, see Zhang \& Zwier 2003, p. 431-432; also see Zhong \& Yu 2004, p. 433-436.

850 Under Art. 64 of the Code, 'The people's court shall, in accordance with the procedure prescribed by law, collect and examine evidence comprehensively and objectively'.

851 Zhong \& Yu 2004, p. 433-436.

852 Uzelac 2010, p. 390.
} 
said to have repealed the doctrine of factuality, ${ }^{853}$ the traditional preference for material truth and the retention of the judge's ex officio powers of investigation and evidence collection suggest that the doctrine of factuality still exerts considerable influence over contemporary civil adjudication in China.

\subsubsection{Judicial Clarifications in Chinese Civil Fact-finding}

Article 3 of the Civil Evidence Rules provides, 'The People's court shall inform the parties concerned of the requirements for producing evidences and of the corresponding legal liabilities so that the parties concerned may produce evidence actively, completely, correctly and honestly within the reasonable time period'. In the context of judicial clarifications (richterliche Aufklärung), it is clearly inadequate if the court only provides general clarifications on the evidentiary requirements. Zhang observed that any direction from the court must be made after carefully considering the party's allegations made. ${ }^{854}$ The clarifications should preferably be concrete and specific. In practice, the lack of clarification has caused parties to omit evidence resulting in the failure to establish the facts on which their allegations were based. ${ }^{855}$ Unclear clarification would also result in delay in evidence production. However, it is unrealistic (and objectionable from a procedural efficacy perspective) to require the judge to micromanage the parties' evidence production exercise. A balance needs to be struck.

Another example is Article 35 of the Civil Evidence Rules. Under the rule, 'If, in the process of litigation, the nature of the legal relations alleged by the parties concerned or the validity of the civil acts are inconsistent with the findings of fact made by the People's court on the basis of the facts of the case, the provisions of Article 34 of the present Provisions shall not be applicable, and the people's court shall inform the parties concerned that the allegations [of the] litigation may change' ${ }^{856}$ For instance, if the contract that forms the basis of the plaintiff's claim for the repayment of a loan was determined to be invalid by the court, the court will notify the plaintiff and the plaintiff would need to decide whether to amend his claim (e.g. from a contractual claim to a proprietary claim) ${ }^{857}$ Inconsistency between an allegation and the facts would only lead the litigation to a dead end causing undue delay. The rule allows some leeway for the plaintiff to modify his claim and saves time and cost.

These examples illustrate the importance of judicial clarifications in Chinese civil fact-finding.

\subsubsection{Evidence Exchange and Management with Efficiency in Mind}

An example of evidence management is the regulation of the production of new evidence. Under Article 125 of the Code, parties may present new evidence during trial (first instance hearing) or on appeal (second instance hearing). This rule has been

\footnotetext{
853 Zhang \& Zwier 2003, p. 451.

854 Zhang W.P. 2006, p. 142.

855 Ibidem.

856 Zhang W.P. 2006, p. 143.

857 Zhang W.P. 2006, p. 144.
} 
criticised for causing undue delay. ${ }^{858}$ However, if one looks at Article 125 of the Code in conjunction with Articles 40 to 45 of the Civil Evidence Rules, the parties' right to present new evidence is not unrestricted. ${ }^{859}$ In the case of Guo Chun Xuan v Liu Zong $L a i,{ }^{860}$ the plaintiff applied to the Zhengzhou City Intermediate Court to produce supplemental evidence. The court rejected the application on the basis that the supplemental evidence was not 'new evidence', as it was already in 'objective existence' (and in the custody of the plaintiff) during the time period for producing evidence. ${ }^{861}$ The 'objective existence' test ${ }^{862}$ is contrasted with the more sophisticated test in Hong Kong for adducing new evidence on appeal pursuant to the principles in Ladd v Marshall. ${ }^{863}$

A second example is the introduction of time-limits for producing evidence. As a general principle under the Civil Evidence Rules, parties are required to produce evidence 'actively, completely, correctly and honestly within the reasonable time period'. ${ }^{864}$ On this basis, the Chinese Judiciary is determined to establish the normative effect of time-limits by providing a severe 'sanction' for non-observance of time-limits. Failure to submit evidence within the time period shall be deemed as giving up the right to produce evidence. ${ }^{865}$ The position on time-limits has been further clarified since the promulgation of the Notice of the Supreme People's Court on Applying the Provisions on Time-Limits for Producing Evidence of Some Provisions on Evidence in Civil Procedures, ${ }^{866}$ which provides for detailed regulations on time-limits for different types of procedures (e.g. summary procedure and jurisdictional challenge).

A third example is the exchange of evidence. Article 39 of the Civil Evidence Rules provides that the court shall manage the process of exchange of evidence and '[in] the process of exchanging evidences, the judges shall record in the case files the facts and evidences to which the parties concerned have no objection'. The evidence not subject to objection is deemed to be 'affirmed' or 'admitted' by the parties. Such evidence

858 Zhang and Zwier noted, 'It is very common that a party refuses to produce or exchange evidence before the trial, but presents the evidence to the court during the trial by surprise, or even on appeal. Even where a party has presented no evidence during the trial, he could present to the appellate court "new" evidence in his favour.' See Zhang \& Zwier 2003, p. 430-431; also see Uzelac 2010, p. 392.

859 'New evidence' is clearly defined. For instance, in relation to the first instance hearing, Art. 41 of the Civil Evidence Rules states, 'The new evidences of the first instance hearing include: the evidences newly found by the parties concerned after the expiration of the time period for producing evidences in the first instance court hearing; the evidences which the parties concerned cannot provide during the time period for producing evidences due to objective reasons and still cannot provide during the extended time period approved by the People's court.'

860 (2008) zheng min san chu zi (No. 99) [reported civil judgment of the Zhengzhou Intermediate People's Court, Henan Province]. It is a first instance hearing.

861 (2008) zheng min san chu zi (No. 99) [reported civil judgment of the Zhengzhou Intermediate People's Court, Henan Province].

862 Art. X of the Notice of the Supreme People's Court on Applying the Provisions on Time-Limits for Producing Evidence of Some Provisions on Evidence in Civil Procedures.

863 [1954] 1 WLR 1489, 1491. For the Hong Kong test, consider Wilkinson, Cheung \& Booth 2009, p. 953: 'The Court of Appeal has power to receive further evidence on questions of fact, but no such further evidence (other than evidence as to matters which have occurred after the date of the trial or hearing) shall be admitted except on special grounds [as set out in Ladd v Marshall].'

866 Promulgated by the SPC on 11 December 2008; effective since 11 December 2008. 
would be taken as the basis for affirming the facts of the case without crossexamination ${ }^{867}$ Where there are any objections, the objecting party must provide reasons. Being satisfied with the reasons, the judge will record such evidence in accordance with the classified facts that need to be provided. By managing the exchange of evidence, it is intended that the major factual issues of the case are determined in advance of trial. ${ }^{868}$ There is a statutory limit on the exchange of evidence: there can be no more than two rounds of exchange of evidence, unless the case is very important or very complicated and the court believes it is necessary to have another round of exchange of evidence. ${ }^{869}$

\subsubsection{Institutional constraints in reforming Chinese civil fact-finding}

In relation to civil fact-finding in Mainland China, the next stage of reform must involve the entrenchment of the principle of party presentation, without which there can be no true party empowerment. Noting the relatively weak positions of the parties in rural China, such reform efforts may proceed in stages based on geographical differentiation.

The individual Chinese judge is institutionally weak. External interference with the adjudicatory process is the norm, rather than the exception. ${ }^{870}$ Wang has warned that the 'bureaucratization of the court', a widespread phenomenon in China, has stripped every opportunity to develop adjudicatory independence in China. The collective decision of the court organization trumps the decision of the individual judge, despite the individual judge having superior knowledge and understanding of the case. ${ }^{871}$ The individual judge's deference to the court leadership (coupled with external interferences with adjudication) makes it almost impossible to construct a fair factfinding regime. Factors completely unrelated to the adjudication of the case could affect the fact-finding process. Unfortunately, recent reform efforts in relation to factfinding focused on minor technicalities without due consideration on how to promote fundamental principles in this area. ${ }^{872}$

For Hong Kong, the task going forward is to test the effectiveness of the new tools introduced by the CJR (such as the power of the court to limit discovery) ${ }^{873}$ designed to enhance efficiency in fact-finding. ${ }^{874}$

867 Art. 47(2) of the Civil Evidence Rules; also see Zhang \& Zwier 2003, p. 448.

Under Article 66 of the Code, cross-examination is a prerequisite to admission of evidence (with the exception of evidence 'admitted' by the parties). The purpose is to ensure that the evidence is reliable and avoid discrepancies in the fact-finding process. Also see Arts. 47-62 of the Civil Evidence Rules on cross-examination.

868 Art. 39 of the Civil Evidence Rules.

869 Art. 40 of the Civil Evidence Rules.

870 A noteworthy example is the existence of an adjudicative committee in every court in China. In certain important and complex cases, the judge must first refer such cases to the adjudicative committee for discussion. The judgment must implement the decision/opinion of the adjudicative committee. See Chen 2011, p. 186.

Another example is the system of advisory requests (qingshi). Consider the views of Minzner 2011a, p. 58-59: 'To avoid appellate reversal, lower Chinese courts and judges rely on an illdefined system of advisory requests (qingshi) to solicit the views of higher courts and judges on how to decide pending cases.'

871 Wang Y.X. 2011, p. 1.

872 Ibidem.

873 RHC O. 24, r. 15A. 
The policy preference for court mediation obscures the function of fact-finding in the Chinese courts. Under the artificial settlement culture in China, court mediation is at risk of losing its function as an alternative dispute resolution method as parties no longer truly voluntarily submit to mediation. ${ }^{875}$

\subsection{Chapter conclusion}

Court mediation is considered an 'adjudicatory act' (shanpan xingwei). A 'mediation statement' reached through court mediation (tiaojie shu) has the effect of a civil judgment. Hence the principles governing adjudication should equally apply to court mediation (even without the express requirements under Article 93 of the Code). The analysis of the two fundamental tenets of Chinese civil adjudication in this chapter is crucial as it provides a solid conceptual foundation to better understand the intricate dynamics in Chinese court mediation. Without such a conceptual premise, it would be difficult to rationalize the predominant role of the judge-mediator, the deference of parties to the judge-mediator in the mediation process and the unique judicial 'logic' that any mediated settlement must be consistent with the factual findings of the case and the substantive law in question.

874 The CJR emphasizes on identification of the issues at an early stage of the proceedings so that the court can take proactive steps to ensure this initial step of fact-finding is carried out expediently and appropriately. This is envisaged, for example, under RHC O.24, r. 15A: see HSBC Private Bank (Suisse) SA v Mission Bridge Ltd, unreported, HCA 406/2008, 2538/2009, 212/2012, 18 June 2012

875 Minzner noted, "Alternative dispute resolution succeeds when it truly represents an "alternative" to litigation... But that is not the case when alternative dispute resolution becomes an artificial panacea for social stability'. See Minzner 2011b, p. 963. 


\section{Chapter 8:}

\section{Trial Management in China:}

The Institutionalisation of Judicial Preference for Court Mediation in Civil Litigation Overview of Principles and Practice 


\section{TRIAL MANAGEMENT IN CHINA: THE INSTITUTIONALIATION OF JUDICIAL PREFERENCE FOR COURT MEDIATION IN CIVIL LITIGATION - OVERVIEW OF PRINCIPLES AND PRACTICE}

\subsection{Trial management and civil justice: bureaucratic justice or managerial excellence?}

In China, the concept of 'trial management' (also known as 'judicature management') (shenpan guanli (审判管理)) is categorically different from the Western concept of 'case management'. Apart from considering the efficiency of handling cases, the concept of 'trial management' embraces an administrative perspective of managing the court institution, the individual judge (including disciplinary matters) and the implementation of policy objectives in civil adjudication (e.g. the policy objective of preferring mediation over adjudication). From the Chinese perspective, the court's main function is dispute resolution. ${ }^{876}$ The Chinese contemporary concept of 'dispute resolution' captures a fundamental policy objective of civil justice - achieving a state where 'the case is closed and the dispute is [truly] resolved' (anjie shiliao (案结事 了)). Anjie shiliao is not a purely procedural concept but rather a socio-legal phenomenon. It means that the disposal of a lawsuit is insufficient unless it is coupled with the quelling of discontent on the social level in relation to the dispute. Trial management measures the procedural efficacy and social effect of court work and processes by meticulously collecting and analyzing data on case processing. Among other benchmarks, trial management takes indices such as 'mediation settlement rate', 'withdrawal rate', 'actual enforcement rate' and 'the rate of reversal and new trial by remittal of first instance decisions (decisions in error)' into account in its assessment of judicial merit. These benchmarks feature in a scoring matrix that measures the level of fairness (公正指标), efficiency (效率指标) and effectiveness (效果指标) in the handling of cases by the court under review.

Some academics in Mainland China have questioned the appropriateness of using indices like 'mediation settlement rate' as a point of reference for the assessment of judicial work. For instance, Cai argued:

'Meanwhile, the Supreme People's Court has included the mediation rate in the indexes for evaluating the effectiveness of the Judiciary in its relevant case management documents, and the various levels of courts have refined the relevance of these indexes by taking them as a point of departure when evaluating judges and courts in their assessments at the end of the year as well as when selecting senior judges. This stimulates the judges to actively (perhaps excessively) increase the mediation rate. In some regions, this mediation rate has acquired a predominant role under the name of "innovation", and courts in a few regions even initiate "none-judgment campaigns", which results in judges viewing mediation as a mandatory step in litigation, consciously or subconsciously, and persuading or even threatening the parties to mediate. ${ }^{, 877}$

\footnotetext{
${ }^{876}$ Fu \& Cao 2012, p. 495-519.

${ }^{877}$ Cai 2014, p. 46.
} 
This chapter surveys the key policy principles underlying China's civil trial management system by examining the overarching SPC interpretation on 'case quality evaluation' and the actual operation of the system. The chapter also contains the views of judges from both intermediate and basic level courts that tend to validate the basic argument advanced in this chapter: that trial management is a mass caseprocessing system designed predominantly to alleviate social discontent in line with the political goal of maintaining public order and social stability (weiwen). With such institutional and political backdrop of trial management, it is not difficult to understand the judiciary's tolerance of abusive practices in court mediation. Coercive mediation/conciliation tactics are seen as a necessary evil in the routine disposal of cases.

The trial management system regulates procedural matters in litigation and manages the ever-increasing caseload within Chinese courts. While effective as a caseprocessing mechanism, it serves predominantly institutional goals. Fairness in the individual case becomes secondary when the institutional needs become pressing (e.g. the need to clear backlogs). This has far-reaching ramifications for the administration of justice in China. The problem is further complicated by the rigid and artificial criteria for evaluating 'case quality' under the system.

The specific criteria for assessing a judge's performance (faguan kaohe) vary from court to court. However, some common criteria are ascertainable. The promotion of court settlement through mediation is one of them.

In 2011, the SPC issued an opinion to provide guidance on trial management: Supreme People's Court's Several Opinions on Strengthening Trial Management Work in the People's Courts (SPC Trial Management Opinion). ${ }^{878}$ The opinion sets out a high-level framework for trial management:

(a) Functional scope of trial management: the scope of trial management is extremely wide, encompassing the evaluation of 'case quality', promoting effectiveness and efficiency of litigation, and managing processes and workflow of the court. ${ }^{879}$ Trial management covers all procedural stages of the civil process. ${ }^{880}$

(b) Functional position of the Trial Management Office: the Trial Management Office is a 'conduit' between the Adjudication Committee (the most powerful organ within the court structure) and different departments/ divisions of the court. $^{881}$ The Trial Management Office advises the Adjudication Committee on all matters relating to trial management and supervises the day-to-day management of court processes and workflow on behalf of the Adjudication Committee. $^{882}$

\footnotetext{
878 Judicial Notice (fafa) [2011], No.2.

${ }^{879}$ Part 3 of the SPC Trial Management Opinion.

880 Article 4 of the SPC Trial Management Opinion.

881 For instance, the trial management office should liaise with the court's personnel management unit: see Article 17 of the SPC Trial Management Opinion.

882 Part 4 of the SPC Trial Management Opinion.
} 
(c) Basic objectives of trial management: achieving anjie shiliao (i.e. 'the case is closed and the dispute is [truly] resolved'). The 'social effect' in a judgment is all-important from a trial management perspective. Higher courts should supervise lower courts in trial management. ${ }^{83}$

\subsection{An overview of the 2011 SPC Case Quality Opinion}

The promulgation of the Supreme People's Court Guidance Opinion Relating to the Commencement of the Work on Case Quality Evaluation (2011 SPC Case Quality Opinion $)^{884}$ is a landmark development in trial management. ${ }^{885}$

There are four main themes in the 2011 SPC Case Quality Opinion: (1) unifying standards in the case quality evaluation system with the view to promote efficiency and fairness in litigation; (2) constructing a sophisticated, 'scientific' and systemic evaluation framework encompassing adjudicatory matters and non-adjudicatory matters (e.g. enforcement work, management of judicial personnel); (3) institutionalizing the system of case quality evaluation such that there is a clear delineation of responsibilities of different court divisions as well as institutionalizing the supervisory and evaluative powers of higher-level courts over lower courts in relation to case quality; and (4) improving data collection, analysis and management, and establishing effective reporting channels on matters concerning case quality evaluation.

In spite of its name, the actual operation of the 'case quality evaluation' system is nothing close to a qualitative assessment. Each court is assessed on a quantitative scale. For instance, a larger number of cases overturned or remitted on appeal would reflect negatively on the court's ability to resolve disputes conclusively. This is the so-called 'scientific' nature of the evaluation system emphasized under the 2011 SPC Case Quality Opinion. Nowhere in the evaluation scale could one find qualitative parameters, such as the quality of the written judgments or the significance of the judgments (e.g. the 'precedential value' of a court decision, obviously 'precedent' in a non-binding sense). The danger of focusing almost completely on numbers is that one would inevitably lose sight of the big picture. A court may be doing a huge service to the local community by accepting cases that are complex and sensitive (or concern novel legal issues), but by doing so causes a higher rate of appellate reversals. Nor does the current scale take into account the attention of each court given to protecting the procedural rights of the parties. Such a number-based system incentivises courts to become a rigid case-processor and discourages the bench to venture into 'hard cases' or do justice in an individual case as doing so may taint the court's record. The individual judge in fact would even be 'penalised' under the system for demonstrating any form of judicial innovation, as an attempt to go against established norms may result in appellate reversal (a key tertiary index in a court's evaluation).

\footnotetext{
883 Articles 4 and 6 of the SPC Trial Management Opinion.

884 Judicial Notice (fafa) [2011], No. 55.

885 The 2011 Case Quality Opinion supersedes the Supreme People's Court Guidance Opinion Relating to the Commencement of the Work on Case Quality Assessment (Test Implementation)(2008).
} 
The case quality evaluation system consists of three levels of indices: (1) the 'primary index', consisting of a single 'Integrated Case Quality Index', which is the 'overall score' of the court under evaluation; (2) the secondary indices, consisting of the Fairness Index (has a weighting of $40 \%$ of the primary index), Efficiency Index (has a weighting of $30 \%$ of the primary index) and Effectiveness Index (has a weighting of $30 \%$ of the primary index); and (3) the tertiary indices (each being grouped under a secondary index), consisting of 31 indices encompassing a wide range of matters, each with different weighting.

Among the 31 tertiary indices, the following indices explicitly encourage and incentivise courts to resort to mediation or persuade the claimant to withdraw the claim:

(a) 'mediation settlement rate' (调解率) (tertiary index no. 23): this index, which constitutes $8 \%$ of the Efficiency Index (secondary index), encourages courts to settle dispute through court mediation at all stages of proceedings (including appellate and re-adjudication stages). The underlying principle is that a high mediation settlement rate reflects positively on the court's ability to resolve disputes with maximizing the 'social effect' (社会效果) in mind. In other words, scoring well in this index shows the court is able to maintain social stability within the community and avoid escalation (e.g. avoiding citizens petitions). ${ }^{886}$

(b) 'withdrawal rate' (撤诉率) (tertiary index no. 24): this index, which constitutes $6 \%$ of the Efficiency Index (secondary index), is a catch-all parameter to measure the court's ability to resolve disputes through nonadjudicative means other than court mediation. A claimant may withdraw the lawsuit of his own accord or does so after the court has invested time in 'facilitating' a withdrawal. Similar to the mediation settlement rate, a high withdrawal rate reflects positively on the court's ability to resolve disputes with maximizing the 'social effect' in mind. ${ }^{887}$

Among the tertiary indices, the following indices have the direct effect of encouraging a court to prefer mediation (instead of rendering a judgment):

(i) 'rate of reversal and new trial by remittal of first instance decisions (decisions in error)' (一审判决案件改判发回重审率（错误）) (tertiary index no. 3): this index, which constitutes $19 \%$ of the Fairness Index (secondary index), penalizes courts for rendering erroneous first instance decisions (including factual errors, errors in the application of law and procedural errors). The index captures not only appellate reversals (and remittals) but also reversals (and remittals) resulting from procuratorial challenges (抗诉). This index greatly affects the way judges view the role of court mediation in civil litigation. Given the substantial weighting of this index, judges tend to favour mediation, because a mediated settlement

\footnotetext{
${ }^{886}$ See Appendix to the 2011 SPC Case Quality Opinion.

887 Ibidem.
} 
cannot be appealed (and rarely becomes the subject of a procuratorial challenge). As discussed in earlier chapters, this institutionalized incentive to avoid mistakes unduly distorts the role and function of court mediation. ${ }^{888}$

(ii) 'rate of reversal and new trial by remittal of effective decisions' (生效案 件改判发回重审率) (tertiary index no. 7): this index, which constitutes 21\% of the Fairness Index (secondary index), penalizes courts for rendering erroneous second instance decisions (including factual errors, errors in the application of law and procedural errors). Similar to tertiary index no. 3, this index encourages judges to push for settlements, because if a case is settled, it is less likely that it would be reopened through the adjudication supervision procedure. ${ }^{889}$

(iii) 'rate of application for leave to re-adjudicate' (再审审查率) (tertiary index no. 29): this index, which constitutes $10 \%$ of the Effectiveness Index (secondary index), captures the rate of applications for leave to readjudicate what are otherwise effective judgments and non-appealable mediation statements. The relevance of this index as a factor for evaluating the quality of adjudication is questionable. The fact that a party applied for leave to re-adjudicate does not impute error in the adjudication process on the part of the court under review. The prospect of any effective judgment subject to applications for leave to re-adjudicate discourages judges to adjudicate. This is particularly true when the rate of applications has no necessary link with the quality of justice delivered. ${ }^{890}$

Among the tertiary indices, the following indices have the indirect effect of encouraging courts to prefer mediation (instead of rendering a judgment):

(i) Tertiary indices nos. 13-16 and $18^{891}$ (which constitutes $48 \%$ of the Efficiency Index (secondary index)) concern the speediness of civil procedure. It is unrealistic to expect judges to dispose of cases within a rigid timeframe when the caseload remains unreasonably high. ${ }^{892}$ The inflexible nature of these indices (which do not take into account the real situation of individual courts) pushes judges to resort to non-adjudicative means (such as mediation) to close cases within the designated timeframes if adjudication is unlikely to bring forth a quick resolution. ${ }^{893}$

(ii) Tertiary indices nos. 10-21 (which constitutes 34\% of the Efficiency Index (secondary index)) concern the volume of cases disposed of within a given year. For instance, tertiary index no. 21 imposes a requirement on the court to ensure that the (judge) per capita disposal of cases remains high

\footnotetext{
888 Ibidem.

889 Ibidem.

890 Ibidem

${ }^{891}$ For instance, tertiary index no. 16 is called the 'Index of the average time in disposing a case' (平均 审理时间指数).

892 Interview Ref: 2012/7

${ }^{893}$ See Appendix to the 2011 SPC Case Quality Opinion.
} 
every year. In other words, it is not enough to have a high overall volume of disposal; the court leadership must also ensure that each individual judge meets (or beats) expectation in case disposal every year. These indices encourage judges to resort to non-adjudicative means (such as mediation) if they are more effective in achieving case disposal targets. ${ }^{894}$

(iii) Tertiary index no. 17 (which constitutes 9\% of the Efficiency Index (secondary index)) and tertiary index no. 25 (which constitutes $15 \%$ of the Effectiveness Index (secondary index)) concern the speediness and effectiveness of enforcement proceedings. ${ }^{895}$ Tertiary index no. 17, known as the 'Average Enforcement Time Index', measures the efficiency of the court in enforcement. The index calculates the average speed of enforcement vis-à-vis the statutory time limit for enforcement. The intention of this index is to encourage courts to push for speedy enforcement and observe the statutory time limit for enforcement. Tertiary index no. 25, known as the 'Actual Enforcement Rate', calculates the proportion of 'entirely enforced' (执行完毕) judgments in the total number of court enforcement processes completed within a given year. The rationale behind this index is that the completion of court enforcement process does not necessarily mean that a judgment is 'entirely enforced'. For instance, a judgment creditor may invoke court enforcement proceedings in connection with a part of the judgment debt (Judgment Debt X), thinking that he is able to recover on his own the remaining part of the judgment debt (Judgment Debt Y). It turns out that while the court enforcement process was duly completed (i.e. Judgment Debt $\mathrm{X}$ is recovered), Judgment Debt $\mathrm{Y}$ remains outstanding. In this situation, the court enforcement process is 'complete' but the judgment debt is not 'entirely enforced'. ${ }^{896}$ The problem with pushing courts to deliver quantitative enforcement results is that the quality of justice could be jeopardized. This problem is further complicated by the fact that courts tend to resort to the 'enforcement reconciliation procedure' to achieve a speedy enforcement. ${ }^{897}$ The problematic procedure is discussed in Chapter 4. To summarize, where it is not possible to enforce to the full extent of the judgment debt, parties may agree to settle upon payment of a fraction of the judgment debt. For example, the claimant was awarded RMB 2 million in damages in a simple breach of contract dispute. However, the defendant was unwilling to pay and the claimant brought enforcement proceedings at the court. Noting the difficulty to push the defendant to pay the damages in full, the court encouraged the claimant to negotiate with the defendant with a view to reach a settlement. The claimant, fearing that he may recover nothing if he insisted on enforcing the entire judgment debt, compromised in the negotiation and agreed to take RMB 1 million. The enforcement reconciliation procedure, while technically not court mediation, is conducted under the guidance of the enforcement judge. When the enforcement division of every court is busy chasing numbers to

\footnotetext{
894 Ibidem.

895 Ibidem

896 Zhang J. 2011, p. 206-208.

897 See Chapter 4 of this book for an overview of the enforcement settlement procedure.
} 
satisfy tertiary indices nos. 17 and 25 , the enforcement reconciliation procedure is likely to be abused. Taking advantage of the court's need to complete enforcement processes speedily, judgment debtors may deliberately drag their feet so that the court would put pressure on the judgment creditor to settle for a lesser sum.

\subsection{Operational aspects of civil trial management in China}

\subsubsection{The Trial Management Office}

The Trial Management Office (审判管理办公室 shenpan guanli bangongshi) (Office), a constituent unit of the court system, has the mandate to manage all aspects of adjudication in a court. Accountable to the court president and the court adjudication committee, the Office is responsible for managing court processes (i.e. the workflow manager), evaluating case quality, assessing overall effectiveness of the court's adjudication work, and assisting in the evaluation of the work of individual judges. ${ }^{898}$ The Office, however, is not empowered to make decisions in the evaluation of individual judges. When commenting on the functions of the Office, an intermediate court judge referred to the master in common law courts and noted there are certain similarities between the two in terms of the function of managing pre-trial procedural matters. $^{899}$

The Office may issue guidelines on trial management but cannot sanction an individual judge directly for failure to comply with its guidelines. The Office will work out with the judges the number of cases each judge should accept within a given period to maintain standard.

The Office is set up with a strong policy objective in mind - the court is an instrument for social control. Meeting these indices can be extremely tiring for the judge. It takes time away from his work as an adjudicator, and the rigidity of the indices sometimes hamper his ability to effectively handle his cases. ${ }^{900}$ Offering false statistics in the case quality evaluation exercise is also a survival tactic for some courts. $^{901}$

\subsubsection{Assessment of individual judges}

An intermediate court judge said that judges in China generally see themselves as 'bureaucrats' rather than the vanguards of justice. The overwhelming volume of cases means that judges must work in a 'factory style' where no time/attention can be given to the quality of justice. No judge would be willing to go out of the way to do justice (especially if doing so could contravene the directions and policies of the court

\footnotetext{
898 This 'job description' may vary slightly with different courts. This 'list' is taken from a trial management circular published by a high court in an inland province in China.

${ }^{899}$ Interview Ref: 2013/2. The judge said that the Office is also involved in managing trial time limits (suxian) and makes expert determination on evidence (jian ding).

${ }^{900}$ Interview Ref: 2012/1: The judge being interviewed said in China the central question of the court is not so much about efficiency in case management in the Western sense. The greatest question is how to effectively manage the judges in such a way that indices are met within a framework designed to preserve social stability.

${ }^{901}$ Cai 2014, p. 39-58.
} 
leadership) given the personal risks involved. Complying with performance evaluation indices and avoiding complaints are the best guarantee to career stability. $^{902}$

Chapter 16 of the Judges Law of the People's Republic of China ${ }^{903}$ governs assessment of judges by stipulating that each court should establish a 'commission for examination and assessment of judges' (法官考评委员会). Article 48 of the Judges Law states, '[The] functions and duties of a commission for examination and assessment of judges are to guide the training, examination, appraisal and assessment of judges. Specific measures in this regard shall be formulated separately.' Article 49 of the Judges Law provides for the structure of the commission, '[The] number of persons on a commission for examination and assessment of judges shall be five to nine. The chairman of a commission for examination and assessment of judges shall be assumed by the president of the court it belongs to.'

A basic court judge described how judges are generally evaluated on their performance. For instance, the 'commission for examination and assessment of judges' would review reversed judgments to see if the individual judge under evaluation was 'at fault' (fan cuo (犯错)). In more serious cases, judges could be disciplined for reversed decisions where serious fault was found (e.g. accepting a bribe, complete neglect of the law). 'Lesser faults' (such as wrong interpretation of the law) would result in the deduction of 'marks/points' in the court's internal assessment record, which in turn affects the overall performance evaluation of the judge. Even where the judge was not at fault, a reversal 'taints' the record of the judge and renders the judge less competitive in a promotion process. When the judicial 'merit system' is tied directly to minimizing the number of reversals of judgments, judges would inevitably prefer mediation, as a mediation statement (tiaojie shu) cannot be appealed (hence cannot be reversed). The basic court judge further noted that the membership of the 'commission for examination and assessment of judges' varies from court to court. Chaired by the president of the court, the common members of the commission include the heads and deputy heads of various divisions of the court and other senior judges. The commission is an internal arrangement. While its establishment is provided under the Judges Law, its detailed operations are governed under internal regulations of the specific court. ${ }^{904}$

Cai interviewed ten judges and found that the judges are increasingly burdened by the case quality evaluation system:

'This [case quality evaluation] system and the accompanying organizational culture substantially affect the judicial work of the court leaders. The front-line judge now more often than before directly feel the stress from struggling with the internal case quality evaluation system. According to these judges, most judges still have to adapt

\footnotetext{
902 Interview Ref: 2012/1.

903 Effective since 1 July 1995; amended in 2001 (amended version effective since 1 January 2002).

${ }^{904}$ Interview Ref: 2013/2.
} 
themselves to the evaluations and organizational culture which highlight their performance ${ }^{, 905}$

\subsubsection{Mass case-processing in China, not a rights-based justice}

Despite being given the name 'Case Quality Evaluation', the whole trial management system (ironically) is based substantially on quantitative efficiency (how efficiently a court can dispose of cases) rather than an attempt to enhance the overall 'quality' of justice by improving access to justice or to protect fairness in the litigation process.

Wang wrote in rebuttal to the philosophical underpinnings of the Chinese trial management system:

'It seems that the major problem of the administration of justice in China does not lie with the introduction of the trial management assessment system, but with the incorrect understanding of the meaning of this assessment system. In a modern society, performance evaluation exists in many different areas. It is, therefore, also reasonable to evaluate the performance of judges. The purpose of the evaluation is to promote the improvement of justice. It should be carried out by a comprehensive committee comprised of judges, lawyers and non-legal professionals. The evaluation standards should target issues such as impartiality, legal knowledge and understanding of the law, communication skills, trial preparation, the accuracy of judgments and monitoring the procedure. Management should be based on full reliance on and respect for the judges. However, the trial management assessment system in China is usually controlled by non-legal professionals. In such a situation, the autonomy of the courts and the judges cannot be guaranteed. ${ }^{906}$

\subsubsection{Constitutional dimensions}

Article 126 of the PRC constitution reads:

'The people's courts exercise judicial power independently, in accordance with the provisions of the law, and are not subject to interference by any administrative organ, public organization or individual.'

The trial management system allows an 'administrative organ' within the court (trial management office) or 'individuals' (trial management office members) to interfere with the adjudicatory decisions of the individual judge and imposes quantitative parameters on how cases should be disposed of. The system robs judges the freedom to decide the case on its facts free from interference. Every judge in China would need to succumb to the standards and expectations enshrined in the 'case quality evaluation' system for career advancement or to avoid disciplinary consequences. 'Trial management' becomes a hanging dagger for judges. The evaluation covers even the most minute details of the judge's conduct at court hearings, as an 'observer log' shows. ${ }^{907}$

\footnotetext{
905 Cai 2014, p. 53.

906 Wang F.H. 2014, p. 63.

${ }^{907}$ An 'Observer Log' for civil and commercial cases of an intermediate court in an inland province in China.
} 
Trial management is a glaring violation of Article 126 of the PRC constitution. The all-pervasive nature of trial management violates adjudicatory independence of the tribunal. While the Chinese constitution is not directly enforceable in a lawsuit, the principles enshrined in it should give courts (especially the SPC) a moment of pause to think about whether this quantitative evaluation system is conducive to improving the overall quality of justice in China.

\subsection{Effect of the trial management system on court mediation in China: an institutionalized distortion of (what is supposed to be) an ADR mechanism}

Mounting caseload in the Chinese court system calls for immediate measures to keep the influx of lawsuits to a manageable level. The trial management system was introduced in part as a measure to manage caseload. A fundamental principle for managing the Chinese judicature is the notion of placing mediation at the top of the court's agenda. Since 2008, court policy encouraged settlement through mediation to such an extent that local courts compete on mediation settlement rates.

A lawyer based in a leading commercial city noted that mediation always has its attraction for judges, as a mediated settlement could not be overturned (unless in a very special situation where a retrial is ordered). This inherent incentive to resort to mediation would not change even where judicial policy places less emphasis on mediation going forward. So long as the evaluation of case quality and assessment of judicial performance are pegged to mediation settlement rate, court mediation would still be the judge's 'all-time favourite'. ${ }^{908}$ The lawyer added that mediation guarantees speed in dispute resolution especially for simple civil cases (as opposed to complex commercial cases). It simply does not make sense from a practical perspective to go through formal procedures when dealing with these types of cases. ${ }^{909}$

Mediation therefore primarily serves institutional purposes in China. The weighting given to a court's ability to dispose of cases by mediation in the evaluation process distorts the original function of mediation and the interest-based nature of settlements.

\subsection{A critical examination of Case Quality Evaluation system from the perspective of procedural justice}

Zuckerman made it clear that the role of the court is not limited to dispute resolution. The civil court, like its criminal counterpart, plays an important role in rights enforcement. ${ }^{910}$ If the court is the enforcer of rights, a judiciary that overemphasizes mediation settlement rates and other quantitative results cannot at the same time be a good enforcer of rights. The trial management system is flawed in the following aspects:

\footnotetext{
908 Interview Ref: 2014/1.

${ }^{909}$ Interview Ref: 2014/1.

${ }^{910}$ Zuckerman 2009, p. 53.
} 
(1) Danger of encouraging efficiency without considering the context: Efficiency (in terms of the quantity of cases processed within a given timeframe) ${ }^{911}$ does not necessarily represent effectiveness of the system. The mechanical processing of cases is different from giving due regard to the merits of each case with a view of delivering justice, ensuring like cases are treated alike and the protection of fundamental rights. The over-emphasis on the caseprocessing function (which is a vital but not predominant function of the court) would inevitably result in sloppy adjudication in which the judge simply applies the law in such a way that would ensure the least criticism from a superior court or the leaders of the same court within a prescribed timeline. While undue delay is undesirable, cost-effectiveness of adjudication is not measured simply by applying a straight-jacket test of "who disposes the highest number of cases within one year'. Proportionality, on the other hand, is a vital consideration for case management, in that important and complex cases (especially those cases with possible precedent value) should be devoted proportionally more judicial resources than routine cases. Such a quantitative test in the Chinese judiciary obscures the true test of case management effectiveness.

(2) Bureaucratic and populist orientations of the evaluation system: judges in China are more like government bureaucrats than judicial officers. The evaluation system provides a mechanical (and statistical) assessment of the work of courts in a format that can equally apply to any unit of the bureaucracy. The second-tier effectiveness index comprises of 'user satisfaction' factors such as third-tier indices that evaluate the 'letters and visits rate' and 'general public satisfaction rate'. ${ }^{912}$ As the emphasis of the system is on case-processing, judicial work is given an administrative spin in that the 'best civil servant' is the most diligent one in handling the files on hand. It is questionable whether this form of evaluation is capable of assessing the quality of justice delivered in an individual court given judicial work is unique and definitely not a routine civil servant's task. This form of assessment also deprives the court of its adjudicative autonomy. As the level of user satisfaction (which could be highly objective and populist) could affect the court's ranking among other courts and the allocation of scarce judicial resources, courts are inclined to serve populist goals and keep litigants satisfied, when in fact the main role of the court should be to enforced the rules and uphold the rule of law.

(3) Irrelevance of evaluation factors: certain third-tier indices under the 'effectiveness index' are simply irrelevant in the assessment of adjudicatory effectiveness. For instance, the index of the 'voluntary enforcement of judgment rate' evaluates the rate of voluntary enforcement of judgments by parties. ${ }^{913}$ The rationale for this index is that a higher voluntary enforcement rate is the inevitable result of the higher quality of judgments. ${ }^{914}$ Yet it does

\footnotetext{
${ }^{911}$ For instance, see tertiary indices 20 and 21, Appendix to the 2011 SPC Case Quality Opinion.

912 See tertiary indices 30 and 31, Appendix to the 2011 SPC Case Quality Opinion.

913 See tertiary index 27, Appendix to the 2011 SPC Case Quality Opinion. The formula is 1 minus the number of application for court enforcement multiplied by the total number of enforceable judgments.

${ }^{914}$ Zhang J. 2011, p. 371.
} 
not take an expert to explain that an array of different factors contribute to the failure of voluntary enforcement, for example, the losing party becoming impecunious. To suggest that a low voluntary enforcement rate is reflective of poor adjudication neglects numerous other possibilities that could have contributed to non-enforcement. Effectiveness of judgment cannot be assessed by simply referring to the number of cases of voluntary enforcement.

(4) The negative effect of penalizing the judge for every incorrect judgment: throughout Chinese legal history, magistrates were held liable and suffer negative consequences for rendering incorrect judgments. ${ }^{915}$ This tradition survived the demise of the Chinese empire. Under the contemporary evaluation system, courts and individual judges still face adverse consequences for incorrect decisions. For an individual judge, having a substantial record of appellate reversal (or having his judgment frequently reopened under the adjudication supervision procedure) is not only a guaranteed career suicide, but also stigmatizes the judge as someone who is sloppy and unprofessional (e.g. some courts notoriously circulate the names of those judges who were underperforming). ${ }^{916}$ A fault adverse culture makes judges prefer mediation over adjudication as a mediated settlement insulates the judge from being criticized for mistakes (a settlement through court mediation is non-appealable). The combination of this fault adverse culture and the active institutional encouragement of mediation ${ }^{917}$ creates an absurd norm where courts would press for a mediated settlement, at times without true consideration of parties' wishes. This norm is antithetical to the black-letter law that all court mediations must be based on the principle of party voluntariness. $^{918}$

(5) Compromising procedural justice: An evaluation system based on mechanical application of (predominantly) quantitative indices not only ignores the quality of substantive justice but also waters down procedural justice. Judges are preoccupied with hitting quantitative targets such that the fairness and sanctity of procedure become less of a pressing concern.

(6) Autonomy of the individual judge under siege: when a court is under such a quantitative evaluation system, its leadership would no doubt push individual judges to serve the bureaucratic goals of the court, rather than focusing on delivering quality justice by exercising the necessary judicial acumen and creativity. The autonomy of adjudication is therefore subject to the institutional needs of the court structure. In other words, the evaluation matrix creates a bizarre 'merit system' where the non-adjudicator (who has no knowledge of the context or content of individual cases) evaluates the adjudicator on almost every aspect of litigation by using a straightjacket checklist that measures predominantly quantitative excellence only. Such a 'merit system' may be suitable for junior level bureaucrats, but it is definitely unsuitable for the judiciary.

\footnotetext{
915 Minzner 2011a, p. 58-90.

${ }^{916}$ Interview Ref: 2012/3.

917 See tertiary indices 23 and 24, Appendix to the 2011 SPC Case Quality Opinion.

${ }^{918}$ Article 93 of the Code.
} 


\subsection{Chapter conclusion}

Trial management frustrates the ability of the individual judge to handle cases independently. While a degree of bureaucratic interference (e.g. in matters like managing personnel and work delegation) is expected given China's legal tradition, it is a totally different level of intervention when the 'case quality evaluation' trespasses into the actual adjudicatory work of individual judges. The system requires judges to follow fixed parameters without any regard to the actual circumstances of the individual case (e.g. complexity, the actual liability of parties and whether there are any special circumstances). Institutional goals therefore override the imperative of defending justice in the individual case. A civil court that follows strictly the "case quality evaluation' system is at best a centre for mass case processing, not a forum for upholding rights. The business of adjudication becomes a game of avoiding mistakes and 'toeing the party line'. Judges are inevitably risk adverse in that a judge is unlikely to jeopardize his career by rendering a just ruling but by doing so violates the institutional parameters under the system. It follows that, given such risk adversity, judges are likely to continue to rely heavily on mediation, as a settlement is almost an ironclad guarantee of 'anjie shiliao'. Any reform effort to change China's judicial culture of preferring mediation would be an uphill battle as long as the mentality of its leaders focuses on the 'social effect' of civil litigation and the ill-defined concept of 'anjie shiliao', which is difficult to conceptualize from a legal scientific perspective and impossible to empirically quantify. 


\section{Chapter 9:}

Conclusion

Seven Areas of Tension in Chinese Disputes Resolution -

The Impact on In-Court and Out-of-Court Mediation 


\section{CONCLUSION: SEVEN AREAS OF TENSION IN CHINESE DISPUTES RESOLUTION - THE IMPACT ON IN-COURT AND OUT-OF-COURT MEDIATION}

\section{1. 'Chinese Exceptionalism' and civil justice}

When some Americans say the United States is the indispensible global power with a very special mission to maintain order and peace in the world, China also developed her own understanding of the concept of 'exceptionalism'. The elite class in China in general believes that the country occupies a unique position in the history of Asia (and perhaps the world). In their view, it is unfair for China to be subjected to norms of international practice at this critical current stage of the country's development. This is partly justified as China's unparalleled breadth of history and heritage, rich tradition and uncompromising national pride do not necessarily sit in well with every aspect of the modern international order. 'Chinese exceptionalism', as the West sometimes calls it, has clear characteristics. Just to name a few: (a) rights of individuals, while important, must give way to collective interests in the name of patriotism (or nationalism, whatever one calls it) if the two cannot co-exist; (b) the state has a predominant (if not all-encompassing) presence in the everyday life of the individual, partly justified by the need for public security and order; (c) the well established concept of separation of powers (allowing checks and balances among different branches of the government) is flatly rejected by the Chinese ruling elite as something distinctly Western (therefore, foreign) that is incompatible with the realities of China's political tradition and contemporary situation; (d) the idea of a civil society is the antithesis to the contemporary governing ideology that sees the Chinese society as a dependent entity supervised, lead and controlled by the ruling Chinese Communist Party; and (e) the Western concept of 'the rule of law', which entails the establishment of independent institutions to protect individuals' rights, runs contrary to the Chinese concept that the law should be promulgated and interpreted by 'the people', a synonym for the Chinese Communist Party. Contemporary leaders in China advocate a form of 'rule by law' (or 'ruling the country by law' (依法治国)), which involves the strengthening of law enforcement and the normative force of legislative instruments, as part of the strategy to combat the lousiness of courts in enforcing rules and procedures during Wang Shengjun's era (March 2008 - March 2013. However, 'the rule by law' is by no means 'the rule of law'. The Chinese ruling elite is still categorically against an independent judiciary and any form of strong institution outside the power structure of the Party.

The above characteristics are visible in the way China conducts its foreign policy, maintains law and order, establishing legal or quasi-legal institutions, conducting trade and many other facets of state affairs. But these are beyond the scope of this book. One of the purposes of this book is help identify how China sees itself 'exceptional' in the administration of civil justice (in particular, in developing and managing its mediation regime). Civil and commercial disputes resolution 'with Chinese characteristics' (to use the popular Chinese saying) embodies at least seven areas of tension that have enormous impact on the conduct of mediation. 


\subsection{First Area of Tension in Chinese disputes resolution: Black-Letter Law v.s. Judicial Practice}

A consistent observation from the interviews with Chinese judges is that law and judicial practice in China are two very different things. Despite the official line-totake for the judiciary (and all government authorities) is 'to apply the law' (依法) in everything it does, the reality projects a much more complex phenomenon. On the one hand, judges are aware of the need to be seen as following the rules; but on the other hand, they are equally aware of the necessity to 'bend' the rules at times to suit the practical needs of the parties or to hit the benchmarks set by court leaders. A division head of a provincial high court was quite blatant about his willingness to abridge procedures and sidestep rules of practice as a means to achieve substantive justice.

In the context of mediation (particularly court mediation), the inconsistencies between black-letter law and judicial practice, as illustrated in Chapter 4 of the book, frustrate the ADR function of mediation, infringes upon party autonomy and parties' access to court in the following respects: (a) judges may pressure the parties to settle (for different reasons), contrary to the written principle of voluntariness; (b) judges may abuse their adjudicative powers to steer the mediation towards institutional or other goals, contrary to the wishes of the parties; (c) disputants may be denied access to court if the court deliberately delays the docketing process with the view to have the dispute settled out of court; and (d) judges may use mediation (judicial conciliation to be precise) to 'do justice' if they think the plaintiff deserves to recover something but lacks the legal basis to render a judgment in favour of the plaintiff.

From a broader perspective, mediation, while being a conciliatory process, looks to court decisions as a starting point for reaching settlement. If court decisions lacked uniformity (which has been a serious problem in China, hence the introduction of 'guiding cases' by the SPC in recent years) or if decisions were reached without observance of procedures, court decisions could hardly be a useful benchmark for settlement.

\subsection{Second Area of Tension in Chinese disputes resolution: Official representation of justice vs. the reality of mass case-processing needs}

The Chinese judiciary, in particular with the recent tides of reforms, emphasizes the imperative of delivering timely and accurate judgments in order to re-establish the public's confidence in the court system. The official representation is that problems of the past (particularly during Wang Shengjun's era), such as non-observance of procedural rules, coerced mediation (as in court mediation), deliberately delaying the docketing of cases and, in more general terms, all shortcomings of an overly populist civil justice system, could be overcome by simply requiring judges to adjudicate strictly by the 'book'. Such a representation paints a rosy picture of Chinese justice where a decade-long culture of judicial populism and lax in procedural discipline could somehow be transformed, within a short timeframe, into a formalist regime of adjudication. This official representation obviously fails to take into account a very critical factor: the enormous caseload of the individual judge. Judges in China today face a common problem of docket overload (the popular saying is 'too many cases, 
too few people [judges]' (案多人少)). It is not uncommon that an individual judge handles over 200 cases per year. An experienced litigation lawyer based in a leading commercial city said a judge handling 400 cases per year was not particularly unusual given the enormous caseload in each court. With such an enormous caseload, it is difficult to deliver quality justice as the judge on a daily basis is performing mass case-processing. The populist judicial culture promised quick solutions that generate positive social effect. This culture, which began in the early days of the People's Republic and reached its heights during Wang Shengjun's era, has an undeniable advantage of keeping 'trouble' away from the judge in the sense that litigants are less likely to complain or lodge petitions against the judgment. It is therefore foreseeable that despite the will of the SPC leaders to inject a new culture of judicial formalism and certainty, the populist culture that is so ingrained in Chinese courts (especially basic-level courts of less developed regions) is unlikely to be uprooted overnight. This is particularly so when the individual judge is struggling with his or her everexpanding docket on a day-to-day basis. There is simply no time to engage in intense intellectual exercises or elaborate jurisprudential thinking when hearing cases in a crowded courtroom.

Mediation, whether in-court or out-of-court, has always been a popular caseload management tool for judges in China. The flexibility of the process allows the judge, especially in the case of judicial conciliation, to sidestep strict procedural rules and produce a result in a timely and controlled manner. While two of the key purposes of mediation are costs-savings and procedural expedition, the focus must be on the parties. While it is appropriate to deploy alternative procedures (such as mediation) to help lower the docket pressure and increase the efficiency of the court as a whole, it serves no legitimate purpose if the judge abuses the mediation process and pressures parties into settlements simply because he has too much on his plate.

\subsection{Third Area of Tension in Chinese disputes resolution: SPC Policy vs. local implementation}

'The mountains are high, and the emperor is far away.' No one in China is unfamiliar with this saying that describes the Chinese imperial order, a saying that still holds true today. The imperial political structure of China projects an all-powerful image of the emperor; but the reality of distribution of power was very different. Imperial edicts left the capital city with no guarantee that they would be followed by local governments. At times, provincial leaders simply gave lip service to directions from the central authority that were not in line with their regional agenda. This political culture survived the collapse of the empire. Today, central-regional conflicts and tensions dominate much of the drama in the political arena.

With this backdrop in mind, it is not difficult to understand the enormous difficulty the SPC is currently facing when it seeks to implement a reform package to a colossal court system. To add to the complexity of the matter, courts of all levels are (in principle) funded by the local governments and are held accountable to the local people's congresses. Local governments also make decisions on key personnel of the courts. Current reforms are working towards an overhaul in court financing, appointment of key personnel and management of court resources (the so-called control over 'personnel, finances and resources' (人财物)) by centralizing control of court resources and budgets in the hands of provincial high courts (i.e. taking power 
away from local governments and hand them to the provincial high courts). However, the attempt to realign power is bound to face opposition from local special interests. It is foreseeable that in the future local forces (be it the local government or powerful businesses) would scramble for resources and influence at local courts, even to the extent of ignoring orders from the provincial high courts. As discussed earlier, courts are institutionally inferior within the Chinese realpolitik structure where executive power is predominant. It remains to be seen whether provincial high courts (being superior state organs) could truly control all the affairs of local courts free from executive interference.

In the context of mediation, as much as the SPC would like to 'normalize' the position of court mediation by eradicating absurd practices of Wang Shengjun's era and by deviating from the policy of 'prioritizing mediation', it remains to be seen whether judges at basic-level courts would follow suit. Interviews with judges at basic-level courts reveal that it is more or less 'business as usual' when it comes to court mediation, i.e. that judges still believe that the policy of 'prioritizing mediation' has not changed at all (or has not undergone substantial revision).

\subsection{Fourth Area of Tension in Chinese disputes resolution: Procedural justice vs. substantive justice}

As discussed in Chapter 7, the Chinese judiciary focuses on substantive justice while deliberately downplaying the importance of procedural formalism. Despite the SPC now promotes procedural formalism in the recent civil justice reform, judges of the people's courts (especially basic-level courts) are much more interested in seeing the final resolution of a dispute where parties are satisfied with the outcome. The goal of 'anjie shiliao' (i.e. the case is closed and the dispute is [truly] resolved) remains an overriding objective in Chinese civil justice.

The preoccupation with substantive justice throws mediation into uncertain waters. Mediation, as a procedural alternative to litigation, could only function effectively when placed within an appropriate and predictable procedural matrix. By focusing too much on substantive justice, judges in China frequently overlook the importance of procedural discipline and safeguards in conducting court mediation or referring a case for settlement out of court. When mediation is steered towards adjudicative agendas (which generally sought to achieve substantive justice for the community as a whole and to avoid petitions), resulting settlement is usually artificial and prone to manipulation by the judge.

Another angle to approach this issue is the constant tension between the desire to establish a 'rule by law' in China and the innate tendency of the court to maximize the 'social effect' of adjudication. Taken on a conceptual level, this conflict is unresolvable because a social-engineering court agenda cannot co-exist with the notion that the enforcement of the law has priority over all other goals. It is submitted that this tension can only be removed by disbanding 'social effect' as a factor in the adjudicative decision-making matrix. Ultimately, the establishment of formal legal institutions, in particular a judiciary that is robust and insulated from external interference depends very much on whether judges generally accept that it is not their duty to enforce a 'social agenda'. Nor should they be pressured into deviating from the strict letter of the law just because of 'pressing' populist demands. 


\subsection{Fifth Area of Tension in Chinese disputes resolution: Bureaucratic Supervision vs. Adjudicatory Autonomy}

As discussed in Chapter 7, the individual Chinese judge is institutionally weak. External interference with the adjudicatory process is the norm, rather than the exception. Wang has warned that the 'bureaucratization of the court', a widespread phenomenon in China, has stripped every opportunity to develop adjudicatory independence in China. The collective decision of the court organization trumps the decision of the individual judge, despite the individual judge having superior knowledge and understanding of the case.

The way that judicial conciliation is conducted requires apt judgment on the part of the judge. A weak judge seldom enjoys flexibility in adjudication, which also includes the flexibility in presiding over judicial conciliation. If the court leadership wants results in terms of settlement rate (or in terms of other indices that could impact on the use and abuse of judicial conciliation), the individual judge has little or even no autonomy to deviate from the demands of his leaders. Such a skewed institutional landscape distorts the intended function of the conciliatory process and opens the door for top down policies to influence the process.

As much as a young generation of judges, many of whom are top graduates of law schools, would like to see the system reformed and see themselves assume the role of the vanguards of justice, reality has a tendency to disappoint people. Within the grand state architecture of China, judges are no different from police officers and procurators. They are all 'law enforcement' bureaucrats of the state machinery with clear mandates to preserve law and order. Judges may have an additional role of regulating society on a 'civil level' (hence the policy preferring mediation during Wang Shengjun's era (March 2008- March 2013)), but they never received the kind of recognition and respect from the ruling elite that allowed them to perform their role as vanguards of justice. A judicial decision must fall within the scope of acceptable behaviour as delineated by the Chinese administration. In other words, judges are at no liberty to rule on cases involving special interests or complex political background according to their own conscience. One should expect external forces to play a role in such cases. The limited role of the judge in China predetermines the future of its civil justice: cases are generally decided according to the law, but the system would not go one step further to defend fairness and righteousness if the case is sensitive or involves matters that are beyond the perceived limited powers of the courts.

\subsection{Sixth Area of Tension in Chinese disputes resolution: International Norms of Practice vs. Chinese Exceptionalism}

'Chinese exceptionalism' is deliberately encouraged by the government as it fuels nationalistic sentiments, something highly valuable when the ruling elite needed a distraction for its population from internal strife and inequities. With this backdrop in mind, it is not difficult to understand why judges (especially senior judges) believe that European (or more generally Western) theories in mediation have no application in China. The 'exceptional' circumstances in China, for example the extreme rural- 
urban division and rising tide of mass protests, call for a unique mediation system that places social agendas ahead of the individual interests of parties.

Chinese exceptionalism blurs the lens of policy-makers, causing them to think that all domestic problems call for domestic solutions. No one is suggesting that there should a wholesale adoption of Western procedural system. Chinese policy-makers must draw the line between upholding national pride (which comes with confidence in one's culture and heritage, and a strong belief in what the nation stands for in this world) and banking on the insights of others. China does very well in terms of improving its 'hardware' by learning from others, but faces psychological hurdles when it comes to emulating 'soft skills' of others. This is particularly true for civil justice in China. The Chinese courtrooms have introduced state-of-the-art video recording systems. It is moving to a semi-paperless trial. Very soon, many courts in China will have the case files available on the internet. But seldom would you see judges studying European experiences in judicial mediation without adding a caveat that every aspect of the procedure needs to sit well with the 'special circumstances of China'. Under this kind of culture, it is difficult to push for a cross-fertilization of 'soft skills' in the realm of Chinese civil procedure and mediation.

\subsection{Seventh Area of Tension in Chinese disputes resolution: Regulatory State vs. 'Autonomy' of the Judiciary}

The notion of 'rule by law' encompasses a paradoxical understanding of the law: while compliance with the law is taken seriously, the real purpose of establishing a rules-abiding culture is not to achieve 'the rule of law', but rather to grease the governing superstructure, making it more effective and easier to control. This paradox is fleshed out in the 'regulatory state' that the ruling elite in China is constructing: i.e. to subsume the ruling ideology in a detailed set of rules encompassing all aspects of life in order to perpetuate the existing governing structure by subjecting society in general to this set of rules, which is to be enforced meticulously by the court.

The 'regulatory state' sees institutional independence inherently contradictory to its basic tenets. A strong judiciary, for instance, takes power away from the administration and diminishes governing predictability. As such, the regulatory state's primary strategy is how it can effectively control all its constituent entities with a gloss over of legal legitimacy.

It is expected that the regulatory state would empower courts only to an extent of a 'loyal' and effective enforcer of the law, but never to the extent of an independent judiciary. It remains to be seen how the regulatory state sees the position of civil adjudication. Again, a paradoxical view is likely to emerge in the midst of China's recent reforms of her courts. The ruling elite is well aware of the embarrassingly low level of public confidence in the civil justice system. This undesirable state of affairs calls for prompt actions to establish an image of fairness in the court process, which, among other things, entail granting the individual judge or tribunal greater autonomy in deciding cases. In other words, the autonomy of the individual judge in adjudication is the ability to render decisions free from policy influence and external interference. Having said that, however, the regulatory state cannot overpromise on autonomy as doing so compromises the ultimate objective of predictability of 
governance and effectiveness of control. It is likely, therefore, that stringent control over the evaluation of individual judges and interventionist procedures in the civil process are likely to stay for the foreseeable future.

\subsection{Final Remarks}

\subsubsection{Empowering Chinese courts in the civil process}

The civil justice system during Wang Shengjun's era (March 2008 - March 2013) was not a historical coincidence. Its populist trajectory, social engineering objective and policy-driven nature are rooted in the Ma Xiwu trial model. This model, in the early days of the People's Republic, was transformed into a systemic and institutionalized court-directed conciliatory model under which both out-of-court mediation and incourt mediation were highly policy-driven with social stability as its primary objective. President Wang Shengjun and the policy-makers of the SPC only revived the institutionalized model at a time when social conflicts (which usually revealed themselves in the form of xinfang) were getting out of hand and the courts were called upon to alleviate the enormous pressure other state authorities were shouldering. While most judicial systems around the world are expected to shoulder certain responsibilities that are ideally dealt with by the executive branch, they are nowhere near the unparalleled magnitude of the responsibility dumped on the Chinese judiciary. Under Wang Shengjun, the Chinese courts had in effect turned into statesponsored mediation centres. The concept of anjie shiliao (which is still very much the main goal of civil procedure today according to the empirical findings in Chapter 5) epitomizes the social function of courts from the perspective of China's policymakers. No matter how much the current SPC leadership wanted to change the outlook of the judicial process, the 'innateness' of the concept of anjie shiliao in the DNA of Chinese judges suggest that reforming China's civil justice system takes much more than simply changing its rules of procedure and management structure.

Ultimately, the fundamental question is whether the Chinese ruling elites are willing to take the courageous step of granting the necessary autonomy to the courts so that the administration of justice is truly separated from the administration. Courts function best when they are left alone. This is why judges occupy a unique position in a polity, a position that allows them to enforce the legal rules and norms without the usual political and bureaucratic dynamics of any other state organ. As long as the Chinese ruling elites continue to see China's courts as 'their courts', rather than a truly neutral forum for disputes resolution and declaring legal norms, any reform effort could only be superficial in nature. As idealistic as it may sound, an 'autonomous judiciary' (not judicial independence in the common law sense) is not unachievable in China if certain aspects of the power matrix were taken into account in a pragmatic strategy to reinvent China's justice system. The greatest hurdle to granting more power to the courts is the fear that the judiciary would amass sufficient authority and influence that threatens the de facto single-party structure of China. To address this concern, one could adopt a staggered reform process in judicial reform: (a) begin with reforming the civil justice domain, deliberately leaving the criminal and administrative domains untouched; and (b) ring-fencing the civil justice domain from all other judicial processes. Civil and commercial claims are predominantly purely 'private' in nature. Here 'private' (in the Chinese sense) means that government or 
government related special interests are not involved in the case. Unlike criminal and administrative cases, granting greater autonomy to the courts in dealing with private disputes does not pose any threat to the ruling structure. The courts in 'private' civil cases are not ruling on (nor are they declaring norms relating to) the position of public authority vis-à-vis the private sector. For the so-called 'non-private' civil and commercial disputes, the Adjudication Committee of the court in question can make a value judgment as to whether the 'non-private' element could be severed from the case. If it is possible, then the remaining issues could still be handled by the civil court. If that is not possible, and where necessary for political or other reasons, the case could be dealt with by a special tribunal set up by the Adjudication Committee outside the realm of the civil court, comprising of Specialist Members of the Adjudication Committee (审判委员会专业委员). That way, the court is able to insulate the civil process from the politically oriented and policy-driven processes.

It makes perfect sense to focus the reform on civil justice even as a general strategy. Civil disputes constitute the bulk of judicial work of modern courts. If the civil process becomes procedurally mature, other court processes tend to follow suit. For instance, certain sophisticated procedural principles that worked well within the civil process (such modern principles of burdens of proof) could be transplanted to the administrative litigation process or even the criminal process when the time is ripe.

\subsubsection{The position of court mediation in Chinese civil justice going forward}

With Anjie shiliao continuing as the guiding principle of civil justice, it is difficult to see how it is possible to 'normalize' the position of court mediation, i.e. releasing mediation (especially judicial conciliation) from the policy manacles and allowing it to play its ADR function as it was meant to be.

Institutional constraints at times rob the judge of his liberty to decide how the case is to be handled. As long as social impact remains a key factor in civil adjudication and disposal of a lawsuit is insufficient unless there is complete closure on a social level, judges would still treat mediation as their tactical tool instead of a genuine ADR option for parties. Court mediation is indeed the judge's 'best friend'. Settlements reached through court mediation are not appealable and are rarely reopened under the adjudication supervision procedure. Promoting settlement under the court mediation procedure also minimizes the risk of citizen petitions (xinfang). By actively pushing parties to mediate, judges avoid the need to deal with thorny legal and factual issues that could potentially come back to haunt it if the judgment is later challenged. The advantage of mediation is further entrenched under the perverse evaluation system for judicial competence that rewards settlements (or withdrawals) and penalizes reversals of judgments. The irony of this is obvious: what is supposed to be the vanguard of justice and enforcer of the law became an institution that evades dealing with legal problems and finding truth. The judiciary's attempt to 'gloss things over' (huo xini) using mediation is at the heart of China's failure to establish procedural formalism in civil litigation.

As much as the leaders of the SPC are aware of the need to strengthen the courts role in declaring legal norms and enforcing private proprietary rights, the goal of reviving adjudicative formalism is likely to be caught between a rock and a hard place in that 
lower courts (for caseload management or other reasons) are likely to continue to use court mediation (especially judicial conciliation) for institutional strategic purposes, while state organs superior to the judiciary might see the recent focus on adjudicative formalism as a temporary tactic to win back the public's trust and confidence in the judicial system, and therefore might not support a genuine overhaul of the civil procedural structure.

One cannot change the culture of litigation overnight. Old habits of abusing the judge's position in judicial conciliation are part and parcel of the entrenched predominance of the bench in civil litigation, something that judges are unlikely to be willing to part with as a matter of self-interest. An even more objective constraint is the growing backlogs in the dockets of Chinese courts. Many judges still think that court mediation is the best antidote for ever-increasing caseload, something that is both crippling their careers and health. As revealed in the interviews, judges who are less senior within the judicial hierarchy tend to express a unanimous view that the position of court mediation under the Wang Courts would remain despite reform efforts to promote 'the rule by law'. Pragmatism dictates the majority of Chinese judges, who are not high-ranking court leaders but rank-and-file trial judges dealing with a case a day or more, would passively resist any top-down direction that takes away their discretion to use mediation as their tactical tool to manage caseloads.

\subsubsection{The position of people's mediation in Chinese civil justice going forward}

As discussed in Chapter 3, the Grand Mediation system helps channel disputes away from the dockets, thereby reserving those disputes that truly require judicial expertise for the courts. As a result, the judiciary could focus their efforts on dealing with the truly controversial and important cases, allowing the majority of disputes to be settled by calling upon the disputes resolution capabilities of the community.

People's Mediation in China (which is the predominant constituent of the Grand Mediation system) is not just about disputes resolution. At the dawn of the People's Republic, People's Mediation played a highly political role in the mass-line revolutionary movements. This revolutionary-political role transformed into a social role today where the PMCs became community mediation centres with the mandate to quell conflicts and maintain harmony within the community.

PMCs throughout the country operate under the directions of the administrative bureaux of justice at the same level. While the local administration supervises the institutional aspects of PMCs, local courts have power to give directions on the operational aspects of mediation. The structure of direct administrative control (and judicial supervision) over PMCs suggests that People's Mediation serves the purpose of social control in addition to the propagated role of inexpensive alternative dispute resolution.

People's Mediation is non-facilitative in nature. In practice, it shares certain adjudicative attributes in that the people's mediator conduct fact-finding, express views regarding issues on liability and quantum and proposes terms of settlement. The process is highly evaluative and directive. It is called people's 'mediation' mainly because the outcome is couched in a settlement agreement and not a judgment 
or award, and the wishes of the parties are taken into account in formulating the settlement.

The leaders of the SPC hope that by strengthening the nexus between the civil litigation process and people's mediation, the majority of civil disputes could be resolved outside of court with settlement agreements capable of being 'confirmed' (and thereby directly enforceable) under the formal judicial process. This way courts could concentrate on adjudicating the complex and important cases. The logic is theoretically sound: when the court has less on its plate, it could allocate more resources to enhancing the quality of adjudication, rather than unduly relying on court mediation as a tactical means to manage its docket. The court would be able to perform its original function of norm-declaration and rights enforcement, instead of being reduced to a state-sponsored mediation centre, which was the case during Wang Shengjun's era (March 2008 - March 2013). However, in reality, the channelling function that People's Mediation could play is limited. First, litigants in China prefer a swift decision from the court. Although public confidence in the judicial system have been dropping in the past years, litigants still see the court as the 'formal' disputes resolution forum that could generate decisions that give a degree of certainty in enforcement. Second, it might be difficult to draw the line between turning away cases at the dockets on a legitimate basis and abusing the power of denying litigants access to court. Third, People's Mediation has many limitations (see Chapter 3 for details) so much so that it could only absorb some of the cases that the courts have turned back. The remaining cases require novel ADR avenues (such as a more professional mediation body that practises facilitative mediation).

\subsection{Legal culture and civil mediation in China}

The traditional Chinese understanding of mediation is categorically different from modern-day concepts of mediation. The common term for mediation in imperial China is tiaochu (调处), which translate into a process that combines conciliation with adjudicative discretions. Magistrates, who represented the emperor on the local level, had a fused role of being both the chief administrator as well as chief adjudicator of the particular county. Hence, the adjudication of civil disputes by the magistrate could not be divorced from his political mandate of maintaining law and order (among other things) within the territorial domain of the magistracy. Swayed by the Chinese ideological preference for harmony (i.e. the concept of wusong (无 讼)), the magistrate would resort to conciliatory processes, both 'in-court' (conducted by the magistrate himself or his staff) and 'out-of-court' (conducted usually by community leaders), to deal with 'civil' matters within the community. The conciliatory processes during the imperial times, in its various forms, were designed not just to provide an alternative to litigation, but also to showcase the moral virtues of resolving disputes in an amicable manner. The 'didactic function' of conciliation epitomized the soft power of imperial rule: using the conciliation of community disputes to illustrate what the 'desired norms' of practice were and educate the public who were generally ignorant of the law and policies of the imperial state. To achieve these goals, the conciliator must be prepared to be interventionist, evaluative and even express his own views on what the moral, customary or legal norms were. That is why conciliation in imperial China (in its various forms) was never a facilitative process that respected party autonomy. 
The imperial legal culture in relation to conciliation survived the collapse of the empire. Even nowadays, where the law has supposedly entrenched principles of party voluntariness and impartiality of the conciliator, conciliation processes frequently take the form of the conciliator directing what the parties should do, in terms of what facts were to be established, what the relevant substantive legal provisions were, and what the possible settlement options were. These traits look very familiar to how community mediators operated during the imperial times in 'lecturing' the disputants on Confucian concepts of acceptable behavior and recommending settlement options that were consistent with the interests of the community. The discussion on contemporary Chinese mediation is placed into the appropriate context when one understands that conciliatory processes in China today (whether it is judicial conciliation or People's Mediation) still operate to a certain extent under the shadow of China's historical legal culture. On the one hand, the official representation is that of the idealistic notion that peace and harmony within the community is more important than self-centered goals of the disputants. On the other hand, policy-makers are highly pragmatic in using mediation as a tool to quell social conflicts and strengthen their grasp of power on the local level. Such paradoxical combination of idealism and pragmatism explains why it is so difficult to understand the fabric of Chinese mediation.

\subsection{Political culture and civil mediation in China}

Chinese culture pays particular attention to hierarchy and seniority, especially in the realm of politics. When the incumbent and former members of the Standing Committee of Politburo of the Chinese Communist Party line up for a photo-opt, the immediate past general secretary always comes second in the queue after the incumbent general secretary. Technically speaking, the immediate past general secretary should not even be in the queue as a 'retired' statesman, yet he (never a she to date) is 'ranked' second as a matter of political convention, i.e. superior to all other incumbent Politburo members except the incumbent general secretary. This kind of political culture extends the 'soft power' of elder statesmen and entrenches an institutional habit of emphasizing personal political power.

The Chinese judiciary occupies a relatively inferior position within the constitutional structure as compared with its counterparts in Europe. It is accountable to the national legislature, the National People's Congress, while the Supreme People's Procuratorate exercises a number of supervisory powers over courts. The executive branch, i.e. the State Council on the national level, is a much more powerful state organ than the judiciary. While no laws formalizes the superior status of the executive vis-à-vis the courts, such status is understood as a matter of political convention. As for the status within the Chinese Communist Party, judges are usually ranked lower than procurators within the nomenklatura, not to mention the extremely powerful Central Political and Legal Affairs Commission which basically controlled the entire law enforcement, judicial and procuratorate machinery in China. As much as the leaders of the SPC would like to see a higher degree of operational autonomy be given to the courts, the institutional inferiority of the judiciary is something structural and therefore cannot be changed overnight. The self-esteem of individual judges is another problem. When judges (especially young judges) do not see themselves as the vanguards of justice, but rather a class of mid to low ranking civil 
servants, there could hardly be any true reform to strengthen the power of the judiciary.

Civil justice, unlike criminal justice and administrative litigation, attracts less extrajudicial intervention given the general non-public nature of civil disputes. However, civil adjudication is limited to the disputes resolution function in China. The function of rights enforcement and declaration of legal norms are not emphasized in the last decade or so until recently. As a result, the prevailing belief among judges (especially at basic-level courts in less developed regions of the country) is that as long as the cases were disposed of, everything else does not really matter. The perceptions of judges regarding the role they play in civil justice greatly affect the position and practice of mediation. If judges see themselves as the defender of rights and standardbearers of the law, mediation (whether in-court or out-of-court) would be confined to its rightful place of being an alternative means to litigation. However, if the disputes resolution function of courts were overemphasized, mediation would become a strategic tool for courts to meet case-processing targets. Hence, the issue at the end of the day is how the leaders of the Chinese judiciary could reshape the ingrained belief that courts are simply disputes-resolution centres and promote a multifaceted judicial agenda that takes both disputes resolution and the normative function of adjudication on rights enforcement seriously. It is submitted that despite the changing views of SPC leaders, it would be difficult for the judiciary to reverse the structural deficits of courts given the colossal magnitude of the historical weight of China's hierarchy political culture.

\subsection{A final word}

Mediation plays a critical role in the development of any civil justice system. When used well as a true alternative to litigation, mediation could alleviate the zero-sum effect of litigation and introduce flexibility in the disputes resolution process. However, the positive effects of mediation could only manifest if the process is protected in ways that allow parties to truly be able to choose what is best in their interests and explore options free from interference from anyone else. The Chinese legal and political culture, coupled with a systemic distortion of the function of mediation during Wang Shengjun's period (March 2008 - March 2013), made it very difficult to develop an authentic mediation system that places party autonomy and other core principles (such as confidentiality) at the heart of process. Judges generally view mediation as a convenient way to manage the court dockets. Judicial conciliation is still preferred by many judges given the inherent advantage of a conciliated settlement from a career perspective (i.e. a settlement cannot be appealed and a high settlement rate is favourable to the evaluation of the judge). According to the empirical findings in Chapter 5, Anjie shiliao is still a very important goal in Chinese civil justice, which means that it would be difficult to separate mediation (in whatever form) from the prevailing policies of the state that place great premium on any measures that could help maintain social order. An overhaul of the mediation system in China, therefore, requires an institutional separation (not independence, since one should not aim for the impossible) of the judiciary from the rest of the state machinery (at least in the realm of civil procedure) in a way that the judiciary is given the simple task of delivering justice unadulterated by interventionist state policies and populist trends. Only by doing that could there be 'normalization' of mediation, i.e. mediation simply playing an ADR function and nothing more. While the SPC leaders 
are keen to achieve 'normalization', the practical constraints (especially at basic-level courts where the dockets are flooded with cases) make it very difficult, if not impossible, for courts to view mediation as a purely alternative disputes resolution mechanism under which party autonomy is paramount. This is the tension that China's policy-makers must realize and tackle going forward in constructing a modern, effective and authentic mediation system.

Based on the procedural and empirical analyses of this work, the main research question set out in Chapter 1 of this book is answered in the negative. To be specific, given the current judicial culture that emphasizes the social effect of the civil process, it is not practically feasible for the mediation of civil disputes in China to take the shape of genuine alternative dispute resolution. Rather, mediation is still considered by the establishment as a means to preserve social stability. Under the prevailing principle of Anjie shiliao, the civil process in China is tainted by political needs and the populist agenda. The conduct of mediation today, whether in-court or out-ofcourt (with only limited exceptions, like private commercial mediation), must still be consistent with the overarching political goal of preserving social stability. The situation is particularly true for in-court mediation (especially for the process of judicial conciliation). This is the reality despite the official talk of 'normalizing' the function of mediation. 


\section{Afterward}

The Recent Judicial Reforms in China and Its Impact on Civil Justice and Mediation 


\section{AFTERWARD: THE RECENT JUDICIAL REFORM IN CHINA: ITS IMPACT ON CIVIL JUSTICE AND MEDIATION}

\subsection{Pre-reform indicators}

Even before concrete reform measures were introduced, there were already signs as early as 2013 that there would be an overhaul of the Chinese judiciary, both in terms of administrative restructuring and fundamental policy shifts.

Early signs indicated that the reform would encompass the following areas:

(a) An overhaul of the 'chain of command' of Chinese courts, i.e. judicial personnel on the local level (including both basic-level and intermediate courts) would be determined by the provincial high court. There would also be a nationwide restructuring of the financing of courts.

(b) Raise the profile of the courts and alleviate the public's concerns in relation to judicial competency and fairness. Public confidence in the court system hit an all time low by the end of Wang Shengjun's tenure as president of the SPC (March 2008 - March 2013). The poor public image was the result of multiple factors, including the lack of adjudicatory independence, local nepotism that sought to influence court decisions, and the abusive use of court mediation. As such, a main theme of the reform is likely to be the task of implementing 'adjudicatory independence'. The concept of 'adjudicatory independence' must be distinguished from 'judicial independence', in that the former concerns only the notion of minimizing (or eradicating, in the ideal case) extra-judicial interferences of the adjudicatory process that are not specifically prohibited under the law. While procuratorial supervision over courts is most likely to continue or even strengthen, other interferences (e.g. from local governments and people's congresses) would most probably be curbed by clear policy guidelines (if not prohibited outright under law).

(c) With the restructuring underway, it is suggested that the policy of "prioritizing mediation' (tiaojie youxian (调解优先)) is likely to undergo some adjustment (or 'relaxation'). For instance, under the new policy, for cases involving issues of social significance or possibly possessing 'precedential' value, ${ }^{919}$ the SPC would ask the courts to adjudicate rather than pushing for settlement against the will of parties. Yet, even if the SPC is determined to completely revoke the policy of prioritizing mediation, it is unlikely that the judicial culture towards settlement would change in any significant way in the near future. As long as judges are evaluated under benchmarks that reward closure of disputes and penalize reversals of judgments, mediation would still continue to be the preferred avenue regardless of what policy is in place. Furthermore, the role of the court to extinguish disputes within society would not change as long as state policies still place a high premium on the court's ability to act as an agent for securing public order.

\footnotetext{
919 'Precedent' here obviously does not denote a binding effect of judgment, but only denotes the value of a judgment as a reference for lower courts. The idea of establishing such references by higher courts is consistent with the SPC's policy of implementing the 'guiding case' regime.
} 


\subsection{Pilot Programmes and SPC Circuit Courts}

Even before the detailed reform measures were outlined in 2015 by the SPC, ${ }^{920}$ six regions (five provinces and one municipality directly under the control of the Central People's Government) initiated pilot programmes to spearhead the reform effort (Pilot Programmes). ${ }^{921}$ A particular focus of the Pilot Programmes was to deal with the problem of regional protectionism in civil justice. In the past, the finances of local courts were predominantly controlled by local governments. The Pilot Programmes sought to unify financial control at the provincial level (including autonomous regions and municipalities directly under the control of the Central People's Government). In other words, local authorities going forward would have no control over the court budget. Instead, the provincial high court (and higher level courts of autonomous regions and municipalities directly under the control of the Central People's Government) will be conferred the exclusive power over court finances within the province. The reform is not limited to court financing. The transfer of control over 'personnel, finances and resources' (人财物) of local courts to the provincial high courts signifies a comprehensive shift of power within the Chinese judicial structure. Under the current system, promotion within the judiciary is based on an evaluation conducted by leaders of the same court. This arrangement is far from desirable as it opens the door for cronyism. Under the Pilot Programmes, the power to evaluate judges is transferred to the provincial high court. The transfer of power would most certainly help sever nepotistic links between local courts and regional special interests. $^{922}$

The idea of establishing 'Supreme People's Court's Circuit Courts' (SPC Circuit Courts) has the objective of unifying jurisprudence in mind. The lack of certainty and uniformity in Chinese jurisprudence has led to the introduction of the 'Guiding Cases' system. Yet, the effect of guiding cases is limited ${ }^{923}$ as trial judges at basiclevel courts seldom refer to the guiding cases in adjudication. Even if guiding cases were taken seriously by all the judges, the small volume of guiding cases to date published by the SPC could hardly be sufficient as de facto precedents in adjudication. This is why the SPC established the circuit courts system to exercise greater oversight on the norm-declaration function of courts.

\footnotetext{
${ }^{920}$ Prior to the SPC 2015 Reform Opinion, the crux of China's judicial reform plan was documented in The Opinion for Deepening Judicial System and Social System Reforms and Working Plan for Implementation (关于深化司法体制和社会体制改革的意见及贯彻实施分工方案) and The Framework Opinion on Several Issues Relating to Judicial System Reform Pilot Programmes (《关于 司法体制改革试点若干问题的框架意见》) promulgated by the Central Leading Team for Comprehensively Deepening Reform (中央全面深化改革领导小组).

921 The six regions that implemented the Pilot Programmes are Hainan Province, Hubei Province, Qinghai Province, Shanghai, Guangdong Province and Jilin Province.

$922 \mathrm{http}: / /$ news.xinhuanet.com/legal/2014-06/15/c 1111149887.htm (last consulted 29 June 2014).

923 Interview 2013/4.
} 
The First SPC Circuit Court was established on 28 January 2015, with its seat in Shenzhen, Guangdong. It accepts cases within the jurisdiction of the SPC from Guangdong, Guangxi and Hainan Provinces. It also accepts Xinfang cases from the three provinces. The decision of the SPC Circuit Court is considered to be the decision of the SPC itself.

\subsection{The latest SPC reform package (2015)}

\subsubsection{Overview}

The Supreme People's Court's Opinions on the Comprehensive Entrenchment of Reforms in the People's Courts (Fourth Five-Year Reform Outline of the People's Courts) ${ }^{924}$ (SPC 2015 Reform Opinion) outlined in detail China's latest judicial reform package.

Article 1 of the SPC 2015 Reform Opinion sets the tone of the reform: i.e. the construction of a judicial system where 'the people feel that justice is done (公平正义) in every single court case'. This tone marks a clear departure from the previous emphasis on the social impact of court decisions and the disputes resolution function of the court. Article 1 also touched on the importance to ensure that courts adjudicate independently (which, in fact, is a constitutional guarantee) free from outside interference. Article 2 then outlines five key principles that underscored the reform: (1) upholding the political leadership of the Chinese Communist Party in judicial reforms; (2) respecting that the judiciary is a unique organ of the state in that the adjudication process must be afforded such procedural protections for it to function independently and impartially; (3) propelling the reform efforts in a stable and progressive manner based the law (e.g. entrenching reform measures through timely legislation); (4) focusing on the key problems first, i.e. tackling structural problems such as external interference with adjudication; and (5) strengthening top-down supervision and high-level planning, but at the same time allowing sufficient room for local innovation (e.g. pilot programmes on the local level should be encouraged).

There are seven key aspects of the reform: (i) reforming the administrative structure of the court system; (ii) constructing an 'adjudication-centred' judiciary; (iii) formalizing and strengthening the functional systems within courts with clear 'terms of reference' (e.g. docketing system); (iv) improving and calibrating the operational mechanisms of the adjudicative process; (v) constructing an 'open, dynamic, transparent and people-centred' judicial system; (vi) formalizing and professionalizing court personnel appointment and management; (vii) guaranteeing the independent exercise of adjudicative powers by the courts.

\subsubsection{Reforming the administrative structure of the court system}

The intention (while not publicized by the judiciary) behind reforming the administrative structure of the court system is to separate, to the extent possible, the overlaps between the executive branch and the judiciary. In other words, by

${ }^{924}$ Effective since 4 February 2015 (Judicial Notification (fafa) [2015], No. 3). 
restructuring the court system, the SPC seeks to reduce executive influence over adjudication and other affairs of the court.

An examples of concrete measures in this area of reform is the establishment of SPC Circuit Courts, which was explored above in the context of unifying jurisprudence. From a restructuring perspective, it is submitted that SPC Circuit Courts serve at least four purposes: (1) help coordinate the work of courts at different levels (from basiclevel courts to provincial high courts) with the physical presence of the SPC in the locality; (2) deal with 'significant' civil and commercial cases (significant in terms of quantum of the claim and/or the complexity of the issues and/or the sensitivity of the case); (3) making policy-related decisions where local courts lack the authority to make; (4) mediate tension between the judiciary and local authorities, resolving conflicts and safeguarding adjudicatory autonomy.

Another example is the proposal to establish 'Trans-Jurisdictional Courts' designed to take up 'special cases' that involve a multiplicity of interests and parties across administrative boundaries. For instance, a trans-jurisdictional court could be established across the Pearl River Delta to deal with complex commercial cases involving foreign investment in this fast-growing region.

\subsubsection{Constructing an 'adjudication-centred' judiciary}

It may sound counter-intuitive to think that a judiciary can be anything other than 'adjudication centred'. However, in China, given Wang Shengjun's policy (March 2008-March 2013) that prioritized mediation, Chinese courts at times looked more like state-sponsored mediation centres than genuine tribunals of law. This left a lasting impression, while public confidence on courts was at an all time low. The new SPC leadership wanted to reverse this impression and bolster public confidence in the judicial system. The 2015 SPC Reform Opinion specifically mentioned the importance of protecting the right of access to court and entrenching the principle of party disposition and principle of party presentation. Special attention was given to the fact-finding rules in civil procedure. The opinion reiterated the overarching principle that fact-finding in civil litigation is a party-driven process. ${ }^{925}$ This is a timely and important reminder as courts in China still remained highly inquisitorial despite the Civil Evidence Rules provided for a party-driven proof-taking regime. ${ }^{926}$ Another key area is the formalization of asset preservation procedures in civil litigation. ${ }^{927}$

\subsubsection{Formalizing the functional systems within courts with clear 'terms of reference'}

A common criticism of the Chinese court system is the lack of clear differentiation of work and responsibilities among the various functional units. For instance, the docketing division of the court should only deal with the question of whether a dispute qualifies to be docketed, and nothing else. However, in practice, the docketing division plays the unwarranted role of pushing cases away by delaying the

\footnotetext{
${ }^{925}$ Article 14 of the SPC 2015 Reform Opinion.

${ }^{926}$ See Chapter 8 of this book for further elaboration.

${ }^{927}$ Article 16 of the SPC 2015 Reform Opinion.
} 
docketing process or pressuring parties to settle. The reform seeks to formalize the functional role of each division/unit within the court with a view to avoid abuse of power. The new 'docket registration regime' is a good example. A very positive development is the proposal to regulate the autonomy and integrity of adjudication at each instance, i.e. first instance, second instance and re-adjudication. ${ }^{928}$ Essentially, the vague demarcation of the various instances of adjudication in the past where the first instance court's decision could be swayed by the views of the second instance court (with or without a 'request for instructions' (Qingshi (请示)) from the lower court), was undesirable and inconsistent with the procedural standards of a modern civil court. The proposal also seeks to clarify the jurisdiction of each level of court based primarily on the value of the claim, rather than other factors. For example, it is possible in the future that basic-level courts cannot take any case in which the remedy sought is beyond a certain monetary threshold, no matter what the circumstances are.

\subsubsection{Improving and calibrating the operational mechanisms of the adjudicative process}

An important aspect of reform in the adjudication process is the heightened requirement of providing sufficient and proper reasoning in judgments, especially in complex, controversial or socially significant cases. ${ }^{929}$ Chinese judgments are known for their brevity, especially when it comes to reasoning. The reform seeks to change this by incentivizing the drafting of better judgments by pegging it to the career development of the judge.

Perhaps the most fundamental change in this area is the proposal to clearly separate citizens' petition (Xinfang) from adjudication. ${ }^{930}$ Xinfang has long been a hazardous territory for civil justice given its propensity to sway adjudication and affect the procedural rights of parties. Courts, fearing that a high Xinfang rate would result in their negative evaluation, had not been hesitant in bending procedural rules and infringing principles of justice to ensure that the impact of Xinfang is contained. A complete separation of Xinfang from adjudication (including the revamping of evaluation criteria for judges relating to their work that involves Xinfang) could potentially cure this problem. However, no procedural details have been announced at this stage.

\subsubsection{Constructing an 'open, dynamic, transparent and people-centred' judicial system}

The SPC's objective of constructing an 'open, dynamic, transparent and peoplecentred' judicial system is to regain the public's trust and confidence in the system, so much so that the judiciary becomes an asset, not liability, of the ruling superstructure. While procedural safeguards in the form of black letter law have never be lacking, it is a totally different question whether such safeguards were in fact implemented effectively in adjudication. The Chinese judiciary has long struggled to remove the

\footnotetext{
${ }^{928}$ Article 19 of the SPC 2015 Reform Opinion.

${ }^{929}$ Article 34 of the SPC 2015 Reform Opinion.

${ }^{930}$ Article 36 of the SPC 2015 Reform Opinion.
} 
stigma that courts are not open and transparent. Arbitrary and haphazard decisions of judges made behind closed-doors (whether in adjudication or court mediation) were not unusual occurrences but a fact of life in many of China's basic-level courts. Judges simply do not believe that procedural rules that safeguard openness and transparency were necessarily strict rules that need to be followed to the tee. An overhaul of the system by unveiling what used to be sensitive areas of the judiciary gives the perception that the courts have nothing to hide. Among other measures, the judiciary would now manage a nationwide webpage that help litigants track the status of their lawsuits. The ultimate aim of the project is to digitize all court documentation submission and storage. ${ }^{931}$ The reform also includes an ambitious project of publishing the vast majority of judgments online. The guiding policy going forward is to publish judgments as the common practice and only to refrain from publishing in exceptional cases. $^{932}$

'Litigation service centres' is another feature that demonstrates the determination of the judiciary to improve access to justice. The centres provide a service hotline for litigants (called '12368 hotline') and operate on-line reservation systems for court services (e.g. a litigant can now book an appointment on-line to file a lawsuit with the docketing division of the court). ${ }^{933}$

\subsubsection{Formalizing and professionalizing court personnel appointment and management}

The reform also seeks to formalize the appointment and management of court personnel. The aim is to establish a fully modern court personnel management system by 2017. Among other measures, the reform seeks to define clearly the role of judicial assistants, court clerks and enforcement officers, with clear terms of reference. The plan includes a complete revision of the appointment criteria for judges of different court levels, i.e. different sets of criteria should apply to different judicial appointments in the four levels of the judiciary. ${ }^{934}$ The plan also envisions the stepping up of training of judges, e.g. in drafting skills. ${ }^{935}$

The pay scale of judges will undergo a major overhaul. Currently, judges are paid on the basis of the pay scale applicable to all civil servants in China. This will change fundamentally with the reform, with the judiciary devising an independent pay scale for its judges. ${ }^{936}$

\footnotetext{
${ }^{931}$ Article 38 of the SPC 2015 Reform Opinion.

932 Article 39 of the SPC 2015 Reform Opinion.

933 Article 43 of the SPC 2015 Reform Opinion.

${ }^{934}$ Article 50 of the SPC 2015 Reform Opinion.

935 Article 52 of the SPC 2015 Reform Opinion.

${ }^{936}$ Article 53 of the SPC 2015 Reform Opinion.
} 


\subsubsection{Guaranteeing the independent exercise of adjudicative powers by the courts.}

The autonomous exercise of adjudicatory powers by courts is supposedly guaranteed under the PRC Constitution and the Organic Law. ${ }^{937}$ In reality, however, interference from the local government, people's congress and other authorities had been a main concern. The presidents of local court are selected by the people's congresses of the same level. Judges of local courts are appointed by the standing committees of the people's congresses of the same level. All judges of intermediate courts are appointed by the standing committee of the people's congress at the provincial level. Court finances are still partly controlled by the local administration. These links strain the ability of the court to act independently. Special interests find their way into the courtroom, at times influencing the outcome of lawsuits.

The reform seeks to confer powers of nomination of judges of all intermediate and basic level courts within the province on the provincial high court. ${ }^{938}$ It remains to be seen how this shift in nomination power would be executed in practice, e.g. whether the provincial high court is capable of fending off interference from other state organs in the appointment process (the formal appointment power still vests with the people's congresses and their standing committees at the corresponding level). In the long run, it is submitted that the Organic Law should be amended so that the appointment power of all judges below the provincial level should vest exclusively with the provincial high court.

The reform establishes an interesting protocol that leaders of the court are now required to take the oath of office by swearing allegiance to the PRC Constitution. ${ }^{939}$ While ceremonial in nature, the protocol helps promote the perception that judges are a unique type of state officers who exercises powers with a wide degree of autonomy.

The provincial high court can also make fiscal decisions within its provincial judicial system. As such, all the finances of China's intermediate and basic level courts will be managed exclusively by their respective provincial high court, not the local government or central authorities. ${ }^{940}$ The fiscal powers of the provincial high court include the power to collect and manage the income of courts under its jurisdiction.

\footnotetext{
${ }^{937}$ Article 126 of the PRC Constitution: 'The people's courts exercise judicial power independently, in accordance with the provisions of law, and not subject to interference by any administrative organ, public organization or individual; Article 4 of the Organic Law: 'The people's courts shall exercise judicial power independently, in accordance with the provisions of law, and shall not be subject to interference by any administrative organ, public organization or individual.'

938 Article 54 of the SPC 2015 Reform Opinion.

939 Article 60 of the SPC 2015 Reform Opinion.

${ }^{940}$ Article 63 of the SPC 2015 Reform Opinion.
} 


\subsection{Redefining the power structure: Re-distributing powers of the Chinese Communist Party to procurators and courts}

In Chapter 8, the author criticized the expansion of procuratorate powers in the 2012 revision of the Code in the context of adjudication supervision and called for greater powers to be devolved to the courts themselves. However, one cannot overlook the intention behind strengthening procuratorate powers in civil litigation and in the broader landscape of court proceedings. The Central Political and Legal Affairs Commission of the Chinese Communist Party Central Committee (中共中央政法委员会) (Commission) has the mandate to supervise and oversee law enforcement, courts and procurators. The Chinese court system is therefore an interlocking system with each court under the supervision of the corresponding leaders of the Commission. The Commission sometimes interfere with the adjudication supervision process and other processes in civil litigation. The intention of the 2012 revision of the Code is to formalize the adjudication supervision procedure by transferring powers of the Commission to the procurators. Enhancing the position of procurators also has the effect of countering interference from local authorities and vested interests in the adjudication process.

\subsection{Concluding remarks: Reform's impact on mediation: superficial change or real overhaul?}

The origins of the problems arising from the policy of preferring mediation lies not in the technicalities of the policy (as policies can changed) but the underlying power structure and judicial culture in China. Traditionally, courts were seen as mere forum of dispute resolution where their case-processing function is emphasized. From the perspective of the ruling elites, the paramount role of the judiciary is a socio-political one, i.e. the extent to which courts operate effectively such that social stability can be best preserved. The inherent constitutional inferiority of the judiciary seals the fate of civil justice in China, a civil justice that prizes utilitarian achievements, rather than doing justice in the individual case with due process in mind. Tasked with the mission to serve the greater social good, court leaders are left with no choice but to employ self-evaluative criteria that emphasize quantitative achievements and a superficial notion of efficiency. Judges, as a result, are motivated to close cases as soon as possible, and utilize tactics (be it mediation or something else) that help tally the highest rate of case disposal. This kind of judicial culture thwarts any meaningful attempt to construct proceduralism in Chinese civil litigation. While 'adjudicatory autonomy' emphasized in the reform may address some of these concerns, the institutional weakness of the individual judge, exacerbated by the political tradition that subordinates should defer to the 'leader', makes it almost impossible for the judge to insist on his position in a case when the court leaders have clearly expressed a different view.

In fact, as discussed in Chapter 4, a higher mediation settlement rate does not necessarily mean that a community is more harmonious. Also, achieving the goal of social harmony does not necessarily entail the enlisting of courts to adopt abusive tactics in the initiation and conduct of mediation. Courts should do what they are best at (and what they are designed to do) - adjudicate. Even if the policy of prioritizing 
mediation does in fact change, the concerns regarding due process in court mediation would persist given the fused role of the adjudicator and conciliator in judicial conciliation. The judiciary has an inherent duty to deliver justice, not a distorted version of 'justice' with a superimposed goal from other branches of government. The process of reaching a fair conclusion of a dispute requires the observance of procedural rules and an insulated environment under which the decision of the adjudicating judge is not under threat of being overturned unless it were successfully challenged by a party under the appeal procedure. Chinese judges are trained to obey the orders of their superiors. Even where graduates leave law schools with great dreams to defend the law as they enter their profession as judges, the judicial culture of bureaucratic obedience and the lack of adjudicatory autonomy would eventually wear away any shred of idealism. Court leaders, who are seemingly powerful within the court structure, would inevitably bow to external forces when their own careers are on the line. While the prospective reform seeks to sever the links between the local government and courts, the 'invisible link' paved by decades of interactions (and indeed political trades) between government officials and judges cannot be removed overnight. The power imbalance is further exacerbated by the fact that judicial leaders are usually ranked at the lower end of the nomenklatura, even behind senior procurators and security bureau chiefs.

Even where the policy in favour of mediation is repealed, it is unlikely that the populist tendency of the judiciary would change. Another method would eventually take the stage in place of court mediation. The rise of 'expedited procedures' (速裁程 序) is a good example.

It is unlikely that the practice of preferring mediation would change in any fundamental way. Even if the SPC changes the black letter of the policy, there are other incentives for mediation that would continue to make mediation a preferred choice for judges. However, a policy change on this front is welcomed. At least it would be able to correct the absurdity of courts competing with one another for the highest mediation settlement rate. What must also be changed, apart from issuing new guidelines, is the evaluation criteria for courts and appraisal system for judges. As long as the performance of courts and judges is linked to mediation settlement rates, there is no hope of eradicating the ills of an abusive court mediation system. Furthermore, the overemphasis on lowering appellate reversal and re-adjudication rates is an important contributing factor for judges to resort to mediation whenever possible (and even using inappropriate tactics to press parties to settle). However, due regard must be given to why such decisions are overturned, i.e. whether is it because the judge made a blatant and serious error, or the appellate court simply had a divergent interpretation of the law. A mere reversal may not necessarily imply poor trial quality. For instance, a trial judge may be adopting a liberal interpretation of a statutory provision which was never attempted before. The appellate court no doubt has the power to overrule the first instance decision, yet the trial judge should not be accused of having made a 'mistake' just because his or her decision was overturned on appeal. The contemporary evaluation criteria on appellate reversals and readjudication fail to give regard to the circumstances of each individual case and simply adopt a quantitative benchmark in assessing the so-called 'accuracy' of a judgment. When assessment parameters truly cater for the review of the quality of justice delivered, rather than based purely on numbers and figures, judges will only 
then focus on improving the quality of adjudication instead of trying to push for settlement out of fear of penalty.

A civilized society responds favourably to a judiciary that does its job well in delivering quality justice. A well-reasoned judgement rendered under guarantees of procedural justice speaks much louder than engineered figures of mediated settlements. When justice is seen to be done, one single case could turn public sentiments around in trusting that fairness is not beyond reach. This is not to suggest that a judge should be swayed by the public opinion in adjudication. Quite the contrary, judges should be impervious to what the man on the street may gossip about and focus only on enforcing the law and the rights of litigants. Social problems within the community can only be solved by its civil society. In the case of China, where civil society is weak, such problems are best tackled by the executive branch under clearly defined policy objectives and fair regulations, rather than enlisting judges to help shoulder the responsibility. A judge's sacred task is to hear cases and arrive at the fairest possible outcome. While policy considerations would sometimes influence a decision, judges must not take on a populist agenda in handling lawsuits. 
APPENDICES 


\section{APPENDIX I:}

\section{Bibliography}

\section{Alexander 2006}

Alexander, N. (ed.), Global Trends in Mediation, 2nd edn., Alphen aan den Rijn: Kluwer Law International, 2006.

\section{Alexander 2009}

Alexander, N., International and Comparative Mediation: Legal Perspectives, Alphen aan den Rijn: Kluwer Law International, 2009.

\section{Allee 1994}

Allee, M.A., 'Code, Culture, and Custom: Foundations of Civil Case Verdicts in a Nineteenth-Century County Court', in K. Bernhardt and P.C.C. Huang (eds.), Civil Law in Qing and Republican China, Stanford: Stanford University Press, 1994, p. 122-141.

\section{Andrews 2012}

Andrews, N., The Three Paths of Justice: Court Proceedings, Arbitration, and Mediation in England (Ius Gentium: Comparative Perspectives on Law and Justice, Vol. 10), Dordrecht, Heidelberg, London, New York: Springer, 2012.

\section{Cai 2014}

Cai, Y.M, 'Case Management in China's Civil Justice System', in: C.H. van Rhee \& Y.L. Fu (eds.), Civil Litigation in China and Europe: Essays on the Role of the Judge and the Parties (Ius Gentium: Comparative Perspectives on Law and Justice, Vol. 31), Dordrecht, Heidelberg, London, New York: Springer, 2014 forthcoming, p. 3958 .

\section{Cao 2006}

Cao, L.J., 'Combining Conciliation and Arbitration In China: Overview and Latest Developments', International Arbitration Law Review, 2006 (9:3), p. 84-93.

\section{Chan 2012a}

Chan, P.C.H., 'The Enigma of Civil Justice in Imperial China: A Legal Historical Enquiry', Maastricht Journal of European and Comparative Law, 2012 (19:2), p. 317-337.

\section{Chan 2012b}

Chan, P.C.H., 'Efficiency and Truth in Civil Fact-finding: The Evolving Role of the Judge in Mainland China and Hong Kong and the Effect of the Policy Preference for Court Mediation on Fact-finding in the People's Courts', in: C.H. van Rhee \& A. Uzelac (eds.), Truth and Efficiency in Civil Litigation: Fundamental Aspects of Factfinding and Evidence-taking in a Comparative Context, Antwerp: Intersentia, 2012, p. 231-260. 


\section{Chan, Chan \& Chen 2014}

Chan, P.C.H., Chan, D. \& Chen, L., 'China: Hong Kong. Selective Adoption of the English Woolf Reforms', in C.H. van Rhee \& Y.L. Fu (eds.), Civil Litigation in China and Europe: Essays on the Role of the Judge and the Parties (Ius Gentium:

Comparative Perspectives on Law and Justice, Vol. 31), Dordrecht, Heidelberg, London, New York: Springer, 2014, p. 71-125.

\section{Chen 1999}

Chen, A.H.Y., 'Confucian Legal Culture and Its Modern Fate', in R. Wacks (ed.), The New Legal Order in Hong Kong, Hong Kong: Hong Kong University Press, 1999, p. 505-533.

\section{Chen 2011}

Chen, A.H.Y., An Introduction to the Legal System of the People's Republic of China, 4th edn., Hong Kong: LexisNexis, 2011.

\section{Chen L. 2010}

Chen, L., 'The Historical Development of the Civil Law Tradition in China: A Private Law Perspective', The Legal History Review, 2010(78), p. 159-181.

\section{Clarke 1996}

Clarke, D.C., 'Power and Politics in the Chinese Court System: The Enforcement of Civil Judgments', Columbia Journal of Asian Law, 1996 (10), p. 1-92.

\section{Clermont \& Sherwin 2002}

Clermont, K.M. \& Sherwin, E., 'A Comparative View of Standards of Proof', The American Journal of Comparative Law, 2002 (50:2), p. 243-276.

\section{Corne 1990}

Corne, P.H., 'The Influence of Traditional Normative Mechanism of Behaviour on the Japanese Legal System', Sydney Law Review, 1990 (12), p. 346-361.

\section{De Palo \& Keller 2013}

De Palo, G. \& Keller, L., 'Mediation in Italy: Alternative Dispute Resolution for All', in: K.J. Hopt \& F. Steffek (eds.), Mediation: Principles and Regulation in Comparative Perspective, Oxford: Oxford University Press, 2013, p. 667-696.

\section{Ding et. al. 2011}

Ding, S.Q., et. al. (eds.), Practical Guide to Formalizing People's Mediation Documentation Format and Statistical Reports, Beijing: China Legal Publishing House, 2011.

[丁淑清 主编《人民调解文书格式及统计报表规范化制作：实用指南》（2011） 中国法制出版社 北京].

\section{Fu 1992}

Fu, H.L., 'Understanding People's Mediation in Post-Mao China', Journal of Chinese Law, 1992 (6), p. 211-246. 


\section{Fu 2005}

Fu, Y.L., 'The Function and Structure of Civil Appeal Procedures - A Study of the Two-Instance Appellate Model from a Comparative Perspective', Law Review, 2005(4), p. 36-44.

[傅郁林 “论民事上诉程序的功能与结构-一比较法视野下的二审上诉模式” 2005 年第 4 期《法学评论》36-44]

\section{Fu \& Cao 2012}

Fu, Y.L. \& Cao, Z.X., 'The Position of Judges in Civil Litigation in Transitional China - Judicial Mediation and Case Management', in: L. Chen, L. \& C.H. (Remco) van Rhee (eds.), Towards a Chinese Civil Code: Comparative and Historical Perspectives, Leiden, Boston: Martinus Nijhoff Publishers, 2012, p. 495-519.

\section{Fu \& Cullen 2011}

Fu, H.L. \& Cullen, R., 'From Mediatory to Adjudicatory Justice: The Limits of Civil Justice Reform in China', in: M.Y.K. Woo \& M.E. Gallagher (eds.), Chinese Justice: Civil Dispute Resolution in Contemporary China, New York: Cambridge University Press, 2011, p. 25-57.

\section{Gao 2005}

Gao, N., 'A Study on Civil Property Disputes and Lawsuits in the Song Dynasty' (Doctoral Dissertation: Hebei University, published on China Doctoral Dissertations Full-text Database), 2005.

\section{[高楠《宋代民间财产组纷与诉讼研究》(2005) 博士论文（河北大学） 载于《中國博士學位論文全文數據庫》]}

\section{Gu 2011}

Gu, W.X., 'China's Arbitration: Restricted reform', in: G.H. Yu (ed.), The

Development of the Chinese Legal System, Oxford: Routledge, 2011, p. 272-292.

\section{Gu 2012}

Gu, W.X., Arbitration in China: Regulations of Arbitration Agreements and Practical Issues, Hong Kong: Sweet \& Maxwell, 2012.

\section{Halegua 2005}

Halegua, A., 'Reforming the People's Mediation System In Urban China', Hong Kong Law Journal, 2005 (35), p. 715 - 750.

\section{Han 2000}

Han, X.T., 'The System of Hearing by Community Elderly in Early-Ming Dynasty Found in the Book Jiao Min Bang Wen', Cass Journal of Law, 2000 (3), p. 137-147.

[韩秀桃 “ 《教民榜文》所见明初基层里老人理讼制度” 2000 年第 3 期《法学研 究》137-147] 


\section{He 2009}

He, X., 'Enforcing Commercial Judgments in the Pearl River Delta of China', The American Journal of Comparative Law, 2009 (57), p. 419-457.

\section{Hilmer 2009}

Hilmer, S. E., Mediation in the People's Republic of China and Hong Kong (SAR), Utrecht: Eleven International Publishing, 2009.

\section{Hopt \& Steffek 2013}

Hopt, K.J \& Steffek, F., 'Mediation: Comparison of Laws, Regulatory Models Fundamental Issues', in: K.J. Hopt \& F. Steffek (eds.), Mediation: Principles and Regulation in Comparative Perspective, Oxford: Oxford University Press, 2013, p. 3130.

\section{Hu 2001}

$\mathrm{Hu}$, X.D., 'Research on the function of the village community in the Yuan Dynasty', Journal of Yunan Normal University, 2001 (33:4), p. 41-45.

[胡兴东 “元代 “社” 的职能考辨” 2001 年第 4 期 《云南师范大学学报》41-45 ]

\section{Hu 2007}

Hu, X.D., 'Study of the Folk Solving Dispute Mechanism Regulated by the State Law in the Periods of the Yuan, Ming and Qing', Journal of Yunnan University Law Edition, 2007 (20:4), p. 42-50.

[胡兴东“元明清时期国家法对民间纠纷解决机制的规制研究' 2007 年第 4 期 《云南大学学报法学版》42-50]

\section{Huang 1994}

Huang, P.C.C., 'Codified Law and Magisterial Adjudication in the Qing', in K. Bernhardt and P.C.C. Huang (eds.), Civil Law in Qing and Republican China, Stanford: Stanford University Press, 1994, p. 142-186.

\section{Huang 1996}

Huang, P.C.C., Civil Justice in China: Representation and Practice in the Qing, Stanford: Stanford University Press, 1996.

\section{Huang 2001}

Huang, P.C.C., Code, Custom, and Legal Practice in China: The Qing and the Republic Compared, Stanford: Stanford University Press, 2001.

\section{Huang 2006}

Huang, P.C.C., 'Court Mediation in China, Past and Present', Modern China, 2006 (32:3), p. 275-314. 


\section{Huang 2010}

Huang, P.C.C., Chinese Civil Justice, Past and Present, Lanham, MD: Rowman \& Littlefield Publishers Inc., 2010.

\section{Hung 2011}

Hung, D.Y., A Study of the Evolution of Contemporary Chinese Mediation Systems, Shanghai: Shanghai Renmin Publishing House, 2011.

\section{[洪冬英《当代中国调解制度变迁研究》（2011）上海人民出版社 上海 ]}

\section{Jagtenberg \& de Roo 2011}

Jagtenberg, R. \& de Roo, A., 'Frame for a Dutch portrait of mediation', Customized conflict resolution: Court-connected Mediation in the Netherlands 1999-2009, The Judiciary Quarterly, 2011, p. 7-23.

\section{Jiang 2010}

Jiang, W., 'Frontiers of the theoretical issues of the Civil Procedure Law', Journal of National Prosecutors College, 2010 (18:2), p. 152-160.

[江伟 ‘民事诉讼法前沿理论问题” 2010 年第 18 卷第 2 期《国家检察官学院学 报》152-160]

\section{Jiang, Sun \& Wang 2012}

Jiang, B.X., Sun X.Z. \& Wang C.H., Lectures On Civil Trial Supervision Procedure, Beijing: Law Press China, 2012.

[江必新/孙祥壮/王朝辉《新民事诉讼法: 审判监督程序讲座》（2012）法律出 版社 北京]

\section{Jin 2012}

Jin, Z.B., 'From a Supplementary Legislator to a Legitimate Judicial Lawmaker - On the Role of the Supreme People's Court in Developing the Law in Mainland China' in: L. Chen \& C.H. van Rhee (eds.), Towards a Chinese Civil Code: Comparative and Historical Perspectives, Leiden: Martinus Nijhoff Publishers, 2012, p. 29-60.

\section{Kaufmann-Kohler \& Fan 2008}

Kaufmann-Kohler, G. \& Fan, K., 'Integrating Mediation into Arbitration: Why It Works in China', Journal of International Arbitration, 2008 (25:4), p. 479-492.

\section{Lenhoff 1954}

Lenhoff, A., 'The Law of Evidence: A Comparative Study Based Essentially on Austrian and New York Law', The American Journal of Comparative Law, 1954 (3:3), p. 313-344. 


\section{Li 2013}

Li, H., 'On Separating Mediation from Trial in Civil Justice', China Legal Science, 2013(3), p. 5-18.

[李浩 “调解归调解, 审判归审判: 民事审判中的调审分离, 2013 年第 3 期《中 国法学》5-18]

\section{Li Z.J. 2010}

Li, Z. J., On the System of Intermediation: The Harmonious Settlement of Conflicts, Beijing: Law Press China, 2010.

[李祖军《调解制度论: 冲突解决的和谐之路》（2010）法律出版社 北京]

\section{Liang 2007}

Liang, L.X., Delivering Justice in Qing China: Civil Trials in the Magistrate's Court, Oxford University Press: Oxford, 2007.

\section{Liang J.Q. 2008}

Liang, J.Q., 'The Enforcement of Mediation Settlement Agreements in China', American Review of International Arbitration, 2008 (19), p. 489-519.

\section{Liebman 2007}

Liebman, B.L., 'China's Courts: Restricted Reform', Columbia Journal of Asian Law, 2007 (21:1), p. 1-44.

\section{Liebman 2011}

Liebman, B.L., 'A Populist Threat to China's Courts?', in: M.Y.K. Woo, \& M.E. Gallagher (eds.), Chinese Justice: Civil Dispute Resolution in Contemporary China, New York: Cambridge University Press, 2011, p. 269-313.

\section{Lin 2002}

Lin, D., Confucian Ethics and Legal Culture: A Social Scientific Enquiry, Beijing, China University of Political Science and Law Press, 2002.

[林端《儒家伦理与法律文化: 社会学观点的探索》（2002）中国政法大学出版 社 北京]

\section{Lin 2003}

Lin, D., Weber's Commentary on Traditional Chinese Law: A Critique of the Weberian Comparative Sociology, Taipei: San Min Book Co. Ltd., 2003.

[林端《韋伯論中國傳統法律 : 韋伯比較社會學的批判》(2003) 三民書局股份 有限公司 臺北]

\section{Liu 1999}

Liu, N.P., 'A Vulnerable Justice: Finality of Civil Judgments in China', Columbia Journal of Asian Law, 1999 (13), p. 35-98. 


\section{Liu M., 2001}

Liu, M., 'On the Modern Court Mediation System', Social Science Research, 2001 (5), p. 90-95.

\section{[刘敏 “论现代法院调解制度’ 2001 年第 5 期《社会科学研究》90-95]}

\section{Liu M. 2012}

Liu, M., 'On Innovation and Development of People's Mediation System', Law Science Magazine, 2012 (3), p. 59-65.

[刘敏 “人民调解制度的创新与发展’ 2012 年第 3 期《法学杂志》59-65]

\section{Mann 1984}

Mann, M., 'The Autonomous Power of the State: Its Origin, Mechanisms and Results', European Journal of Sociology, 1984 (25), p. 109-136, quoted in P.C.C. Huang, Chinese Civil Justice, Past and Present, Lanham, MD: Rowman \& Littlefield Publishers Inc., 2010, p. 76.

\section{Minzner 2011a}

Minzner, C.F., 'Judicial Disciplinary Systems for Incorrectly Decided Cases: The Imperial Chinese Heritage Lives On', in: M.Y.K. Woo \& M.E. Gallagher (eds.), Chinese Justice: Civil Dispute Resolution in Contemporary China, New York: Cambridge University Press, 2011, p. 58-90.

\section{Minzner 2011b}

Minzner, C.F., 'China's Turn Against Law', American Journal of Comparative Law, 2011 (59:4), p. 935-984.

\section{Mo 2009}

Mo, J.S., 'Understanding the Role of People's Mediation in the Age of Globalization', Asia Pacific Law Review, 2009 (17), 2nd Supp. (Special Issue on Mediation), p. 7588.

\section{Murray \& Sturner 2004}

Murray, P.L. \& Sturner, R., German Civil Justice, Durham, NC: Carolina Academic Press, 2004.

\section{Ng \& He 2014}

Ng, K.H. \& He X., 'Internal Contradictions of Judicial Mediation in China', Law \& Social Inquiry, 2014 (39:2), p. 285-312.

\section{Norton 2007}

Norton, P.M., 'Informal Dispute Settlement Approaches' in M.J. Moser (ed.), Managing Business Disputes in Today's China: Duelling with Dragons, Alphen aan den Rijn: Kluwer Law International, 2007, p. 19-44. 


\section{NPCSC Publication 2007}

Office for Civil Law of the Legislative Affairs Commission of the National People's Congress Standing Committee (ed.), The Civil Procedure Law of the People's Republic of China: Annotated Provisions, Legislative Reasoning and Related Regulations, Beijing: Peking University Press, 2007.

[全国人大常委会法制工作委员会民法室 编 《中华人民共和国民事诉讼法条文 说明, 立法理由及相关规定》 (2007) 北京大学出版社 北京]

\section{NPCSC Publication 2012}

Office for Civil Law of the Legislative Affairs Commission of the National People's Congress Standing Committee (ed.), The Civil Procedure Law of the People's Republic of China: Annotated Provisions, Legislative Reasoning and Related Regulations (2012 revised edition), Beijing, Peking University Press, 2012.

[全国人大常委会法制工作委员会民法室 编《化人民共和国民事诉讼法条 文说明, 立法理由及相关规定 (2012 修订版》（2012）北京大学出版社＼cjkstart北京]

\section{Oberhammer \& Domej 2005}

Oberhammer, P. \& Domej, T., 'Germany, Switzerland and Austria', in: C.H. Van Rhee (ed.), European Traditions in Civil Procedure, Oxford/Antwerp: Intersentia, 2005, p. 295-305.

\section{Pan \& Liu 2010}

Pan, J.F. \& Liu, Z.W., 'The Relationship Between Court Mediation and Dispute Resolution - From the Perspective of Constructing A Harmonious Society', Journal of Comparative Law, 2010 (4), p. 70-81.

[潘剑锋/刘哲玮 '论法院调解与纠纷解决之关系一从构建和谐社会的角度展' 2010 年第 4 期《比较法研究》70-81]

\section{Peerenboom 2000}

Peerenboom, R., 'The Evolving Regulatory Framework for Enforcement of Arbitral Awards in the People's Republic of China', Asia-Pacific Law and Policy Journal, 2000 (1), p. 1-69.

\section{Peerenboom 2003}

Peerenboom, R., 'The X-Files: Past and Present Portrayals of China's Alien "Legal System”, Washington University Global Studies Law Review, 2003 (2), p. 37-95.

\section{Peerenboom \& He 2009}

Peerenboom, R. \& He, X., 'Dispute Resolution in China: Patterns, Causes and Prognosis', East Asia Law Review, 2009 (4), p. 1-61.

\section{Peerenboom \& Scanlon 2005}

Peerenboom, R. \& Scanlon, K., 'An Untapped Dispute Resolution Option: Mediation Offers Companies Distinct Advantages in Certain Cases', The China Business Review, 32 (4), 2005, p. 36-41. 


\section{Peng 2011}

Peng, S.Z., 'Orientation of the Civil Mediation Reform and Judicial Activism

Outlook—_Reflection on the court's “zero judgment", Journal of Jinan University (Philosophy \& Social Science Edition), 2011 (1), p. 52-58.

[彭世忠 ‘能动司法视野下民事调解改革的径向选择: 对某些地方法院追求 “零判 决” 现象的反思” 2011 年第 1 期《暨南学报 (哲學社會科學版)》52-58]

\section{People's Mediation Law Annotation 2010}

Office for Civil Law of the Legislative Affairs Commission of the National People's Congress Standing Committee \& the Department of Legislative Affairs of the Ministry of Justice of the People's Republic of China (eds.), The People's Mediation Law of the People's Republic of China: Annotated Provisions, Beijing, China Legal Publishing House, 2010.

[全国人大常委会法制工作委员会民法室，中华人民共和国司法部法制司 编《中 华人民共和国人民调解法解读》 (2010) 中国法制出版社 北京]

\section{Pissler 2013}

Pissler, K.B., 'Mediation in China: Threat to the Rule of Law?' , in: K.J. Hopt \& F. Steffek (eds.), Mediation: Principles and Regulation in Comparative Perspective, Oxford: Oxford University Press, 2013, p. 959-1009.

\section{Qu 2003}

Qu, C.L., 'Analysis of the Civil Appellate Procedure in Song Dynasty', 25 Modern Law Science, 2003 (25:2), p. 92-96.

[屈超立 “宋代民事案件的上诉程序考述” 2003 年第 25 卷第 2 期 《现代法学》 92-96]

\section{Roth \& Gherdane 2013}

Roth, M. \& Gherdane, D., 'Mediation in Austria: European Pioneer in Mediation Law and Practice', in: K.J. Hopt \& F. Steffek (eds.), Mediation: Principles and Regulation in Comparative Perspective, Oxford: Oxford University Press, 2013, p. 247-332.

\section{Schmidt 2003}

Schmidt, P.J., 'A Review of China's New Civil Evidence Law', Pacific Rim Law \& Policy Journal, 12 (2), 2003, p. 291-313.

\section{Shiga 1988}

Shiga, S., 'A Study of Chinese Legal Culture-Focusing on the Litigation Landscape', Journal of Comparative Law, 1988(3), p. 18-26.

[滋贺秀三 ‘中國法文化的考察以訴訟的形態為素材’ 1988 年第 3 期《比较法 研究》18-26] 


\section{Spinei 2011}

Spinei, S., 'The Romanian Legal Profession', in: C.H. van Rhee \& A. Uzelac (eds.), The Landscape of the Legal Professions in Europe and the USA: Continuity and Change, Antwerp: Intersentia, 2011, pp. 41-54.

\section{Swedberg 2005}

Swedberg, R., The Max Weber Dictionary: Key Words and Central Concepts, Stanford: Stanford University Press, 2005.

\section{Terada 2005}

Terada, H., 'The Nature of Social Agreements (Yue) In the Legal Order of Ming And Qing China (Part One)', International Journal of Asian Studies, 2005 (2:2), p. 309327.

\section{Tian 2009}

Tian, T., 'Preliminary Study of Societal Mediation Agreement in the Huizhou Region', The Rule of Law Forum, 2009 (24:1), p. 1-10.

[田涛 “徽州地区民间纠纷调解契约初步研究” 2009 年第 24 卷第 1 期 《法治论 丛》1-10]

\section{Uzelac 2010}

Uzelac, A., 'Survival of the Third Legal Tradition?', in: J. Walker \& O.G. Chase (eds.), Common Law, Civil Law and the Future of Categories, Markham: LexisNexis, 2010, p. 377-396.

\section{Wang 2009}

Wang, L.M., 'Characteristics of China's Judicial Mediation System', Asia Pacific Law Review, 2009 (17:2), Supp. (Special Issue on Mediation), p. 67-74.

\section{Wang F.H. 2014}

Wang, F.H., 'From "Trial Management" to "Case Management"', in: C.H. van Rhee \& Y.L. Fu (eds.), Civil Litigation in China and Europe: Essays on the Role of the Judge and the Parties (Ius Gentium: Comparative Perspectives on Law and Justice, Vol. 31), Dordrecht, Heidelberg, London, New York: Springer, 2014, p. 59-68.

\section{Wang L.M. 2010}

Wang, L.M., 'Form of Ma Xiwu Is a Successful Way of Trial', Law Science Magazine, p. 69-72.

[王立民 ‘马锡五审判方式是成功的审判方式” 2010 年第 10 期《法学杂志》6972] 


\section{Wang T.S. 1998}

Wang T.S., 'The Operation of the Law in Taiwan During the Qing Dynasty Observations Based on the Dan-Xin Archives), Research Report of the National Science Council, 1998, p. 45-49, cited in D. Lin, Weber's Commentary on Traditional Chinese Law: A Critique of the Weberian Comparative Sociology, Taipei: San Min Book Co. Ltd., 2003, p. 101.

[王泰升《從淡新檔案觀察清治台灣官府法律之運作》（1998）國立臺灣大學 法律學系暨研究所研究 45-49, 載於林端《韋伯論中國傳統法律: 韋伯比較社 會學的批判》(2003) 三民書局股份有限公司 臺北 101]

\section{Wang Y.X. 2011}

Wang, Y.X., 'The Preinstall Premises to Understand the Differences Between the Current Chinese Civil Litigation Practice and Western Legal Tradition' (unpublished), Expert Meeting Paper, The Role of the Judge and the Parties in Civil Litigation: Towards an Efficient Procedure under the Rule of Law in China and the $E U$, Maastricht, 12-14 September 2011 (research project funded by the China-EU School of Law at the China University of Political Science and Law, 2011-2012).

\section{Wilkinson, Cheung \& Booth 2009}

Wilkinson, M., Cheung, E.T.M. \& Booth, C.N. (eds.), A Guide to Civil Procedure in Hong Kong (Incorporating the New Civil Justice Reform Rules), 3rd edn., Hong Kong: LexisNexis, 2009.

\section{Wilkinson, Cheung \& Booth 2011}

Wilkinson, M., Cheung, E.T.M. \& Booth, C.N. (eds.), A Guide to Civil Procedure in Hong Kong, 4th edn., Hong Kong: LexisNexis, 2011.

\section{Woo 1991}

Woo, M.Y.K., 'Adjudication Supervision and Judicial Independence in the P.R.C.', American Journal of Comparative Law, 1991 (39:1), p. 95-119.

\section{Woo \& Wang 2005}

Woo, M.Y.K. \& Wang, Y.X., 'Civil Justice in China: An Empirical Study of Courts in Three Provinces', American Journal of Comparative Law, 2005 (53:4), p. 911-940.

\section{Xiao 2009}

Xiao, J.G., 'A Study on the Judicial ADR Commissioned Mediation System Under Construction - Focusing on Contemporary Chinese Court Practice, Law Review), 2009 (3), p. 135-144.

[肖建国 ‘司法 ADR 建构中的委托调解制度研究一以中国法院的当代实践为中 心’ 2009 年第 3 期《法学评论》135-144] 


\section{Xie 2009}

Xie, D.H., 'An Investigation of the Civil Mediation System under the Nanjing

Nationalist Government', Social Sciences In Nanjing, 2009 (10), p. 86-93.

[谢冬慧 “南京国民政府民事调解制度考论’ 2009 年第 10 期《南京社会科学》 86-93]

\section{Yearbook 2009}

Law Yearbook of China Editorial Division (eds.), Law Yearbook of China (2009), Beijing: Press of Law Yearbook of China, 2009.

[中国法律年鉴编辑部 编 《中国法律年鉴 (2009)》(2009) 中国法律年鉴社 北京]

\section{Yearbook 2010}

Law Yearbook of China Editorial Division (eds.), Law Yearbook of China (2010), Beijing: Press of Law Yearbook of China, 2010.

[中国法律年鉴编辑部 编 《中国法律年鉴 (2010)》 (2010) 中国法律年鉴社 北京]

\section{Yearbook 2011}

Law Yearbook of China Editorial Division (eds.), Law Yearbook of China (2011), Beijing: Press of Law Yearbook of China, 2011.

[中国法律年鉴编辑部 编 《中国法律年鉴 (2011)》 (2011) 中国法律年鉴社 北京]

\section{Yearbook 2012}

Law Yearbook of China Editorial Division (eds.), Law Yearbook of China (2012), Beijing: Press of Law Yearbook of China, 2012.

[中国法律年鉴编辑部 编 《中国法律年鉴 (2012)》(2012) 中国法律年鉴社 北京]

\section{Yearbook 2013}

Law Yearbook of China Editorial Division (eds.), Law Yearbook of China (2013), Beijing: Press of Law Yearbook of China, 2013.

[中国法律年鉴编辑部 编 《中国法律年鉴 (2013)》 (2013) 中国法律年鉴社 北京]

\section{Yearbook 2014}

Law Yearbook of China Editorial Division (eds.), Law Yearbook of China (2014), Beijing: Press of Law Yearbook of China, 2014.

[中国法律年鉴编辑部 编 《中国法律年鉴 (2014)》(2014) 中国法律年鉴社 北京] 


\section{Zhang B.S. 2008}

Zhang, B.S. (ed.), Uniform Provisions of Evidence of the People's Court: Proposal for Judicial Interpretations and Drafting Commentary, Beijing: China University of Political Science and Law Press, 2008.

[张保生 主编《人民法院统一证据规定》司法解释建议稿及论证》（2008）中国 政法大学出版社＼cjkstart北京］

\section{Zhang J. 2011}

Zhang, J. (ed.), People's Court Case Quality Evaluation System: Explanatory Notes and Annotations on Application, Beijing: The People's Court Press, 2011.

[张军 编《人民法院案件质量评估体系理解与适用》（2011）人民法院出版社 北京]

\section{Zhang M. 2002}

Zhang, M., 'International Civil Litigation in China: A Practical Analysis of the Chinese Judicial System', Boston College International and Comparative Law Review, 2002 (25), p. 59-96.

\section{Zhang W.P. 2006}

Zhang, W.P., 'On the Concept of Aufklärung in Civil Procedures', Peking University Law Journal, 2006 (18:2), p. 129-146.

[张卫平 ‘民事诉讼 “释明” 概念的展开” 2006 年第 2 期《中外法学》129-146]

\section{Zhang W.P. 2007}

Zhang, W.P., 'Court mediation: an analysis of the contemporary situation', Legal Science, 2007 (5), p. 18-27.

[张卫平 “诉讼调解:时下势态的分析与思考’ 2007 年第 5 期 《法学》18-27]

\section{Zhang W.P. 2009}

Zhang, W.P., 'Reconsideration of "Ma Xi-wu-styled Trial"', Modern Law Science, 2009 (5), p. 139-156.

[张卫平 “回归 “马锡五” 的思考” 2009 年第 5 期 《现代法学》139-156]

\section{Zhang W.P. 2011}

Zhang W.P. (ed.), On Civil Procedure (Vol. 7): Amendment Draft and Annotation for the Civil Procedure Law of the People's Republic of China, Xiamen: Xiamen University Press, 2011.

[张卫平主编《民市程序法研究（第七辑）：《中华人民共和国民事诉讼 法》修改建议稿及释义》（2011）厦门大学出版社 厦门] 
Zhang W.P. 2012

Zhang, W.P. (ed.), Lectures on Civil Procedure Law of the People's Republic of

China, Beijing: China Legal Publishing House, 2012.

[张卫平主编《新民事诉讼法专题讲座》（2012）中国法制出版社 北京]

Zhang W.Y. 2010

Zhang, W.Y., 'Special Features of Civil Adjudication in the Song Dynasty', Lanzhou Academic Journal, 2010 (2), p. 137-140.

[张文勇 “论宋代民事审判的时代特点”2 010 年第 2 期 《兰州学刊》137-140]

Zhang X.P. 1983

Zhang, X.P., The Ma Xiwu Adjudication Method, Beijing: Law Press China, 1983.

[张希坡 《马锡五审判方式》（1983）法律出版社 北京]

\section{Zhang \& Li 2012}

Zhang, W.P. \& Li, H., Principles and Application of the New Civil Procedure Law, Beijing: Courtpress, 2012.

[张卫平/李浩 《新民事诉讼法原理与适用》（1992）人民法院出版社 北 京]

\section{Zhang \& Walton 2010}

Zhang, N.N. \& Walton, D., 'Recent Trends in Evidence Law in China and the New Evidence Scholarship', Law, Probability \& Risk, 2010 (9), p. 103-129.

\section{Zhang \& Zwier 2003}

Zhang, M., \& Zwier, P.J., 'Burden of Proof: Developments in Modern Chinese Evidence Rules', Tulsa Journal of Comparative \& International Law, 2002-2003 (10:2), p. 419-471.

Zeng 2009

Zeng, X.Y., 'Mediation in China-Past and Present', Asia Pacific Law Review, 2009 (17), No. 2 Supp. (Special Issue on Mediation), p. 1-30,

\section{Zhong \& Yu 2004}

Zhong, J.H., \& Yu, G.H., 'Establishing the Truth on Facts: Has the Chinese Civil Process Achieved This Goal?', Journal of Transnational Law \& Policy, 2004 (13), p. 393-445.

\section{Zhou J.H. 2013}

Zhou, J.H., 'A Discussion of the Judicial Confirmation Procedure for Mediation [Settlement] Agreements', in: W.P. Zhang (ed.), On Civil Procedure (Vol. 9), Xiamen: Xiamen University Press, 2013, p. 122-134.

[周建华《论调解协议的司法确认程序》载于张卫平主编《民市程序法研 究 (第九辑) 》（2013）廈门大学出版社 厦门] 


\section{Zhu 2010}

Zhu, S.L., 'The Party and the Courts', in: R. Peerenboom (ed.), Judicial Independence in China: Lessons for Global Rule of Law Promotion, New York: Cambridge University Press, 2010, p. 52-68.

\section{Zimmerman 2010}

Zimmerman, J. M., China Law Deskbook: A Legal Guide for Foreign-Invested Enterprises, 3rd edn., Chicago: American Bar Association, 2010.

\section{Zuckerman 2009}

Zuckerman, A., 'The Challenge of Civil Justice Reform: Effective Court Management of Litigation', City University of Hong Kong Law Review, 2009 (1:1), p. 49-71. 


\section{APPENDIX II:}

\section{Table of Key Statutes, Statutory Instruments, Judicial Interpretations, Rules and Regulations of the Supreme People's Court and Abbreviations}

\section{Abbreviation \\ Civil Evidence \\ Rules}

Code

Organic Law

People's

Mediation Law

SPC

\section{Civil}

Mediation Rules

2007 SPC Opinion

2009 SPC Opinion

最高人民法院关于建立

健全诉讼与非诉讼相衔

接的矛盾纠纷解决机制

的若干意见

\section{解法}

最高人民法院

最高人民法院关于人民 法院民事调解工作若干 问题的规定

\section{English translation}

Some Provisions of the Supreme People's Court on Evidence in Civil Procedure

Civil Procedure Law of the People's Republic of China ${ }^{941}$

Organic Law of the People's Courts of the People's Republic of China

People's Mediation Law of the People's Republic of China

\section{最高人民法院关于进一 步发挥诉讼调解在构建 社会主义和谐社会中积 极作用的若干意见} Several Opinions of the Supreme People's Court on Further Displaying the Positive Roles of Court Mediation in the Building of a Socialist Harmonious Society

Provisions of the Supreme People's Court about Several Issues Concerning the Civil Mediation Work of the People's Court

Several Opinions of the Supreme People's Court on Establishing a Sound Conflict and Dispute Resolution Mechanism that Connects Litigation and Non-litigation

\section{Notes}

Judicial Interpretation [2001], No 33

[法释 [2001] 33 号]

Effective since 1 April 2002

Effective since 1991

Amended in 2007 and 2012

Effective since 1 January 1980 Amended in 1983, 1986 and 2006

Effective since 1 January 2011

Judicial Interpretation [2004], No. 12 [法释 [2004] 12 号] Effective since 1 November 2004

Judicial Notice [2007], No. 9 [法发 [2007] 9 号]

Effective since 6 March 2007

Judicial Notice [2009], No. 45

[法发 [2009] 45 号]

Effective since 24 July 2009

\footnotetext{
941 Note that the Civil Procedure Law (which came into effect in 1991) has been revised twice, in 2007 and 2013 respectively. The second amendment was passed on 31 August 2012 (by way of the Decision of the Standing Committee of the National People's Congress on Amending the Civil Procedure Law of the People's Republic of China (2012)) and has come into effect on 1 January 2013. References in this book are made to the latest version of the Civil Procedure Law.
} 
最高人民法院关于进一

步贯彻 “调解优先,调

判结合”工作原则的若

干意见

\section{Judicial \\ Confirmation \\ Rules}

2015

Interpretation

\section{Registration}

Rules
最高人民法院关于人民 调解协议司法确认程序

的若干规定

最高人民法院关于适用

中华人民共和国民事诉

讼法的解释

最高人民法院关于人民

法院登记立案若干问题

的规定

最高人民法院关于加强

人民法院审判管理工作

的若干意见

最高人民法院关于开展 案件质量评估工作的指

导意见
Several Opinions of the Supreme People's Court on Furthering the Implementation of the working principle of 'Prioritizing Mediation, Fusing Mediation and Adjudication'

Several Provisions of the Supreme People's Court on the Judicial Confirmation Procedure for the People's Mediation Agreements

Interpretation of the Supreme People's Court on the Application of the Civil Procedure Law of the People's Republic of China

Regulations of the Supreme People's Court on Several Issues Relating to the Docketing Registration of Cases in the People's Courts

Supreme People's Court's Several Opinions on Strengthening Trial Management Work in the People's Courts

Supreme People's Court Guidance Opinion Relating to the Commencement of the Work on Case Quality Evaluation
Judicial Notice [2010], No. 16

[法发 [2010］16 号]

Effective since 7 July 2010

Judicial Interpretation [2011], No. 5 [法释 ［2011］5 号]

Effective since 30 March 2011

Judicial Interpretation [2015], No. 5 [法释［2015］5 号]

Effective since 4 February 2015

Judicial Interpretation [2015], No. 8 [法释 [2015］８号]

Effective since 1 May 2015

Judicial Notice [2011], No.2

[法发 [2011] 2 号]

Effective since 6 January 2011

Judicial Notice [2011], No. 55

\section{SPC Case Quality Opinion}




\section{APPENDIX III:}

\section{Interview Log}

\section{Part A: $\quad$ Pre-March 2013 Interviews $^{942}$}

\section{(i) Interviews in $\mathbf{2 0 1 2}$}

\section{Interview Ref: $2012 / 1$}

Judge of an intermediate court in a leading commercial city in northern China.

Interview date: 2 September 2012

\section{Interview Ref: $2012 / 2$}

Head of division of a provincial high court of a major landlocked province in the southeast of China. This senior judge specialises in foreign-related commercial disputes.

Interview date: 14 May 2012

\section{Interview Ref: $\mathbf{2 0 1 2 / 3}$}

Senior litigation lawyer based in a leading commercial city in northern China.

Interview date: 12 June 2012

\section{Interview Ref: $2012 / 4$}

Head of a medical dispute people's mediation commission in a leading commercial city in China.

Interview date: 13 June 2012

\section{Interview Ref: $2012 / 5$}

Interviewing a group of judges from various basic-level courts in a leading commercial city in northern China.

Interview date: 9 June 2012

\footnotetext{
942 Interviews conducted during the tenure of former SPC President Wang Shengjun. Wang stepped down as SPC president in March 2013.
} 


\section{Interview Ref: $2012 / 6$}

Judge of a basic-level court in a leading commercial city in northern China. The judge specialises in intellectual property disputes.

Interview date: 4 May 2012.

\section{Interview Ref: $2012 / 7$}

Former judge of a basic-level court in a municipal district of a major coastal province in China. At the time of the interview, the judge worked in the research department of the court.

Interview date: 25 May 2012

\section{Interview Ref: $2012 / 8$}

Judge of an intermediate court in a leading commercial city in northern China. The judge specializes in family, property and intellectual property disputes

Interview date: 4 June 2012

\section{Interview Ref: 2012/9}

Judge of a municipal district basic-level court in a leading commercial city in northern China. The judge handles predominantly civil cases.

Interview date: 24 May 2012

\section{Interview Ref: $2012 / 10$}

Senior lawyer at a local firm in a leading commercial city in northern China.

Interview date: 12 June 2012

Note: The interviewee was accompanied by an SPC judge, who responded to some of the interview questions.

\section{Interview Ref: 2012/11}

Interviewing a group of judges at a municipal district basic-level court in a leading commercial city in northern China.

Interview date: 11 June 2012 


\section{Interview Ref: $2013 / 1$}

Judge of a municipal district basic-level court in a leading commercial city in northern China. The judge handles predominantly civil cases.

Interview date: 4 February 2013

Note: same interviewee as Interview Ref: 2012/9

\section{Interview Ref: $2013 / 2$}

Judge of a basic-level court in a leading commercial city in northern China. The judge specialises in intellectual property disputes.

Interview date: 10 January 2013

Note: same interviewee as Interview Ref: $2012 / 6$

\section{Part B: $\quad$ Post-March 2013 Interviews ${ }^{943}$}

\section{Interview Ref: $2013 / 3$}

Former intern at a municipal basic-level court in a major coastal province in China. The interviewee is currently a legal scholar in the same province.

Interview date: 11 Nov 2013 and number of other dates in 2013

\section{Interview Ref: $2013 / 4$}

Judge of a basic-level court in a leading commercial city in northern China. The judge specialises in intellectual property disputes.

Interview date: 20 March 2013

Note: same interviewee as Interview Ref: 2012/6

\footnotetext{
943 Interviews conducted since the commencement of the tenure of current SPC President Zhou Qiang (in March 2013).
} 


\section{Interview Ref: $2013 / 5$}

Judge of a basic-level court in a leading commercial city in northern China. The judge specialises in intellectual property disputes.

Interview date: 10-11 December 2013

Note: same interviewee as Interview Ref: 2012/6

\section{Interview Ref: $2013 / 6$}

Senior litigation lawyer based in a leading commercial city in northern China.

Interview date: 3 December 2013

Note: same interviewee as Interview Ref: 2012/3

\section{Interview Ref: $2013 / 7$}

Vice-President of an intermediate court in a major coastal city in northern China.

Interview date: 15 May 2013

\section{Interview Ref: $2013 / 8$}

Former judge of a basic-level court in a municipal district of a major coastal province in China. At the time of the interview, the judge worked in the research department of the court.

Interview date: 4 December 2013

Note: same interviewee as Interview Ref: 2012/7

\section{Interview Ref: 2013/9}

Judge of a basic-level court in a leading commercial city in northern China. The judge specialises in intellectual property disputes.

Interview date: 3 December 2013

Note: same interviewee as Interview Ref: 2012/6

\section{Interview Ref: $2013 / 10$}

Former judge of an intermediate court in a major city in the northwest of China.

Interview date: 2 December 2013 


\section{Interview Ref: 2013/11}

Judge of a municipal district basic-level court in a leading commercial city in northern China. The judge handles predominantly civil cases.

Interview date: 12 December 2013

Note: same interviewee as Interview Ref: 2012/9

\section{Interview Ref: 2013/12}

Judge of a municipal district basic-level court in a leading commercial city in northern China.

Interview date: 3 December 2013

\section{Interview Ref: 2013/13}

Judge of an intermediate court in a leading commercial city in northern China.

Interview date: 4 Dec 2013

Note: same interviewee as Interview Ref: 2012/1

\section{Interview Ref: $2013 / 14$}

Head of division of a provincial high court of a landlocked province in the southeast of China. This senior judge specialises in foreign-related commercial disputes.

Interview date: 28 November 2013

Note: same interviewee as Interview Ref: 2012/2

\section{(iii) Interviews in $\mathbf{2 0 1 4}$}

\section{Interview Ref: 2014/1}

Lawyer of an international firm based in a leading commercial city in northern China.

Interview date: 3 January 2014 


\section{Interview Ref: $2014 / 2$}

Judge of a municipal district basic-level court in a leading commercial city in northern China.

Interview date: 29 January 2014 (by telephone call) and 6 February 2014 (by exchange of emails)

\section{Interview Ref: $2014 / 3$}

Judge of a municipal district basic-level court in a leading commercial city in northern China. The judge handles predominantly civil cases.

Interview date: 22 September 2014

Note: same interviewee as Interview Ref: 2012/9

\section{(iv) Interviews in 2015}

\section{Interview Ref: $2015 / 1$}

Former intern at a municipal basic-level court in a major coastal province in China. The interviewee is currently a legal scholar in the same province.

Interview date: 25 Feb 2015 (by exchange of emails)

Note: same interviewee as Interview Ref: 2013/3 


\section{APPENDIX IV: \\ Survey Questionnaires and \\ Master List of Interview Questions}


(A1) Questionnaire for judges on judicial conciliation (original version in

\section{Chinese):}

\section{法院调解问卷 \\ (民事／商事诉讼)}

(A) 问卷目的，个人资料保密及相关研究员联络方法:

此问卷的目的是收集有关民事和商事诉讼中法院调解的资料和调研实际操作情 况, 作学术研究用途。有关阁下的个人资料（即所属法院名称）, 会绝对保密。 问卷所得资料, 只会作学术研究用途, 不会作任何其他用途。

填妥问卷请发送到以下电邮:

相关研究员：陈志轩

联络电邮: lawyer2238@gmail.com

（B） 问卷回应者资料：

（i）请阁下提供以下资料:

所属法院名称（包括级别及所在地）：[

（ii）请阁下提供以下相关资料:

担任法官 (从助理审判员起算) 几年？［］年

阁下所处理案件的类别：[

阁下每年平均处理案件数量（大概数）：[ ]

阁下每年处理的案件平均的调撤率（大概数）：[ ]

(C) 问卷填写说明（重要说明）：

阁下请回答以下十四条问题。请先选择最合适答案, 选好后在 “答案：［ ] ” 空格里填写英文字母。选择一般由 $\mathrm{a}$ 到 $\mathrm{d}$ 。

例如所选答案是 $\mathrm{c}$, 请这样填写 “答案: [ $\mathbf{c}]$ ”。 
填写答案后, 在 “请作进一步解释: ” 下面的空位, 烦请阁下就所选答案作进 一步文字解释及提供相关资料。谢谢!

\section{问卷内容（共十四题）}

1. 一般来说, 以调解结案还是以判决结案所需的时间较长?
a. 以调解结案
b. 以判决结案
c. 不能一概而论，要看情况而定
d. 其他 /很难判断

答案: $[$ ]

请作进一步解释：

2. 如调解没结果, 还是要判决, 在调解过程中当事人的陈述 (和透露的资 料）会否影响您最后的判决?
a. 会影响最后的判决
b. 不会影响最后的判决
c. 不能一概而论，要看情况而定
d. 其他 / 很难判断

答案: [ ]

请作进一步解释：

3. （跟进上述第 2 题）如在调解过程中当事人的陈述（和透露的资料）影 响了您最后的判决, 是如何影响?
a. 影响案件中有关责任的裁决
b. 影响案件中有关赔偿的裁决
c. 影响责任的裁决, 同时影响赔偿的裁决
d. 其他 / 很难判断

答案: [ ]

请作进一步解释： 
4. 在调解的过程中, 您会否向当事人透露, 假如调解失败了您判决的倾向?
a. 会明示判决的倾向
b. 会暗示判决的倾向
c. 绝对不会透露判决的倾向
d. 不能一概而论, 要看情况而定
e. 其他／很难判断

答案: [ ]

如会透露判决的倾向（明示或暗示）, 是如何透露？请作进一步解释：

5. 您一般在审判的什么阶段进行调解？
a. 在开庭前进行调解
b. 在法庭调查终结后进行调解
c. 在法庭辩论终结后, 最后陈述前进行调解
d. 在庭审后 (判决之前) 进行调解
e. 在其他阶段进行调解 (请指明 :
f. 不能一概而论, 要看情况而定

\section{答案: [ ]}

为何一般在这阶段进行调解? 请作进一步解释 (如选 $\mathrm{f}$ 请解释为何不能 一概而论，要看情况而定）：

6. 你会否用调解的过程帮助查明事实, 以供判案之用 (假若调解最后失败, 还是要判）?
a. 会
b. 不会
c. 不能一概而论, 要看情况而定
d. 其他 /很难判断

答案: [ ]

如会, 在调解中查明的事实会否成为判案的依据？请作进一步解释： 
7. 当事人在案中的法律责任会不会影响调解的结果?
a. 会
b. 不会
c. 不能一概而论, 要看情况而定
d. 其他 /很难判断

答案: [ ]

如会, 当事人的法律责任如何影响调解的结果? 请作进一步解释：

8. “调解优先” 的政策有没有减少您判案的总数量（即如果没有这政策， 所判案件应该会较多）?
a. 有减少判案的总数量, 而且明显地减少
b. 有减少判案的总数量, 但并不明显
c. 完全没有减少判案的总数量
d. 其他 / 很难判断

答案: [ ]

请作进一步解释：

9. 如何判断什么案件当调, 什么案件该判?
a. 看案件的种类及性质
b. 看当事人之间的关系
c. 看法院的政策
d. 上述所有的因素
e. 其他因素 / 很难判断

答案: [ ]

请作进一步解释 : 
10. “调解优先” 的政策近来是否有变? 请根据阁下法院的实况作评论。
a. 调解优先政策已被废除
b. 调解优先政策有一些改变（政策没有废除，但不再强调）
c. 调解优先政策没有改变, 法院仍然强调 “调解优先”
d. 其他／很难判断

\section{答案: [ ]}

如 “调解优先” 的政策有变, 您认为有没有影响您对调解的应用? 请作 进一步解释 :

11. 法官评核准则鼓励调解，对您对调审的选择有什么影响?
a. 有颇大影响, 会因此很重视调解
b. 有一些影响, 会因此较重视调解
c. 完全没有影响
d. 其他 / 很难判断

答案: [ ]

请作进一步解释：

12. 相对而言, 民事案件比商事案件较适宜调解。
a. 同意
b. 不同意
c. 不能一概而论，要看情况而定
d. 其他 / 很难判断

答案: [ ]

请作进一步解释： 
13. 在您所属的法院里, 以调解结案的案件的强制执行率大概情况如何?
a. 很高
b. 偏高
c. 中等
d. 偏低
e. 很低

答案: [ ]

请作进一步解释（如有实际数字，请提供）：

14. 您认为 “案结事了” 仍然是重要的民诉目标吗?
a. 仍然非常重要
b. 仍然重要, 但没有已往那么重要
c. 已不再重要
d. 其他 / 很难判断

答案: [ ]

请作进一步解释 : 


\author{
Questionnaire on Judicial Conciliation \\ (Civil and commercial litigation)
}

\begin{abstract}
(A) The aim of the survey, confidentiality of personal information and contact details of the relevant researcher
\end{abstract}

This survey aims at (for academic research purposes) collecting information and investigating the operational aspects of judicial conciliation in civil and commercial litigation. Your personal information (including the name of your court) will be kept strictly confidential. Information obtained in this survey will only be used for academic research purposes and for no other purposes.

Once you have completed the questionnaire, please email it to:

Relevant researcher: Peter C.H. Chan

Email: lawyer2238@gmail.com

(B) Personal information of the respondent

(i) please provide the following information:

The name of your court (including court level and location): [

(ii) please provide the following relevant information:

How many years have you been working as a judge (starting from the date you worked as an assistant adjudicator)?: [ ] years

What type of cases do you handle: [ ]

How many cases do you handle each year (approximate figure): [

What is the rate of settlement/withdrawal each year (approximation): [ ]

(C) Note on completing the questionnaire (Important note):

Please respond to the 14 questions below. Please select the most appropriate answer [multiple choice] and fill in the blank "Answer: [ ]". The choices are generally (a) through (d).

For example if the selected answer is c, then fill in "Answer: [c]".

Once you have filled in your answer, please provide written explanation of your answer and relevant information in the space below under "Please provide further explanation". 
1. Generally speaking, is it more time consuming to dispose of a case by conciliation or adjudication (i.e. rendering a judgment)?
a. Disposal of case by conciliation
b. Disposal of case by adjudication [i.e. by way of rendering a judgment]
c. Depends on the circumstances, cannot generalize
d. Others/ difficult to determine

\title{
Answer: [ ]
}

Please provide further explanation:

2. If the conciliation did not result in a settlement and a judgment has to be rendered, would statements made by parties (and information disclosed) during the conciliation in any way affect your ultimate judgment?
a. Yes. Will affect the ultimate judgment
b. No. Will not affect the ultimate judgment
c. Depends on the circumstances, cannot generalize
d. Others/ difficult to determine

\author{
Answer: [ ] \\ Please provide further explanation:
}

3. (Following up on Question 2 above) if statements made by parties and information disclosed during the conciliation process affected your ultimate judgment, how do they affect your ultimate judgment?
a. affected the ultimate decision on liability
b. affected the ultimate decision on quantum
c. affected the ultimate decision on both liability and quantum
d. others/ difficult to determine

Answer: [ ]

Please provide further explanation: 
4. During the judicial conciliation process, will you disclose your inclination regarding the case [i.e. preliminary decision] to parties where no settlement is reached?

a. Yes. Will blatantly disclose to the parties what your preliminary decision is

b. Yes. Will hint to the parties what your preliminary decision is

c. No. Definitely would not disclose your preliminary decision

d. whether or not you would disclose your preliminary decision in a conciliation session depends on the circumstances, cannot generalize

e. others/ difficult to determine

\section{Answer: [ ]}

If you do disclose your preliminary decision (whether blatantly or by way of hinting), how do you disclose? Please provide further explanation:

5. At what stage of the hearing do you usually conduct conciliation?
a. right before the start of the substantive hearing.
b. after court investigation
c. after party debate and before final
d. after the hearing (before the rendering of judgment)
e. conciliation usually takes place in none of the above stages (please indicate the specific stage you usually conduct conciliation:
f. Depends on the circumstances, cannot generalize

\section{Answer: [ ]}

Why do you conduct conciliation at this particular stage? Please provide further explanation (if you choose $\mathbf{f}$, please explain why it depends on the circumstances):

6. Will you make use of the conciliation process to assist with the fact-finding in the ensuing proceedings should the case fail to settle?
a. Yes
b. No
c. Depends on the circumstances, cannot generalize
d. others/ difficult to determine

Answer: [ ]

If yes, will the findings of fact made during the conciliation process form the basis of your judgment? Please provide further explanation: 
7. Will the party's legal liability in the case affect the result of the conciliation?
a. Yes
b. No
c. Depends on the circumstances, cannot generalize
d. Others/ difficult to determine

\title{
Answer: [ ]
}

If yes, how does the party's legal liability affect the result of the conciliation? Please provide further explanation:

8. Did the policy of 'prioritizing conciliation' reduce the total number of judgments rendered by you (that is, if there is no such a policy, the number of judgments will be higher)?
a. Yes. The total number of judgments rendered is significant reduced.
b. Yes. The total number of judgments rendered is reduced, but the reduction is not significant.
c. No. The total number of judgments rendered is not reduced at all.
d. others/ difficult to determine

\author{
Answer: [ ] \\ Please provide further explanation:
}

9. What factors do you consider in determining your choice of conciliation or adjudication?
a. The type and nature of the case
b. The relationship between the parties
c. The prevailing policy of the court
d. All of the above
e. Other factors/ difficult to determine

Answer: [ ]

Please provide further explanation: 
10. Is there any change in the policy of 'prioritizing conciliation'? Please comment based on the actual situation in your court.
a. The policy of 'prioritizing conciliation' has been abolished
b. The policy of 'prioritizing conciliation' has undergone 'some changes', i.e. that it is not abolished but is no longer emphasized by the court
c. The policy of 'prioritizing conciliation' is still in force and emphasized by courts
d. Others/ difficult to determine

\section{Answer: [ ]}

If the policy of 'prioritizing conciliation' has changed, do you think it has affected your use/practice of conciliation? Please provide further explanation:

11. Is your decision on choosing conciliation or adjudication affected by the encouragement of settling cases through conciliation under the performance evaluation of individual judges [and the Case Quality Evaluation?
a. Significantly affected (would place great emphasis on conciliation as a result)
b. Somewhat affected (would place relative emphasis on conciliation as a result)
c. Not affected at all
d. Others/ difficult to determine
Answer: [ ]
Please provide further explanation:

12. Are purely civil cases comparatively more suitable for judicial conciliation than commercial cases?
a. Yes.
b. No
c. Depends on the circumstances, cannot generalize
d. Others/ difficult to determine

Answer: [ ]

Please provide further explanation: 
13. What is the approximate overall rate of mandatory enforcement of mediation statements in your court?
a. Very high;
b. On the high side
c. Moderate
d. On the low side
e. Very low.

Answer: [ ]

Please provide further explanation (please provide specific figures, if any):

14. Do you think "Anjie shiliao" is still an important goal of civil justice?
a. Yes. It is still very important
b. Yes. It is important, but not as important as before
c. No. It is no longer important
d. Others/ difficult to determine

Answer: [ ]

Please provide further explanation: 
(B1) Questionnaire for litigation practitioners on judicial conciliation (original version in Chinese):

\author{
法院调解问卷 \\ (民事／商事诉讼) \\ 执业诉讼律师
}

(A) 问卷目的，个人资料保密及相关研究员联络方法：

此问卷的目的是向有诉讼经验的执业律师收集有关民事和商事诉讼中法院调解 的资料和调研实际操作情况, 作学术研究用途。有关阁下的个人资料, 会绝对 保密。问卷所得资料, 只会作学术研究用途, 不会作任何其他用途。

填妥问卷请发送到以下电邮:

相关研究员：陈志轩

联络电邮: lawyer2238@gmail.com

（B）问卷回应者资料：

（i）请阁下提供以下资料:

所属律师事务所名称及所在地： [ 名称：

[所在地:

（如不便提供事务所名称, 请提供事务所大概所在地及主要业务) [ ]

（ii）请阁下提供以下相关资料:

所属部门（律师事务所部门）：［ ～］

执业资历（即民商事诉讼执业经验）：［］年

阁下所处理诉讼案件的类别：［］

阁下每年平均处理诉讼案件数量（大概数）：［］

阁下每年处理的诉讼案件中以法院调解结案的平均比率（大概数率） ～］％ 
阁下过往三年处理的诉讼案件一般在哪些法院审理?（请列明法院名称和级 别）:

(i)

(ii)

(iii)

(iv)

(v)

\section{(C) 问卷填写说明（重要说明）：}

阁下请回答以下十四条问题。请先选择最合适答案, 选好后在 “答案: [ ] ” 空格里填写英文字母。选择一般由 $\mathrm{a}$ 到 $\mathrm{d}$ 。

例如所选答案是 $\mathrm{c}$, 请这样填写 “答案: [ $\mathbf{c}]$ ”。

填写答案后, 在 “请作进一步解释：”下面的空位，烦请阁下就所选答案作进 一步文字解释及提供相关资料。谢谢! 


\section{问卷内容（共十四题）}

1. 根据您的诉讼经验, 一般来说, 以调解结案还是以判决结案所需的时间 较长?
a. 以调解结案
b. 以判决结案
c. 不能一概而论，要看情况而定（如：法官的审案方式各有不同）
d. 其他 / 很难判断

答案: [ ]

请作进一步解释：

2. 如调解没结果, 还是要判决, 在调解过程中当事人的陈述（和透露的资 料）您觉得会否影响法官最后的判决？
a. 会影响最后的判决
b. 不会否影响最后的判决
c. 不能一概而论, 要看情况而定
d. 其他 / 很难判断

答案: [ ]

请作进一步解释：

3. （跟进上述第 2 题）如在调解过程中当事人的陈述（和透露的资料）影 响了法官最后的判决，是如何影响?
a. 影响案件中有关责任的裁决
b. 影响案件中有关赔偿的裁决
c. 影响责任的裁决, 同时影响赔偿的裁决
d. 其他／很难判断

答案: [ ]

请作进一步解释 : 
4. 在调解的过程中, 有没有法官向当事人透露, 假如调解失败了法庭判决 的倾向?
a. 有, 法官会明示判决的倾向
b. 有，法官会暗示判决的倾向
c. 从来未遇到法官在调解的过程中向当事人透露判决的倾向
d. 其他 / 很难判断

\section{答案: [ ]}

如法官有透露判决的倾向（明示或暗示），是如何透露？请作进一步解释：

5. 法官一般在审判的什么阶段进行调解?
a. 在开庭前进行调解
b. 在法庭调查终结后进行调解
c. 在法庭辩论终结后, 最后陈述前进行调解
d. 在庭审后 (判决之前) 进行调解
e. 在其他阶段进行调解（请指明：
f. 不能一概而论, 要看情况而定

答案: [ ]

请作进一步解释： 
6. 当事人在案中的法律责任会不会影响调解的结果?
a. 会
b. 不会
c. 不能一概而论, 要看情况而定
d. 其他 /很难判断

答案: [ ]

如会, 当事人的法律责任如何影响调解的结果? 请作进一步解释:

7. “调解优先” 的政策有没有影响您当事人对调审的选择自由?
a. 有影响, 而且明显地影响了当事人对调审的选择自由
b. 有影响当事人对调审的选择自由，但并不明显
c. 完全没有影响当事人对调审的选择自由
d. 其他 /很难判断

答案: [ ]

请作进一步解释：

8. 法官一般用什么准则判断什么案件当调, 什么案件该判?
a. 看案件的种类及性质
b. 看当事人之间的关系
c. 看法院的政策
d. 上述所有的因素
e. 其他因素 / 很难判断

答案: [ ] 
请作进一步解释 :

9. “调解优先” 的政策近来是否有变? 请根据阁下处理案件的实况作评论。

a. 调解优先政策已被废除

b. 调解优先政策有一些改变（政策没有废除，但不再强调）

c. 调解优先政策没有改变, 法院仍然强调 “调解优先”

d. 其他／很难判断

答案: [ ]

如 “调解优先” 的政策有变, 您认为有没有影响法官对调解的应用? 请 作进一步解释 :

10. 在执行和解的过程中, 执行法官办演什么角色?
a. 跟法院调解中调解法官的角色完全相同
b. 跟法院调解中调解法官的角色有些相似
c. 跟法院调解中调解法官的角色完全不同 (请解释)
d. 不能一概而论, 要看情况而定
e. 其他 / 很难判断

答案: [ ]

请作进一步解释 :

11. 法官评核准则鼓励调解, 您认为有没有影响法官对调审的选择?
a. 有颇大影响, 会因此很重视调解
b. 有一些影响, 会因此较重视调解
c. 完全没有影响
d. 其他 / 很难判断 
答案: [ ]

请作进一步解释：

12. 相对于较复杂的商事案件, 法院更倾向 (或更愿意) 就纯民事案件进行 调解。您同意吗?
a. 同意
b. 不同意
c. 不能一概而论, 要看情况而定
d. 其他 / 很难判断

答案: [ ]

请作进一步解释：

13. 在您过去三年处理过的民商事案件中, 以调解结案案件的强制执行率大 概情况如何?
a. 很高
b. 偏高
c. 中等
d. 偏低
e. 很低

答案: [ ]

请作进一步解释（如有实际数字, 请提供）： 
14. 您认为 “案结事了” 对现时中国的司法体系而言仍然是重要的民诉目标 吗?
a. 仍然非常重要
b. 仍然重要, 但没有已往那么重要
c. 已不再重要
d. 其他 / 很难判断

答案: [ ]

请作进一步解释： 
(B2) Questionnaire for litigation practitioners on judicial conciliation (English translation)

\section{Questionnaire on Judicial Conciliation \\ (Civil and commercial litigation) \\ [for] Litigation practitioners}

(A) The aim of the survey, confidentiality of personal information and contact details of the relevant researcher

This survey aims at (for academic research purposes) collecting information and investigating the operational aspects of judicial conciliation in civil and commercial litigation from experienced practitioners. Your personal information will be kept strictly confidential. Information obtained in this survey will only be used for academic research purposes and for no other purposes.

Once you have completed the questionnaire, please email it to:

Relevant researcher: Peter C.H. Chan

Email: lawyer2238@gmail.com

(B) Personal information of the respondent

(i) please provide the following information:

The name of your firm and its location): [firm name:

[firm location:

(If it is inconvenient to provide the firm name, please indicate the approximate location of the firm and its main areas of practice) [

(ii) please provide the following relevant information:

The department (in the firm) that you are in: [

How many years have you practiced (civil and commercial litigation experience):

[ ] years

What type of cases do you handle: [

How many cases on average do you handle each year (approximate figure):

[

What is the average rate of settlement in the cases you handled each year (approximation): [ ] ] 
In the past three years, which were the courts that heard the cases of your clients? (please indicate name of the courts and level):

(i)

(ii)

(iii)

(iv)

(v)

(C) Note on completing the questionnaire (Important note):

Please respond to the 14 questions below. Please select the most appropriate answer [multiple choice] and fill in the blank "Answer: [ ]". The choices are generally (a) through (d).

For example if the selected answer is c, then fill in "Answer: [c]".

Once you have filled in your answer, please provide written explanation of your answer and relevant information in the space below under "Please provide further explanation". 


\section{The Questionnaire (14 questions in total)}

1. Based on your litigation experience, generally speaking, is it more time consuming for a case to be disposed by conciliation or adjudication (i.e. rendering a judgment)?

a. Disposal of case by conciliation

b. Disposal of case by adjudication [i.e. by way of rendering a judgment]

c. Depends on the circumstances, cannot generalize (e.g. it depends on the particular judge)

d. Others/ difficult to determine

Answer: [ ]

Please provide further explanation:

2. If the conciliation did not result in a settlement and a judgment has to be rendered, would statements made by parties (and information disclosed) during the conciliation in any way affect the judge's ultimate judgment?

a. Yes. Will affect the judge's ultimate judgment

b. No. Will not affect the judge's ultimate judgment

c. Depends on the circumstances, cannot generalize

d. Others/ difficult to determine

Answer: [ ]

Please provide further explanation:

3. (Following up on Question 2 above) if statements made by parties and information disclosed during the conciliation process affected the judge's ultimate judgment, how do they affect the ultimate judgment?

a. affected the ultimate decision on liability

b. affected the ultimate decision on quantum

c. affected the ultimate decision on both liability and quantum

d. others/ difficult to determine

Answer: [ ]

Please provide further explanation: 
4. During the judicial conciliation process, has the judge ever disclosed his/her inclination regarding the case [i.e. preliminary decision] to your client where no settlement is reached?

a. Yes, by blatantly disclosing to your client(s) his/her preliminary decision

b. Yes, by hinting to your client(s) his/her preliminary decision

c. No. You have never come across a case where the judge disclosed his/her preliminary decision to your client(s) during conciliation.

d. Others/ difficult to determine

\section{Answer: [ ]}

If the judge has disclosed his/her preliminary decision to your client(s) before (whether blatantly or by way of hinting), how was the decision disclosed? Please provide further explanation:

5. At what stage of the hearing does the judge usually conduct conciliation?

a. right before the start of the substantive hearing.

b. after court investigation

c. after party debate and before final

d. after the hearing (before the rendering of judgment)

e. conciliation usually takes place in none of the above stages (please indicate the specific stage that conciliation is usually conducted:

f. Depends on the circumstances, cannot generalize

Answer: [ ]

Please provide further explanation:

6. Will your client's legal liability in the case affect the result of the conciliation?
a. $\quad$ Yes
b. No
c. Depends on the circumstances, cannot generalize
d. Others/ difficult to determine

\section{Answer: [ ]}

If yes, how does your client's legal liability affect the result of the conciliation? Please provide further explanation: 
7. Did the policy of 'prioritizing conciliation' affect your client's freedom to choose between conciliation and adjudication?

a. Yes. My client's freedom to choose between conciliation and adjudication is significantly affected.

b. Yes. My client's freedom to choose between conciliation and adjudication is affected, but the effect is not significant.

c. No. My client's freedom to choose between conciliation and adjudication is not affected at all.

d. others/ difficult to determine

Answer: [ ]

Please provide further explanation:

8. What factors do the judge take into consideration when determining what cases should be tried and what case should be conciliated?
a. The type and nature of the case
b. The relationship between the parties
c. The prevailing policy of the court
d. All of the above
e. Other factors/ difficult to determine

Answer: [ ]

Please provide further explanation:

9. Is there any change in the policy of 'prioritizing conciliation'? Please comment based on your practice.

a. The policy of 'prioritizing conciliation' has been abolished

b. The policy of 'prioritizing conciliation' has undergone 'some changes', i.e. that it is not abolished but is no longer emphasized by the court

c. The policy of 'prioritizing conciliation' is still in force and emphasized by courts

d. Others/ difficult to determine

\section{Answer: [ ]}

If the policy of 'prioritizing conciliation' has changed, do you think it has affected the judge's use/practice of conciliation? Please provide further explanation: 
10. What role does the enforcement judge plays during the enforcement reconciliation process?
a. The same role as the conciliating judge plays in judicial conciliation
b. A role similar to that of the conciliating judge in judicial conciliation
c. A completely different role when compared to the role played by the conciliating judge in judicial conciliation (please explain)
d. Depends on the circumstances, cannot generalize
e. Others/ difficult to determine

\section{Answer: [ ]}

Please provide further explanation:

11. Is the judge's decision on choosing conciliation or adjudication affected by the encouragement of settling cases through conciliation under the performance evaluation of individual judges [and the Case Quality Evaluation]?
a. Significantly affected (the judge will place great emphasis on conciliation as a result)
b. Somewhat affected (the judge will place relative emphasis on conciliation as a result)
c. Not affected at all
d. Others/ difficult to determine

Answer: [ ]

Please provide further explanation:

12. As opposed to commercial cases, the court more inclined (or more willing) to conduct judicial conciliation for purely civil cases. Do you agree?
a. Yes
b. No
c. Depends on the circumstances, cannot generalize
d. Others/ difficult to determine

Answer: [ ]

Please provide further explanation: 
13. What is the approximate overall rate of mandatory enforcement of mediation statements in all the civil and commercial cases you have handled in the past three years?
a. Very high;
b. On the high side
c. Moderate
d. On the low side
e. Very low.

Answer: [ ]

Please provide further explanation (please provide specific figures, if any):

14. Do you think "Anjie shiliao" is still an important goal for China's civil justice system?
a. $\quad$ Yes. It is still very important
b. Yes. It is important, but not as important as before
c. No. It is no longer important
d. Others/ difficult to determine

Answer: [ ]

Please provide further explanation: 


\section{(C) Master list of interview questions for judges}

Note: this is not an exhaustive list of the questions actually asked during interviews

1. Generally speaking, which is more time-consuming - adjudication or judicial conciliation?

2. Is the fact that a mediation statement is not subject to appeal a factor you will take into account in deciding whether or not to conciliate a case?

3. During the conciliation process, would you hint to the parties what your preliminary judgment is as a tactic to secure settlement?

4. When is conciliation most likely to take place? Please specify the procedural stage.

5. From your experience, is conciliation at the appellate stage similar to conciliation at first instance? Any procedural difference?

6. Do you record the process of conciliation in the case file? Or just the result?

7. Would you make settlement proposals to the parties? If so, when would you do this?

8. Is coerced mediation prevalent in your court? How would you define 'coerced mediation'?

9. Do you think the court's function of enforcing rights and declaring norms is diminished as a result of the policy that prioritized conciliation?

10. Is Anjie shiliao (i.e. the case is closed and the underlying dispute is [truly] resolved) still an overriding objective of Chinese civil justice?

11. Is conciliation at the re-adjudication stage common?

12. Is conciliation usually carried out by a single judge (i.e. the Responsible Judge)? How often does the tribunal conduct conciliation as a collegiate bench?

13. Would you hold any views against the party of it refuses to conciliate and/or accept (in your view) a 'fair' settlement proposal? If so, would this affect your final judgment of the case (should the case failed to settle)?

14. Do you think conciliation helps the judge to manage his/her cases case on an individual level?

15. Do you think that courts are most effective in discharging their duties if they operate like mediation centers?

16. Do you notice a significant variation of the practice of conciliation with different judges? What would you say are unique in your conciliation methods/ tactics?

17. What cases would you never conciliate? What cases would you be reluctant to conciliate? What cases you would definitely conciliate?

18. Do you discuss with the parties factual and legal issues in judicial conciliation? Do you discuss with parties' relative positions in the case in judicial conciliation?

19. Name two methods/tactics that you find particularly useful that you have used in judicial conciliation.

20. Do you think mediation confidentiality is important in judicial conciliation? Do you think existing rules of mediation confidentiality are observed in practice?

21. Are there any internal rules or directions that regulate judicial conciliation in your court? If so, please provide details. 
22. Do you think conciliated settlement promises true finality? Or is noncompliance with settlement agreements a common occurrence?

23. Are you accountable (or do you feel that you are accountable) to your court leadership for your mediation/ withdrawal rates?

24. Is judicial conciliation of commercial disputes different from general civil matters? If so, how so?

25. What do you think of the fused role of the adjudicator/conciliator in judicial conciliation? Do you agree with the view to completely separate the role of the adjudicator and conciliator in civil litigation?

26. Please discuss the effectiveness of court-annexed mediation arrangement(s) in your court. Please highlight any problem areas. 
APPENDIX V: $\quad$ List of published articles by the author: the contents of which were repeated in this book

1. 'Efficiency and Truth in Civil Fact-finding: The Evolving Role of the Judge in Mainland China and Hong Kong and the Effect of the Policy Preference for Court Mediation on Fact-finding in the People's Courts', in C.H. van Rhee \& A. Uzelac (eds.), Truth and Efficiency in Civil Litigation: Fundamental Aspects of Factfinding and Evidence-taking in a Comparative Context, Antwerp: Intersentia, 2012, p. 231-260.

2. 'China: Hong Kong. Selective Adoption of the English Woolf Reforms', in C.H. van Rhee \& Y.L. Fu (eds.), Civil Litigation in China and Europe: Essays on the Role of the Judge and the Parties (Ius Gentium: Comparative Perspectives on Law and Justice, Vol. 31), Dordrecht, Heidelberg, London, New York: Springer, 2014. [co-authored with David Chan and Lei Chen]

3. 'Civil Justice with Multiple Objectives: the Unique Path of Hong Kong's Civil Justice Reform', in A. Uzelac (ed.), Goals of Civil Justice and Civil Procedure in Contemporary Judicial Systems (Ius Gentium: Comparative Perspectives on Law and Justice, Vol. 34), Dordrecht, Heidelberg, London, New York: Springer, 2014. [co-authored with David Chan]

4. 'Civil Appeals and Other Means of Recourse Against Judgments in China: A Critical Review of the Procedural Issues', in C.H. van Rhee \& A. Uzelac (eds.), Nobody's Perfect: Comparative Essays on Appeals and other Means of Recourse against Judicial Decisions in Civil Matters, Antwerp: Intersentia, 2014, p. 161210.

5. 'Three Years of Civil Justice Reform: Constructing a Cost-Effective and Efficient Civil Procedure in Hong Kong', Acta Universitatis Lucian Blaga, No. 2, 2011, p. 181-202.

6. 'The Enigma of Civil Justice in Imperial China: A Legal Historical Enquiry', Maastricht Journal of European and Comparative Law, Vol. 19(2), 2012, p. 317337.

7. 'OPCIONES DE MEDIACIÓN PARA RESOLVER DISPUTAS COMERCIALES EN CHINA' [Mediation Options for Resolving Commercial Disputes in China: A Guide for Foreign Enterprises], Revista Chilena de Derecho, 41(1), 2014, p. 153-170 (in Spanish); also published in Tijdschrift voor Civiele Rechtspleging, No. 2, 2012, p. 49-56 (in English). 


\section{APPENDIX VI:}

\section{Valorization Addendum}

Civil justice in China is in a state of flux. On the one hand, court leaders are struggling hard to push ahead reform measures that were intended to significantly transform the old landscape of civil litigation by reestablishing the position of adjudication and enforcing procedural formalities. On the other hand, the judicial culture that overly emphasize the search for substantive justice is so ingrained that a mere change in the procedural rules is not going to bring about real change in civil court proceedings. Hence, the research adopted an approach that combines the proceduralist perspective with an empirical enquiry covering 24 different courts in China. The research gives attention not only to the theoretical or 'black-letter law' aspects of procedure, but also addresses pragmatic issues that the Chinese courts are facing in the context of civil mediation. The ultimate objective is to provide concrete solutions to existing problems that can be valorized to bring tangible and meaningful change to the practice of civil litigation in China.

\section{What is the social and/or economic relevance of your research results?}

The research is intended for an international academic audience, as well as judges and legal practitioners in the West, with interest in Chinese civil procedure and the operational mechanics of Chinese courts. It offers a proceduralist perspective on the subject and offers solid recommendations on civil justice reform, e.g. recommendations to bring Chinese court mediation more in line with international standards of practice. The views expressed in the work would equally benefit policymakers of the Supreme People's Court (SPC) and drafters of civil procedure at the National People's Congress in their tireless efforts to bring about real change in the Chinese civil justice system.

\section{To whom, in addition to the academic community, are your research results of interest and why?}

The research methodology adopted is catered for practical application of research findings. The research adopted a predominantly proceduralist approach in dissecting the intricate relations among stakeholders of Chinese civil justice with the view of aiding future rule-making and influencing the policies of the SPC. The proceduralist approach is supplemented by a thorough qualitative empirical enquiry into the practice of judicial conciliation. The empirical analysis, which challenges the effectiveness of the current judicial reform effort insofar as it relates to judicial conciliation, is the starting point of a wider debate on what it takes to modernize civil justice in China.

To be more specific, the empirical research results are mainly addressed to the SPC, which apart from being the highest court in the land also plays an important regulatory role within the Chinese judiciary. The important finding that the vast majority of judges in the survey still consider the principle of Anjie shiliao (i.e. to resolve disputes in such a way that the case is closed and the dispute is [truly] 
resolved') as an important objective of civil justice should be of particular interest for the SPC. Since 2013, the SPC has implemented a number of reform measures with the aim of establishing procedural formalism in civil justice. However, top-down policy changes are only effective if the underlying judicial culture is willing to change as well. The empirical findings will help the policy-makers of the SPC understand the magnitude of the challenge that lies ahead and be able to devise a realistic and effective way to implement the reform.

Practitioners are very much disoriented with where China's civil justice reform is going. The research findings (especially the findings that reveal the mind-set of judges) will help manage the expectations of practitioners, and provide useful practical insight for more junior practitioners on handling civil and commercial lawsuits in China.

The research results also help bring to light in the international legal community the destructive practices of coerced mediation in China, particularly during the time of former SPC President Wang Shengjun's tenure (March 2008 - March 2013). It serves as a case study and timely reminder for courts in China and abroad that a judiciary driven by policy risks losing its intended functions (such as the enforcement of rights of citizens) and endangering access to justice.

\section{Into which concrete products, services, processes, activities or commercial activities will your results be translated and shaped?}

On the basis of my research results, I will develop a practical procedural guide on mediation for foreign enterprises litigating in China. To date, such practical guides in the English language are scant.

A meeting of experts, involving Chinese and international academics, judges and practitioners, will be organized to review the current practice of mediation in China. The objective of the expert meeting is to devise proposals for better regulating mediation in China.

The research results can also be valorised by way of framing them in the form of draft judicial interpretations of the SPC. This is the most practical and effective way to valorise the research as judicial interpretations of the SPC have the normative effect of statutes. If this valorised product is considered by the policy-makers of the SPC and influenced the next SPC judicial interpretation on civil procedure, the research will have national influence.

\section{To what degree can your results be called innovative in respect to the existing range of products, services, processes, activities and commercial activities?}

The dissertation is innovative in three aspects: (1) it is the first piece of major research intended for an international audience that critically reviews China's mediation system as a whole from a Western proceduralist perspective; (2) it provides practical recommendations for reform with the objective of arousing interest within the international legal community and triggering a debate that would eventually bring about substantive and concrete changes to the mediation system in China; and (3) it 
presents the findings of perhaps one of the most extensive qualitative empirical surveys on the practice of judicial conciliation in the English language.

While there are quite a number of articles on the subject of Chinese civil justice from a socio-legal perspective, ${ }^{944}$ a focused procedural study of this subject in the English language is lacking. The intention of the research is to fill this gap in the international literature. It is hoped that by drilling into detailed procedural rules of practice, a critical and holistic view of the subject can be presented.

As stated above, the practical recommendations in the dissertation can be valorised by way of framing them in the form of draft judicial interpretations on civil procedure of the SPC.

The proceduralist approach is supplemented by a thorough qualitative empirical enquiry into the practice of judicial conciliation in China. Unlike existing empirical studies on Chinese courts that tend to focus only on a few courts, ${ }^{945}$ this empirical study covers 24 courts from a wide geographical spread. ${ }^{946}$ The larger scope of the survey strengthens the representativeness of the study. China's geographic diversity in judicial practice calls for a wider sampling.

\section{How will this/these plan(s) for valorization be shaped? What is the schedule, are there risks involved, what market opportunities are there and what are the costs involved?}

Valorization will be carried out in three stages.

Stage 1 involves organizing a meeting of experts to bring together international and Chinese proceduralists, judges and practitioners to review the current practice of mediation in China with a view to better regulate mediation in China. This should happen between late 2016 to mid 2017, depending on the scale of the meeting and availability of speakers. A possible output of the meeting is an edited book (Conference Book) that captures the competing views of experts on the subject.

Stage 2 involves the drafting of a practice manual on court mediation for foreign enterprises litigating in China. The manual focuses on judicial conciliation, providing updates on practice and identifying trends. The practice manual, which is intended to be a high-level guide, is expected to complete by the end of 2017.

Stage 3 involves the drafting of judicial interpretations (in Chinese) for the SPC to consider. The draft should be based on concrete recommendations set out in the Conference Book. The timeline of this stage depends on the actual timing of Stages 1 and 2.

\footnotetext{
${ }^{944}$ For example, see $\mathrm{Ng} \& \mathrm{He} 2014$, p. 285-312.

945 See Ng \& He 2014, p. 288.

${ }^{946}$ The survey encompasses courts from a wide geographical span: 5 intermediate courts and 6 basiclevel courts are located in first-tier coastal cities, 3 intermediate courts and 4 basic-level courts are located in second-tier costal cities or mid-sized coastal counties, 3 intermediate courts and 3 basic-level courts are located in inland cities or counties. Needless the say, the first-tier coastal cities are wealthier and more densely populated than the second-tier/ mid-sized coastal cities. Comparatively, inland cities or counties tend to be less developed than coastal cities in China.
} 


\section{APPENDIX VII:}

\section{English Summary}

The aim of this work is to explore key procedural issues of mediation in China's civil justice system and provide concrete recommendations for reform. While there are a number of articles and books on the subject, a focused and comprehensive procedural study in the English language is lacking. The intention of the dissertation is therefore to fill a gap in the international literature. The fundamental question that needs to be answered is whether mediation will remain a policy tool for courts in China. This question is particularly relevant given the history of courts using mediation to further the agenda of the ruling elite during Wang Shengjun's tenure as president of the Supreme People's Court (SPC) (March 2008 - March 2013). This question is important not only as a procedural topic, but also from a socio-legal standpoint. From a procedural perspective, mediation occupies a unique position in any civil justice system in that it (if appropriately deployed) provides an alternative to litigation while preserving the parties' right of access to court. The procedural nature and function of mediation changes if policy is allowed to dictate the mediation process, especially when such policy contravenes the law. This is exactly what happened in China under Wang Shengjun's presidency. Mediation, in particular the unique procedure of judicial conciliation, became a policy tool to further the ruling objective of 'maintaining social harmony', at times even at the expense of procedural justice. This work tracks the influence of Wang's policies in shaping China's mediation regime and the extent to which Wang's legacy affected the construction of a modern civil justice system in China in the wake of current judicial reforms. From a socio-legal perspective, a broader issue needs to be considered: is the ruling elite in China still using courts as a medium to secure its dominance, rather than respecting the judicial process as a uniquely important domain in its constitutional matrix that is best left to do its business alone without external interference. This question is particularly relevant to an international audience that seeks to understand what China is doing in its new wave of judicial reform that allegedly aims to construct 'the rule by law'. The proceduralist perspective in this work is supplemented by an empirical enquiry covering 24 different courts in China. The research gives attention not only to the theoretical or 'black-letter law' aspects of procedure, but also addresses pragmatic issues that the Chinese courts are facing in the context of civil mediation. The ultimate objective is to provide concrete solutions to existing problems that can bring tangible and meaningful change to the practice of civil litigation in China.

Mediation plays a critical role in the development of any civil justice system. When used well as a true alternative to litigation, mediation could alleviate the zero-sum effect of litigation and introduce flexibility in the disputes resolution process. However, the positive effects of mediation could only manifest if the process is protected in ways that allow parties to truly be able to choose what is best in their interests and explore options free from interference from anyone else. The Chinese legal and political culture, coupled with a systemic distortion of the function of mediation during Wang Shengjun's period, made it very difficult to develop an authentic mediation system that places party autonomy and other core principles (such as confidentiality) at the heart of the process. Judges generally view mediation as a 
convenient way to manage the court dockets. Judicial conciliation is still preferred by many judges given the inherent advantage of a conciliated settlement from a career perspective (i.e. a settlement cannot be appealed and a high settlement rate is favourable to the evaluation of the judge). According to the empirical findings, the goal of 'Anjie shiliao' (i.e. to resolve disputes in such a way that 'the case is closed and the dispute is [truly] resolved') is still considered important in Chinese civil justice, which means that it would be difficult to separate mediation (in whatever form) from the prevailing policies of the state that place great premium on any measures that could help maintain social order. An overhaul of the mediation system in China, therefore, requires an institutional separation of the judiciary from the rest of the state machinery in the realm of civil procedure in a way that the judiciary is given the simple task of delivering justice unadulterated by interventionist state policies and populist trends. Only by doing that could there be 'normalization' of mediation, i.e. mediation simply playing an ADR function and nothing more.

The dissertation is divided into nine chapters. Chapter 1, the introductory chapter, laid the foundation of the dissertation. It outlines the research question, the methodology and key concepts in contemporary Chinese civil justice. Given the main target audience of the dissertation is European, the chapter identifies and explains the fundamental conceptual differences between contemporary Chinese mediation and mediation processes in Europe.

Chapter 2 explores the legal history of China in relation to civil disputes resolution, from the imperial periods to the early days of the People's Republic of China. The discussion on contemporary Chinese mediation is placed into the appropriate context when one understands that conciliatory processes in China today still operate to a certain extent under the shadow of China's historical legal culture.

Chapter 3 reviews the practice of people's mediation in China, the policy of 'Grand Mediation' and the nexus between out-of-court mediation and court proceedings. The policy that pushed for the settling of disputes out-of-court gives rise to concerns that courts are not docketing cases as they should be. It is not infrequent that parties experience delay when the court is considering whether or not the case should be docketed for reasons outside the scope of the relevant procedural law.

Chapter 4 seeks to explore the impact of overusing judicial conciliation on access to justice during Wang's period. As much as the leaders of the SPC today are aware of the need to strengthen the courts role in declaring legal norms and enforcing private proprietary rights, lower courts are likely to continue to use judicial conciliation for institutional or strategic purposes.

Chapter 5 presents an empirical study on the practice of judicial conciliation. The gap between law and practice, particularly in the context of civil litigation, is especially wide in China. It is therefore important to capture the actual dynamics of the law in a systematic way. Empirical work on Chinese courts written for an international audience emerged not so long ago. Ethnographic research helped reveal what really happens in Chinese courtrooms. A number of these studies helped dispel certain generalizations or misconceptions arising from official representation of the judicial process. The value of qualitative empirical work is obvious: the judiciary tends to be 
highly secretive when it comes to sharing what really happens in the courtrooms and qualitative empirical research helps pierce the mystical veil of Chinese courts.

Chapter 6 discusses the three mediation options for resolving commercial disputes in China from the perspective of foreign enterprises. These mediation options are court mediation, mediation conducted in the course of arbitration proceedings (commonly known as 'med-arb'), and private mediation through professional third-party mediation institutions (also known as institutional commercial mediation).

Chapter 7 discusses the fundamental tenets of contemporary Chinese civil justice. Contrary to the modern emphasis on procedural justice, the Chinese judiciary focuses on substantive justice while deliberately downplaying the importance of procedural formalism. A key guiding principle in Chinese civil adjudication is that it is the duty of the judge to find the 'material truth' in every case. The fact-finding process is still in practice dominated by judges despite efforts in civil procedural rule-making to entrust parties with greater fact-finding responsibilities.

Chapter 8 , the last substantive chapter, surveys the principles underlying the concept of 'trial management' by examining in detail the operation of the 'case quality evaluation' system. 'Trial management' is a mass case-processing system designed predominantly to alleviate social discontent in line with the political goal of maintaining public order and social stability. With this backdrop in mind, it is not difficult to understand the judiciary's tolerance of abusive practices in mediation so long as such practices produce positive 'social effect'.

The conclusion of the dissertation, in Chapter 9, highlights how China sees itself as 'exceptional' in the administration of civil justice and the areas of tension in the management of the country's civil disputes resolution processes.

One cannot change the culture of litigation overnight. Old habits of abusing the judge's position in judicial conciliation are part and parcel of the entrenched predominance of the bench in civil litigation, something that judges are unlikely to be willing to part with as a matter of self-interest. Despite efforts of the SPC to eradicate abusive mediatory practices, pragmatism dictates that the majority of Chinese judges are likely to passively resist any top-down direction that takes away their discretion to use mediation as their tactical tool to manage caseloads and meet institutional goals.

The development of China's civil justice system during Wang's period was not a historical coincidence. Its populist trajectory, social engineering objective and policydriven nature are rooted in the country's legal history. No matter how much the current SPC leadership wanted to change the outlook of the judicial process, the 'innateness' of the concept of Anjie shiliao in the DNA of Chinese judges suggest that reforming China's civil justice system takes much more than simply changing its rules of procedure and management structure. Ultimately, the fundamental question is whether the Chinese ruling elites are willing to take the courageous step of granting the necessary autonomy to the courts so that the administration of justice is truly separated from the administration. Courts function best when they are left alone. This is why judges occupy a unique position in a polity, a position that allows them to enforce the legal rules and norms without the usual political and bureaucratic dynamics of a regular state organ. 


\section{APPENDIX VIII:}

\section{Curriculum Vitae}

Peter C.H. Chan (Hong Kong, 1981) joined the City University of Hong Kong in 2009 to teach in the Postgraduate Certificate in Laws programme (PCLL). He received his degrees of LLB, LLM and PCLL at the University of Hong Kong. Since graduation, Mr. Chan worked at a leading international firm, specializing in commercial litigation and contentious financial regulatory practice.

Mr. Chan publishes in comparative civil procedure regularly. His main research focus is Chinese civil procedure and judicial behaviour in the People's Courts. He is a member of the International Association of Procedural Law, an Invited Fellow of the Maastricht European Private Law Institute, a Research Guest (April-May 2015) at the Max Planck Institute Luxembourg for International, European and Regulatory Procedural Law, and a Visiting Professor (in 2013) at the Law Faculty, Kazan (Volga Region) Federal University.

Mr. Chan is an editor of the Hong Kong Lawyer, the official journal of the Law Society of Hong Kong, an examiner of the Overseas Lawyers Qualification Examination in Hong Kong and a member of Standing Committee on Legal Education and Training. He is currently the PCLL programme director at the School of Law, City University of Hong Kong. 